Otimização de desempenho de aerofólios supercríticos: uma abordagem baseada em algoritmos genéticos

Rafael Gigena Cuenca 



\title{
Otimização de desempenho de aerofólios supercríticos: uma abordagem baseada em algoritmos genéticos
}

\author{
Rafael Gigena Cuenca
}

Orientador: Prof. Dr. Leandro Franco de Souza

Dissertação apresentada ao Instituto de Ciências Matemáticas e de Computação - ICMC-USP, como parte dos requisitos para obtenção do título de Mestre em Ciências - Ciências de Computação e Matemática Computacional.

USP - São Carlos

Fevereiro/2009 



\section{Agradecimentos}

O homem deve procurar progredir, mas não pode fazer isso sozinho porque não dispõe de todas as faculdades; eis por que precisa se relacionar com outros homens. No isolamento, se embrutece e se enfraquece. (Livro dos Espíritos)

Na misericórdia e no amor de Deus, ainda incompreensíveis para nós, criaturas em crescimento, somos postos a viver em sociedade. No convívio diário com o próximo, repleto de defeitos e virtudes, aprendemos com suas experiências e reconhecemos nele os nossos próprios defeitos, que devem ainda ser depurados, fazendo com que ele se torne nosso professor e mestre. Na reflexão final característica do fim dos estágios da vida, é tarefa imperiosa reconhecer a importância desse tipo de pessoa. Ao longo de todo o processo de aprendizado do mestrado, tive a felicidade de ter o apoio das amizades e inimizades para me direcionar neste trabalho final e no amadurecimento pessoal, ainda em seu início.

Durante a pós-graduação, tive o apoio de novas amizades, encontradas aqui. Os momentos de reflexão e descontração com as turmas do LCAD e do LOT foram importantes no sustento psicológico de que eu precisei. Agradeço principalmente à Tamara pela amizade incondiocional e disponível nos momentos mais conturbados e pelo trabalho de cupido esforçado.

Nos quatro anos do desenvolvimento deste trabalho, tive o apoio muito importante de dois professores que, extra-oficialmente, se revezavam na orientação: Leandro Franco de Souza e Rodrigo Fernandes de Mello. Ambos me transmitiram conhecimento e experiências durante todo o trabalho e tiraram leite de pedra, muitas vezes, para aumentar meu pequeno potencial. A orientação do Leandro me possibilitou ter contato com outros pesquisadores que me ajudaram muito. Devo agradecimentos a toda a turma do CTA.IAE, especialmente ao João e ao Edson, por todas as ajudas relacionadas aos métodos computacionais no estudo aerodinâmico. Agradeço também ao Biga pelas orientações quando tive problemas com o Roe.

Todos os meus professores, na graduação ou na pós, me forneceram embasamento teórico, muitas vezes não valorizado no momento. Às amizades na Engenharia Aeronáutica, agradeço pelas inúmeras conversas esclarecedoras relacionadas a questões técnicas e conceituais da área. E também pelos momentos de descontração no Campus II (vulgo Roça), nas brincadeiras com 
helicópteros made in China na companhia do mestre Paulo e do mestre ¿Dirso¿, nos cafés com o Claudinho e com o "forróide". Como ocorre na área, muitos já se mudaram, mas agradeço por ter conhecido a Elizangela, o Zé Eduardo, o Hiltão...

Concomitantemente aos estudos acadêmicos, aprendi muito nos estudos espíritas junto ao grupo do qual fui integrante. Conheci Clélia, Maria, Rosa, Gilberto, Vanessa, Fabrício e muitos outrso que foram e vieram ao longo de seis anos. Espero ser capaz de pôr em prática tudo o que aprendi com eles e sei que sempre terei seu carinho.

Devo especial agradecimento à minha família ¿ não apenas os natos, mas também os adquiridos. Toda a família Lamas sempre me recebeu muito bem, não por causa de minha grandeza, mas por seus imensos corações. À família da Mari, que me recebeu como membro, de tal forma que os pais dela nem parecem meus sogros. À Mari, agradeço por toda a paciência com o meu estresse e pelo amor durante todo o tempo. Aos meus pais, devo de tudo um pouco da minha história, pessoas tão queridas e com qem ainda tenho tanto para aprender.

(...) Que eu jamais me esqueça que Deus me ama infinitamente! (...) (Francisco Cândido Xavier) 
Somos os responsáveis por nossa tragédia e por nossa glória. (Francisco Cândido Xavier)

Deixe algum sinal de alegria, onde passes.

(Francisco Cândido Xavier)

(...) Preciso é que tudo se destrua para renascer e se regenerar. Porque, o que chamais destruição não passa de uma transformação, que tem por fim a renovação e melhoria dos seres vivos. (...) (Livro dos Espíritos) 

O presente trabalho tem por objetivo o estudo da otimização multiobjetivo aplicada ao projeto de perfis aerodinâmicos em regime transônico, analisando comparativamente diferentes formas de definir as funções objetivo. A otimização é efetuada pelo algoritmo genético NSGA-II. Os resultados são avaliados utilizando métricas de diversidade da população e otimalidade das soluções, das quais duas são propostas. As funções objetivo são constituidas de diferentes parametrizações da geometria e diferentes técnicas de simulação numérica. A parametrização da geometria é feita utilizando a paramentrização Parsec ou a parametrização baseada em pontos de controle. A discretização do domínio espacial é feita utilizando malha estruturada conformada ao perfil e suavização por EDP elíptica. As duas técnicas de volumes finitos com diferentes modelos para o cálculo do fluxo na face do volume implementadas foram o método de Jameson (esquema centrado) e o método de Roe (esquema upwind). As comparações feitas são as seguintes: utilização de modelo viscoso e invíscido, com o uso do código Mses com a parametrização por ponto de controle; a utilização da parametrização por ponto de controle e parametrização Parsec usando o método de Jameson; e a comparação entre o método centrado e o upwind, utilizando a parametrização Parsec. Conclui-se dos resultados obtidos que a utilização da parametrização por pontos de controle é melhor. Entretanto, ainda é necessária a utilização de uma parametrização que garanta maior suavidade ou a imposição de restrições sobre a suavidade da solução. A utilização do modelo viscoso torna os resultados da otimização melhores do ponto de vista da otimalidade. Na utilização de modelos de correção viscosa, como no caso do Mses, é necessária a utilização de métodos invíscidos que forneçam resultados com maior representatividade física. 

The objective of present study is analyze the multi-objective optimization applied to transonic airfoils project comparing different ways to define the objective functions. The optimization is evaluated by the genetic algorithm NSGA-II. The results is analyzed using metrics of diversity and optimality for multi-objective problems, which two are proposed. The objective functions are defined by different parametrizations of geometry and different techniques of numerical simulation. The geometry parametrization was made by two distinct forms: using Parsec parametrization; and the control points based parametrization. The space domain discretization was made using structured body-fitted mesh with elliptical PDE smooth. A finite volume code with two different techniques for calculations of flux interface had been implemented: the Jameson's method (centered); and the Roe's method (it upwind). For viscous model usage analysis was used the Mses code that has implemented a finite volumes technique with viscous model correction. The following comparisons has been made: viscous and inviscid model using the Mses code with the control points parametrization; the control points and Parsec parametrizations using the Jameson's method; and the comparison among the centered method and upwind using the parametrization Parsec. From the results, it is concluded that the used of control points parametrization is interesting. Although, is still needed the used of a parametrization that guarantees a better smoothness or the imposes of a geometrical or property distribution restriction. The uses of viscous model gives better optimizations results in optimality requirement. It is needed the uses of inviscid method that forces better physical representation when using viscous correction model. 



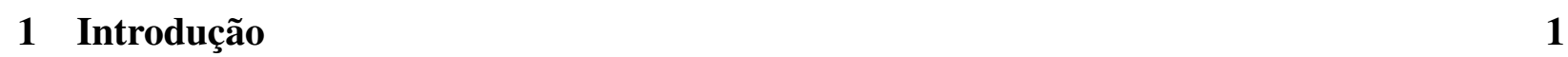

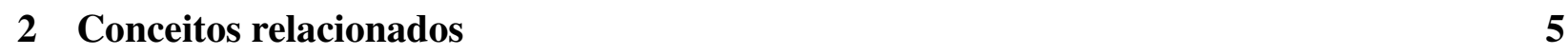

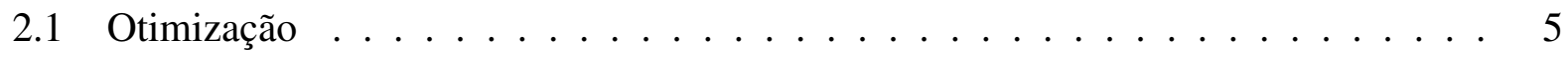

$2.1 .1 \quad$ Otimização multiobjetivo . . . . . . . . . . . . . . . . . 6

2.1 .2 Classificação por dominância . . . . . . . . . . . . . . . . 7

2.1 .3 Algoritmo genético . . . . . . . . . . . . . . . . . . . . . . . . . . . . . . .

2.2 Aerodinâmica compressível . . . . . . . . . . . . . . . 8

2.2 .1 Teoria do perfil . . . . . . . . . . . . . . . . 10

2.2.2 Teoria do perfil: cálculo das forças e coeficiente de pressão . . . . . . . . . 11

2.2 .3 Influência da compressibilidade e Mach de divergência . . . . . . . . . . . 14

2.2 .4 Dinâmica dos fluidos computacional . . . . . . . . . . . . . 16

3 Simulação numérica de escoamentos compressíveis 21

3.1 Volumes Finitos . . . . . . . . . . . . . . . . . . . . . . 22

3.1 .1 Modelo viscoso: Mses . . . . . . . . . . . . . . . . . 22

3.1 .2 Método centrado: Jameson . . . . . . . . . . . . . . . . . . . 23

3.1 .3 Método Upwind: Roe . . . . . . . . . . . . . . . . . . . . . . 24

3.1 .4 Condições de contorno . . . . . . . . . . . . . . . . . . 35

3.1 .5 Técnicas para aceleração de convergência . . . . . . . . . . . . . . 38

3.2 Geração de Malha . . . . . . . . . . . . . . . . . . . . . . . 40

3.3 Parametrização da geometria . . . . . . . . . . . . . . . . . 41

4 Algoritmo genético e otimização multi-objetivo 45

4.1 Algoritmos genéticos . . . . . . . . . . . . . . . . . 46

$4.1 .1 \quad$ Non-Dominated Sorting Genetic Algorithm II . . . . . . . . . . . . . . . . 49

4.1 .2 Parâmetros de desempenho de soluções multiobjetivo . . . . . . . . . . . 50

4.2 Técnicas de visualização de dados . . . . . . . . . . . . . . . . 53 
$4.2 .1 \quad$ Matriz de gráficos de dispersão. . . . . . . . . . . . . . . . . . . 54

4.2 .2 Gráfico de coordenadas paralelas.$\ldots \ldots \ldots \ldots \ldots$

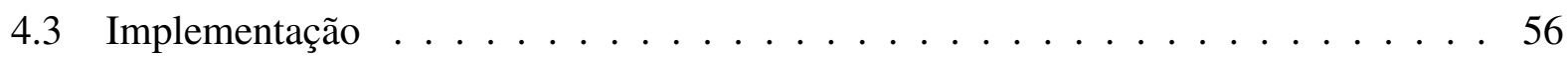

5 Verificação e validação

5.1 Validação da técnica de volumes finitos $\ldots \ldots \ldots$. . . . . . . . . 60

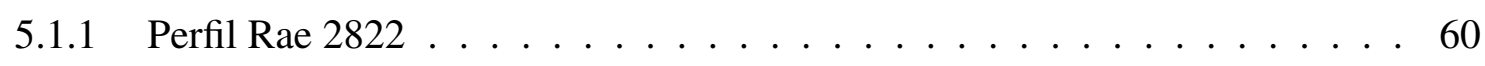

5.1 .2 Perfil Naca $0012 \ldots \ldots \ldots \ldots$

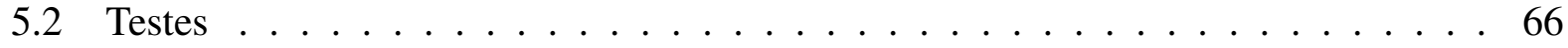

5.2 .1 Limitador de fluxo: valor para $\epsilon_{L I M} \ldots \ldots \ldots \ldots$. . . . . . . 66

5.2 .2 Tamanho do domínio computacional . . . . . . . . . . . . . . 67

5.2 .3 Número de pontos na direção radial $\ldots \ldots \ldots \ldots \ldots$

5.2 .4 Número de pontos em torno do perfil $\ldots \ldots \ldots \ldots \ldots . \ldots 72$

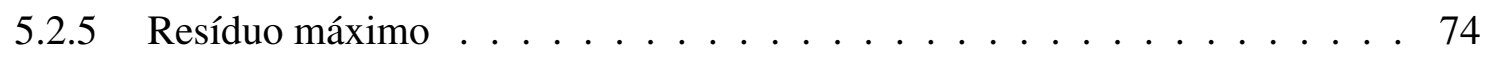

$5.2 .6 \quad C F L$ e resíduo suavizado $\ldots \ldots \ldots \ldots \ldots \ldots$

5.3 Verificação do algoritmo genético … . . . . . . . . . . . . . . 77

5.3 .1 Problema com uma variável de projeto . . . . . . . . . . . . . 78

5.3 .2 Problema com duas variáveis de projeto $\ldots \ldots \ldots \ldots$. . . . . . . 79

6 Resultados $\quad 83$

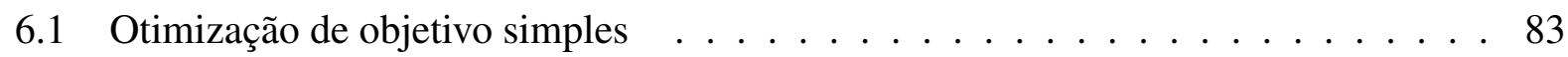

6.2 Otimização multiobjetivo $\ldots \ldots \ldots \ldots \ldots \ldots \ldots$

$6.2 .1 \quad$ Soluções de referência . . . . . . . . . . . . . . . . . . . . . . . . . 89

6.2 .2 Comparação entre modelo viscoso e invíscido: Mses . . . . . . . . . . 93

6.2 .3 Comparação entre as parametrizações $\ldots \ldots \ldots$. . . . . . . . . . 98

6.2 .4 Comparação entre esquema centrado e upwind $\ldots \ldots \ldots$. . . . . . 102

\begin{tabular}{lll}
\hline 7 Conclusão & 107
\end{tabular}

$\begin{array}{lll}8 & \text { Trabalhos Futuros } & 111\end{array}$

\begin{tabular}{|lr|}
\hline A Gráficos de resultado das otimizações & 113
\end{tabular}

A.1 Parametrização por pontos de controle . . . . . . . . . . . . . . . . . . . 113

A.1.1 Mses modo invíscido . . . . . . . . . . . . . . . . . . . . 113

A.1.2 Mses modo viscoso . . . . . . . . . . . . . . . . . . . . . . . . 122

A.1.3 Método centrado Jameson . . . . . . . . . . . . . . . . . . . . 130

A.2 Parametrização Parsec . . . . . . . . . . . . . . . . . . . . 138

A.2.1 Método centrado Jameson . . . . . . . . . . . . . . . . . . . . 138

A.2.2 Método upwind Roe . . . . . . . . . . . . . . . . . . . 146 


\section{Lista de Figuras}

2.1 Força aerodinâmica em torno do perfil: componentes longitudinais e transversais. . 11

2.2 Força aerodinâmica em torno do perfil: componentes de sustêntação e arrasto. . . . 12

2.3 Orientação da área infinitesimal para integração de superfície da pressão. . . . . . . . 13

2.4 Influência da compressibilidade no arrasto do aerofólios. . . . . . . . . . . . . 15

2.5 Influência da compressibilidade na distribuição de $\mathrm{Cp}$. . . . . . . . . . . . 16

3.1 Elemento quadrangular para Volumes Finitos . . . . . . . . . . . . . . . . 23

3.2 Condição inicial para o problema de Riemann . . . . . . . . . . . . . . . . 25

3.3 Condição de contorno da parede (escorregamento) . . . . . . . . . . . . . 38

3.4 Perturbação do perfil na fronteira livre . . . . . . . . . . . . . . . . . 39

3.5 Malha estruturada tipo $O:$ Esquema $\ldots \ldots \ldots \ldots \ldots \ldots$

3.6 Malha estruturada tipo $O:$ Exemplo $\ldots \ldots \ldots \ldots \ldots \ldots \ldots$

3.7 Variáveis da família Parsec. . . . . . . . . . . . . . . . . . . . . 42

3.8 Geometria base (Rae 2822) e pontos de controle. . . . . . . . . . . . . . 43

4.1 Representação gráfica de problema multiobjetivo . . . . . . . . . . . . . . 46

4.2 Operador de cruzamento: um ponto. . . . . . . . . . . . . . . . . . 47

4.3 Operador de Cruzamento: dois pontos. . . . . . . . . . . . . . . . . . . . . . . . . . . . . . . .

4.4 Fluxo de dados típico de um algoritmo genético. . . . . . . . . . . . . . . . . . 49

4.5 Esquema da seleção elitista do NSGAII. . . . . . . . . . . . . . . . . . . . . . . . . . . . . . 50

4.6 Classificação por dominância - métricas . . . . . . . . . . . . . . . . . 52

4.7 Evolução das métricas de desempenho . . . . . . . . . . . . . . . . . . . . 54

4.8 Matriz de Gráfico de Dispersão . . . . . . . . . . . . . . . . . . . . . . 55

4.9 Gráfico de coordenadas paralelas . . . . . . . . . . . . . . . . . . . . . . . . . . . . . . . . . . . . . .

4.10 AG esquema de implementação . . . . . . . . . . . . . . . . . 56

5.1 Rae 2822 à Mach $0,725 \alpha 2,31^{\circ}$ validação $\ldots \ldots \ldots \ldots$. . . . . . . . . . . . . . . . . . . . 60

5.2 Rae 2822 à Mach $0,725 \alpha 2,31^{\circ}$ convergência $\ldots \ldots \ldots \ldots$. . . . . . . . . 61 
5.3 Naca 0012 Mach $0,3 \alpha 0,0^{\circ}$ validação $\ldots \ldots \ldots \ldots$. . . . . . . . . 62

5.4 Naca 0012 Mach $0,3 \alpha 4,0^{\circ}$ validação $\ldots \ldots \ldots$. . . . . . . . . . . 62

5.5 Naca 0012 Mach $0,5 \alpha 0,0^{\circ}$ validação $\ldots \ldots \ldots$. . . . . . . . . . 62

5.6 Naca 0012 Mach $0,5 \alpha 4,0^{\circ}$ validação $\ldots \ldots \ldots \ldots$. . . . . . . . . . . . . . . . . . . . 63

5.7 Naca 0012 Mach $0,5 \alpha 8,0^{\circ}$ validação $\ldots \ldots \ldots \ldots \ldots$. . . . . . . . 63

5.8 Naca 0012 Mach $0,6 \alpha 4,0^{\circ}$ validação $\ldots \ldots \ldots$. . . . . . . . . . . . 64

5.9 Naca 0012 Mach $0,7 \alpha 0,0^{\circ}$ validação . . . . . . . . . . . . . . . . . 64

5.10 Naca 0012 Mach $0,7 \alpha 4,0^{\circ}$ validação . . . . . . . . . . . . . . . . . . . 64

5.11 Naca 0012 Mach $0,75 \alpha 0,0^{\circ}$ validação . . . . . . . . . . . . . . 65

5.12 Naca 0012 Mach $0,75 \alpha 4,0^{\circ}$ validação . . . . . . . . . . . . . . 65

5.13 Naca 0012 Mach $0,8 \alpha 0,0^{\circ}$ validação $\ldots \ldots \ldots \ldots$. . . . . . . . . 65

5.14 Naca 0012 Mach $0,83 \alpha 0,0^{\circ}$ validação $\ldots \ldots \ldots$. . . . . . . . . 66

5.15 Teste de $\epsilon_{L I M}$ : Distribuição de $\mathrm{Cp} \ldots \ldots$. . . . . . . . . . . . 67

5.16 Teste de $\epsilon_{L I M}$ : Histórico de convergência . . . . . . . . . . . . . . 67

5.17 Teste de malha (Jameson): tamanho do domínio . . . . . . . . . . . . . . . 68

5.18 Teste de malha (Roe): tamanho do domínio . . . . . . . . . . . . . . . 69

5.19 Teste de malha (Jameson): Pontos na direção $\eta$. . . . . . . . . . . . . . . 70

5.20 Teste de malha (Roe): Pontos na direção $\eta$. . . . . . . . . . . . . . . . 71

5.21 Teste de malha (Jameson): Pontos na direção $\xi \ldots \ldots$. . . . . . . . . . . 72

5.22 Teste de malha (Roe): Pontos na direção $\xi \ldots \ldots$. . . . . . . . . . . . . 73

5.23 Teste de malha (Jameson): Resíduo máximo . . . . . . . . . . . . . . . . . 74

5.24 Teste de malha (Roe): Resíduo máximo . . . . . . . . . . . . . . . . 75

5.25 Teste de malha (Jameson): Suavização implícita de resíduo . . . . . . . . . . . . 76

5.26 Teste de malha (Jameson): Suavização implícita de resíduo . . . . . . . . . . . . 77

5.27 Verificação do AG: problema 1-2-1 . . . . . . . . . . . . . . . 78

5.28 Verificação do AG: problema 1-2-2 . . . . . . . . . . . . . . . . . . . 79

5.29 Verificação do AG: problema 2-2-1 . . . . . . . . . . . . . . . . . 80

5.30 Verificação do AG: problema 1-2-1 . . . . . . . . . . . . . . . 81

$6.1 \quad$ Otimização de objetivo simples Caso 1: Curvas de $\mathrm{Cp} \ldots \ldots$. . . . . . . . . . . 84

6.2 Otimização de objetivo simples Caso 1: Fitness e Mach . . . . . . . . . . . . . . 85

6.3 Otimização de objetivo simples Caso 2: Curvas de Cp . . . . . . . . . . . . . . 86

6.4 Otimização de objetivo simples Caso 2: Fitness e Mach . . . . . . . . . . . . . . . 86

6.5 Otimização de objetivo simples Caso 3: Curvas de Cp . . . . . . . . . . . . . . 87

6.6 Otimização de objetivo simples Caso 3: Fitness e Mach . . . . . . . . . . . . . . 87

6.7 Otimização de objetivo simples comparação: Curvas de Cp . . . . . . . . . . . . . 89

6.8 Otimização multiobjetivo Cp (Mses invíscido): agrupamentos 1 à 6 . . . . . . . . . 94

6.9 Otimização multiobjetivo Cp (Mses invíscido): agrupamentos 7 à 9 . . . . . . . . . 95

6.10 Otimização multiobjetivo $\mathrm{Cp}$ (Mses viscoso): agrupamentos 1 à 6 . . . . . . . . . 96 
6.11 Otimização multiobjetivo Cp (Mses viscoso): agrupamentos 7 à 10 . . . . . . . . . 97

6.12 Otimização multiobjetivo Cp (Jameson - pontos de controle): agrupamentos 1 à 6 . 99

6.13 Otimização multiobjetivo Cp (Jameson - pontos de controle): Pico se sucção . . . . 100

6.14 Otimização multiobjetivo Cp (Jameson - pontos de controle): agrupamentos 7 à 10100

6.15 Otimização multiobjetivo Cp (Jameson - Parsec): agrupamentos 1 à 6 . . . . . . . 101

6.16 Otimização multiobjetivo Cp (Jameson - Parsec): agrupamentos 7 à 9 . . . . . . . 103

6.17 Otimização multiobjetivo Cp (Roe - Parsec): agrupamentos 1 à 6 . . . . . . . . . . 104

6.18 Otimização multiobjetivo Cp (Roe - Parsec): agrupamentos 7 à 10 . . . . . . . . . 105

A.1 Evolução da factibilidade: Mses invíscido . . . . . . . . . . . . . . . . . 114

A.2 Evolução da métrica Spacing: Mses invíscido . . . . . . . . . . . . . . . . . . 114

A.3 Evolução da métrica ARAI: Mses invíscido . . . . . . . . . . . . . . . . 115

A.4 Evolução da métrica ER: Mses invíscido . . . . . . . . . . . . . . . . 115

A.5 Evolução da métrica InvER: Mses invíscido . . . . . . . . . . . . . . . 116

A.6 Evolução da métrica GER: Mses invíscido . . . . . . . . . . . . . . . . . . 116

A.7 $\quad$ Evolução da métrica $N D W D_{G E R}$ : Mses invíscido . . . . . . . . . . . . . 117

A.8 Perfis da frente de Pareto: Mses invíscido . . . . . . . . . . . . . . . . 118

A.9 Cromossomos da frente de Pareto: Mses invíscido . . . . . . . . . . . . . . . . . 119

A.10 Frente de Pareto: Mses invíscido . . . . . . . . . . . . . . . . . . . . 120

A.11 Parâmetros geométricos da frente de Pareto: Mses invíscido . . . . . . . . . . . . 121

A.12 Evolução da factibilidade: Mses viscoso . . . . . . . . . . . . . . . . . . . . . . . . . . . . . . . . . . . . .

A.13 Evolução da métrica Spacing: Mses viscoso . . . . . . . . . . . . . . . . . . 123

A.14 Evolução da métrica ARAI: Mses viscoso . . . . . . . . . . . . . . . . . . 123

A.15 Evolução da métrica ER: Mses viscoso . . . . . . . . . . . . . . . . . . . . . . 124

A.16 Evolução da métrica InvER: Mses viscoso . . . . . . . . . . . . . . . . . . . 124

A.17 Evolução da métrica GER: Mses viscoso . . . . . . . . . . . . . . . . . . 125

A.18 Evolução da métrica $N D W D_{G E R}$ : Mses viscoso . . . . . . . . . . . . . . 125

A.19 Perfis da frente de Pareto: Mses viscoso . . . . . . . . . . . . . . . . . 126

A.20 Cromossomos da frente de Pareto: Mses viscoso . . . . . . . . . . . . . . . . . . 127

A.21 Frente de Pareto: Mses viscoso . . . . . . . . . . . . . . . . . . . . . . . . 128

A.22 Parâmetros geométricos da frente de Pareto: Mses viscoso . . . . . . . . . . . . . 129

A.23 Evolução da factibilidade: Jameson - ponto de controle . . . . . . . . . . . . . . 130

A.24 Evolução da métrica Spacing: Jameson - ponto de controle . . . . . . . . . . . . . 131

A.25 Evolução da métrica ARAI: Jameson - ponto de controle . . . . . . . . . . . . . 131

A.26 Evolução da métrica ER: Jameson - ponto de controle . . . . . . . . . . . . . . . . 132

A.27 Evolução da métrica InvER: Jameson - ponto de controle . . . . . . . . . . . . . 132

A.28 Evolução da métrica GER: Jameson - ponto de controle . . . . . . . . . . . . . . 133

A.29 Evolução da métrica $N D W D_{G E R}$ : Jameson - ponto de controle . . . . . . . . . 133

A.30 Perfis da frente de Pareto: Jameson - ponto de controle . . . . . . . . . . . . . . 134 
A.31 Cromossomos da frente de Pareto: Jameson - ponto de controle . . . . . . . . . . 135

A.32 Frente de Pareto: Jameson - ponto de controle . . . . . . . . . . . . . . . 136

A.33 Parâmetros geométricos da frente de Pareto: Jameson - ponto de controle . . . 137

A.34 Evolução da factibilidade: Jameson - Parsec . . . . . . . . . . . . . . . . . 138

A.35 Evolução da métrica Spacing: Jameson - Parsec . . . . . . . . . . . . . . . . . 139

A.36 Evolução da métrica ARAI: Jameson - Parsec . . . . . . . . . . . . . . . . . . . 139

A.37 Evolução da métrica ARAI: Jameson - Parsec . . . . . . . . . . . . . . . . . . 140

A.38 Evolução da métrica InvER: Jameson-Parsec … . . . . . . . . . . . . . 140

A.39 Evolução da métrica GER: Jameson - Parsec . . . . . . . . . . . . . . . . . . . 141

A.40 Evolução da métrica $N W D W_{G E R}$ : Jameson - Parsec $\ldots \ldots \ldots \ldots . \ldots 141$

A.41 Perfis da frente de Pareto: Jameson - Parsec . . . . . . . . . . . . . . . . . . . 142

A.42 Cromossomos da frente de Pareto: Jameson - Parsec. . . . . . . . . . . . . . . . 143

A.43 Frente de Pareto: Jameson - Parsec . . . . . . . . . . . . . . . . . . . . . . . . . 144

A.44 Parâmetros geométricos da frente de Pareto: Jameson - Parsec . . . . . . . . . 145

A.45 Evolução da factibilidade: Roe - Parsec . . . . . . . . . . . . . . . . . . 146

A.46 Evolução da métrica Spacing: Roe - Parsec . . . . . . . . . . . . . . . . . 147

A.47 Evolução da métrica ARAI: Roe - Parsec … . . . . . . . . . . . . . . . . 147

A.48 Evolução da métrica ER: Roe - Parsec . . . . . . . . . . . . . . . . . . . . 148

A.49 Evolução da métrica InvER: Roe - Parsec . . . . . . . . . . . . . . . . . . 148

A.50 Evolução da métrica GER: Roe - Parsec . . . . . . . . . . . . . . . . . . . . . . 149

A.51 Evolução da métrica $N W D W_{G E R}$ : Roe - Parsec $\ldots \ldots \ldots$

A.52 Perfis da frente de Pareto: Roe - Parsec . . . . . . . . . . . . . . . . . . 150

A.53 Cromossomos da frente de Pareto: Roe - Parsec . . . . . . . . . . . . . . . 151

A.54 Frente de Pareto: Roe - Parsec . . . . . . . . . . . . . . . . . . . . . 152

A.55 Parâmetros geométricos da frente de Pareto: Roe - Parsec . . . . . . . . . . . . 153 


\section{Lista de Tabelas}

3.1 Limitante dos parâmetros. . . . . . . . . . . . . . . . . . 42

3.2 Pontos de controle base para a parametrização da geometria. . . . . . . . . . . . 43

5.1 Casos de validação Perfil Naca 0012. . . . . . . . . . . . . . . . . . . 61

5.2 Teste de malha (Jameson): tamanho do domínio . . . . . . . . . . . . . . 68

5.3 Teste de malha (Roe): tamanho do domínio . . . . . . . . . . . . . . . . . . 69

5.4 Teste de malha (Jameson): Pontos na direção $\eta \ldots \ldots \ldots 70 \ldots \ldots$

5.5 Teste de malha (Roe): Pontos na direção $\eta \ldots \ldots \ldots \ldots . \ldots \ldots 71$

5.6 Teste de malha (Jameson): Pontos na direção $\xi \ldots \ldots \ldots$. . . . . . . . 73

5.7 Teste de malha (Roe): Pontos na direção $\xi \ldots \ldots \ldots$. . . . . . . . . . . 73

5.8 Teste de malha (Jameson): Resíduo máximo $\ldots \ldots \ldots \ldots \ldots$. . . . . . 75

5.9 Teste de malha (Roe): Resíduo máximo . . . . . . . . . . . . . . . . 75

6.1 Otimização de objetivo simples comparação: Cromossomos … . . . . . . . 88

6.2 Otimização de objetivo simples comparação: Coeficientes aerodinâmicos . . . . 88

6.3 Soluções de referência: método centrado . . . . . . . . . . . . . . . . 90

6.4 Soluções de referência: método upwind $\ldots \ldots \ldots \ldots$. . . . . . . . . . . 91

6.5 Soluções de referência: Mses invíscido . . . . . . . . . . . . . . . . . . 91

6.6 Soluções de referência: Mses viscoso $\ldots \ldots \ldots \ldots$. . . . . . . . . . 92 



\section{Lista de abreviações e siglas}

1D - Unidimensional

2D - Bi-Dimensional

3D - Tri-Dimensional

AE - Algoritmos evolucionários

AG - Algoritmos genéticos

ARAI - Avarege relative accuracy index

CFD - Dinâmica dos fluidos computacional

CFL - Número de Courant

CI - Condiçao inicial

CPU - Unidade de processamento

EDO - Equação diferencial ordinária

EDP - Equação diferencial parcial

ENO - Essentially non-oscillatory

ER - Error ratio

FCT - Correção de transporte de fluxo

FD - Diferenças finitas

FDS - Separação de diferença de fluxo

FE - Elementos finitos 
FV - Volumes finitos

GBM - Gradient-based methods

GD - Generational distance

GER - Generalized error ratio

InvER - Inverse error ration

LI - Linearmente independente

Mses - Código de simulação aerodinâmica desenvolvido por Mark Drela

MUSCL - Monotone upstream-centred scheme for conservation laws

NACA - National Advisory Committee for Aeronautics

NASA - National Aeronautics and Space Administration

NDWD - Normalized dominance weighted distance

NSGA-II - Non-dominated sorting genetic algorithm II

OMO - Otimização multi-objetivo

Parsec - Parametric section

$P F$ - Fronteira de Pareto

$P F_{\text {known }}$ - Fronteira de Pareto conhecida

$P F_{r e f}-$ Fronteira de Pareto de referência

$P F_{\text {true }}$ - Fronteira de Pareto verdadeira

PMO - Problema multi-objetivo

$P R$ - Pareto rank

SP - Solução de Pareto

SDF - Separação de diferença de fluxo

SVF - Separação de vetor de fluxo

TVD - Total variation diminishing

VDT - Variable density tunnel

WP - Weighted product 


\section{Lista de simbolos}

\section{Simbolos latinos}

a Velocidade do som

A Matriz jacobiana

$A^{+}, A^{-}$Matriz jacobiana de autovalores positivos e nagativos respectivamente

$\tilde{A}\left(Q_{L}, Q_{R}\right)$ Aproximação de Roe para a matriz jacobiana

$A R_{w}$ Razão de aspecto da asa

$\tilde{B}, \tilde{C}$ Matrizes de transformaçãode $Z$ para $F$ e $Q$ respectivamente

c Comprimento característico ou corda

Cd Coeficinete de arrasto 2D

$C l$ Coeficiente de sustentação 2D

$\mathrm{Cm}$ Coeficiente de momento 2D

$C p$ Coeficiente de pressão

$C p_{c r}$ Coeficiente de pressão crítico

$C x$ Coeficiente de força aerodinâmica da direção $\mathrm{x}$

Cy Coeficiente de força aerodinâmica da direção y

$C D$ Coeficinete de arrasto 3D

$C D_{i}$ Coeficinete de arrasto induzido

$C D_{\text {trim }}$ Coeficinete de arrasto de trimagem 
$C L$ Coeficiente de sustentação 3D

$C L_{h}$ Coeficiente de sustêntação da empenagem horizontal

CM Coeficiente de momento 3D

$\vec{d}$ Versor direção da força aerodinâmica

$d v$ Diferencial do volume

$D$ Arrasto aerodinâmico

$\operatorname{Da}(Q)$ Dissipação artificial

$e$ Energia interna do escoamento

$H$ Entalpia do escoamento

$e_{w}$ Coeficiene de Oswald da asa

$f_{i} \quad i$-ésimo objetivo de um problema multi-objetivo

$\overrightarrow{f a}$ Força aerodinâmica adimensional

Fa Intensidade da força aerodinâmica

$F$ Vetor de fluxo na direção $\mathrm{x}$

$\bar{F}_{k} \quad$ Vetor de fluxo médio na direção x na face do volume finito

$F\left(x_{j}\right)$ Vetor de solução muli-objetivo

$\mathcal{F}_{i} \quad i$-ésimo conjunto de soluções não dominadas

$G$ Vetor de fluxo na direção y

$\bar{G}_{k}$ Vetor de fluxo médio na direção y na face do volume finito

$\vec{i}_{x}, \vec{i}_{y} \quad$ Versores das coordenadas cartesianas

$K$ Matriz de autovetores da matriz jacobiana

$K^{(i)} i$-ésimo autovetor da matriz jacobiana

$\tilde{K}$ Matriz de autovetor da matriz de Roe

$L$ Sustentação aerodinâmica

$\frac{L}{D}$ Eficiência aerdinâmica 
Dimensão da matriz jacobiana

$M$ Tamanho da população

Ma Número de Mach

$M a_{c r} \quad$ Número de Mach crítico

$M a_{\infty} \quad$ Número de Mach do escoamento livre

$M_{\tilde{\lambda}_{i}}$ Fator de correção para $\tilde{\lambda}_{i}$

$\hat{n}$ versor de direção normal

$n_{x}, n_{y}$ componentes em $\mathrm{x}$ e y do versor $\hat{n}$

ncell $_{i}$ Número de pontos da malha na direção $\xi$

ncell $_{j}$ Número de pontos da malha na direção $\eta$

nident Número de identificação do PMO de teste

nobj Número de objetivos do PMO

nvar Número de variáveis do PMO

$N$ Número de objetivos

$p_{i} \quad$ Peso do $i$-ésimo objetivo

$P$ Pressão estática

$P_{\infty}$ Pressão estática do escoamento livre

$P(\xi, \eta), Q(\xi . \eta) \quad$ Termos fonte de controle de aglomeramento do pontos da geração de malha

$P(x)$ Produto ponderado da técnica WP

$q_{\infty}$ Pressão dinâmica do escoamento livre

$q_{h}$ Pressão dinâmica na empenagem

$Q$ Vetor de variáveis conservadas

$\bar{Q}_{i, j} \quad$ Vetor de variáveis conservadas médias do volume finito

$Q_{g}$ Vetor de variáveis conservadas dos volumes fantasmas

$Q_{R}$ Vetor de variáveis conservadas à direita da descontinuidade 
$Q_{L}$ Vetor de variáveis conservadas à esquerda da descontinuidade

$r_{k}$ Razão de gradientes para o cálculo do limitador de fluxo

$R$ Matriz de rotação para leis de conservação 2D

$R^{ \pm}$Invariantes de Riemann

Re Número de Reynolds

$\vec{s}$ Vetor de superfície

$\Delta \vec{S}_{i \pm \frac{1}{2}, j}, \Delta \vec{S}_{i, j \pm \frac{1}{2}}$ Vetor de superfície da face do volume finito

$S$ Área alar

$S_{h}$ Área de planta da empenagem horizontal

$S_{\text {ref }}$ Área de de referência da aeronave

SFC Specific Fuel Consuption

$t$ tempo

$\vec{t}$ Vetor de direção tangente à face do volume

$T(Q)$ Balanço de fluxo

$u, v$ Componentes da velocidade do ar nas direções $\mathrm{x}$ e y respectivamente

$u(x, t)$ Propriedade transportada

$\tilde{u}, \tilde{v}, \tilde{\rho}, \tilde{H} \quad$ Média de Roe para as propriedades na interface

$U$ Vetor de estados

$V$ Velocidade local do escoamento

$V_{\infty}$ Velocidade do escoamento livre

$V_{i, j}$ Volume interno do volume finito

$w_{i} \quad i$-ésima variável característica

$W \quad$ Vetor de variáveis características

$W_{0}$ Peso vazio da aeronave

$W_{f}$ Peso de combustível carregado pela aeronave 
$x, y$ Coordenadas cartesianas

$x_{1}, x_{2}$ Vetores de variáveis de projeto

$x^{*} \quad$ Vetor de variáveis de projeto para solução não dominada

$Z \quad$ Vetor de propriedades de Roe

\section{Subescrito}

$g$ Relativo ao volume fantasma

$i \pm \frac{1}{2}, j \quad$ Face entre os volumes $i$ e $i \pm 1$

$i, j \pm \frac{1}{2} \quad$ Face entre os volumes $j$ e $j \pm 1$

$L, R$ Lado esquerdo e direito da interface do problema de Riemman

\section{Simbolos gregos}

$\alpha$ Incidência do perfil

$\alpha_{i}$ Coeficiente da combinação linear de $Q_{L}$

$\tilde{\alpha}_{i}$ Intensidade de onda do problema aproximado

$\beta_{i}$ Coeficiente da combinação linear de $Q_{R}$

$\delta_{i} \quad$ Salto das propriedades do problema de Riemann

$\eta, \xi$ Coordenadas curvilineas

$\epsilon_{L I M}$ Limiar para o limitador de fluxo

$\epsilon_{\text {Roe }}$ Limiar do fator de correção de $\tilde{\lambda}_{i}$

$\Phi$ Limitador de fluxo

$\gamma$ Razão de calor específico

$\Gamma$ Circulação do aerofólio

$\lambda_{i} \quad i$-ésimo autovalor da matriz jacobiana $A$

$\lambda_{i}^{+}, \lambda_{i}^{-}$autovalor positivo e negativo respectivamente

$\tilde{\lambda}$ Auto valor da matriz de Roe

$\Lambda$ Matriz de autovalores da matriz jacobiana 
$\Lambda^{+}, \Lambda^{-}$matriz de autovalores positivos e negativos respectivamente

$\mu$ Viscosidade do ar

ПI Produtório

$\rho$ Densidade do ar 
Por que nem sempre a terra produz o suficiente para fornecer o necessário ao homem? (...) A Terra produziria sempre o necessário se o homem soubesse se contentar. (...) (Livro dos Espíritos)

Atualmente, o Brasil é, no cenário internacional, um dos principais países a desenvolver tecnologia aeronáutica, tendo como maior propulsor a companhia EMBRAER (Empresa Brasileira de Aeronáutica). Empresas desse setor têm investido em formas de aprimoramento tecnológico para sustentar e melhorar os níveis de competitividade nacionais e internacionais.

No desenvolvimento de projetos aeronáuticos, a aerodinâmica ocupa posição de destaque, dada a sua relação direta com o desempenho da aeronave. Essa relação é expressa por sua influência em fatores como razão de planeio, razão de subida, alcance, autonomia, velocidade de cruzeiro e carga máxima.

Estudos aerodinâmicos podem ser conduzidos de forma experimental e numérica. O primeiro tipo envolve ensaios em túneis de vento, os quais têm alto custo operacional: custo financeiro, disponibilidade do recurso, construção de modelos apropriados, mão-de-obra especializada e manutenção. Esses fatores têm motivado, cada vez mais, o emprego da análise numérica. Essa abordagem é conduzida por meio de simulações computacionais, que têm menor custo financeiro, maior flexibilidade para avaliação de geometrias aerodinâmicas diversas, e maior volume de informações para análise.

Outro fator que motiva a adoção de análise numérica advém da possibilidade de acoplá-la a técnicas computacionais que auxiliem o projeto de geometrias, que envolve um amplo conjunto de variáveis e restrições associadas à aplicação da geometria em estudo, caracterizando-o como um problema de otimização. Para isso existem métodos de otimização aplicáveis, entre eles os 
algoritmos genéticos (AG) com números reais codificados, e híbridos de AGs e métodos baseados em gradiente (GBM - do inglês gradient-based methods). Essas técnicas podem ser aplicadas no contexto de objetivo simples (uma única função objetivo) ou multiobjetivo (várias funções objetivo).

A geometria que mais influencia o desempenho de uma aeronave é a asa, fato que tem motivado estudos sobre sua otimização. Esse componente é o principal responsável pela sustentação e por uma grande parcela do atrito aerodinâmico. Consequentemente, um bom projeto aerodinâmico da asa define, em grande parte, os parâmetros aerodinâmicos da aeronave. Roskan \& lan (1997) definiram uma série de relações entre as características aerodinâmicas e os requisitos de projeto. Por exemplo, o arrasto está relacionado à obtenção da velocidade máxima de cruzeiro, a razão de planeio para os valores de $C l$ aplicados afeta a razão de subida e o alcance, a espessura tem relação com a redução do peso estrutural e a distribuição da espessura influencia a área interna da asa para acomodar combustível e sistemas.

A definição do formato da asa considera duas geometrias básicas: o planforme ou formato de planta da asa e o formato de sua seção transversal, perfil da asa ou aerofólio. O planforme tem grande influência no comportamento tridimensional da aerodinâmica da asa, porém é o perfil que define, de forma mais significativa, seu desempenho. Dada a importância da asa, muitos esforços têm sido despendidos no estudo e desenvolvimento de métodos de otimização (Ray \& Tsai, 2004, Holst, 2004; Song et al., 2003; Oyama et al., 2000c|a; Obayashi, 1995; Oyama et al., 2001).

A otimização de uma seção transversal pode ser conduzida por meio de duas abordagens: a análise numérica direta e o projeto inverso (Song \& Keane, 2004b; Yamamoto \& Inoue, 1995). A técnica numérica direta emprega análise computacional ou teórica para obter as características do perfil, considerando sua geometria. O projeto inverso obtém uma geometria a partir de uma distribuição de pressão previamente definida sobre o perfil. Diante dessas duas escolhas de projeto, pode-se aplicar diferentes técnicas de otimização, variando tanto na qualidade da solução obtida quanto no custo computacional para obtê-la.

Os métodos baseados em gradientes necessitam do cálculo das derivadas da função objetivo. Para isso, pode-se aplicar cálculo aproximado ou manipular a função objetivo definindo a derivada. A primeira tem um custo computacional associado e a segunda incorpora ao método informação sobre o problema, tornando essa abordagem menos prática que os AGs. Além disso, os GBM são aplicados a problemas de um objetivo. Para obter resultados multiobjetivos é necessário proceder como Nemec et al. (2002), definindo uma ponderação para os objetivos, e aplicar várias otimizações com ponderações distintas.

Nessas circunstâncias, pode-se aplicar técnicas de otimização capazes de propor, qualificar e selecionar geometrias mais adequadas de acordo com restrições de projeto. Isso tem motivado o estudo e avaliação de diferentes técnicas de otimização de projetos aerodinâmicos.

Uma questão relevante é como considerar uma otimização multiobjetivo para melhorar os critérios de desempenho de um perfil de asa considerando a sustentação, o arrasto e outros. AGs e 
AEs são apropriados para resolver esses problemas, motivando muitos trabalhos. Esses algoritmos são aplicados com sucesso para problemas de otimização tais como de perfis aerodinâmicos (Quagliarella \& Cioppa, 1994; Yamamoto \& Inoue, 1995), perfis multielementos (Cao \& Blom, 1996), perfis subsônicos (Obayashi \& Oyama, 1996) e asas supersônicas (Oyama et al., 1999).

Do estudo desses trabalhos, observa-se que o algoritmo genético é de fácil acoplamento com a função objetivo, sem necessitar da definição de derivadas como ocorre nos GBM, assim como a fácil aplicação ao problema multiobjetivo com descontinuidade das funções objetivo. Nota-se também que os trabalhos se concentram na aplicação, mas não avaliam a influência da função objetivo na qualidade da otimização ou no custo computacional, fato que motiva este estudo.

Por tal motivação, o objetivo do presente trabalho é estudar de forma comparativa o comportamento do problema multiobjetivo para distintas funções objetivo. A partir dessa comparação é possível analisar as vantagens e desvantagens de tais funções, que são definidas com base em duas definições para a geometria: parametrização Parsec e parametrização por ponto de controle. Também são comparadas as otimizações efetuadas com a técnica centrada e upwind. E, por fim, há uma comparação entre os resultados de um modelo invíscido e um modelo viscoso, utilizando o código Mses.

Este texto está organizado da seguinte forma: o capítuo 2 apresenta a revisão bibliográfica da aplicação de otimização em projetos aerodinâmicos e da teoria do perfil; o capítulo 3 descreve o método de volumes finitos e a discretização dos termos convectivos pelas técnicas centrada e upwind, a técnica de geração de malha adotada e as parametrizações utilizadas para definir a geometria do perfil; no capítulo 4, está definido o problema multiobjetivo adotado no trabalho, o algoritmo genético adotado, os parâmetros de avaliação para problemas multiobjetivo e as técnicas de visualização utilizadas para analisar os dados; o capítulo 5 tem a validação e verificação dos códigos de CFD implementados, os testes de convergência de malha e a verificação do algoritmo genético; e o capítulo 6 apresenta a discussão dos resultados obtidos pelo trabalho e a conclusão. 



\section{Conceitos relacionados}

O rio atinge seus objetivos porque aprendeu a contornar obstáculos. (Lao-Tsé)

Este capítulo apresenta conceitos adotados para a simulação e otimização de perfis aerodinâmicos. A seção 2.1 descreve o problema de otimização multiobjetivo, sua aplicação na engenharia aeronáutica e conceitos sobre algoritmos genéticos. A seção 2.2 apresenta a teoria do perfil, com uma breve revisão histórica e de técnicas de aerodinâmica computacional.

\subsection{Otimização}

Em geral, problemas de engenharia encontrados em projetos são intrinsecamente multiobjetivos, ou seja, necessitam de mais de um parâmetro de avaliação. Além disso, as técnicas existentes para resolvê-los, normalmente, combinam simulações numéricas, cálculos analíticos e seleções por categoria. Conseqüentemente, o cálculo de derivadas de funções objetivo é complexo e, em alguns casos, impossível de ser realizado. De acordo com Anderson (2000), métodos de otimização não baseados em gradientes se adaptam bem a esses problemas. Esse autor ainda conclui que métodos de otimização têm sido cada vez mais adotados em projetos de engenharia, pois simplificam o desenvolvimento de suas atividades.

Nas otimizações em engenharia, é muito importante compreender o conceito de variáveis de projeto. Essas variáveis representam parâmetros que podem ser previamente definidos ou alcançados. Existem algumas categorias de variáveis de projeto, e dentre elas pode-se mencionar duas com alto grau de importância no contexto deste trabalho (Anderson, 2000):

- Variáveis de projeto independentes: normalmente denominadas variáveis de projeto, representam valores definidos pelo projetista e que não são modificadas por outros parâmetros. 
Exemplos da área de engenharia aeronáutica incluem a geometria, o material utilizado e o acabamento superficial;

- Variáveis de projeto dependentes: são aquelas que não são diretamente definidas, porém são obtidas por meio de ajustes em variáveis independentes. Como exemplo, tem-se o desempenho dinâmico da aeronave e o peso estrutural.

No ambiente de projetos de engenharia, é comum utilizar técnicas para ajustar as variáveis independentes a fim de parametrizar variáveis dependentes, como no projeto de sistemas de controle. Essa é uma das principais contribuições das técnicas computacionais.

\subsubsection{Otimização multiobjetivo}

O problema de otimização multiobjetivo (PMO) envolve várias funções objetivo. Esses problemas podem ser simplificados e abordados por meio de técnicas de objetivo simples, contudo, podem somente ser resolvidos por técnicas de otimização multiobjetivo (OMO). De acordo com Marler \& Arora (2004), existem muitas formas de resolver as OMO. Este trabalho se concentra em dois desses métodos: o de classificação de dominância de Pareto (PR - do inglês Pareto Rank), que utiliza o conceito de dominância de solução ; e o método do produto ponderado (WP - do inglês Weighted Product), que reduz os objetivos de vários para um, utilizando um produto ponderado.

A dominância de solução utiliza as seguintes definições: seja $x$ vetor de variáveis de projeto e $f_{i}$ o $i$-ésimo objetivo de um problema de $N$ objetivos, o vetor de solução do problema é dado por $F(x)=\left\{f_{1}(x) \ldots f_{N}(x)\right\}$. Sendo $x_{1}$ e $x_{2}$ dois vetores de variáveis de projeto, diz-se que $x_{1}$ não é dominado por $x_{2}$, em um problema de minimização, quando satisfaz:

$$
\begin{array}{ll}
\text { condição1 }: & f_{i}\left(x_{1}\right) \leq f_{i}\left(x_{2}\right) \text { para todo } i, \\
\text { condição2 }: & f_{i}\left(x_{1}\right)<f_{i}\left(x_{2}\right) \text { para algum } i,
\end{array}
$$

Quando uma solução não é dominada por todas as soluções do espaço busca, essa solução é dita solução de Pareto (SP) e é representada por $F\left(x^{*}\right)$.

O conceito de dominância de solução permite definir a frente de Pareto ( $P F$ - do inglês Pareto Front). Essa frente é o conjunto de todas as soluções não dominadas do espaço de busca. Outro conceito importante é a generalização do conceito de PF. Em um conjunto de soluções, pode-se classificar seus elementos em frentes de dominância, onde uma frente representa o subconjunto que não tem dominância entre seus elementos, porém pode ser dominado ou dominar outros. Ao definir um PMO, tem-se a chamada Frente de Pareto verdadeira ( $P F_{\text {true }}$ - do inglês True Pareto Front). Durante o processo de otimização, a técnica empregada define um conjunto de soluções não dominadas, chamadas de Frente de Pareto conhecida ( $P F_{\text {known }}$ - do inglês Pareto Front Known). 
Nesse estudo, o autor denomina Reference Pareto Front $\left(P F_{\text {ref }}\right)$ a frente de Pareto de referência utilizada no cálculo das métricas de desempenho da técnica de otimização. O $P F_{\text {ref }}$ pode ser o $P F_{\text {true }}$, mas para a maioria das aplicações é um conjunto de soluções pré-estabelecidas pela experiência.

No WP é necessário escolher uma ponderação dos objetivos para definir uma função global responsável por avaliar soluções. O produto resultante é apresentado na Equação (2.2), onde $p_{i}$ é o peso do objetivo $i$. Esse método considera uma otimização de objetivo simples. De acordo com Coello et al. (2002), essa solução pertence à $P F$, portanto é não dominada pelas demais.

$$
P(x)=\prod_{i=1}^{N} f_{i}^{p_{i}}(x) .
$$

Deve-se, ainda, ressaltar uma outra forma de aplicar a OMO, forma que visa reduzir as funções objetivo adotadas. Venter \& Sobieszczanski-Sobieski (2002) aplicam uma otimização multidisciplinar para o projeto da asa de uma aeronave de transporte. As otimizações aerodinâmica e de peso estrutural, com restrição de falhas estruturais, são aplicadas.

\subsubsection{Classificação por dominância}

A classificação por dominância (Pareto Rank) é utilizada para ordenar soluções em níveis de dominância, formando Frentes de Dominância. Essa técnica de classificação é composta pelos seguintes passos:

1. Aplica-se a análise de dominância em todas as soluções do conjunto inicial para determinar soluções não dominadas;

2. As soluções encontradas no passo anterior recebem um valor de classificação chamado de rank e passam a pertencer ao conjunto $\mathcal{F}_{i=1}$;

3. Essas soluções são retiradas do conjunto, formando um subconjunto de soluções;

4. Retoma-se o primeiro passo, utilizando o novo subconjunto encontrado.

Esses passos são aplicados por várias iterações, até obter um conjunto vazio, quando todas as soluções terão sido classificadas. O valor de classificação é definido da seguinte forma:

1. O primeiro conjunto de soluções obtido recebe o valor máximo para sua classificação;

2. Os conjuntos seguintes irão receber uma classificação igual à do anterior, reduzida de uma unidade;

3. O último conjunto obtido terá classificação 1 . 
Esses passos são utilizados por muitos algoritmos genéticos multiobjetivo, pois não priorizam soluções de acordo com as frentes de dominância. No trabalho de Deb et al. (2002), é proposto um algoritmo de baixo custo computacional para desempenhar a classificação por dominância.

\subsubsection{Algoritmo genético}

Ao longo da década de 1990, os algoritmos genéticos (AG) foram extensivamente utilizados como ferramentas de busca e otimização para problemas de diversas áreas, incluindo ciências, economia e engenharia. De acordo com Goldberg (1989), a primeira razão do sucesso dessa abordagem é sua ampla aplicabilidade, facilidade de uso e sua generalização do espaço de busca.

O conceito de algoritmos genéticos foi inicialmente concebido por Holland (1975). Inúmeras pesquisas e vertentes foram propostas com o intuito de melhorar a abordagem inicial (Goldberg, 1989; Gen \& Cheng, 1997; Holland, 1975; Michalewicz, 1992; Mitchell, 1996; Deb, 2004).

Esse algoritmo considera aspectos da teoria da seleção natural de Charles Darwin. Nela, indivíduos são representados pela sua informação genética (cromossomos). Um grupo de indivíduos (população) é colocado em um ambiente específico (função avaliadora ou fitness). Os indivíduos mais aptos são selecionados (seleção) para gerar novas populações a partir da mistura de informação gênica (cruzamento ou crossover) e mudanças aleatórias dessa informação (mutação). Assim como na natureza, no AG, a geração de novos indivíduos a partir dos mais aptos converge para um grupo bem adaptado ao ambiente. Fazendo a analogia com um problema de otimização, o processo converge para soluções de boa qualidade. Na seção 4.1 são detalhados os principais conceitos sobre AGs e na seção 4.3 sua integração com a dinâmica dos fluidos computacional (CFD - do inglês Computational Fluid Dynamics).

\subsection{Aerodinâmica compressível}

De acordo com Anderson (1999), o desenvolvimento histórico da aerodinâmica e, conseqüentemente, do projeto de aerofólios, se iniciou no século XIX. Nesta seção são apresentados os principais marcos do desenvolvimento científico e técnico de acordo com o autor:

1858 - Teoria de filamento de vórtice de Helmholtz (do inglês vortex filament theory);

1891 - Frederick Lanchester estuda perfis aerodinâmicos e teoriza sobre a circulação, gerando a sustentação;

1891-4 - Lanchester concebe o modelo da asa finita, teoria da linha de sustentação (do inglês Lifting line theory), no mesmo período em que Samuel Langley projeta seu avião a vapor e Lilienthal voava seus planadores; 
1902 - Wilhelm Kutta recebe o diploma de Ph.D em Matemática com a tese sobre a sustentação aerodinâmica. Esse é o primeiro cálculo de sustentação para um perfil com camber e evidenciou a incapacidade do método de calcular o arrasto (paradoxo de D'Lambert);

1906 - Nikolai Joukowski publica 2 trabalhos sobre seus resultados relacionados a sustentação com a teoria da circulação $\left(L=\rho V_{\infty} \Gamma\right)$;

1910 - Joukowski desenvolve a transformação conformal que será conhecida como perfil de Joukowski;

1912-13 - Os perfis desenvolvidos por Lanchester têm uma melhora de 10\% ( $L / D=17)$ em comparação com os perfis da época;

1917 - Ludwig Prandtl mostra a superioridade do perfil espesso para Número de Reynolds altos (usuais para os aviões da época), evidenciando o erro dos estudos experimentais anteriores que negligenciaram a influência do parâmetro e haviam concluído que os perfis finos eram melhores;

1922 - Surge a teoria do aerofólio fino de Michel Max Munk;

1925 - Consolidação do estudo sistemático para desenvolvimento de novos perfis e o estudo em escala real desses no túnel de vento NACA-VDT (do inglês Variable Density Tunnel);

1926 - Glauert aplica a série de Fourier na teoria de Munk para resolver as integrais e calcular a sustentação e o momento do perfil;

1927 - Contribuição de Glauert para o estudo de escoamentos compressíveis;

1930 - Significante progresso no estudo e projeto de perfis devido à teoria de Theodorsen e os estudos de Eastmen Jacob no VDT em Langley;

1931 - Theodore Theodorsen propõe um método analítico para solução exata de perfis espessos com formato arbitrário;

1931-2 - Jacob e sua equipe concebem a família de perfis Naca 4 dígitos;

1935 - Jacob e sua equipe desenvolvem a nova família de perfis Naca 5 dígitos. No mesmo ano Jaboc vai a um congresso em Roma onde conhece Geoffrey I. Taylor e Melvill Jones. Estes dividem com Jacob seus resultados sobre o estudo de camada limite e a relação do gradiente de pressão com a separação. Jacob volta para seu laboratório convencido de desenvolver perfis com escoamento laminar para redução do arrasto;

1939 - Consolidação dos perfis laminares por Jacob, modificando a teoria de Theodorsen, criando o método inverso (publicado no Naca annual report) - A primeira união da teoria com o experimentalismo; 
1960s - Whitcomb desenvolve o estudo de perfis em regime transônicos e desenvolve os primeiros perfis transônicos;

1972 - A NASA apresenta para a comunidade os perfis supercríticos.

Na seqüencia é apresentada a principal nomenclatura relacionada à teoria do perfil.

\subsubsection{Teoria do perfil}

Estudos sobre aerofólios levaram a uma série de definições e nomenclaturas que se consolidaram no meio aeronáutico. A seguir, é apresentada uma lista de definições importantes:

- Circulação: grandeza que relaciona a sustentação de um corpo com a sustentação de um cilindro rotativo em escoamento potencial;

- Bordo de ataque: é a região a montante no escoamento. Geralmente (salvo para os primeiros perfis supersônicos estudados) a superfície com maior curvatura do perfil;

- Raio de bordo de ataque: é o raio de curvatura do bordo de ataque;

- Bordo de fuga: é a região a jusante no escoamento, em formato de ponta;

- Linha de corda: é o segmento de reta que vai do bordo de fuga até o bordo de ataque, passando pelo centro do círculo de bordo de ataque. Para algumas famílias de perfis, como a Parsec (Sobieczky, 1998), essa definição não é aplicada;

- Extradorso e intradorso: são as superfícies superior e inferior do perfil, respectivamente;

- Linha de camber ou média: é a linha formada pelo lugar geométrico equidistante do extradorso e do intradorso;

- Camber: é o valor da maior distância da linha de camber com a corda, sendo positivo para y positivo;

- Drop: característica de alguns perfis que apresentam o bordo de ataque defletido para baixo;

- Espessura: é a maior distância entre o extradorso e o intradorso;

- Distribuição de espessura: é a curva definida pela distância entre o extradorso e o intradorso;

- Incidência: ângulo formado entre a linha de corda e a velocidade do escoamento não perturbado;

- Força aerodinâmica: força gerada pela interação entre o perfil e o escoamento livre; 
- Sustentação: componente da força aerodinâmica perpendicular ao escoamento livre;

- Arrasto: componente da força aerodinâmica na direção do escoamento livre;

- Momento de arfagem: é o torque gerado pela distribuição de pressão em torno do aerofólio. Neste trabalho adota-se o momento a $1 / 4$ do bordo de ataque. Sua intensidade tem sentido positivo, conforme Figura (2.2).

Esses estudos geraram a teoria do aerofólio, permitindo estudos sobre o comportamento das forças em uma determinada geometria de perfil, variando a incidência, o Mach e o número de Reynolds Anderson (1995); Milne-Thomson (1958); Roskan \& lan (1997). A seguir, apresenta-se, de forma simplificada, a teoria do aerofólio, parte integrante do presente trabalho.

\subsubsection{Teoria do perfil: cálculo das forças e coeficiente de pressão}

A intensidade e a direção da força aerodinâmica em torno da asa são funções da velocidade do escoamento $V$, da densidade do ar $\rho$, da área alar $S$, da viscosidade do ar $\mu$, da velocidade do som $a$ e da incidência $\alpha$. Denominando por $\vec{d}=\vec{d}(V, \rho, S, \mu, a, \alpha)$ a direção da força e por $F a=F a(V, \rho, S, \mu, a, \alpha)$ a intensidade (Figura 2.1), obtem-se a adimencionalizanção da força:

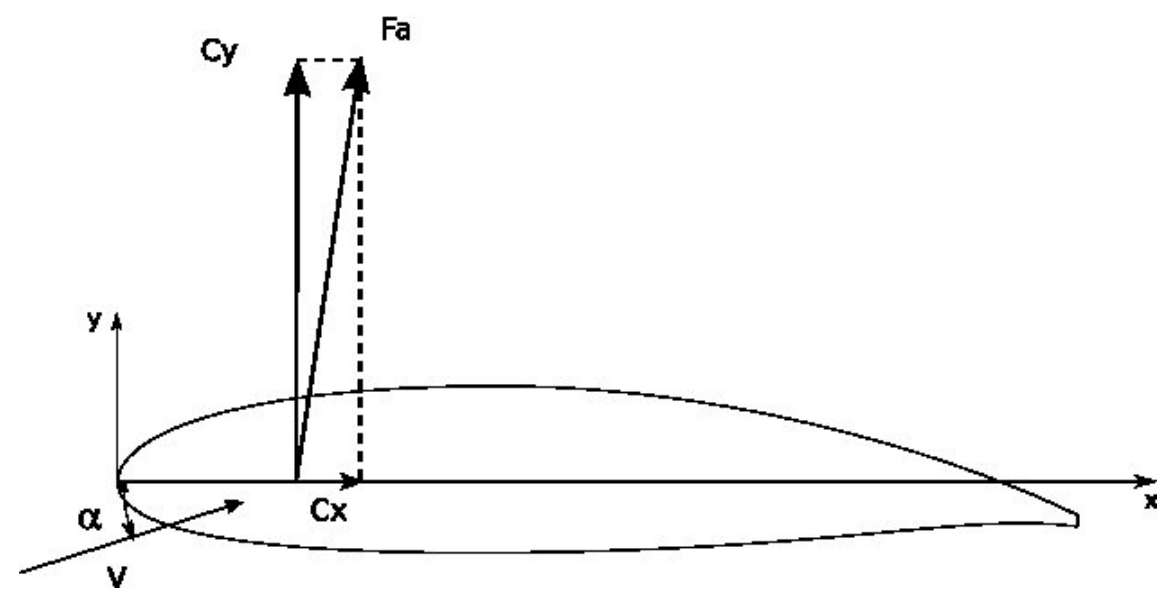

Figura 2.1: Força aerodinâmica em torno do perfil: componentes longitudinais e transversais.

$$
\overrightarrow{f a}=\frac{\overrightarrow{F a}}{q_{\infty} S}=f a\left(R e, M a_{\infty}, \alpha\right) \cdot \vec{d}\left(R e, M a_{\infty}, \alpha\right),
$$

onde $q_{\infty}$ é a pressão dinâmica do escoamento livre. Separando nas componentes longitudinal e transversal ao escoamento (Figura 2.2) se têm:

$$
\begin{aligned}
C L & =\frac{L}{q_{\infty} S}=C L(R e, M a, \alpha) \\
C D & =\frac{D}{q_{\infty} S}=C D(R e, M a, \alpha) .
\end{aligned}
$$




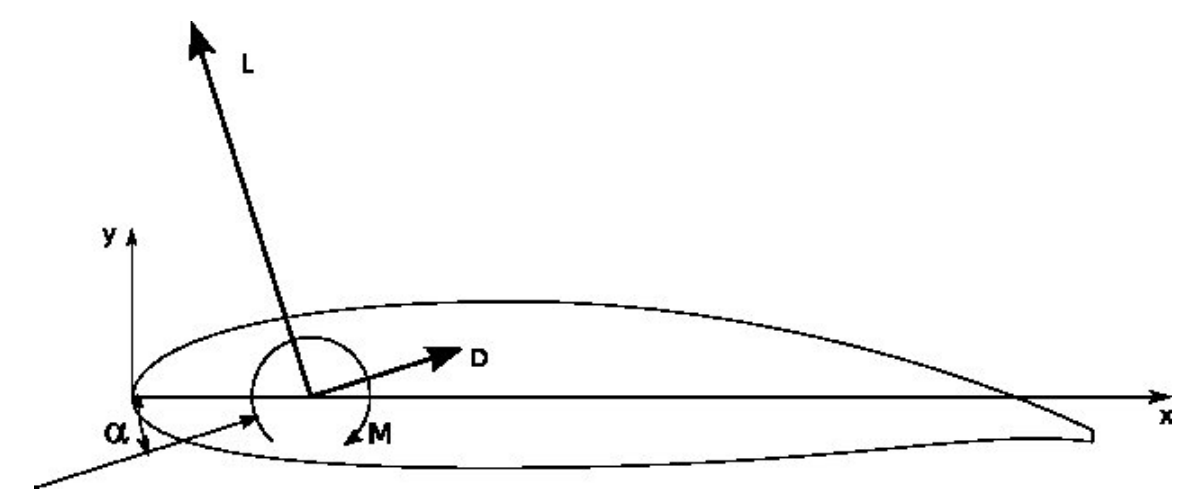

Figura 2.2: Força aerodinâmica em torno do perfil: componentes de sustêntação e arrasto.

Analogamente, o momento das forças em torno do perfil é dado pela equação adimensional:

$$
C M=\frac{M}{q_{\infty} S c}=C M(R e, M a, \alpha) .
$$

Formalmente, para o caso 2D, simplifica-se $S=c \cdot 1$ e a nomenclatura se altera para $C l, C d$ e $C m$ em substituição à $C L, C D$ e $C M$, respectivamente. Outro parâmetro importante no estudo do perfil é o coeficiente de pressão, definido como a pressão adimensional em relação a uma pressão de referência. Para o perfil, a pressão de referência é a do escoamento livre. Expressa-se o coeficiente de pressão por:

$$
C p=\frac{P-P_{\infty}}{q_{\infty}}
$$

De acordo com Roskan \& lan (1997), utilizando a equação de Bernoulli (Anderson, 1995), para o caso incompressível, escreve-se a Equação 2.6 na forma:

$$
C p=1-\left(\frac{V}{V_{\infty}}\right)^{2}
$$

E para o caso compressível em:

$$
C p=\frac{2\left(P-P_{\infty}\right)}{\frac{\gamma}{2} P_{\infty} M a_{\infty}^{2}}
$$

A partir do valor de $C p$ em torno do perfil, é possível calcular os coeficientes de força e momento do aerofólio. O cálculo é feito a partir de uma integral de superfície da pressão (Figura 2.3. Sendo o vetor normal à superfície orientado para fora e assumindo o sentido anti-horário como positivo, tem-se:

$$
\vec{s}=\Delta y \cdot i_{x}-\Delta x \cdot i_{y}
$$

E, aplicando a integral de superfície, tem-se: 


$$
\vec{F}=\int_{S} C p \cdot d \vec{s}=\frac{\int_{S} P \cdot d \vec{s}-\int_{S} P_{\infty} \cdot d \vec{s}}{q_{\infty}}
$$

E para o momento, tem-se:

$$
C m=\int_{s} C p \cdot x(-d x)
$$

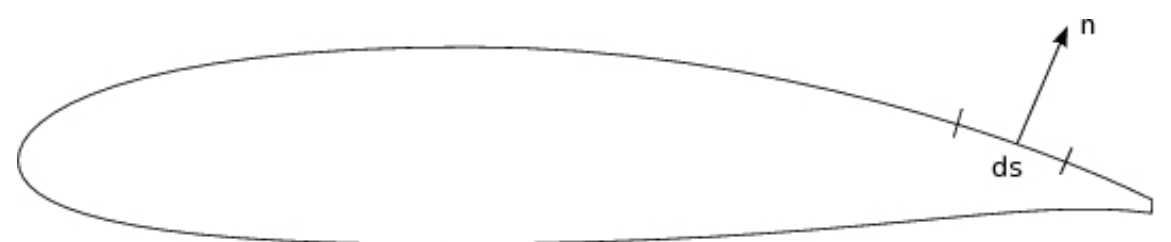

Figura 2.3: Orientação da área infinitesimal para integração de superfície da pressão.

Como $P_{\infty}$ é uma constante, o segundo termo do numerador é zero e tem-se a força sobre o aerofólio na forma adimensional. Separando as componentes normais e longitudinais ao escoamento, tem-se:

$$
\begin{aligned}
C x & =\int_{s} C p d y, \\
C y & =\int_{s} C p(-d x),
\end{aligned}
$$

e as componentes $C x$ e $C y$ são rotacionadas para fornecer os valores de $C l$ e $C d$ :

$$
\left\{\begin{array}{l}
C l \\
C d
\end{array}\right\}=\left[\begin{array}{ll}
\cos \alpha & -\sin \alpha \\
\sin \alpha & \cos \alpha
\end{array}\right] \cdot\left\{\begin{array}{l}
C y \\
C x
\end{array}\right\} .
$$

O cálculo do coeficiente de momento é feito por meio da Equação 2.11. O valor desse coeficiente está diretamente relacionado ao equilíbrio e à estabilidade da aeronave. Para a aeronave ser estável e equilibrada, é necessário utilizar superfícies estabilizadoras. Como descrevem Roskan \& lan (1997), a superfície horizontal utilizada para equilibrar a aeronave, para aviões convencionais, gera uma força vertical para baixo, permitindo o equilíbrio de torque gerado pela asa, aumentando, conseqüentemente, o arrasto da aeronave, dada a necessidade de aumento da sustentação da asa.

Além disso, a sustentação da asa é responsável pelo surgimento do vórtice de ponta de asa que gera o arrasto induzido. Roskan \& lan (1997) descrevem o fenômeno do arrasto e o estima conforme a equação:

$$
C D_{i}=\frac{C l^{2}}{\pi A R_{w} e_{w}}
$$


onde $C l$ é o coeficiente de sustentação da asa, $A R_{w}$ é a razão de aspecto da asa e $e_{w}$ é o coeficiente de Oswald da asa, dependente da geometria.

Esse arrasto é proporcional ao quadrado da sustentação, logo não se pode aumentar indefinidamente o $\mathrm{Cl}$ da asa, pois pode comprometer sua eficiência aerodinâmica. O aumento do $\mathrm{Cl}$ em função da força gerada pela superfície estabilizadora (profundor) leva ao aumento do arrasto induzido, também denominado arrasto de trimagem. Roskan \& lan (1997) afirmam que esse arrasto tem valores típicos entre $0,5 \%$ e $5,0 \%$ do arrasto total.

De acordo com Roskan \& lan (1997), a contribuição desse arrasto de trimagem no arrasto total da aeronave é estimado pela Equação (2.15). Observa-se, portanto, que o arrasto é proporcional ao quadrado da sustentação da superfície horizontal $\left(C l_{h}\right)$. A sustentação necessária para equilibrar a aeronave é, conseqüentemente, proporcional ao momento gerado pela asa, ou seja $\mathrm{Cm}$. Busca-se, portanto, uma menor intensidade de $\mathrm{Cm}$.

$$
C D_{\text {trim }}=\frac{C l_{h}^{2}}{\pi A R_{h} e_{h}}\left(\frac{q_{h}}{q_{\infty}} \frac{S_{h}}{S_{r e f}}\right)^{2}
$$

\subsubsection{Influência da compressibilidade e Mach de divergência}

Os estudos experimentais e teóricos anteriores a Whitcomb (1974) mostraram que, para um $C l$ constante, o arrasto de um determinado perfil se mantém praticamente inalterável dada a variação do número de Mach. Porém, para Mach maior que um determinado valor, o arrasto aumenta drasticamente. Esse é o chamado Mach de divergência de arrasto ou Mach crítico. Apresentam-se, nesta seção, duas definições para a determinação do Mach de divergência:

- Definição de Douglas: o valor a partir do qual $\frac{\partial C d}{\partial M a}=0,1$;

- Definição de Boeing: quando o arrasto é maior em 0,0020 em relação ao arrasto incompressível.

O comportamento do arrasto com o aumento do Mach é observado na Figura (2.4). Os chamados perfis supercríticos foram desenvolvidos por Whitcomb (1974) e sua equipe, buscando o aumento do Mach crítico e a redução do arrasto no regime transônico. O arrasto nesse regime, chamado de arrasto de onda, está diretamente ligado à intensidade da onda de choque formada na superfície da asa. Os aerofólios projetados para o regime transônico aceleram pouco o escoamento, evitando velocidades supersônicas. Por essa característica, as ondas de choque desses perfis, quando ocorrem, se localizam mais próximas ao bordo de fuga e com intensidade menor.

Devido à distribuição de velocidade descrita anteriormente, os perfis transônicos ou supercríticos têm uma distribuição de pressão em sua superfície com características específicas, principalmente se comparadas com os perfis incompressíveis. Na Figura (2.5), pode-se notar a diferença 


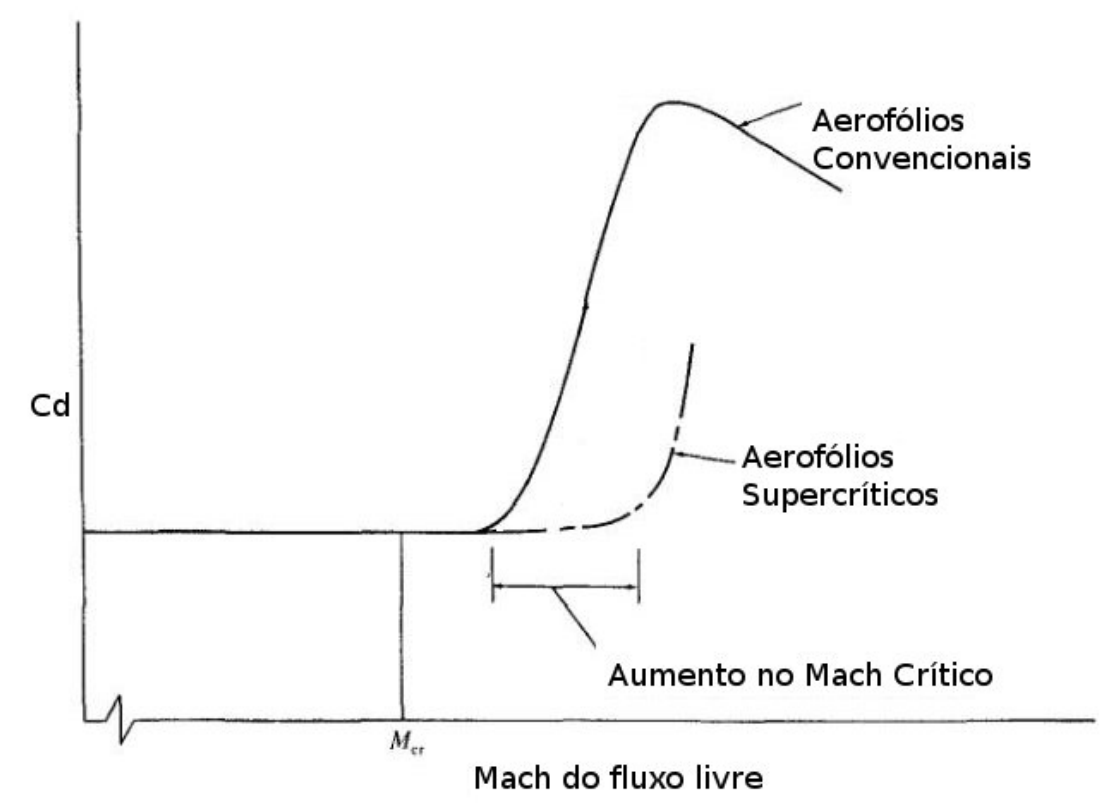

Figura 2.4: Influência da compressibilidade no arrasto do aerofólios.

típica entre perfis transônicos e convencionais. A linha horizontal referenciada representa o coeficiente $C p_{c r}$, denominado $C p$ crítico, o qual está relacionado à velocidade de Mach 1,0 , onde o escoamento passa a ser supersônico. $\mathrm{O}$ valor do $C p_{c r}$ é calculado por:

$$
C p_{c r}=\frac{2}{\gamma M_{\infty}^{2}}\left\{\frac{M_{\infty}^{2}(\gamma-1)+2}{\gamma+1}-1\right\} .
$$

O desempenho da aeronave depende dos seguintes fatores: o sistema de propulsão, os efeitos aerodinâmicos que agem sobre a aeronave e seu peso. Como previamente apresentado, as características aerodinâmicas do perfil determinam, em grande parte, as características aerodinâmicas do avião. Pode-se, portanto, determinar a influência que um perfil terá no desempenho do avião observando a influência de seus coeficientes aerodinâmicos nos parâmetros de desempenho.

O valor do alcance de uma aeronave é estimado pela chamada equação de Breguet:

$$
\text { Alcance }=V_{\infty} \frac{L}{D} \frac{1}{S F C} \log \frac{W_{0}+W_{f}}{W_{0}}
$$

onde $V_{\infty}$ é a velocidade da aeronave, $\frac{L}{D}$ é a eficiência aerodinâmica, $S F C$ é o consumo específico de combustível, $W_{0}$ é o peso vazio da aeronave e $W_{f}$ é a massa de combustível na aeronave.

A velocidade $V$ pode ser escrita em função da velocidade do som do escoamento livre: $V=$ $M a \cdot a_{\infty}$. Portanto, como afirmam Mair \& Birdsall (1998), o alcance da aeronave, no regime transônico, para uma quantidade fixa de combustível, é proporcional ao parâmetro $M a \frac{L}{D}$. Não se pode aumentar o $M a$ arbitrariamente para melhorar o alcance, pois existe o problema de ultrapassar o Mach de divergência. Por isso, torna-se importante a obtenção de perfis com maiores Mach 


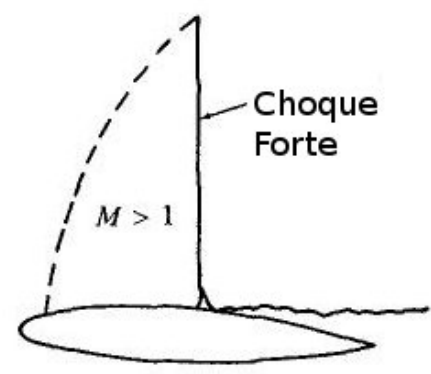

(a)

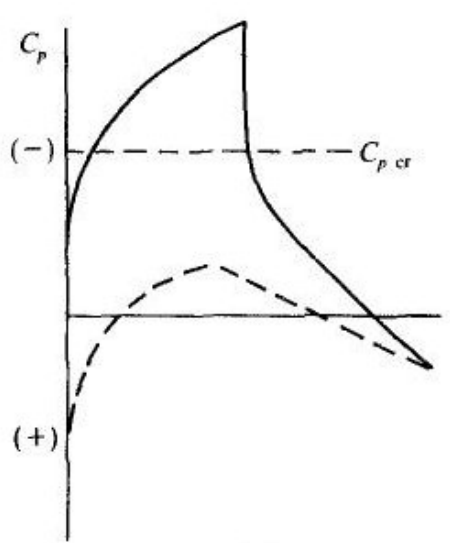

(b)

Naca $64_{2}-\mathrm{A} 215$

$\mathrm{Ma}=0,69$

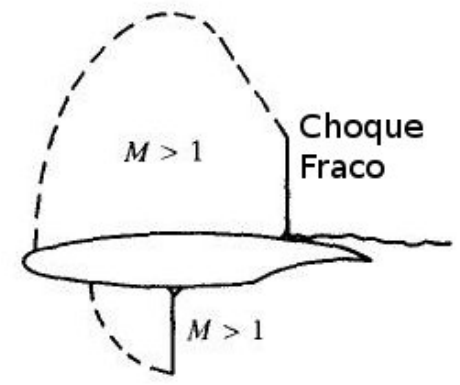

(c)

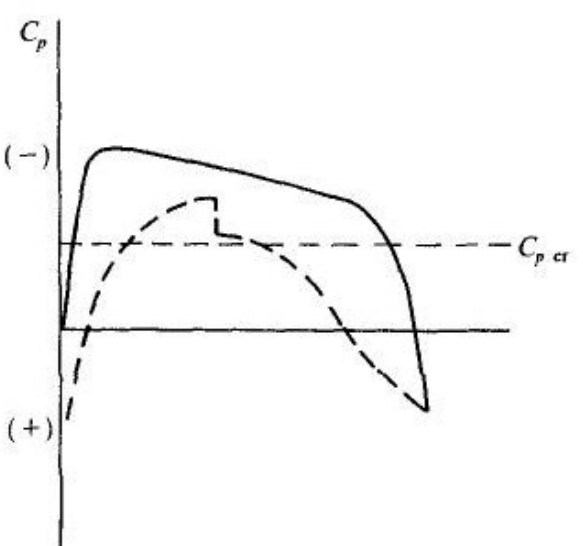

(d)

Perfil Supercrítico $(13,5 \%$ espessura) $\mathrm{Ma}=0,79$

Figura 2.5: Influência da compressibilidade na distribuição de Cp.

críticos. Esse também é um problema encontrado ao desenvolver aeronaves supersônicas de uso comercial (Obayashi \& Sasaki, 2004).

Lembrando da influência do arrasto de trimagem, pode-se observar que ele reduzirá o valor do parâmetro $\frac{L}{D}$.

\subsubsection{Dinâmica dos fluidos computacional}

A popularização do computador digital permitiu o desenvolvimento de métodos numéricos, viabilizando soluções aproximadas de cálculos até então inviáveis, tal como ocorre em estudos aerodinâmicos. A grande dificuldade encontrada pelos aerodinamicistas é a complexidade e a impossibilidade de encontrar soluções analíticas para geometrias arbitrárias sem utilizar aproximações nos modelos matemáticos.

Devido à pouca capacidade dos primeiros computadores, inicialmente, as pesquisas em CFD utilizavam modelos matemáticos mais simples para representar escoamentos. A análise de escoamentos incompressíveis e irrotacionais pela teoria potencial possibilitou o desenvolvimento dos métodos dos painéis, uma das primeiras metodologias aplicadas para prever, numericamente, 
escoamentos. A aplicação do método na aeronáutica foi direta, sendo até hoje uma importante ferramenta para projetos.

As mesmas equações potenciais utilizadas para desenvolver os métodos dos paineis podem ser diretamente resolvidas, a partir de técnicas capazes de calcular, de forma aproximada, equações diferenciais ordinárias ou parciais. Essas técnicas possibilitaram não só a solução de equações potenciais para os escoamentos incompressíveis, como também modelos com variação de densidade. Tem-se como exemplo os trabalhos Jameson (1974, 1978, 1979); Jameson \& Caughey (1977); Jameson \& Chipman (1979), nos quais foram realizados estudos aplicados no projeto e análise de aerofólios transônicos. Apesar da simplicidade dos modelos, essas técnicas necessitam de recursos computacionais que, no passado, eram relativamente escassos. Isso levou ao estudo e desenvolvimento de técnicas para a redução do custo computacional envolvido, assim como métodos implícitos e multigrids.

Apesar dos modelos potenciais fornecerem bons resultados na previsão do escoamento em torno de perfis e asas, eles se limitam ao estudo de escoamentos com ondas de choques fracas, devido à hipótese irrotacional do escoamento. Conseqüentemente foi necessária a utilização de modelos mais completos. Pensando também no estudo de fluidos viscosos, a aplicação de modelos de correção viscosa e solução das equações de Navier-Stokes (Drela \& Giles, 1987) sempre foi uma linha de pesquisa muito explorada, levando ao estudo de modelos de turbulência.

Os métodos de CFD necessitam de um modelo matemático, em geral, equações diferenciais parciais (EDP) e técnicas numéricas para resolvê-las. Essas técnicas discretizam equações e usam aproximações para derivadas ou integrais. Essas aproximações, ao serem aplicadas a um ponto (volume ou elemento), utilizam informações dos pontos (volumes ou elementos) discretos vizinhos a ele. A aproximação discreta das derivadas pode ser feita por diferentes métodos, como por exemplo volume finitos (FV), diferenças finitas (FD) e elementos finitos (FE). Este trabalho se concentra em técnicas FV.

Este trabalho segue as equações de Euler (Hirsch, 1991a). No caso compressível, essas equações são hiperbólicas, apresentando termos convectivos. Esses termos podem ser discretizados por técnicas centradas ou descentradas (upwind). A discretização utilizando técnicas centradas apresentam termos instáveis, sendo necessária a utilização de dissipação artificial para estabilizar o método. Por sua vez, as técnicas upwind apresentam, na própria discretização, termos estabilizantes, não necessitando de dissipação adicional.

\section{Métodos centrados}

Os métodos ou esquemas centrados são aqueles que utilizam discretização espacial centrada no ponto ou célula em questão. Assim, o estêncil da aproximação utiliza informação de todos os vizinhos à célula em questão de forma igualitária. Alguns desses esquemas foram desenvolvidos por Lax \& Wendroff (1960), porém seus métodos são de primeira ordem de precisão. Briley $\&$ McDonald (1975) aplicaram a segunda ordem de precisão para esquemas centrados, Beam \& 
Warming (1976, 1978) desenvolveram esquemas centrados implícitos no tempo e Jameson et al. (1981) projetaram um esquema centrado explícito no tempo utilizando o método de Runge-Kutta de cinco estágios para a integração temporal. Hirsch (1991b) afirma que os trabalhos de Jameson et al. (1981) e Beam \& Warming (1976) usam essencialmente a mesma aproximação espacial para os termos de fluxo, diferindo apenas em sua aplicação prática por razões históricas: o primeiro foi desenvolvido para diferenças finitas em coordenadas curvilíneas e o segundo para volumes finitos.

O método desenvolvido por Jameson et al. (1981), usando a aproximação centrada de segunda ordem para o balanço de fluxo nas interfaces do volume e integração temporal explícita pelo método de Runge-Kutta, necessita de dissipação artificial para estabilizar o método, principalmente em regiões com ondas de choque e escoamentos supersônicos. O método é uma combinação de termos dissipativos eficientes, apropriado para a utilização com aceleração de convergência como o método multigrid ou multimalhas. Além disso, as propriedades do método de Runge-Kutta é aplicável para obter suavidade de propriedades necessárias para o método multigrid.

\section{Métodos upwind}

van Leer (2006) faz uma revisão histórica do desenvolvimento dos métodos upwind usados em CFD. O termo upwind foi primeiramente usado no trabalho de Courant et al. (1952), no qual o uso do esquema descentrado veio como consequiência natural da variante atrasada do método das características, o que geralmente ocorre no estudo dos escoamentos compressíveis (Toro, 1999). Godunov (1959) desenvolveu sua interpretação do esquema donor-cell, que pode ser generalizada, a partir da solução do problema de Riemann, para o caso 1D das equações de Euler.

Fromm (1968) construiu um esquema advectivo de alta ordem com baixa dispersão (Zero Average Phase Error Method) obtendo um estêncil upwind. Ao aplicar o teorema de Parseval para relacionar o erro do método advectivo aplicado a problemas de marcha no tempo, Wesseling (1973) observou que os métodos upwind minimizam o erro quando a solução inicial apresenta descontinuidades.

van Leer (1977) desenvolveu seu método upwind, intrinsecamente de primeira ordem de precisão, a partir dos trabalhos de Godunov. van Leer (1979) discute sobre a obtenção de altas ordens de precisão para esses métodos. Seguindo a mesma linha, Roe (1981) desenvolveu o método upwind tipo Godunov, propondo a solução de um problema de Riemann aproximado. Esse método é do tipo separação de diferença de fluxo (Flux-Difference Splitting). Como exemplo de outro método do tipo tem-se o trabalho de Osher \& Solomon (1982). O trabalho de Roe é descrito, por van Leer (2006), como a aproximação mais detalhada para o sistema de ondas e é um dos métodos upwind mais populares. A aproximação de Roe se desenvolve a partir de uma linearização local das equações de Euler. As ondas de choque são substituídas por simples ondas de compressão. O balanço de fluxo na interface entre 2 células é separado em contribuições das ondas que se movimentam entrando e saindo da célula. 
A utilização do problema de Riemann aproximado é suficiente para a aplicação em volumes finitos, a fim de obter bons resultados em simulações numéricas. Para todos os métodos anteriormente apresentados, o modelo resolve uma onda de choque, ou de compressão, deslocando-se entre as interfaces das células.

\section{Alta ordem de precisão}

Godunov (1959) afirma: "[...]se um esquema advectivo conserva a monotonicidade da solução, o método é de $1^{a}$ ordem[...]". Para conseguir aumentar a ordem de prescrição desses métodos, é necessário aplicar uma reconstrução dos valores das propriedades, inicialmente com aproximação constante na célula, permitindo o cálculo do fluxo na interface. A utilização de alta ordem induz uma oscilação da solução nas vizinhanças da descontinuidade. Boris e seus colaboradores (Boris \& Book, 1973, 1976, Boris et al., 1974) e van Leer (1979) desenvolveram os primeiros estudos para obter métodos upwind de alta ordem de precisão sem oscilações. Basicamente, é introduzido um limitante para os parâmetros durante a reconstrução e a utilização de uma estrutura previsor-corretor, conhecido como transporte de fluxo corrigido (FCT - do inglês Flux-Corrected Transport).

A popularização dos esquemas de alta ordem levaram ao desenvolvimento de limitadores de fluxo eficientes para o caso 1D. Harten (1984) desenvolveu o chamado TVD (do inglês Total Variation Diminishing). Posteriormente, ele se dedicou ao estudo dos métodos ENO (do inglês Essentially Non-Oscillatory).

\section{Extensão para multidimensional}

A técnica mais utilizada para estender os métodos tipo Godunov de 1D para multidimensionais consiste em resolver para cada interface um problema de Riemann na direção normal a ela. Isso acarreta diversos problemas, principalmente quando existem ondas de choques oblíquas à interface. Em Roe (1986), o autor aplicou uma generalização para o problema multidimensionais real.

Neste capítulo, foi apresentada a revisão bibliográfica da aplicação de otimização em aerodinâmica e os conceitos relacionádos de aerodinâmica e otimização. No próximo capítulo, são apresentadas as técnicas aplicadas para a simulação numérica e as parametrizações da geometria. 



\section{CAPÍTULO}

\section{3}

\section{Simulação numérica de escoamentos compressíveis}

A função das asas é elevar algo pesado ao lugar onde ficam os deuses. Mais do que qualquer outra parte do corpo, elas são de natureza divina. (Platão)

As equações que governam os fenômenos para escoamentos bidimensionais compressíveis e invíscidos são:

$$
\frac{\partial Q}{\partial t}+\frac{\partial F}{\partial x}+\frac{\partial G}{\partial y}=0
$$

onde:

$$
\begin{aligned}
Q & =[\rho, \rho u, \rho v, e]^{t}, \\
F & =\left[\rho u, \rho u^{2}+p, \rho u v,(e+p) u\right]^{t}, \\
G & =\left[\rho v, \rho u v, \rho v^{2}+p,(e+p) v\right]^{t}, \\
p & =(\gamma-1)\left[e-0.5 \rho\left(u^{2}+v^{2}\right)\right],
\end{aligned}
$$

onde $\rho$ é a densidade; $u$ é a velocidade na direção $x ; v$ é a velocidade na direção $y$; $e$ é a energia interna do fluido; $p$ é a pressão; $\gamma=\frac{c_{p}}{c_{v}}$, onde $c_{p}$ é o calor específico a pressão constante e $c_{v} \mathrm{o}$ calor específico a volume constante. 
Conforme apresentado no capítulo 1, quatro métodos são utilizados para resolver as equações anteriores para fins de comparação: o método de Jameson (Jameson et al., 1981; Azevedo et al., 1992), o método upwind tipo Godunov proposto por Roe (Roe, 1981, 1986) e Mses nos modos invíscido e viscoso (Drela \& Giles, 1987; Terry, 2004).

Para resolver computacionalmente essas equações, este trabalho emprega os métodos de volumes finitos para discretização dessas equações. Na seção 3.1 são apresentadas as bases para os métodos adotados no presente trabalho.

\subsection{Volumes Finitos}

A técnica chamada de volumes finitos (FV - do inglês Finite Volume) é utilizada para aproximar derivadas espaciais pela forma integral das Equações (3.1). Dessa formulação, assumindo-se as hipóteses de compressibilidade, invíscido e escoamento 2D, obtém-se a equação:

$$
\int_{V} \frac{\partial Q}{\partial t} d v+\int_{S}\left(F \cdot \vec{i}_{x}+G \cdot \vec{i}_{y}\right) d \vec{s}=0 .
$$

Aplicando as aproximações utilizadas em volumes finitos (propriedades uniformes de escoamento dentro do volume e nas faces; malha estacionária $-\frac{\partial V}{\partial t}=0$ - de geometria quadrilateral, como mostrada na Figura (3.1), pode-se discretizar as equações para a forma da Equação (3.4). Essa aproximação requer somente a solução para equação diferencial ordinária (EDO) e a definição para a aproximação para o balanço de fluxo nas faces.

$$
V_{i, j} \frac{\partial \bar{Q}_{i, j}}{\partial t}+\sum_{k=1}^{4}\left(\bar{F}_{k} \cdot \vec{i}_{x}+\bar{G}_{k} \cdot \vec{i}_{y}\right) \cdot \Delta \vec{S}_{k}=0 .
$$

O somatório da Equação 3.4 é denominado $T(Q)$. Portanto, é muito comum encontrar a formulação acima na forma:

$$
\frac{\partial \bar{Q}_{i, j}}{\partial t}=-\frac{1}{V_{i, j}} \cdot T\left(\bar{Q}_{i, j}\right) .
$$

Na próxima seção 3.1.1) é descrito, de forma breve, o código Mses utilizado para avaliar o uso de viscosidade na otimização. Nas seções 3.1.2 e 3.1 .3 são apresentados os métodos adotados para aproximar o balanço de fluxo ou para efetuar a discretização espacial. O primeiro, seção 3.1.2. é o método centrado de Jameson introduzido na seção 2.2.4, o segundo, seção 3.1.3, é o método upwind de Roe, introduzido na seção 2.2.4.

\subsubsection{Modelo viscoso: Mses}

A formulação numérica do Mses consiste na discretização por volumes finitos, sobre uma malha estruturada, das equações de Euler estacionárias, usando uma dissipação artificial com caráter 


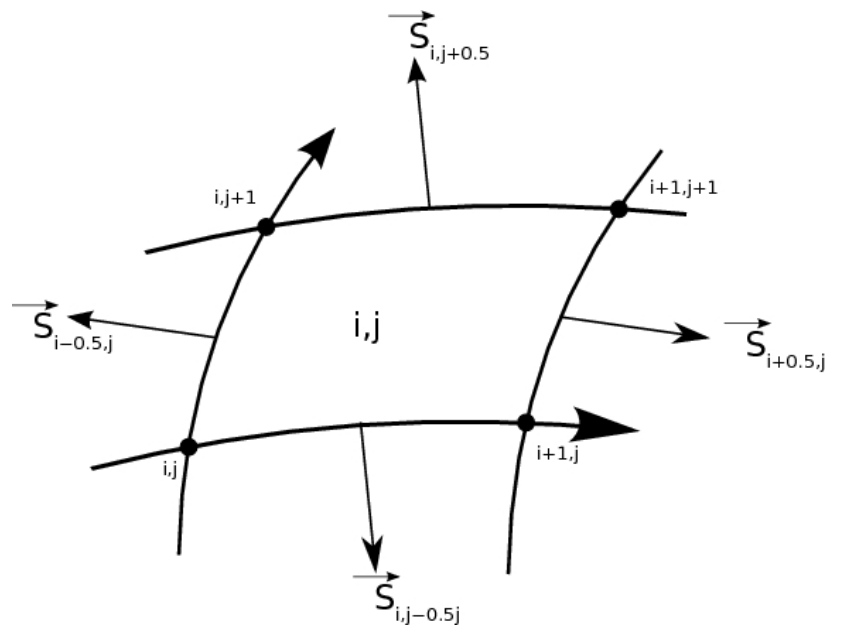

Figura 3.1: Esquema do elemento usado para aplicar a aproximação de volumes finitos para uma malha quadrangular.

upwind. A malha acompanha as linhas de corrente da geometria, permitindo simplificar as equações e, conseqüentemente, diminuindo o número de incógnitas a serem resolvidas. A solução do sistema é efetuada usando o método de Newton para sistemas não lineares (Terry, 2004).

O código utiliza a técnica de solução para escoamentos invíscidos acoplada com a técnica de correção de camada limite para modelar seu efeito. A região viscosa do escoamento (camada limite e esteira) é representada pela teoria da camada limite (Schlichting, 1955). A modelagem é feita pela formulação integral para a camada limite. O acoplamento entre a região viscosa e invíscida é efetuado pela espessura de deslocamento da camada limite ${ }^{1}$.

\subsubsection{Método centrado: Jameson}

Jameson e seus colaboradores, ao longo da década de 1970, trabalharam com métodos para a formulação potencial. Jameson et al. (1981) propuseram um método de volumes finitos com esquema centrado, utilizando dissipação artificial, devido à natureza instável dos métodos centrados aplicados a equações hiperbólicas. Calculando as propriedades do escoamento nas interfaces, como uma média dos valores nas células adjacentes à face, obtém-se:

$$
\begin{gathered}
Q_{i \pm \frac{1}{2}, j}=\frac{Q_{i, j}+Q_{i \pm 1, j}}{2} \\
Q_{i, j \pm \frac{1}{2}}=\frac{Q_{i, j}+Q_{i, j \pm 1}}{2},
\end{gathered}
$$

sendo os valores $Q_{i \pm \frac{1}{2}, j}$ e $Q_{i, j \pm \frac{1}{2}}$ referentes às faces de mesmo índice e, por simplicidade, definese esse vetor como $Q_{f}$. $Q_{f}$ é utilizado para calcular os vetores $F$ e $G$, os quais são aplicados no

\footnotetext{
${ }^{1}$ Maiores detalhes são apresentados por Drela \& Giles (1987).
} 
produto interno com o vetor área. Esse resultado nos fornece o balanço de fluxo nas interfaces da célula com suas vizinhas.

A aproximação de FV, após a adição da dissipação artificial, é:

$$
\frac{\partial Q_{i, j}}{\partial t}=-\frac{T\left(Q_{i, j}\right)-D a\left(Q_{i, j}\right)}{V_{i, j}} .
$$

A dissipação artificial é explicada e exemplificada no trabalho de Jameson et al. (1981). A integração temporal é feita utilizando o método de Runge-Kutta de segunda ordem de cinco passos:

$$
\begin{aligned}
g_{0} & =g^{n} \\
g^{1} & =g_{0}+\frac{d t}{4} g_{0}^{\prime}, \\
g^{2} & =g_{0}+\frac{d t}{6} g^{\prime 1}, \\
g^{3} & =g_{0}+\frac{3 d t}{8} g^{\prime 2}, \\
g^{4} & =g_{0}+\frac{d t}{2} g^{\prime 3}, \\
g^{n+1} & =g_{0}+d t g^{\prime 4} .
\end{aligned}
$$

O termo $g^{\prime}$ é a derivada da EDO. Logo para o método de Jameson, $g^{\prime}=-\frac{T\left(Q_{i, j}\right)-D a\left(Q_{i, j}\right)}{V_{i, j}}$.

\subsubsection{Método Upwind: Roe}

No desenvolvimento de métodos upwind para escoamentos compressíveis, Godunov (1959) propôs a utilização do problema de Riemann para modelar o fluxo entrando ou saindo através de uma interface. Ele resolveu de forma exata o problema exato de Riemann, testando todas as possíveis soluções para as equações. Seguindo a mesma linha, Roe (1981) propôs um problema aproximado de Riemann para modelar os fluxos pela interface. Esse problema aproximado é resolvido de forma exata e é construído para simplificá-lo sem perder consistência física. A seguir, é detalhado o problema de Riemann e sua utilização para desenvolver o método de Roe.

\section{Problema de Riemann: equação hiperbólica linear}

O problema de Riemann escalar é definido pelo transporte de uma descontinuidade com velocidade $a$. A rigor, o problema é definido da seguinte forma: 


$$
\begin{array}{ll}
\text { EDP: } & u_{t}+a \cdot u_{x}=0 \\
\text { CI: } & u(x, 0)=u^{(0)}(x)=\left\{\begin{array}{ll}
u_{L} & \text { para } x \leq 0 \\
u_{R} & \text { para } x>0
\end{array},\right.
\end{array}
$$

onde $q_{L}$ e $q_{R}$ são os valores antes e depois da descontinuidade, $a$ é a velocidade de propagação da descontinuidade, positiva. A condição inicial do problema está ilustrada na Figura (3.2). Como o problema de Riemann é definido pela equação de advecção (Equação 3.9), espera-se que essa descontinuidade caminhe por uma distância $a \cdot t$, e que os estados se mantenham inalterados antes e depois da descontinuidade. A solução analítica para esse problema é dada por:

$$
u(x, t)=u^{(0)}(x-a \cdot t)= \begin{cases}u_{L} & \text { para } x-a \cdot t \leq 0 \\ u_{R} & \text { para } x-a \cdot t>0\end{cases}
$$

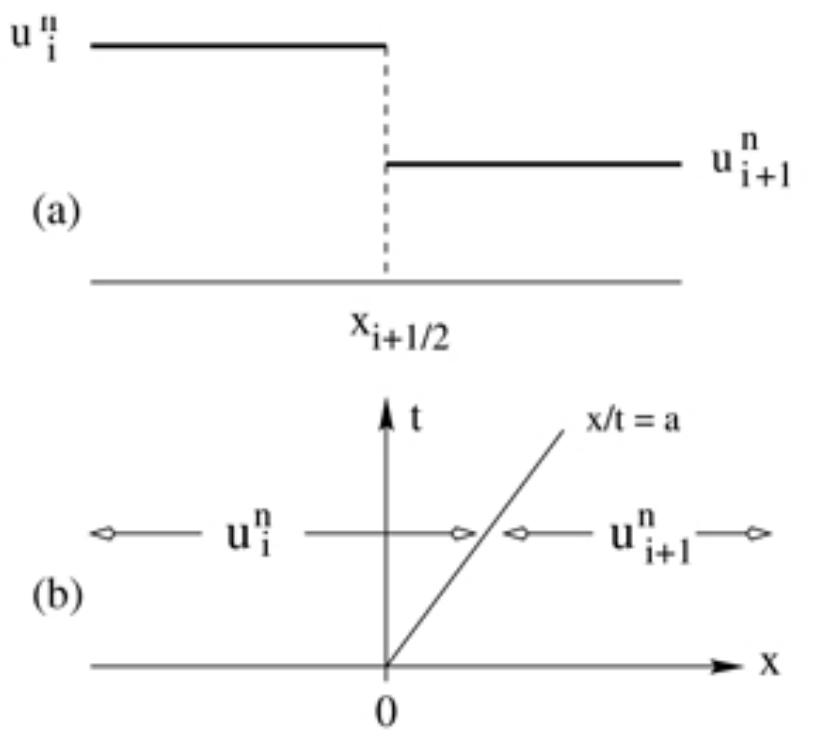

Figura 3.2: Condição inicial do problema de Riemann. (a) No tempo $t=0$ o problema consiste em dois estados constantes separados por uma descontinuidade em $x=0$. (b) Ilustração da solução do problema de Riemann no plano $x \times t$ para a equação de advecção linear com velocidade positiva.

\section{Problema de Riemann: sistema de EDP's hiperbólicas}

Na seção anterior foi apresentado o problema de Riemann para o caso escalar. Nesta seção o problema é estendido para um sistema de $m$ EDP's hiperbólicas lineares e a solução do problema escalar é utilizada para definir a solução geral desse problema. Para o sistema de equações, o problema é definido por: 


$$
\begin{aligned}
& \text { EDP: } \quad U_{t}+A \cdot U_{x}=0 ; \\
& \text { CI: } \quad U(x, 0)=U^{(0)}(x)= \begin{cases}U_{L} & \text { para } x \leq 0 \\
U_{R} & \text { para } x>0\end{cases}
\end{aligned}
$$

onde $Q$ é o vetor de estados, $A$ é uma matriz de coeficientes constantes e $Q_{L}$ e $Q_{R}$ são os vetores de estados à direita e à esquerda da descontinuidade. Assumindo que o sistema é hiperbólico, a matriz $A$ tem $m$ autovalores $\lambda_{i}$ reais e $m$ autovetores $K_{i}$, linearmente independentes (LI). Isso significa que a matriz $A$ é diagonalizável, desacoplando o sistema de equações.

Sendo $K$ a matriz de autovetores de $A$, primeiro se define o vetor de variáveis $W=K^{-1} \cdot Q$, chamadas de variáveis características. Aplicando essas variáveis na Equação 3.12 e prémultiplicando os dois lados da equação por $K^{-1}$ se tem:

$$
W_{t}+\Lambda \cdot W_{x}=0
$$

onde $\Lambda$ é a matriz diagonal dos autovalores de $A$. O problema está desacoplado e pode ser expresso por:

$$
\frac{\partial w_{i}}{\partial t}+\lambda_{i} \frac{\partial w_{i}}{\partial x}=0 ; \text { para } i=1 \ldots m
$$

e a solução do problema escalar pode ser utilizada para resolver o sistema. Consequentemente, aplicando-se a definição de variáveis características, tem-se que a solução do sistema para as variáveis originais, é:

$$
U(x, t)=\sum_{i=1}^{m} w_{i}(x, t) \cdot K^{(i)}=\sum_{i=1}^{m} w_{i}^{(0)}\left(x-\lambda_{i} t\right) \cdot K^{(i)} .
$$

Essa solução para $Q$ pode ser vista como a superposição de $m$ ondas, cada uma se deslocando independentemente sem mudança de forma. Cada onda $i$ tem formato $w_{i}^{(0)}(x) \cdot K^{(i)}$ e velocidade de propagação $\lambda_{i}$. Visando definir a solução geral para o problema em questão, cabe ressaltar que se pode escrever os vetores de estado iniciais utilizando os autovetores como base, da forma:

$$
\begin{aligned}
& U_{L}=\sum_{i=1}^{m} \alpha_{i} \cdot K^{(i)}, \\
& U_{R}=\sum_{i=1}^{m} \beta_{i} \cdot K^{(i)} .
\end{aligned}
$$

Dessa equação, nota-se que o salto de propriedades na descontinuidade é: 


$$
\Delta U=U_{R}-U_{L}=\sum_{i=1}^{m}\left(\beta_{i}-\alpha_{i}\right) \cdot K^{(i)}=\sum_{i=1}^{m} \delta_{i} \cdot K^{(i)},
$$

onde $\delta_{i}$ é a intensidade de onda para a onda $i$.

Sendo $W^{(0)}=K^{-1} Q^{(0)}$, tem-se por conseqüência:

$$
w_{i}^{(0)}(x)=\left\{\begin{array}{cc}
\alpha_{i}, & \text { para } x \leq 0 \\
\beta_{i}, & \text { para } x>0
\end{array},\right.
$$

logo, a solução para cada variável característica se torna:

$$
w_{i}(x, t)=w_{i}^{(0)}\left(x-\lambda_{i} \cdot t\right)=\left\{\begin{array}{cc}
\alpha_{i} & \text { para } x-\lambda_{i} \cdot t \leq 0 \\
\beta_{i} & \text { para } x-\lambda_{i} \cdot t>0
\end{array}\right.
$$

Da equação acima, se tem que o vetor $W^{(0)}(x)$ é formado pelos elementos $\alpha_{i}$ até o valor de $i$, tal que $x-\lambda_{i} \cdot t$ é negativo, e para valores de $i$ maiores, o vetor é composto pelos elementos $\beta_{i}$. Aplicando a definição de variáveis características, pode-se escrever a solução para o problema de Riemann da forma:

$$
U(x, t)=K \cdot W=\sum_{i=1}^{I} \beta_{i} \cdot K^{i}+\sum_{i=I+1}^{m} \alpha_{i} \cdot K^{i}
$$

sendo $I$ o maior valor de $i$, tal que $x-\lambda_{i} \cdot t>0$. A Equação 3.20 é chamada de solução geral para o problema de Riemann.

\section{Problema de Riemann: Leis de Conservação}

As leis de conservação são, geralmente, expressas na forma de sistemas de EDP's não-lineares. O problema de Riemann pode, também, ser definido para essas leis e a metodologia, apresentada nas seções anteriores, pode ser expandida para esses sistemas. Utilizando as equações de Euler, onde $Q$ substitui $U$ na Equação (3.12), para estudar a aplicação do problema de Riemann, tem-se:

$$
\begin{aligned}
Q_{t}+F(Q)_{x} & =Q_{t}+A(Q) \cdot Q_{x}=0 \\
Q(x, 0) & =Q^{(0)}(x)= \begin{cases}Q_{L}, & \text { para } x \leq 0 \\
Q_{R}, & \text { para } x>0\end{cases}
\end{aligned}
$$

O termo do meio da Equação (3.21) é chamado de forma quase linear para as leis de conservação. Esse sistema é hiperbólico, se a matriz jacobiana $A(Q)$ tiver autovalores $\lambda_{i}(Q)$ reais e um conjunto de autovetores $K^{(i)}(Q) \mathrm{LI}$. 
Visando a solução do sistema, utiliza-se a diagonalização aplicada na seção anterior. No caso não-linear, a velocidade de propagação de cada onda depende do vetor de estados $Q(x, t)$, causando distorções no formato da distribuição das propriedades. Entretanto, a solução ao longo das curvas características tem as velocidades de onda constantes, verificando a solução do caso linear ao longo de uma curva característica para o caso não-linear. Aplicando isso às equações de Euler, observam-se as seguintes soluções para a Equação (3.21): onda de contato; onda de choque e onda de expansão ${ }^{2}$.

\section{Equações de Euler: Invariância rotacional}

Uma propriedade muito importante das equações de Euler é a invariância rotacional. Essa propriedade permite provar a hiperbolicidade temporal das equações e também permite a generalização para casos onde o domínio não se alinha às coordenadas cartesianas.

Sendo a matriz de rotação definida por:

$$
R=\left[\begin{array}{llll}
1 & 0 & 0 & 0 \\
0 & \cos (\theta) & \sin (\theta) & 0 \\
0 & -\sin (\theta) & \cos (\theta) & 0 \\
0 & 0 & 0 & 1
\end{array}\right],
$$

que rotaciona o sistema de equações para a direção $\hat{n}$. Um sistema tem a propriedade de invariante rotacional, quando satisfaz a seguinte condição para qualquer $\theta$ e vetor $U$ :

$$
(F, G) \cdot \hat{n}=\cos (\theta) \cdot F+\sin (\theta) \cdot G=R^{-1} \cdot F(R \cdot Q) .
$$

Esta condição é diretamente verificada para as Equações (3.1). Essa propriedade permite a utilização do fluxo definido por $F(Q)$ na direção normal à superfície de controle utilizada para definir a discretização de volumes finitos. Logo, torna-se necessário aplicar o problema de Riemann, apenas na direção normal à face do elemento, simplificando o problema para um do tipo:

$$
Q_{t}+F(Q)_{\hat{n}}=0
$$

\section{Separação de Vetor de Fluxo (SVF)}

De acordo com Toro (1999): "[...] Uma característica distinta dos métodos upwind é que: a discretização da equação em uma malha é feita de acordo com a direção de propagação da informação nesta malha. [...]". A separação de vetores de fluxo é uma das formas para identificar a direção de propagação da informação. van Leer et al. (1987) afirmam que seus esquemas SVF têm uma resolução da onda de choque consideravelmente mais pobre se comparado ao método de

\footnotetext{
${ }^{2}$ Maiores detalhes são apresentados por Toro (1999)
} 
Godunov, que utiliza a técnica de Separação de Diferença de Fluxo (SDF) para definir a direção de propagação da informação. Porém, a maior simplicidade da técnica SVF, e, consequientemente, seu menor custo computacional, torna atrativa sua utilização.

A definição da SVF para as equações de Euler, ou seja, para sistema de equações hiperbólicas não lineares, é efetuada a partir da definição:

$$
\lambda_{i}=\lambda_{i}^{+}+\lambda_{i}^{-}
$$

onde $\lambda_{i}^{+} \geq 0$ e $\lambda_{i}^{-} \leq 0$. Definindo-se também $\lambda_{i}^{+}$e $\lambda_{i}^{-}$da forma:

$$
\begin{aligned}
& \lambda_{i}^{+}=\max \left(\lambda_{i}, 0\right), \\
& \lambda_{i}^{-}=\min \left(\lambda_{i}, 0\right),
\end{aligned}
$$

e aplicando essa definição para a matriz de autovalores, tem-se:

$$
\begin{aligned}
& \Lambda^{+}=\operatorname{diag}\left(\max \left(\lambda_{i}, 0\right), \text { para } i=1 . . m\right), \\
& \Lambda^{-}=\operatorname{diag}\left(\min \left(\lambda_{i}, 0\right), \text { para } i=1 . . m\right) .
\end{aligned}
$$

Deve-se ressaltar que a decomposição (Equação 3.25) se mantém para a matriz $\Lambda$. Definindo a separação da matriz de autovalores, pode-se determinar a separação para a matriz jacobiana, utilizando a matriz de autovetores de $A$.

$$
\begin{aligned}
& A^{+}(Q)=K \Lambda^{+} K^{-1}, \\
& A^{-}(Q)=K \Lambda^{-} K^{-1},
\end{aligned}
$$

e se pode averiguar também que a separação construída para $A$ respeita a restrição $A=A^{+}+A^{-}$. A construção das separações para as matrizes $\Lambda^{ \pm}$e $A^{ \pm}$, apresentada nas Equações (3.27) e (3.28), tem por conseqüência as propriedades:

i ) $\lambda=\lambda^{+}+\lambda^{-} ;|\lambda|=\lambda^{+}-\lambda^{-}$;

ii ) $\Lambda=\Lambda^{+}+\Lambda^{-} ;|\Lambda|=\Lambda^{+}-\Lambda^{-}$;

iii ) $A=A^{+}+A^{-} ;|A|=A^{+}-A^{-}$;

Agora, pode-se definir a separação do vetor de fluxo da forma:

$$
F(Q)=F^{+}(Q)+F^{-}(Q)
$$


Lembrando a Equação (3.21), na qual $F(Q)=A(Q) \cdot Q$, aplica-se essa definição obtendo:

$$
\begin{aligned}
& F^{+}(Q)=A^{+}(Q) \cdot Q \\
& F^{-}(Q)=A^{-}(Q) \cdot Q
\end{aligned}
$$

que respeita a Equação (3.29). No método de Roe, essa separação de fluxo será importante para definir o fluxo na face, a partir de um problema de Riemann aproximado.

\section{Método de Godunov}

O método de Godunov calcula o fluxo na interface, a partir da solução exata do problema de Riemann exato, para as equações de Euler. Essa solução leva a 5 possíveis casos, tanto para o escoamento vindo da esquerda $(L)$ tanto para o escoamento da direita $(R)$. Esses casos são composições de ondas de choque, contato e expansão.

A solução exata do problema de Riemann leva ao cálculo iterativo da pressão e ao teste para definir qual caso será aplicado. Consequentemente, o método é muito oneroso, o que incentivou o desenvolvimento de métodos que: ou resolvem aproximadamente o problema exato de Riemann; ou resolvem exatamente o problema aproximado; ou que resolvem aproximadamente o problema aproximado.

No caso do método proposto por Roe, um problema aproximado é proposto e sua solução é efetuada de forma exata. As próximas seções apresentam a obtenção do problema aproximado e sua solução.

\section{Problema aproximado de Riemann proposto por Roe}

O método upwind de Roe (1981) é talvez o mais conhecido do tipo Godunov voltado para resolver um problema de Riemann aproximado. A definição do problema aproximado se dá pela substituição da matriz jacobiana, dependente do estado, por uma matriz constante, que depende dos estados à direita e à esquerda da interface. Logo o problema 3.21 se torna:

$$
\begin{aligned}
Q_{t}+F(Q)_{x} & \simeq Q_{t}+\tilde{A}\left(Q_{L}, Q_{R}\right) \cdot Q_{x}=0, \\
Q(x, 0) & =Q^{(0)}(x)=\left\{\begin{array}{ll}
Q_{L}, & \text { para } x \leq 0 \\
Q_{R}, & \text { para } x>0
\end{array} .\right.
\end{aligned}
$$

O problema aproximado (Equação 3.31) satisfaz as propriedades: (i) hiperbolicidade; (ii) consistência; e (iii) conservação ao longo das descontinuidades. Como o problema de Riemann é aproximado pela substituição da matriz $A(Q)$ original por uma matriz $\tilde{A}\left(Q_{L}, Q_{R}\right)$ constante, tendo os autovalores $\tilde{\lambda}(\tilde{A})$ da matriz $\tilde{A}$ e seus autovetores $\tilde{K}(\tilde{A})$, pode-se aplicar a solução para o sistema de EDP's hiperbólicas para resolver o problema aproximado. 
Escrevendo o salto de propriedades $\Delta Q=Q_{R}-Q_{L}$ como na Equação (3.17) e chamando de $\tilde{\alpha}_{i}\left(Q_{L}, Q_{R}\right)$ a intensidade de onda para a $i$-ésima onda, a solução do problema aproximado na interface é dada por:

$$
\begin{aligned}
& Q_{i+\frac{1}{2}}=Q_{L}+\sum_{\tilde{\lambda}_{i} \leq 0} \tilde{\alpha}_{i} \tilde{K}^{(i)}, \\
& Q_{i+\frac{1}{2}}=Q_{R}-\sum_{\tilde{\lambda}_{i} \geq 0} \tilde{\alpha}_{i} \tilde{K}^{(i)},
\end{aligned}
$$

e aplicando a definição de $F(Q)=A(Q) \cdot U$ no problema aproximado, pode-se escrever o fluxo na interface por:

$$
\begin{array}{r}
F_{1+\frac{1}{2}}=F_{L}+\sum_{\tilde{\lambda}_{i} \leq 0} \tilde{\alpha}_{i} \tilde{\lambda}_{i} \tilde{K}^{(i)}, \\
F_{1+\frac{1}{2}}=F_{R}-\sum_{\tilde{\lambda}_{i} \geq 0} \tilde{\alpha}_{i} \tilde{\lambda}_{i} \tilde{K}^{(i)}, \\
F_{1+\frac{1}{2}}=\frac{F_{R}+F_{L}}{2}-\frac{1}{2} \sum_{i=0}^{m} \tilde{\alpha}_{i}\left|\tilde{\lambda}_{i}\right| \tilde{K}^{(i)} .
\end{array}
$$

Pode-se interpretar a última Equação (3.33) como uma composição de um termo centrado mais um termo de dissipação, sendo esse último representado pelo somatório. Nota-se que a dissipação artificial do método upwind é dependente dos autovalores da matriz jacobiana. Por conseqüência, a dissipação artificial será baixa em regiões próximas às de escoamentos sônicos e estagnação. Isso é importante devido à necessidade de maior robustez, visto que nessas regiões a dissipação artificial será baixa, podendo levar a instabilidades numéricas ${ }^{3}$ Visto que o fluxo na face está definido pelas Equações (3.33) basta definir a matriz jacobiana que representa a aproximação do problema de Riemann e calcular $\tilde{\lambda}, \tilde{K}$ e $\tilde{\alpha}$ para essa matriz. A construção da matriz $\tilde{A}$ é feita de forma a satisfazer as propriedades (i)-(iii). Para isso, Roe (1981) define um vetor de propriedades $Z$ e escreve os vetores $Q$ e $F$ em função de $Z$. Além disso, o autor define o valor médio na interface a partir de sua média aritmética. Dessa forma, $\Delta F$ e $\Delta Q$ podem ser expressos em função de $\Delta Z$.

\footnotetext{
${ }^{3}$ Para maiores detalhes sobre o desenvolvimento acima se sugere a referência Toro (1999).
} 
O vetor $Z$ definido por Roe, para as equações de Euler 2D, é:

$$
Z=\left\{\begin{array}{c}
z_{1} \\
z_{2} \\
z_{3} \\
z_{4}
\end{array}\right\} \equiv \sqrt{\rho}\left\{\begin{array}{c}
1 \\
u \\
v \\
H
\end{array}\right\} .
$$

sendo $H=\frac{e+p}{\rho}$ onde $e$ é definido pela Equação 3.1 .

Definindo o vetor $\tilde{Z}$ na interface, como a média aritmética entre os vetores à direita e à esquerda, pode-se escrever os vetores $\Delta Q$ e $\Delta F$ da forma:

$$
\Delta Q=\tilde{B} \Delta Z ; \quad \Delta F=\tilde{C} \Delta Z
$$

sendo $\tilde{C}=\tilde{C}(\tilde{Z})$ e $\tilde{B}=\tilde{B}(\tilde{Z})$. Logo, pode-se escrever:

$$
\Delta F=\left(\tilde{C} \tilde{B}^{-1}\right) \Delta Q=\tilde{A} \Delta Q
$$

Com a matriz jacobiana da Equação (3.36), Roe \& Pike (1985) definiram o valor médio das propriedades na interface pela média de Roe (Equações 3.37), e definiram os saltos nas propriedades pela Equação (3.38), os autovalores pela Equação (3.39) e autovetores pela Equação (3.40).

$$
\begin{gathered}
\omega=\frac{\sqrt{\rho_{l}}}{\sqrt{\rho_{l}}+\sqrt{\rho_{r}}}, \\
\tilde{\rho}=\sqrt{\rho_{l} \rho_{r}}, \\
\tilde{u_{f}}=u_{l} \omega+u_{r}(1-\omega), \\
\tilde{v}_{f}=v_{l} \omega+v_{r}(1-\omega), \\
\tilde{H}_{f}=H_{l} \omega+H_{r}(1-\omega), \\
\tilde{\alpha}=\left\{\begin{array}{c}
\Delta \rho-\frac{\Delta P}{\tilde{a}^{2}} \\
\tilde{\rho} \Delta v_{n} \\
\tilde{\rho} \Delta u_{n}+\frac{\Delta P}{2 \tilde{a}^{2}} \\
-\tilde{\rho} \Delta u_{n}+\frac{\Delta P}{2 \tilde{a}^{2}}
\end{array}\right\},
\end{gathered}
$$




$$
\begin{gathered}
\tilde{\lambda}=\left\{\begin{array}{c}
\tilde{u}_{n} \\
\tilde{u}_{n} \\
\tilde{u}_{n}+\tilde{a} \\
\tilde{u}_{n}-\tilde{a}
\end{array}\right\}, \\
\tilde{K}=\left[\begin{array}{cccc}
1 & 0 & 1 & 1 \\
\tilde{u} & n_{y} & \tilde{u}+n_{x} \tilde{a} & \tilde{u}-n_{x} \tilde{a} \\
\tilde{v} & n_{x} & \tilde{v}+n_{y} \tilde{a} & \tilde{v}-n_{y} \tilde{a} \\
\frac{1}{2}\left(\tilde{u}^{2}+\tilde{v}^{2}\right) & \tilde{v}_{n} & \tilde{H}+u_{n} \tilde{a} & \tilde{H}-u_{n} \tilde{a}
\end{array}\right] .
\end{gathered}
$$

Como discutido anteriormente, pode-se notar pela Equação 3.39 que a dissipação é baixa em regiões próximas da estagnação e de escoamento sônico. Visando resolver o problema, o autovalor pode ser corrigido da seguinte forma:

$$
M_{\tilde{\lambda}_{i}}=\left\{\begin{array}{ll}
M_{\tilde{\lambda}_{i}} & M_{\tilde{\lambda}_{i}} \geq \epsilon_{R o e} \\
\frac{1}{2}\left(\epsilon_{R o e}+\frac{M_{\tilde{\lambda}_{i}}}{\epsilon_{R o e}}\right) & M_{\tilde{\lambda}_{i}}<\epsilon_{R o e}
\end{array},\right.
$$

sendo $M_{\tilde{\lambda}_{i}}=\tilde{\lambda}_{i} / a$ e $a$ a velocidade do som. O valor para $\epsilon_{R o e}$ é, geralmente, definido em torno de $\epsilon_{\text {Roe }} \approx 0,05$. Para geometrias mais complexas ou para malhas com volumes de baixa qualidade, valores em torno de $\epsilon_{\text {Roe }} \approx 0,15$ são apropriados. No presente trabalho se adotou o valor $\epsilon_{\text {Roe }}=$ 0,35 .

Utilizando o fluxo na interface definido por Roe, aplica-se a propriedade de invariância rotacional para escrever a formulação de volumes finitos, obtendo-se:

$$
\int_{V} \frac{\partial Q}{\partial t} d v+\int_{S}(\vec{P} \cdot \vec{n}) d s=\int_{V} \frac{\partial Q}{\partial t} d v+\int_{S} F_{n} d s=0,
$$

sendo $F_{n}$ definido pelo fluxo na direção normal à superfície de controle.

Reescrevendo a Equação (3.3), obtém-se a Equação (3.4) da forma:

$$
V_{i, j} \frac{\partial \bar{Q}_{i, j}}{\partial t}+\sum_{k=1}^{4} \tilde{F}_{n} \cdot \Delta S_{k}=0
$$

onde $\tilde{F}_{n}$ representa o fluxo na face definido por Roe. Tem-se com essa formulação a definição do método de FV, utilizando a aproximação de Roe para o fluxo nas faces do volume de controle.

\section{Reconstrução para obtenção de segunda ordem de prescisão}

O desenvolvimento de segunda ordem de precisão para os métodos tipo Godunov foi explorado por van Leer (1979) com a introdução do conceito MUSCL (do inglês, Monotone UpstreamCentred Scheme for Conservation Laws). Esse conceito possibilita a maior ordem de precisão a 
partir de uma reconstrução das propriedades, a qual consiste em assumir uma nova distribuição das propriedades dentro dos volumes, distribuição essa de maior ordem que a hipótese de propriedades constantes. Essa reconstrução fornece valores extrapolados para as propriedades à esquerda e à direita da interface, os quais são utilizados no problema de Riemman.

Para obter segunda ordem de precisão, é necessário aplicar uma reconstrução linear das propriedades. Em (Hirsch, 1991b) está descrita a proposta para a reconstrução adotada neste trabalho. Apesar de a proposta ser aplicada em uma malha unidimensional uniforme, ela foi considerada no domínio lógico da malha estruturada. A utilização de maior ordem de precisão leva ao aparecimento de oscilações das propriedades na região próxima à onda de choque. Para isso se utiliza um limitador de fluxo descrito na seção a seguir.

\section{Limitador de fluxo}

Hirsch (1991b) descreve o conceito de limitador de fluxo. Nesse trabalho é descrita uma técnica proposta para a utilização com o conceito MUSCL. Basicamente, o limitador impõe valores máximos e mínimos às derivadas da reconstrução das variáveis. Essa limitação é construída de forma a impor monotonicidade às variáveis reconstruídas.

O conceito do limitador é, geralmente, desenvolvido para o caso 1D. Bigarella (2007) utiliza os conceitos de Barth \& Jespersen (1989) para generalizar o cálculo da razão de variação das derivadas, permitindo utilizar qualquer limitador definido para 1D nos casos 2D e 3D. De forma breve, a generalização é descrita pela Equação (3.44).

$$
r_{k}= \begin{cases}\text { num }^{+} / \text {den }, & \text { if } \quad \text { den }>0 \\ \text { num }^{-} / \text {den, }, & \text { if } \quad \text { den }<0 ; \\ 1, & \text { if } \quad \text { den }=0\end{cases}
$$

onde $r_{k}$ é a razão para o $k$-ésimo volume. $n u m^{ \pm}$e den são definidor por:

$$
\operatorname{num}^{+}=\max \left(q_{i}, q_{k}\right)-q_{i} ; \quad \operatorname{num}^{-}=\min \left(q_{i}, q_{k}\right)-q_{i} ; \quad \text { den }=\left(q_{i}\right)_{k}-q_{i},
$$

sendo $q_{i}$ a propriedade no volume $i, q_{k}$ a propriedade na face $k$ do volume (ou seja, a média aritmética das propriedades dos volumes vizinhos à face) e $\left(q_{i}\right)_{k}$ é a propriedade do volume $i$ reconstruído na face $k$ do volume.

A utilização dessa generalização permite aplicar o limitador de fluxo de van Albada (van Albada et al., 1982). Sendo $r$ a razão da variação das derivadas, o limitador de fluxo é definido por:

$$
\Phi=\frac{r^{2}+r}{r^{2}+1} .
$$


No presente trabalho, é adotada a implementação do limitador sugerida por Bigarella (2007) e definida na Equação 3.47).

$$
\Phi\left(\text { num }^{ \pm}, \text {den }\right)=\frac{\text { num }^{ \pm}\left(\text {num }^{ \pm}+1\right)+\epsilon_{L I M}}{n u m^{ \pm 2}+\text { den }^{2}+\epsilon_{L I M}} .
$$

Apesar de Bigarella (2007) sugerir a utilização de $\epsilon_{L I M}=10^{-4}$, a seção 5.2.1 apresenta um estudo sobre a influência desse valor na solução e estabilidade do método.

\subsubsection{Condições de contorno}

Para resolver as equações no domínio discretizado é necessário ter o valor das grandezas nas fronteiras da malha. Esses valores são chamados de condições de contorno e representam a porção conhecida do problema (geometria da parede, simetria do escoamento, escoamento livre, etc.). Para isso é necessário modelar as condições físicas representadas pelas fronteiras. No trabalho é necessária a utilização de 3 tipos distintos de condições de contorno nas 4 fronteiras da malha estruturada: escoamento livre não reflexiva; condição de escorregamento na parede; e condição de periodicidade. A última condição é necessária visto que a malha adotada é do tipo $O$, ou seja, duas de suas fronteiras são coincidentes, fechando o domínio físico atrás do bordo de fuga.

As condições são impostas se utilizando os chamados volumes fantasmas ou fictícios, os quais consistem em volumes de controle definidos fora do domínio de cálculo, e cuja função é a implementação das condições de contorno.

\section{Fluxo livre - Invariantes de Riemann}

De acordo com Hirsch (1991b), a condição de contorno de escoamento livre, no caso estacionário, pode ser tratada como entrada de fluxo no domínio ou saída. Para cada um, o fluxo será tratado de forma diferente e sua identificação é necessária. Essa identificação utiliza a técnica baseada nas invariantes de Riemann para um escoamento localmente unidimensional e subsônico, os quais são definidos por:

$$
\begin{aligned}
& R^{-}=u_{n}-\frac{2 a}{\gamma-1} \\
& R^{+}=u_{n}+\frac{2 a}{\gamma-1},
\end{aligned}
$$

onde $u_{n}$ é a componente de velocidade normal à fronteira.

O invariante $R^{-}$é constante ao longo de uma característica que se propaga para o interior do domínio computacional, sendo obtido a partir das propriedades do escoamento não-perturbado. $\mathrm{O}$ invariante $R^{+}$é, por sua vez, constante ao longo de uma característica se propagando para fora do 
domínio. Ele é obtido pela extrapolação das propriedades internas ao domínio. Sendo assim, os invariantes podem se reescrever como:

$$
\begin{gathered}
R_{\infty}^{-}=q_{n_{\infty}}-\frac{2 a_{\infty}}{\gamma-1}, \\
R_{e}^{+}=q_{n_{e}}+\frac{2 a_{e}}{\gamma-1} .
\end{gathered}
$$

Combinando estas expressões, obtêm-se os valores na interface da fronteira na forma:

$$
\begin{aligned}
q_{n_{f}} & =\frac{1}{2}\left(R_{e}^{+}+R_{\infty}^{-}\right), \\
a_{f} & =\frac{\gamma-1}{4}\left(R_{e}^{+}-R_{\infty}^{-}\right) .
\end{aligned}
$$

Deste modo, as propriedades nesta mesma interface são calculadas de acordo com o sinal de $q_{n}$, de tal forma que são possíveis dois casos distintos:

- Fronteira de saída $\left(q_{n_{f}}>0\right)$ : As propriedades do volume adjacente à fronteira são extrapoladas para a célula fantasma da forma:

$$
\begin{aligned}
& \rho_{f}=\left(\frac{\rho_{e}^{\gamma} a_{f}^{2}}{p_{e} \gamma}\right)^{\frac{1}{1-\gamma}}, \\
& u_{f}=u_{e}+\left(q_{n_{f}}-q_{n_{e}}\right) \cdot s x, \\
& v_{f}=v_{e}-\left(q_{n_{f}}-q_{n_{e}}\right) \cdot s y, \\
& p_{f}=\frac{\rho_{f} a_{f}^{2}}{\gamma}, \\
& e_{f}=\frac{p_{f}}{\gamma-1}+\frac{1}{2} \rho_{f}\left(u_{f}^{2}+v_{f}^{2}\right),
\end{aligned}
$$

onde a expressão para a densidade vem da extrapolação da entropia.

- Fronteira de entrada $\left(q_{n_{f}}<=0\right)$ : Neste caso, as propriedades são extrapoladas do escoamento livre: 


$$
\begin{aligned}
& \rho_{f}=\left(\frac{\rho_{\infty}^{\gamma} a_{f}^{2}}{p_{\infty} \gamma}\right)^{\frac{1}{1-\gamma}}, \\
& u_{f}=u_{\infty}+\left(q_{n_{f}}-q_{n_{e}}\right) \cdot s x, \\
& v_{f}=v_{\infty}-\left(q_{n_{f}}-q_{n_{e}}\right) \cdot s y, \\
& p_{f}=\frac{\rho_{f} a_{f}^{2}}{\gamma} \\
& e_{f}=\frac{p_{f}}{\gamma-1}+\frac{1}{2} \rho_{f}\left(u_{f}^{2}+v_{f}^{2}\right) .
\end{aligned}
$$

As expressões para o cálculo da densidade são obtidas da hipótese de escoamento localmente isentrópico, e da definição da velocidade do som. A partir dos valores na interface, pode-se obter o vetor de variáveis conservadas para os volumes fictícios se fazendo:

$$
Q_{g}=2 Q_{f}-Q_{e}
$$

Essa aproximação para a condição de fluxo livre é válida enquanto a fronteira estiver suficientemente distante do aerofólio para que as perturbações induzidas pela circulação sejam pequenas. É comum encontrar trabalhos sugerindo a utilização de um raio para o domínio externo da ordem de 30 à 50 vezes a corda do aerofólio.

A seção 3.1.5 apresenta uma técnica de correção da condição de fronteira livre para reduzir o erro de aproximação, impondo uma componente de perturbação, causada pela circulação do aerofólio.

\section{Escorregamento na parede}

Quando utilizada a formulação invíscida, a condição de contorno de parede sólida considera velocidade tangente à parede. Para isto, impõe-se que a componente da velocidade contra variante normal à parede do volume fantasma seja igual, em intensidade, porém, com sentido contrário, à velocidade contra variante do volume vizinho. Enquanto isso, a componente tangencial de ambas é exatamente igual. Também, impõe-se que os gradientes de pressão e de temperatura sejam nulos na superfície do corpo.

Seguindo, então, o procedimento descrito acima, adotando as definições ilustradas na Figura (3.3), calculam-se as componentes do vetor velocidade como: 


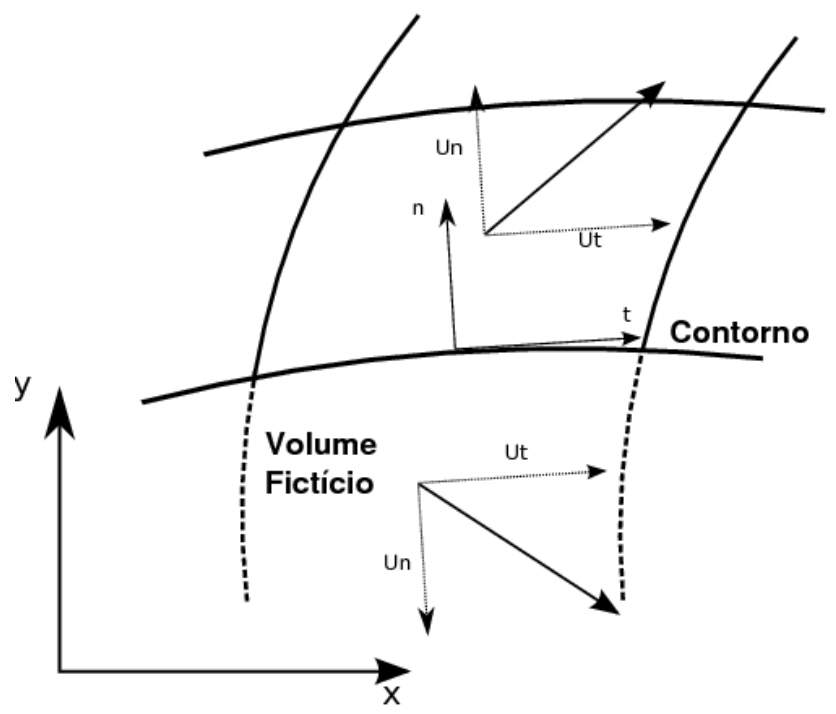

Figura 3.3: Sistema de coordenadas local e componentes das velocidades para cálculo da condição de contorno de parede com escorregamento.

$$
\begin{aligned}
U_{n} & =\vec{V} \cdot \vec{n}=\left(u \vec{i}_{x}+v \vec{i}_{y}\right) \cdot\left(n_{x} \vec{i}_{x}+n_{y} \vec{i}_{y}\right), \\
U_{t} & =\vec{V} \cdot \vec{t}=\left(u \vec{i}_{x}+v \vec{i}_{y}\right) \cdot\left(n_{y} \vec{i}_{x}-n_{x} \vec{i}_{y}\right) .
\end{aligned}
$$

Com isso se tem que as componentes das velocidades do volume fictício são:

$$
\begin{aligned}
& U g_{n}=-U_{n}, \\
& U g_{t}=U_{t} .
\end{aligned}
$$

Logo, recalculando as velocidades nas coordenadas $x$ e $y$ se tem:

$$
\begin{aligned}
& u_{g}=U g_{n} n_{x}+U g_{t} n_{y}, \\
& v_{g}=-U g_{n} n_{y}+U g_{t} n_{x} .
\end{aligned}
$$

\subsubsection{Técnicas para aceleração de convergência}

Técnicas foram implementadas visando a redução de custo computacional. Essas são apresentadas a seguir. 


\section{Passo temporal local variável}

Buscando aumentar a velocidade de convergência para o estado estacionário, cada volume da malha utiliza um valor distinto para o $\Delta t$, sendo limitado pelo valor do $C F L$ máximo, o qual garante a estabilidade.

\section{Resíduo suavizado}

Hirsch (1991b) descreve a técnica que impõem no método explícito um caráter implícito aumentando a estabilidade, permitindo a utilização de valores maiores de $C F L$. A análise de estabilidade por expansão da série de Fourier mostra que se pode aumentar muito o $C F L$ com a utilização da técnica. Outro fato importante é que a técnica não precisa ser utilizada em todos os passos da integração temporal, reduzindo o custo computacional.

\section{Correção de fronteira livre}

A utilização de um domínio com fronteira física distante leva à necessidade de utilizar um grande número de células, aumentando, conseqüentemente, o custo computacional. A redução do diâmetro do círculo utilizado leva ao aumento do erro, devido às perturbações do perfil na fronteira. Para reduzir esse erro se aplica a correção de fronteira livre. A técnica adotada para o trabalho segue a descrição de Hirsch (1991b). A teoria potencial é utilizada para estimar a perturbação que a circulação do aerofólio causa em algum ponto da fronteira externa (Figura 3.4). Essa perturbação é utilizada para corrigir o valor da velocidade na fronteira livre.

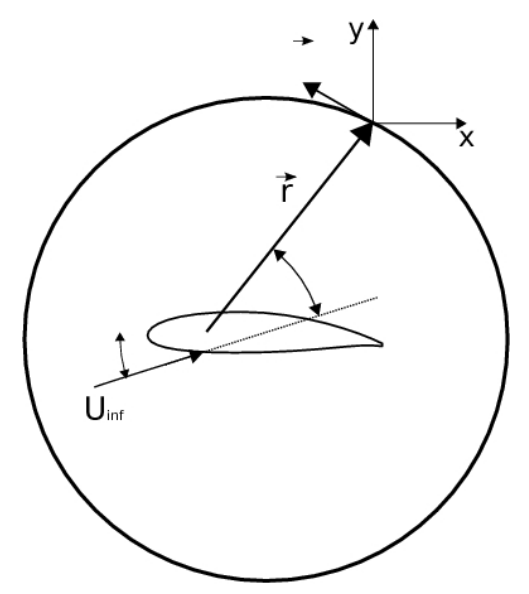

Figura 3.4: Ilustração da aproximação para a perturbação causada pelo perfil na fronteira livre.

A sustentação é calculada por um volume de controle que envolve o perfil, no caso foi utilizado um volume adjacente. Com o valor da sustentação, a circulação é calculada pela expressão:

$$
C l=\frac{2 \Gamma}{V_{\infty} c} .
$$

A circulação é utilizada para calcular o parâmetro $F$ definido pela expressão: 


$$
F=\frac{\Gamma}{V_{\infty}} \frac{\beta}{2 \pi r} \frac{1}{1-M_{\infty}^{2} \sin \left(\theta-\alpha_{\infty}\right)}
$$

$\operatorname{com} \beta=\sqrt{1-M_{\infty}^{2}}$. Com o valor de $F$, pode-se calcular as componentes das perturbações da velocidade pela expressão:

$$
\begin{aligned}
\frac{u_{f}}{V_{\infty}} & =\cos \alpha_{\infty}+F \sin \theta, \\
\frac{v_{f}}{V_{\infty}} & =\sin \alpha_{\infty}-F \cos \theta .
\end{aligned}
$$

\subsection{Geração de Malha}

Para a geração de malha estruturada se adotou o método descrito por Fletcher (1987); ThompSon et al. (1985), que utiliza as equações elípticas para definir $x$ e $y$ em função de $\xi$ e $\eta$ :

$$
\begin{aligned}
& \xi_{x x}+\xi_{y y}=P(\xi, \eta), \\
& \eta_{x x}+\eta_{y y}=Q(\xi, \eta),
\end{aligned}
$$

onde $P$ e $Q$ são definidos por:

$$
\begin{aligned}
P(\xi, \eta)= & -\sum_{m=1}^{M} a_{m} \frac{\xi-\xi_{m}}{\left|\xi-\xi_{m}\right|} * e^{-c_{m} *\left|\xi-\xi_{m}\right|} \\
& -\sum_{n=1}^{N} b_{n} \frac{\xi-\xi_{n}}{\left|\xi-\xi_{n}\right|} * e^{-d_{n} * \sqrt{\left(\xi-\xi_{n}\right)^{2}+\left(\eta-\eta_{n}\right)^{2}}}, \\
Q(\xi, \eta)= & -\sum_{m=1}^{M} a_{m} \frac{\eta-\eta_{m}}{\left|\eta-\eta_{m}\right|} * e^{-c_{m} *\left|\eta-\eta_{m}\right|} \\
& -\sum_{n=1}^{N} b_{n} \frac{\eta-\eta_{n}}{\left|\eta-\eta_{n}\right|} * e^{-d_{n} * \sqrt{\left(\xi-\xi_{n}\right)^{2}+\left(\eta-\eta_{n}\right)^{2}}} .
\end{aligned}
$$

Os termos fontes definidos nas Equações 3.61 são responsáveis pelo controle do refinamento da malha. Para utilizar essas equações, deve-se resolvê-las, numericamente, atribuindo as coordenadas das fronteiras (perfil e fronteira externa) como condições de contorno. Neste trabalho, 
utiliza-se uma malha em $O$, conformada ao perfil, ilustrada na Figura (3.5). A Figura (3.6) apresenta um exemplo de uma malha estruturada na região próxima a um perfil aerodinâmico.
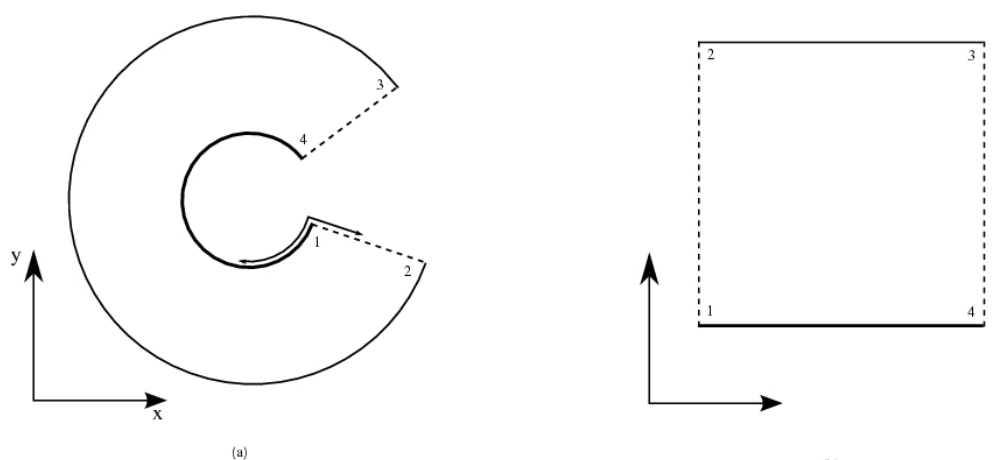

Figura 3.5: Malha estruturada tipo $O$ : domínio físico (a); domínio computacional (b).

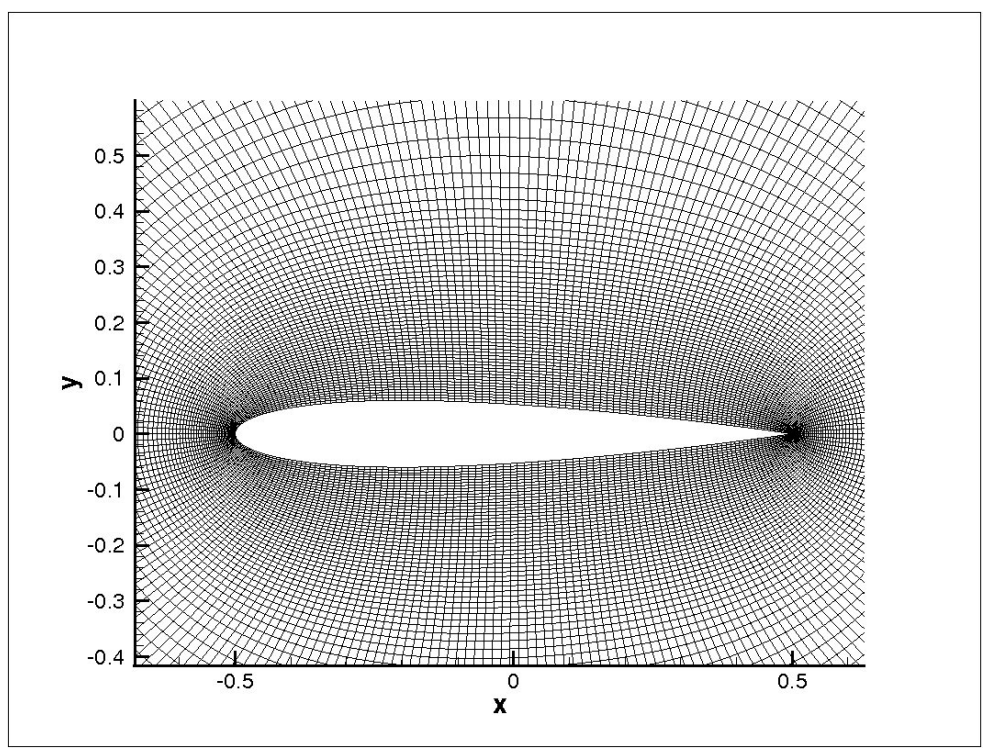

Figura 3.6: Exemplos de malha estruturada em torno de um aerofólio.

\subsection{Parametrização da geometria}

\section{Parsec}

A representação de perfis Parsec emprega um pequeno número de variáveis relacionadas às propriedades geométricas, parametrizando a superfície superior e inferior do aerofólio, utilizando polinômios para as coordenadas x e y na forma:

$$
Y=\sum_{n=1}^{6} a_{n} X^{n-\frac{1}{2}}
$$


onde $a_{n}$ são coeficientes reais. Os parâmetros da família Parsec incluem o raio de bordo de ataque $r_{l e}$, coordenadas $\mathrm{Y}$ da superfície superior e inferior $Y_{U P}, Y_{L O}$ e suas respectivas localizações $X_{U P}$, $X_{L O}$, curvaturas desses pontos $Y_{X X U P}, Y_{X X L O}$, espessura da borda de fuga $\Delta Y_{T E}$ e sua coordenada $Y_{T E}$, e seus ângulos de direção e de abertura $\alpha_{T E}, \beta_{T E}$. Estes parâmetros são mostrados na Figura (3.7), e os limitantes superior e inferior utilizados estão na Tabela (3.1). Mais informações sobre parametrizações de geometrias podem ser encontradas em (Sobieczky, 1998; Song \& Keane, 2004a).

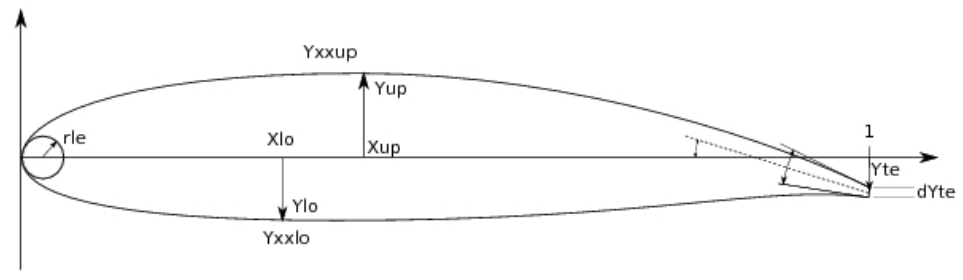

Figura 3.7: Variáveis da família Parsec.

Tabela 3.1: Limitante dos parâmetros.

\begin{tabular}{|c|c|c|c|c|c|c|c|c|c|c|c|}
\hline Param. & $r_{l e}$ & $X_{u p}$ & $Y_{u p}$ & $Y x x_{u p}$ & $X_{l o}$ & $Y_{l o}$ & $Y x x_{l o}$ & $\alpha_{t e}$ & $\beta_{t e}$ & $Y_{t e}$ & $d Y_{t e}$ \\
\hline Lower & 0.0055 & 0.3 & 0.05 & -0.6 & 0.28 & -0.075 & 0.55 & $8^{o}$ & $9.5^{o}$ & 0.0 & 0.0 \\
\hline top & 0.01 & 0.5 & 0.075 & -0.4 & 0.42 & -0.05 & 0.85 & $12^{o}$ & $14.5^{o}$ & 0.0 & 0.0 \\
\hline
\end{tabular}

\section{Pontos de controle}

Para representar, computacionalmente, geometrias, no caso, curvas, pode-se aplicar uma parametrização baseada em pontos de controle. No presente caso, uma curva $2 \mathrm{D}$ é parametrizada com base no parâmetro $\xi$, sendo definida da forma:

$$
x=x(\xi) ; \quad y=y(\xi) .
$$

Esta parametrização é utilizada para definir o perfil. Os pontos são lugares geométricos de coordenadas conhecidas, os quais são utilizados para definir interpolações de $x$ e $y$ em relação à $\xi$. Qualquer polinômio interpolador pode ser utilizado. No presente trabalho, adotou-se a interpolação através de uma Spline cúbica.

Os pontos de controle adotados são baseados no perfil transônico Rae 2822 (Nemec et al., 2002). 13 pontos base em torno do perfil são usados: os pontos $(1,0)$ do bordo de fuga no começo e no final da parametrização; o ponto $(0,0)$ do bordo de ataque; e mais 10 pontos ao longo da corda, sendo 5 no intradorso e 5 no extradorso. As coordenadas dos pontos base estão na Tabela (3.2) 
e a ilustração na Figura (3.8). Os pontos 1,7 e 13 são fixos e os demais têm suas coordenadas $y$ variáveis, sendo que a variação é no máximo $40 \%$ de seu valor para mais ou para menos.

A parametrização descrita é muito prática e tem a vantagem de evitar o grande número de geometrias anômalas, que ocorre no caso da parametrização Parsec. Como desvantagem, essa parametrização permite apenas uma busca local próxima à geometria base, sendo, por isso, muito utilizada em casos de refinamento de projeto de aerofólio.

Tabela 3.2: Pontos de controle base para a parametrização da geometria.

\begin{tabular}{c|c|c|c|c|c}
$i$ & $x$ & $y$ & $i$ & $x$ & $y$ \\
\hline 1 & 1.000 & 0.000 & 8 & 0.066 & -0.032 \\
2 & 0.933 & 0.013 & 9 & 0.249 & -0.055 \\
3 & 0.750 & 0.041 & 10 & 0.500 & -0.050 \\
4 & 0.500 & 0.062 & 11 & 0.750 & -0.016 \\
5 & 0.249 & 0.056 & 12 & 0.933 & 0.000 \\
6 & 0.066 & 0.031 & 13 & 1.000 & 0.000 \\
7 & 0.000 & 0.000 & & &
\end{tabular}

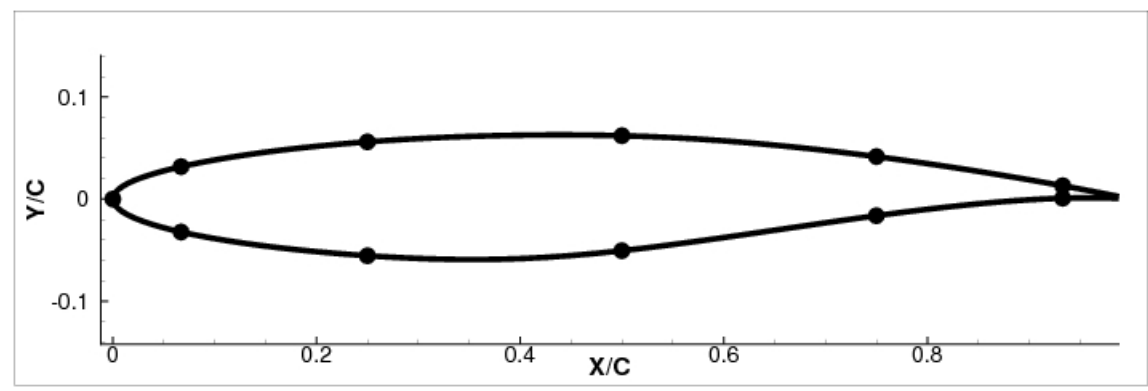

Figura 3.8: Geometria base (Rae 2822) e pontos de controle.

Neste capítulo, foram discutidas as técnicas que viabilizam a definição das funções objetivo para o problema de otimização aerodinâmica. Para efetivar a otimização são necessárias técnicas de otimização, as quais são descritas no próximo capítulo. 



\section{Algoritmo genético e otimização multi-objetivo}

Sendo o progresso uma condição da natureza humana, ninguém tem o poder de se opor a ele. É uma força viva que as más leis podem retardar, mas não sufocar. Quando essas leis se tornam incompatíveis com a sua marcha, ele as destrói e a todos que tentam mantê-las. Será assim até que o homem coloque suas leis em concordância com a justiça e com o bem, e não leis feitas pelo forte em prejuízo do fraco. (Livro dos Espíritos)

No capítulo 2 , foi mostrado que o desempenho da aeronave depende de parâmetros concorrentes como o aumento da velocidade e da sustêntação com a eficiência aerodinâmica, caracterizando um problema multiobjetivo. Logo, para o presente estudo, define-se o problema:

$$
\begin{array}{ll}
\text { Maximizar: } & f_{1}=C l \\
\text { Minimizar: } & f_{2}=C d \\
& f_{3}=|\mathrm{Cm}|
\end{array}
$$

Sujeito a:

restrições de geometria

estabilidade numérica

As restrições geométricas são empregadas para definir infactíveis os perfis anômalos (perfis muito espessos ou com pouca suavidade da linha de camber), possíveis devido às parametrizações 
adotadas. Essas restrições são: não haver crossover de superfícies, espessura máxima de 30\%, e camber máximo de $20 \%$.

Dois objetivos do PMO, definidos acima, são representados na Figura (4.1). Nessa figura podese observar as soluções dominadas e os níveis de dominância. As soluções 8 e 6 estão no conjunto dominado pelo nível representado pela linha tracejada. A solução 7 está em um nível dominado pelas demais. Tem-se, também, que os objetivos $f_{2}$ e $f_{3}$ são intrinsecamente positivos, sendo $f_{2}$ estritamente positivo. Logo, outro indicativo de infactibilidade é dado por valores de $f_{2} \leq 0$, o que indica erro da solução numérica.

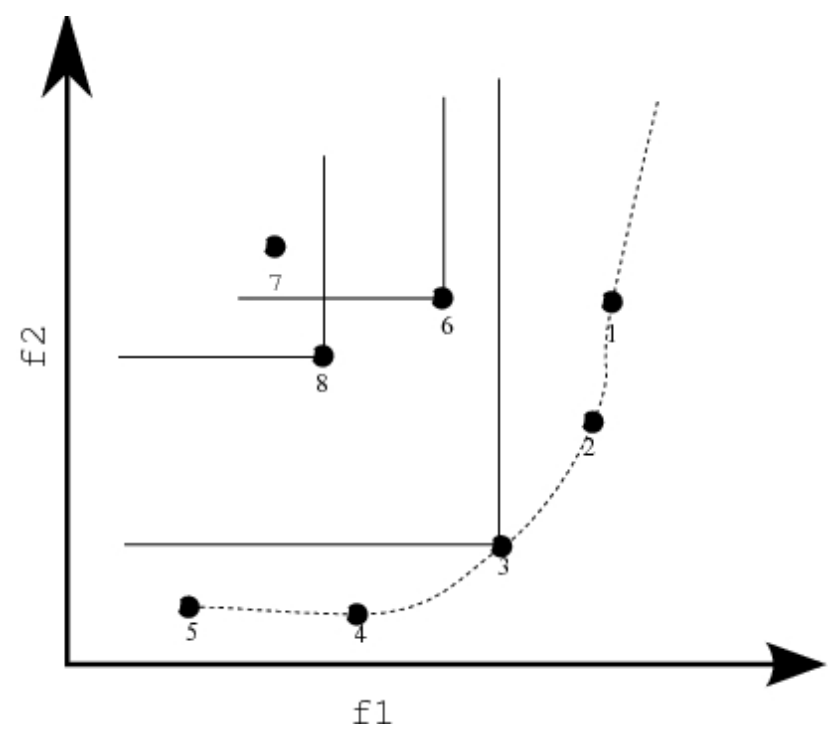

Figura 4.1: Representação de dois objetivos de um PMO de maximização dos objetivos.

\subsection{Algoritmos genéticos}

AGs são aplicados como técnicas de busca e otimização em diversas áreas. São baseados no mecanismo de seleção natural, focando na sobrevivência do indivíduo mais apto. AGs nem sempre encontram a melhor solução possível, porém fornecem boas soluções locais para problemas NP completos (Papadimitriou, 1994).

A solução de problemas utilizando algoritmos genéticos envolve dois aspectos: codificação da solução na forma de cromossomos, onde cada cromossomo representa uma possível solução, e uma função de aptidão (fitness), que é aplicada para encontrar a melhor solução.

Várias técnicas de codificação podem ser utilizadas para diferentes tipos de problemas, como strings binárias, números reais e outras. A função de aptidão é responsável por avaliar os indivíduos. Essa função recebe um cromossomo como parâmetro e retorna um número real que representa a qualidade da solução obtida, por exemplo, o quão adequada é a solução para o problema em estudo. 
Cromossomos mais aptos são identificados e armazenados durante o processo de evolução. Os menos aptos, por outro lado, são eliminados. Diferentes técnicas podem ser aplicadas para a identificação dos melhores cromossomos, como a seleção proporcional ou roleta, seleção por ranking e a seleção baseada em torneio (Baeck et al., 1999).

Na seleção proporcional, indivíduos são transferidos para a geração seguinte de acordo com o valor proporcional ao resultado de sua função de aptidão. Uma das possíveis implementações dessa técnica consiste no uso de uma roleta, dividida em $N$ partes, com $N$ sendo o número de indivíduos (cromossomos) da população atual. O tamanho de cada parte é proporcional ao valor da função de aptidão de cada indivíduo. A roleta é girada $N$ vezes e, a cada turno, o indivíduo apontado é selecionado e inserido na geração seguinte.

A seleção baseada em ranking pode ser dividida em duas etapas. Durante a primeira, as soluções são ordenadas de acordo com seu valor da função de aptidão. Com a lista ordenada, cada indivíduo recebe um novo valor de aptidão de acordo com sua posição no ranking. Depois, um procedimento que seleciona os indivíduos conforme sua posição no ranking é aplicado. Assim, os indivíduos de melhores posições têm maiores chances de serem selecionados.

Na seleção baseada em torneio não se atribui automaticamente probabilidades a indivíduos. Um torneio de tamanho $k$ é definido com $k \geq 2$ indivíduos. Então, $k$ indivíduos são escolhidos aleatoriamente na população atual, e seus valores de aptidão são comparados e o indivíduo com melhor valor de aptidão é selecionado para reprodução. $\mathrm{O}$ valor de $k$ é definido pelo usuário, representando a pressão de seleção, isto é, a velocidade com a qual os indivíduos mais aptos vão dominar a população, gerando o extermínio dos mais fracos.

Uma vez selecionados os indivíduos para reprodução, é necessário modificar suas características genéticas usando técnicas de reprodução conhecidas como operadores genéticos. Os operadores mais comuns são o crossover e a mutação.

O operador de crossover permite a troca de material genético entre dois indivíduos, conhecidos como pais, combinando suas informações de modo a aumentar a possibilidade de gerar um novo indivíduo com melhores características que os originais (Hinterding, 2000).

O crossover de um ponto é o mais usado. Para aplicá-lo, dois indivíduos (pais) são selecionados e dois novos indivíduos são criados a partir deles (filhos). Um único ponto de quebra aleatório é selecionado nos cromossomos pais, e novos cromossomos são criados a partir da combinação dos primeiros, como mostrado na Figura (4.2). A Figura 4.2) (a) mostra os indivíduos pais e o ponto de separação marcado pelo símbolo |. Novos indivíduos criados a partir da combinação dos cromossomos pais são mostrados na Figura (4.2) (b), ilustrando o operador de crossover.

$$
\begin{array}{cc}
X_{1} X_{2} \mid X_{3} X_{4} X_{5} X_{6} & X_{1} X_{2} \mid Y_{3} Y_{4} Y_{5} Y_{6} \\
Y_{1} Y_{2} \mid Y_{3} Y_{4} Y_{5} Y_{6} & Y_{1} Y_{2} \mid X_{3} X_{4} X_{5} X_{6}
\end{array}
$$

(a) Antes do crossover (b) Depois do crossover

Figura 4.2: Operador de cruzamento: um ponto. 
O crossover de dois pontos também é bastante utilizado. Semelhante ao de um ponto, esse operador se diferencia por utilizar dois pontos de quebra aleatórios, ao invés de apenas um. A Figura 4.3 exemplifica um crossover com os locais de quebra representados pelo símbolo |. A Figura (4.3) (a) mostra os cromossomos pais e (b) os gerados após o crossover.

$$
\begin{array}{cc}
X_{1} X_{2}\left|X_{3} X_{4}\right| X_{5} X_{6} & X_{1} X_{2}\left|Y_{3} Y_{4}\right| X_{5} X_{6} \\
Y_{1} Y_{2}\left|Y_{3} Y_{4}\right| Y_{5} Y_{6} & Y_{1} Y_{2}\left|X_{3} X_{4}\right| Y_{5} Y_{6}
\end{array}
$$

(a) Antes do crossover (b) Depois do crossover

Figura 4.3: Operador de Cruzamento: dois pontos.

O operador de mutação é utilizado para alterar um único gene por um valor aleatório. Quando um indivíduo é representado por um bitmap, esse operador escolhe de forma aleatória um gene do cromossomo e troca seu valor de 1 para 0 e vice versa. O objetivo do operador de mutação é manter a diversidade da população, sempre permitindo que um cromossomo cubra um amplo espaço de busca (Hinterding, 2000). Esse operador é geralmente aplicado com baixa probabilidade, pois, com alta, o resultado tende a ser aleatório.

A Figura (4.4) ilustra um fluxo de dados típico de um algoritmo genético. Pode-se observar que a estrutura do algoritmo é simples, fato que o torna muito popular. Cabe citar que além do crossover e da mutação, também se utiliza o operador elitismo para formar a nova geração. Outra característica do método que aumenta sua popularidade é sua facilidade de ser acoplado com qualquer problema de otimização. Faz-se necessária apenas a parametrização do problema e a utilização de uma função de avaliação para a solução. Porém, o método é sensível às diferentes parametrizações (Oyama et al., 2000c) e também é sensível à função de avaliação, incluindo o modelo físico e o método de solução das equações, como é avaliado neste trabalho.

O AG apresentado nessa seção é típico para a aplicação de problemas de um objetivo, ou também conhecido como Single-objective genetic algorithm. Para utilizar o AG para resolver problemas multiobjetivo várias abordagens foram propostas nas últimas décadas 1 .

Uma dessas abordagens é o AG proposto por Goldberg (1989), chamado Goldberg's Pareto Ranking, para resolver o problema de aproximação de Schaffer. Nessa técnica, o indivíduo é classificado de acordo com seu nível de dominância (ou rank descrito na seção 2.1.2). O valor do rank é utilizado como função de avaliação do indivíduo para a seleção. A utilização desse parâmetro permite que soluções com o mesmo nível de dominância sejam igualmente avaliadas e com menor pressão evolutiva, prevenindo convergência prematura.

Deb \& Goldberg (1989) propuseram a utilização de técnicas de niching para prevenir a convergência prematura do algoritmo para uma população com baixa variabilidade, levando a uma representação pobre da fronteira de Pareto.

Por outro lado, Fonseca \& Fleming (1993) propuseram a utilização da técnica de Goldberg com modificação na definição do fitness. Eles propuseram que a classificação do indivíduo seria o

\footnotetext{
${ }^{1}$ Nas referências (Coello et al., 2002) e (Deb, 2004) são descritas muitas dessas abordagem.
} 


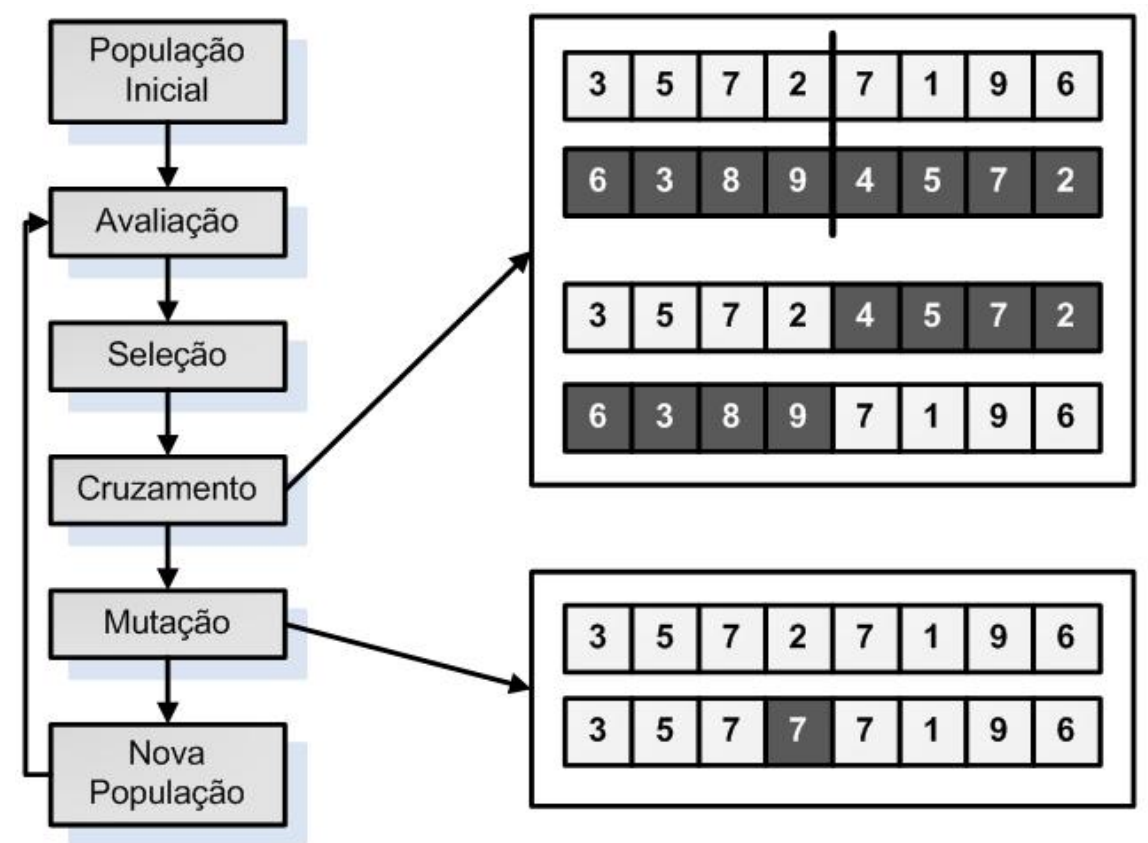

Figura 4.4: Fluxo de dados típico de um algoritmo genético.

número de indivíduos da população pelos quais é dominado somado de um. Sendo assim, todos os indivíduos não dominados terão classificação 1 . O objetivo dessa modificação é priorizar os indivíduos não dominados, porém, conforme Deb \& Goldberg (1989), essa abordagem pode levar a uma convergência prematura.

\subsubsection{Non-Dominated Sorting Genetic Algorithm II}

Deb et al. (2000a b) propuseram a técnica NSGA II (Elitist Non-dominated Sorting Genetic Algorithm II). Visando a utilização de elitismo, é proposta a criação de uma nova população a partir da junção da população de pais e filhos. A classificação por dominância (rank) é aplicada a ela, os indivíduos de uma mesma frente $\left(\mathcal{F}_{i}\right)$ são ordenados pelo critério de Crowd Distance (Deb, 2004) de forma decrescente. Feita essa ordenação, segundo a qual os indivíduos não dominados antecedem e, dentro de uma mesma frente de dominância, aqueles que preservam a diversidade são priorizados, seleciona-se por elitismo toda uma nova população de indivíduos. A Figura (4.5) ilustra o procedimento descrito neste parágrafo.

Após a criação dessa população elitista, a seleção via Crowded Tournament Selection ${ }^{2}$ é aplicada para garantir a variabilidade da população. Depois. utilizam-se os operadores de crossover e mutação para gerar a população utilizada na nova geração. A utilização do operador Crowded Tournament Selection tem como vantagem a eliminação de parâmetros de ajuste, como ocorre com a técnica de Fitness Sharing. Esse fato e a boa distribuição de soluções na $P F$ que a técnica fornece foram os motivos da sua adoção no presente trabalho.

\footnotetext{
${ }^{2}$ para maiores detalhes consulte Deb (2004)
} 


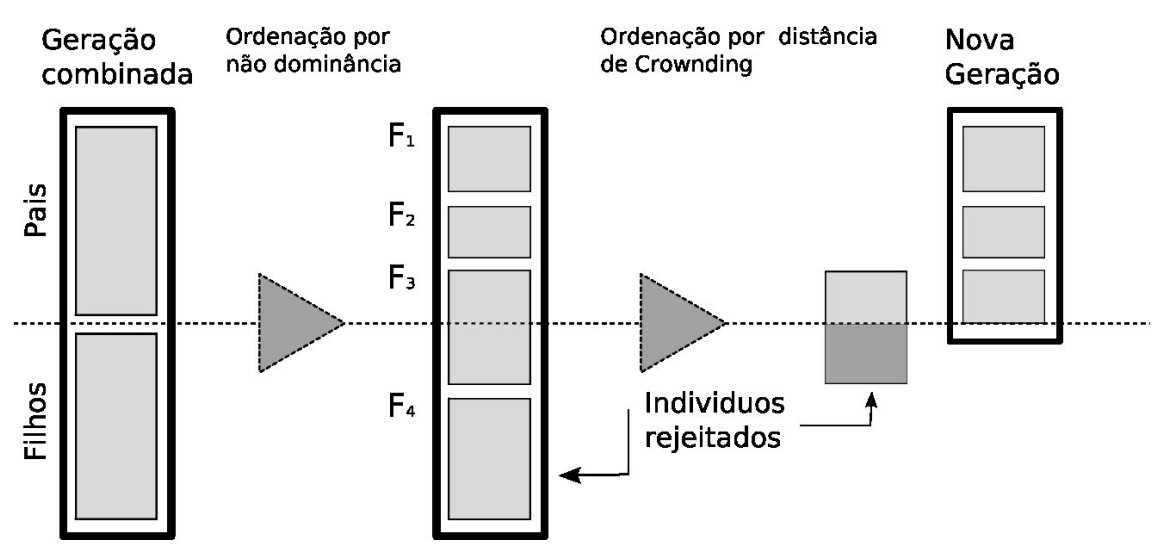

Figura 4.5: Esquema da seleção elitista do NSGAII.

A OMO tem por objetivo básico encontrar a frente de Pareto, que, quando encontrada será definida por soluções discretas, ou seja, um conjunto finito de soluções, os chamados indivíduos no caso das técnicas evolutivas. Para melhor representar a frente, é indesejável que as soluções tenham a tendência de se concentrar em regiões do domínio de soluções. A literatura demonstra que a técnica NSGA-II (Deb et al., 2002, 2000a; Deb, 2004) é eficiente em encontrar uma população que melhor representa a frente de Pareto com soluções bem distribuídas no domínio. A principal característica da técnica que lhe confere esse desempenho é a utilização de Crownd Distance. Essas características motivaram a adoção do NSGA-II no presente trabalho.

Para avaliar o resultado da OMO, na seção (4.1.2) são apresentadas formas de avaliar a qualidade da frente de Pareto encontrada.

\subsubsection{Parâmetros de desempenho de soluções multiobjetivo}

Para avaliar o desempenho do AG nos problemas de otimização de objetivo simples, é comum utilizar a função fitness, o número de avaliações efetuadas e o tempo de CPU, entre outros valores. No caso de problemas multiobjetivo, a análise de desempenho necessita da adoção de métricas apropriadas.

Tendo um conjunto de soluções não dominadas de um problema multiobjetivo, deseja-se que esse conjunto represente bem a $P F$. Isso é possível com uma boa distribuição dos pontos por toda a frente, evitando aglomerados de pontos. Para avaliar esse requisito, existem métricas como a Avarege Relative Accuracy Index (ARAI) (Ang \& Li, 2001) e Spacing (Veldhuizen \& Lamont, 2000), adotados neste estudo.

Outro requisito de qualidade de solução para o problema multiobjetivo é a otimalidade da frente de Pareto encontrada pelo algoritmo. Essa classe de métrica é uma medida de proximidade da $P F_{k n o w n}$ em relação a $P F_{\text {true }}$.

Por exemplo, a métrica Error Ratio (ER) contabiliza a fração de soluções encontradas que pertencem à $P F_{\text {true }}($ Zitzler $\&$ Thiele, 1998a b , 1999). Neste trabalho, o autor propõe duas rein- 
terpretações dessa métrica. As métricas propostas são denominadas Inverse Error Ratio (InvER) e Generalized Error Ratio (GER).

Outro tipo de métrica de otimalidade calcula a distância entre os pontos de $P F_{k n o w n}$ e os pontos da $P F_{\text {true }}$. Para isso, é necessário utilizar soluções de benchmark, e, portante, tais métricas são mais utilizadas em trabalhos de validação de códigos e comparação entre diferentes técnicas. Como exemplo, existe a métrica Generational Distance (GD) (Veldhuizen \& Lamont, 1998). Nesses trabalhos, tais métricas são utilizadas para comparar diferentes AG e outras técnicas de OMO.

Torna-se muito difícil definir a otimalidade do conjunto de soluções em problemas onde não se tem a $P F_{\text {true }}$, o que é muito comum nas aplicações reais e de engenharia. Por essa dificuldade, o autor propõe as métricas $N D W D^{G E R}$ com distância baseada na métrica GD.

A seguir são detalhadas as métricas adotadas no trabalho.

\section{Avarege Relative Accuracy Index}

É usado para avaliar quão precisa é a frente de Pareto. Ang \& Li (2001) afirmam que valores menores que 0,02 são suficientes. A métrica é definida por:

$$
A R A I=\frac{1}{N-1} \sum_{i=1}^{N-1} \sqrt{\sum_{j=1}^{m}\left(\frac{f_{j}^{i}-f_{j}^{i+1}}{\overline{f_{j}}-\underline{f_{j}}}\right)},
$$

onde $N$ é o número de soluções encontradas no Pareto, $m$ é o número de objetivos, $\overline{f_{j}}$ e $f_{j}$ são os limites superior e inferior do objetivo no conjunto de dados.

\section{Spacing}

Proposto por Schott (1995), é uma métrica que mede o espalhamento dos vetores na frente de Pareto encontrada.

$$
\text { Spacing }=\sqrt{\frac{1}{N-1} \sum_{i+1}^{N}\left(\bar{d}-d_{i}\right)^{2}},
$$

onde $d_{i}=\min _{j}\left(\sum_{k}\left|f_{k}^{i}-f_{k}^{j}\right|\right)$ e $\bar{d}$ é a média dos $d_{i}$. Quanto mais próximo de zero, mais equidistante é a distribuição das soluções.

\section{Error Ratio}

Mede a proporção de soluções dominadas pelo $P F_{\text {true }}$. Para isso, é necessário conhecer a solução do problema ou utilizar soluções de referência. Sendo o conjunto de referência as soluções representadas pela linha tracejada na Figura (4.6), as soluções dominadas (solução 7) recebem valor $e_{i}^{E R}=1$ e os demais (soluções 6 e 8 ) recebem $e_{i}^{E R}=0$. 


$$
E R=\frac{\sum_{i=1}^{N} e_{i}^{E R}}{N}
$$

Quando $E R=0$, todas as soluções encontradas pertencem ao Pareto verdadeiro ou de referência.

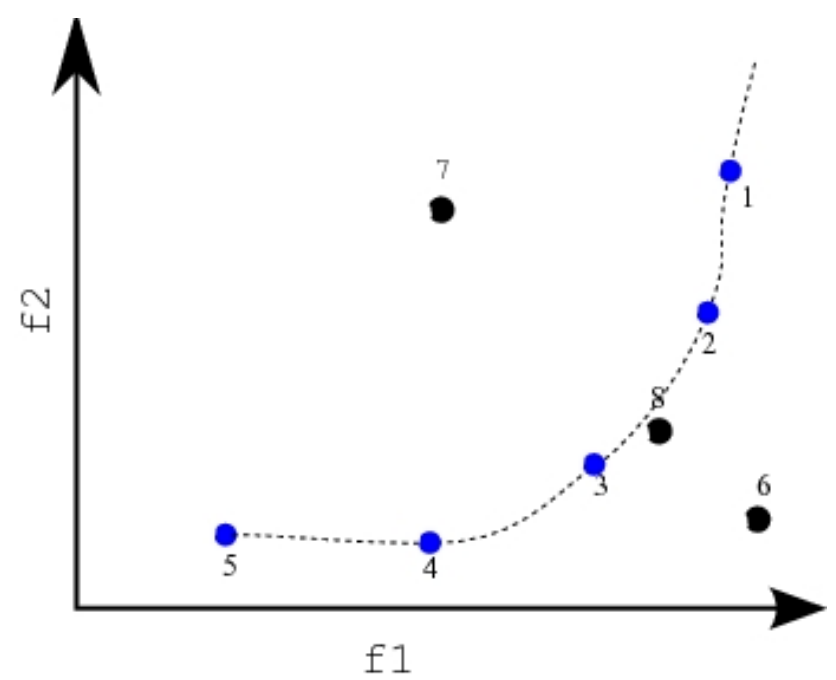

Figura 4.6: Representação gráfica da classificação de uma solução com relação a um conjunto.

\section{Inverse Error Ratio}

A métrica Inverse Error Ratio (InvER) é uma das métricas propostas pelo autor e simplesmente inverte a idéia da métrica $e_{i}^{E R}$, sendo $e_{i}^{I n v E R}=1$ quando a $i$-ésima solução domina alguma solução da referência (solução 6 da figura) e $e_{i}^{I n v E R}=0$ quando a $i$-ésima solução não domina nenhuma solução da referência (soluções 7 e 8 ).

\section{Generalized Error Ratio}

A métrica Generalized Error Ratio (GER) também é proposta pelo autor e contabiliza as soluções que dominam as soluções de referência, sendo $e_{i}^{G E R}=-1$ para as soluções dominadas pela referência, $e_{i}^{G E R}=0$ para as pertencentes ao $P F_{\text {ref }}$ e $e_{i}^{G E R}=1$ para as soluções que dominam a referência. Para ilustrar, a solução 7 da Figura (4.6) recebe valor -1 , a solução 8 valor 0 e a solução 6 valor 1 .

\section{Normalized Dominance Weighted Distance}

Veldhuizen \& Lamont (1998) propuseram a métrica de otimalidade Generational Distance (GD) que calcula a distância entre as soluções do $P F_{\text {known }}$ com relação ao $P F_{\text {true }}$ (Coello et al., 2002). Para cada solução do $P F_{\text {known }}$ é calculada a menor distância com relação aos elementos de $P F_{\text {true }}$, definida por $d_{i}=\min _{j}\left(\left\|f_{\text {true }}^{j}-f_{\text {known }}^{i}\right\|_{2}\right)$. 
Nesta métrica, $d_{i}$ é multiplicada por $e_{i}^{G E R}$, definindo uma ponderação para a distância, e é normalizada da seguinte forma: para cada objetivo $f_{j}^{i}$ do $i$-ésimo indivíduo tem-se $\overline{f_{j}}$ e $\underline{f_{j}}$ definidos acima, e a normalização é obtida pela aplicação $\left(d_{i}-\underline{f_{j}}\right) /\left(\overline{f_{j}}-\underline{f_{j}}\right)$. A métrica é definida por:

$$
N D W D_{G E R}=\sum_{i=1}^{N} e_{i}^{G E R}\left(\frac{d_{i}-\underline{f_{j}}}{\overline{f_{j}}-\underline{f_{j}}}\right) .
$$

A métrica pondera $d_{i}$ diferentemente para cada solução nas posições referentes a seis, sete e oito da Figura (4.6). Logo, valores negativos para a métrica significam que a maior parte de $P F_{\text {known }}$ está dominada por $P F_{\text {ref }}$, valores próximos de zero significam que $P F_{\text {known }}$ se aproxima de $P F_{\text {ref }}$ e valores positivos, que $P F_{\text {known }}$ domina $P F_{\text {ref }}$, em sua maioria. Essa métrica tem a vantagem de representar de forma contínua a posição de $P F_{k n o w n}$.

Deve-se lembrar que, assim como na métrica GD de otimalidade posposta por Veldhuizen \& Lamont (1998), é necessário que $P F_{\text {ref }}$ tenha elementos bem distribuídos no espaço de soluções (Coello et al., 2002). Isso nem sempre é possível, por exemplo, quando utilizadas soluções préestabelecidas na engenharia.

\subsection{Técnicas de visualização de dados}

A facilidade de definir os parâmetros de desempenho para a otimização single objective se reflete na facilidade da visualização dos resultados. O gráfico de evolução dos parâmetros com as gerações e a descrição detalhada do resultado é suficiente para tirar conclusões sobre o problema. No caso multiobjetivo a observação da evolução dos parâmetros de desempenho escolhidos fornece subsídios para a avaliação do algoritmo de otimização. A Figura (4.7), apresentada por Deb \& Jain (2002), mostra um exemplo da evolução dos parâmetros para uma OMO, onde duas regiões são bem visíveis: a convergência para a $P F$ e a evolução da diversidade para uma melhor definição da frente.

Por outro lado, a dificuldade de definir os parâmetros de desempenho para o caso multiobjetivo dificulta a visualização dos dados e dos resultados, principalmente pelo grande número de dimensões do problema (variáveis de decisão e objetivos). Também, quanto maior a dimensão do problema mais difícil é observar a correlação entre os parâmetros e a identificação de padrões. Ao obter os resultados finais da otimização dos perfis, por exemplo, obtém-se uma população toda com características geométricas distintas. Para a parametrização Parsec, a otimização aplicada neste trabalho usa com nove variáveis de decisão. Se forem analisadas as características geométricas de espessura máxima e sua posição, camber máximo e sua posição e área do perfil, tem-se um problema de 14 parâmetros, mais os objetivos. Considerando também a correlação entre variáveis de decisão e parâmetros geométricos ou objetivos e entre esses e os parâmetros geométricos, tem-se 87 correlações e 3 grupos de parâmetros multidimensionais com possíveis formações de padrões. 


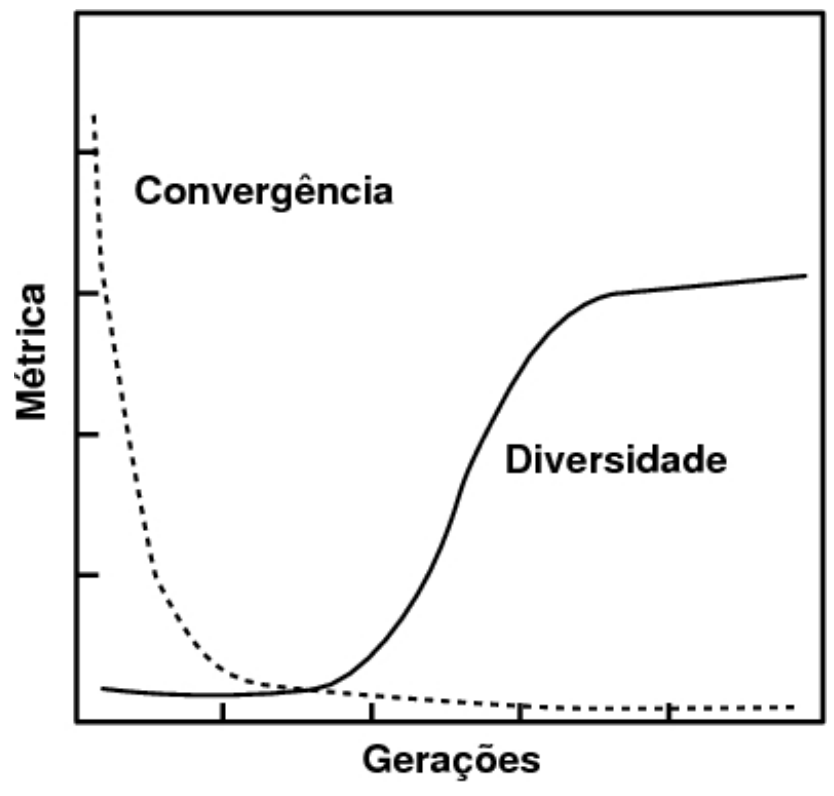

Figura 4.7: Exemplo de Evolução dos parâmetros de desempenho para uma otimização multiobjetivo.

Esse exemplo, aplicado neste trabalho, já mostra a complexidade dos problemas de engenharia devido ao grande número de dimensões do problema.

O tratamento de um conjunto de dados multidimensionais é uma aplicação importante da visualização de dados. Cada ponto é representado por coordenadas n-dimensionais, onde geralmente $n \geq 3$, e ainda é uma área de pesquisa aberta. Existem dois problemas fundamentais quando se aplicam técnicas de visualização multidimensionais: projeção e compreensão dos dados. Neste trabalho, são utilizadas duas técnicas conhecidas pela literatura, o gráfico de eixos paralelos e a matriz de gráficos de dispersão.

\subsubsection{Matriz de gráficos de dispersão}

De acordo com Nielson et al. (1997), esta técnica é a mais popular na estatística e apresenta um conjunto de gráficos de dispersão organizados na forma de uma matriz. A Figura (4.8) apresenta um exemplo com 3 variáveis. Note que nesse caso a matriz de gráficos é simétrica. Porém também existem aplicações nas quais as variáveis nas abscissas da matriz não são as mesmas que as das ordenadas e a matriz não é simétrica. É muito comum, quando se trabalha com matrizes simétricas, aplicar histogramas nos elementos da diagonal. Esses gráficos fornecem a informação da freqüência com que os valores de uma determinada variável aparece.

Uma aplicação dessa técnica é na busca de relações entre as variáveis.Por exemplo, a relação entre as características geométricas do perfil e os coeficientes aerodinâmicos para uma dada parametrização. Outra utilidade é permitir a visualização das projeções da frente de Pareto. Aplicando a técnica aos objetivos ou aos coeficientes aerodinâmicos pode-se observar a estrutura da $P F$ e comparar os resultado para os diferentes casos. Para um número grande de dimensões, a técnica 


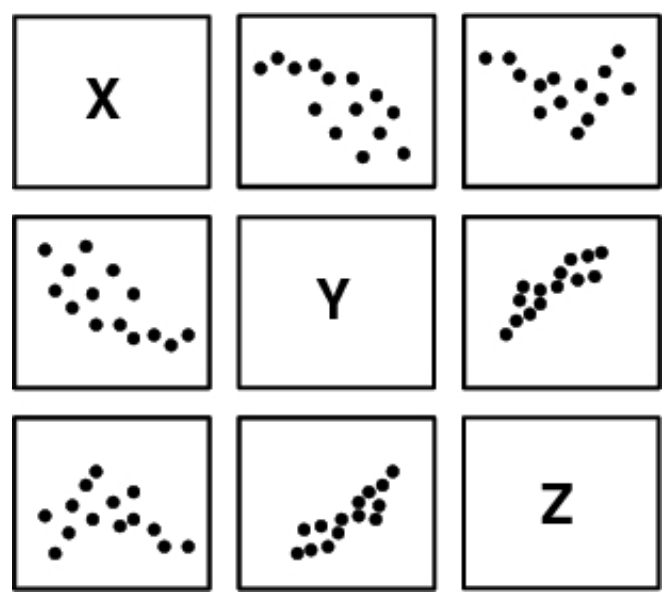

Figura 4.8: Exemplo de uma visualização de 3 variáveis utilizando a técnica de matriz de gráfico de dispersão.

não fornece uma visualização clara, pois a matriz terá muitos elementos, o que também ocorre para números excessivos de pontos nos gráficos, deixando a visualização muito poluída.

\subsubsection{Gráfico de coordenadas paralelas}

Inselberg \& Dimsdale (1987) propuseram uma abordagem para o problema de visualização multidimensional chamada Gráfico de Coordenadas Paralelas. Essa técnica transfere a informação das coordenadas para eixos paralelos, em vez de coordenadas cartesianas, unidas por segmentos de reta. Logo, cada ponto no espaço n-dimensional se transforma em uma curva formada por segmentos de reta. A Figura 4.9) (a) exemplifica a representação de um cromossomo, por exemplo, de 5 genes e a Figura (4.9)(b), a representação de 6 indivíduos. Essa representação facilita a identificação de padrões pelo observador.

(a)

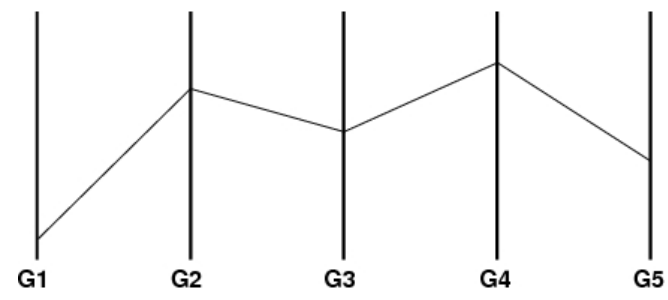

(b)

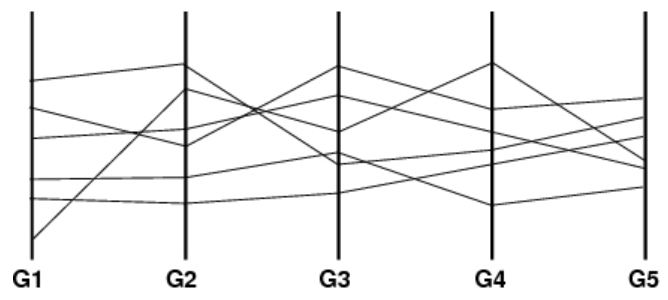

Figura 4.9: Exemplo de uma visualização de pontos n-dimensionais utilizando a técnica de coordenadas paralelas: (a) um cromossomo de 5 genes; (b) 6 indivíduos de 5 genes.

A técnica permite a observação de diferentes padrões do conjunto de dados. Por exemplo, é possível observar um aglomerado de pontos no espaço cartesiano quando aparecem feixes de curvas no gráfico. Também é possível observar relações lineares entre as soluções. Nielson et al. (1997) descrevem como a técnica é capaz de explicitar a existência das relações entre as coordenadas. Quando se observa crossover na mesma região entre dois eixos, uma relação inversamente 
proporcional entre as variáveis está caracterizada. Quando existe um padrão de paralelismo entre as curvas, uma relação de proporcionalidade esta aparente (Tuval \& Reif, 1987; Inselberg \& Dimsdale, 1990). Neste último trabalho, a técnica foi utilizada para o reconhecimento de colisão de aeronaves. Por exemplo, se o conjunto de dados tem uma relação linear entre duas coordenadas, se observa no gráfico um ponto de crossover entre os segmentos de reta.

Apesar de a técnica permitir trabalhar com dimensões maiores em comparação com a técnica de matriz de gráficos de dispersão, os gráficos de coordenadas paralelas se tornam muito densos quando visualizado um número grande de pontos. Outra desvantagem está relacionada com a ordem das coordenadas utilizada. Essa ordem pode não explicitar relações entre as variáveis.

\subsection{Implementação}

Dos métodos utilizados no estudo, aqueles responsáveis pelo maior tempo de processamento são os códigos de CFD. Por isso a implementação, além de visar a precisão numérica, deverá satisfazer o requisito de custo computacional. Visando isso, testes foram realizados para avaliar os valores para os parâmetros, como raio do domínio, número de pontos da malha, $C F L$ e resíduo suavizado, entre outros, sem comprometer o resultado numérico.

Os códigos de simulação aerodinâmica e geração de malha foram implementados em FORTRAN 77. A simplicidade e a velocidade da linguagem a tornam apropriada para a aplicação de CFD em malha estruturada.

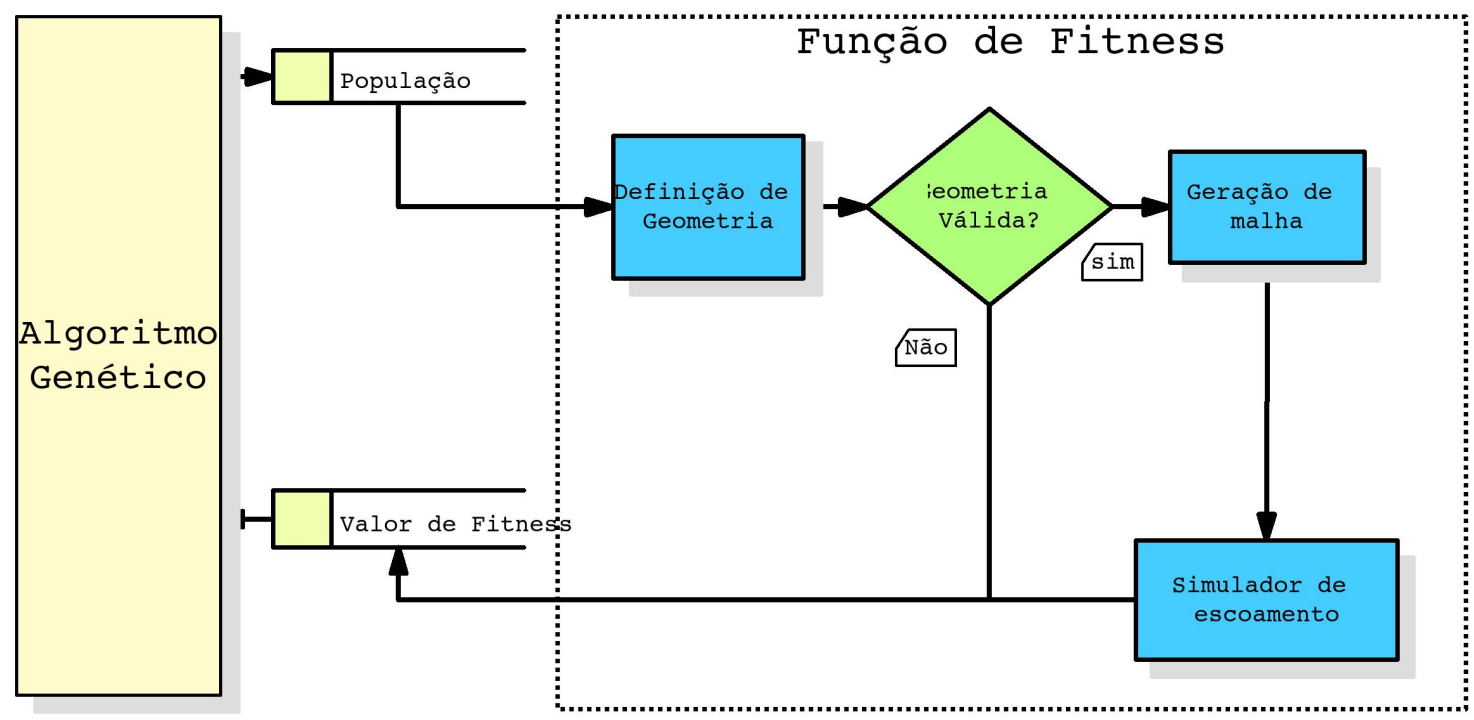

Figura 4.10: Esquema de implementação do algoritmo genético single-objective com o solver.

O código genético foi implementado em linguagem $\mathrm{C}++$. A escolha se deve á facilidade de utilização de estruturas de dados implementadas na biblioteca STL. O conceito de algoritmos evolutivos também é bem adaptado ao paradigma orientado a objetos. O código genético necessitou 
da implementação de uma técnica de restart, que consiste em permitir que o programa seja capaz de retomar o processo no caso de uma interrupção.

Na Figura 4.10 está ilustrado o fluxo de dados da integração dos códigos. Os códigos de CFD e pós processamento serão integrados à aplicação em $\mathrm{C}++$ utilizando a definição de funções extern. Para o algoritmo genético, os códigos de simulação serão apenas funções que retornarão os valores dos objetivos utilizados pelo genético. 



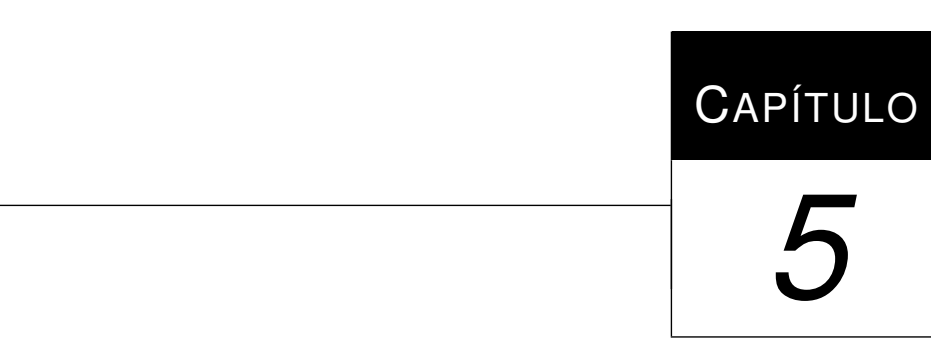

\section{Verificação e validação}

If there is a wrong way to do something, then someone will do it. (Edward A. Murphy Jr.)

Para garantir a representatividade de fenômenos físicos, é necessária a validação dos códigos. Para isso, a distribuição de pressão obtida pelos métodos é comparada com resultados experimentais de perfis aerodinâmicos transônicos. Tanto a fidelidade de representação da pressão como a posição da onda de choque são importantes. Cabe lembrar que, no caso invíscido, é esperado que a onda de choque se localize um pouco atrasado e mais abrupto, em comparação com o caso viscoso, devido a falta de interação entre a onda de choque e a camada limite. Mesmo com esse erro presente no modelo invíscido espera-se que o erro seja sistemático, permitindo a utilização do modelo na otimização. Na seção 5.1, estão os resultados da validação.

São feitos testes de sensibilidade dos coeficientes aerodinâmicos com a variação de parâmetros de malha e critério de parada. Na seção 5.2, estão os testes efetuados e os resultados. Para referenciar uma determinada malha, adota-se a nomenclatura raio - ncellixncellj, onde raio é o número de comprimentos de corda que define a distância entre a origem e a fronteira externa; ncelli é o número de pontos utilizados na direção $\xi$; e ncell $j$, o número de pontos utilizados na direção $\eta$.

Por outro lado, visando garantir a eficiência da otimização, o algoritmo genético é testado usando problemas conhecidos (benchmark). Em geral, busca-se utilizar funções que tenham características próximas às do problema prático. Por exemplo, deseja-se utilizar um AG para um problema com muitos ótimos locais. Ao testar o algoritmo, deve-se usar um problema teste com essa característica. Para problemas práticos com muitas variáveis de projeto, da ordem de centenas, o problema teste deve ter essa ordem de variáveis de projeto ou maior. A literatura apresenta uma série de problemas de benchmark com as mais variadas características. Na seção 5.3, são descritas as funções adotadas e o resultado obtido pelo algoritmo. 
Por organização, os problemas de teste serão denominados da seguinte forma: nvar - nobj nident, onde nvar é o número de variáveis de projeto do problema, nobj é o número de objetivos e nident é um número de identificação, quando houver ambiguidade.

\subsection{Validação da técnica de volumes finitos}

Para validar o código de simulação aerodinâmica buscando a representatividade física do problema, são utilizados os resultados experimentais das geometrias Rae 2822 e Naca 0012. Os resultados do perfil Naca 0012 estão disponíveis em (Thibert \& Ohman, 1979) e do perfil Rae 2822 em (Slater, 2002). Os códigos com a implementação dos métodos de Jameson e Roe de segunda ordem (reconstrução com variáveis conservadas) são validados utilizando uma malha 70 - 251x151, com resíduo máximo para convergência de $10^{-7}$ (lado direito da Equação (3.4)). O CFL adotado foi 0,5 e a técnica de resíduo suavizado foi empregada para garantir estabilidade.

Como será observado nas seções seguintes, os métodos implementados são capazes de prever a distribuição de pressão em torno do aerofólio com boa representatividade física. A diferença entre o modelo viscoso e o invíscido se observa para os regimes transônicos e o erro é sistemático.

\subsubsection{Perfil Rae 2822}

A validação utilizando o perfil Rae 2822 foi aplicada no regime transônico, com Mach 0,725 e incidência $2,310^{\circ}$. A Figura (5.1)(a) mostra a distribuição de $C p$ e na Figura (5.1)(b), o detalhe da onda de choque.

(a)

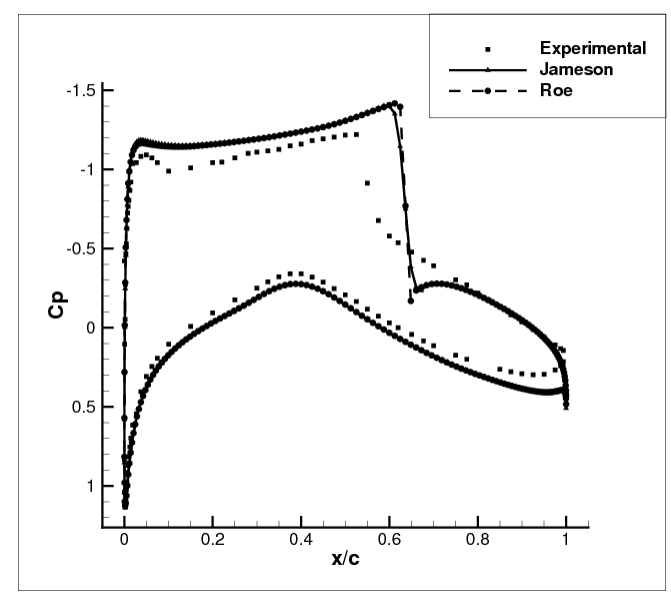

(b)

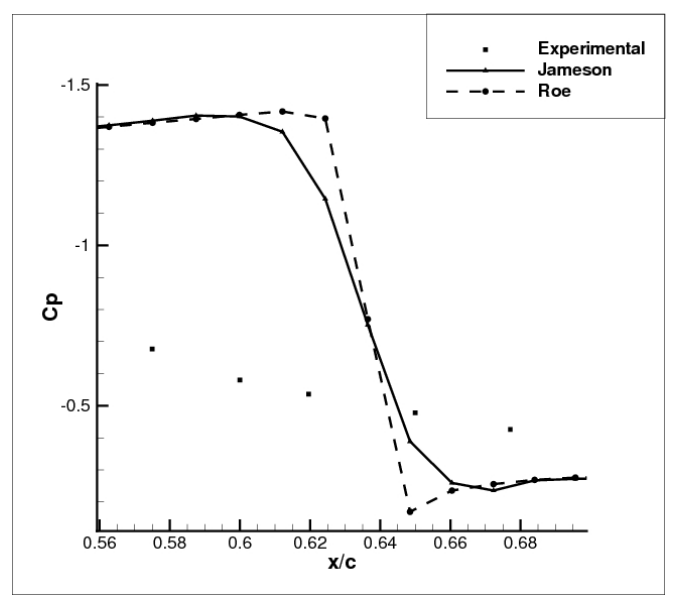

Figura 5.1: Distribuição de Cp para o perfil Rae 2822 à Mach 0,725 e $\alpha=2,31^{\circ}$ : (a) Distribuição global de $C p$; (b) Detalhe da onda de choque.

O resultado mostra que ambos os métodos são capazes de prever a distribuição de pressão em torno do aerofólio. No detalhe da onda de choque 5 5.1(b)) pode-se notar que o método de Jameson 


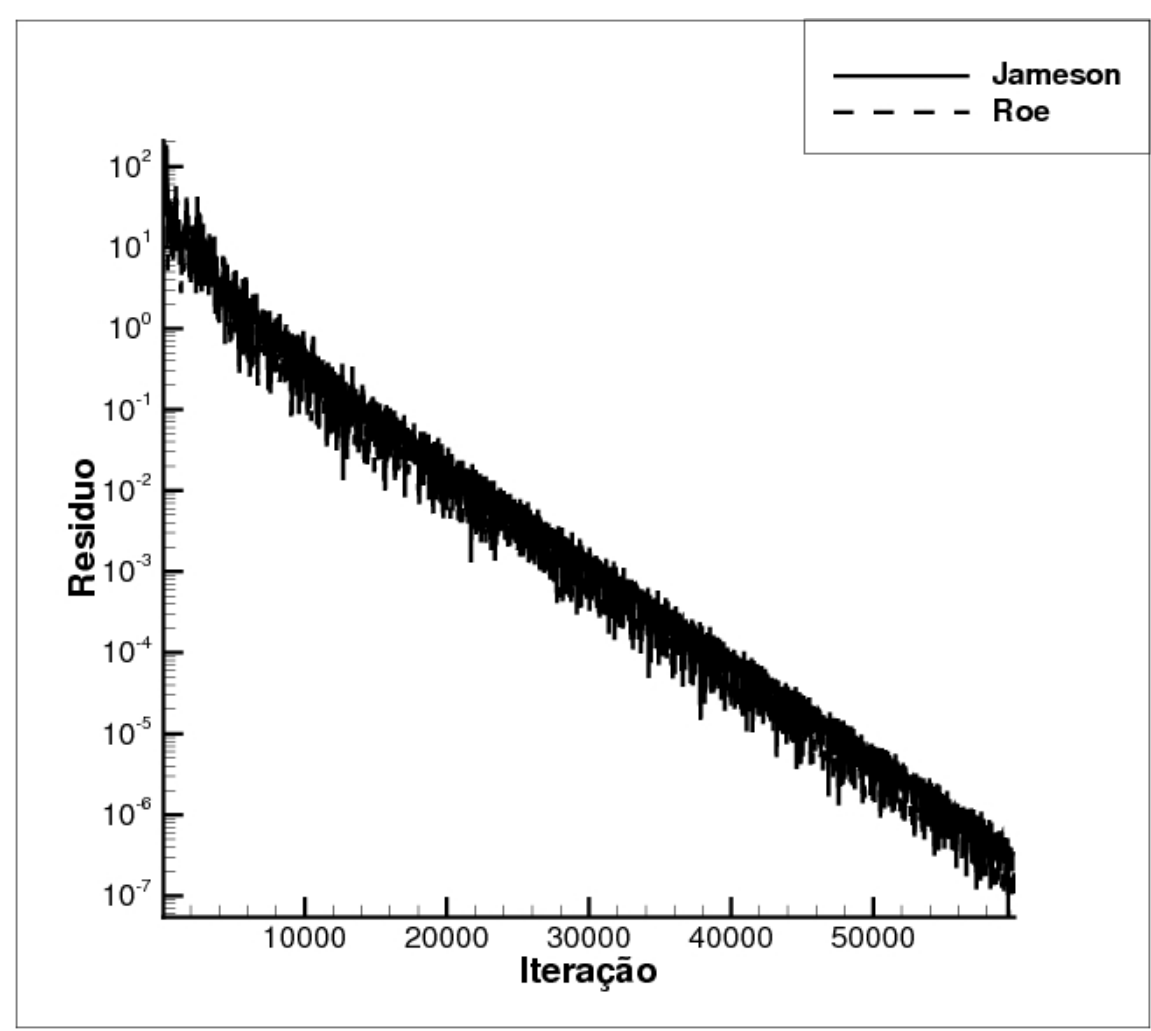

Figura 5.2: Histórico de convergência da simulação de validação para o perfil Rae 2822 à Mach 0,725 e $\alpha=2,31^{\circ}$.

tem uma menor resolução da descontinuidade em comparação com o método de Roe. Para os 2 casos é possível notar que os métodos fornecem resultados muito próximos entre si.

Para o método de Roe nota-se que o limitador de fluxo é efetivo para retirar as oscilações na proximidade da onda de choque, inerentes da reconstrução linear das propriedades na face. Infelizmente os testes mostram que a utilização do método upwind é aproximadamente $40 \%$ mais caro computacionalmente que o método centrado.

\subsubsection{Perfil Naca 0012}

Os resultados experimentais foram obtidos da referência (Thibert \& Ohman, 1979). As distribuições de pressão obtidas no experimento foram medidas para os casos tabelados em (5.1).

Tabela 5.1: Casos de validação Perfil Naca 0012.

\begin{tabular}{cccc|cccc|} 
Caso & $\alpha$ & Mach & figura & Caso & $\alpha$ & Mach & figura \\
\hline 1 & 0,0 & 0,30 & $\overline{5.3}$ & 7 & 0,0 & 0,70 & 5.9 \\
2 & 4,0 & 0,30 & $\overline{\overline{5.4}}$ & 8 & 4,0 & 0,70 & $\overline{5.10}$ \\
3 & 0,0 & 0,50 & $\overline{\overline{5.5}}$ & 9 & 0,0 & 0,75 & $\overline{\overline{5.11}}$ \\
4 & 4,0 & 0,50 & $\overline{\overline{5.6}}$ & 10 & 4,0 & 0,75 & $\overline{\overline{5.12}}$ \\
5 & 8,0 & 0,50 & $\overline{\overline{5.7}}$ & 11 & 0,0 & 0,80 & $\overline{\overline{5.13}}$ \\
6 & 4,0 & 0,60 & $\overline{5.8}$ & 12 & 0,0 & 0,83 & $\overline{5.14}$
\end{tabular}


(a)

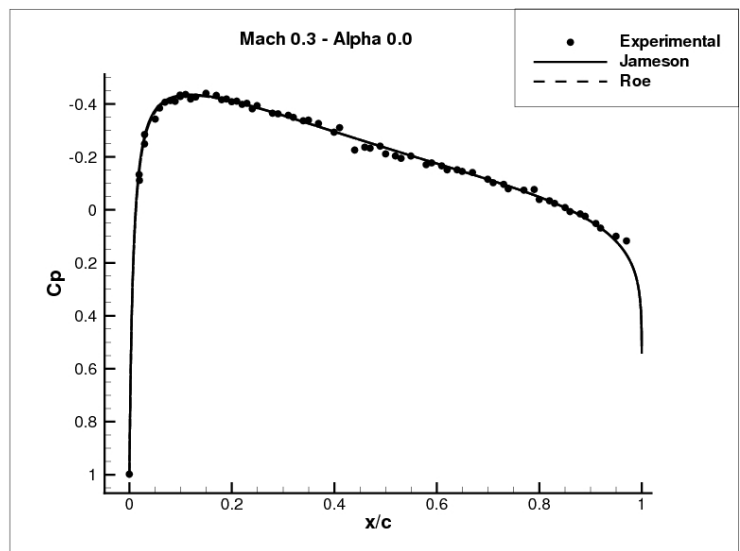

(b)

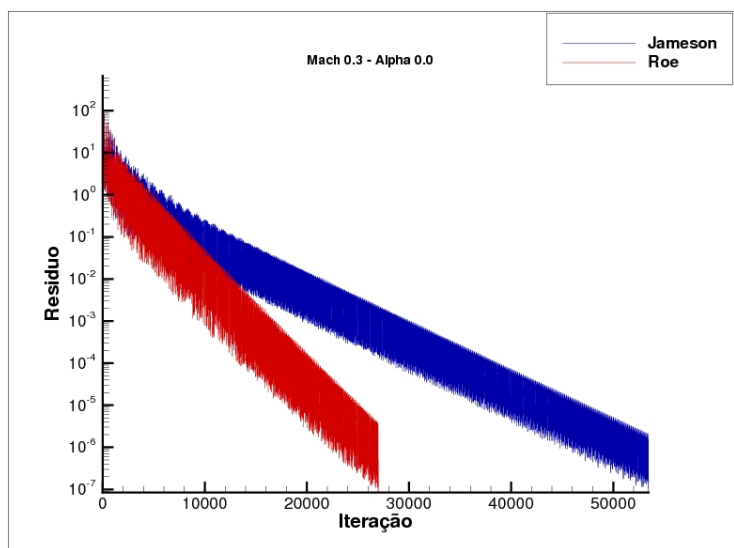

Figura 5.3: Resultado de validação para o perfil Naca 0012 à Mach 0,3 e $\alpha=0,0^{\circ}$ : (a) Distribuição global de $C p$; (b) Histórico de convergência.

(a)

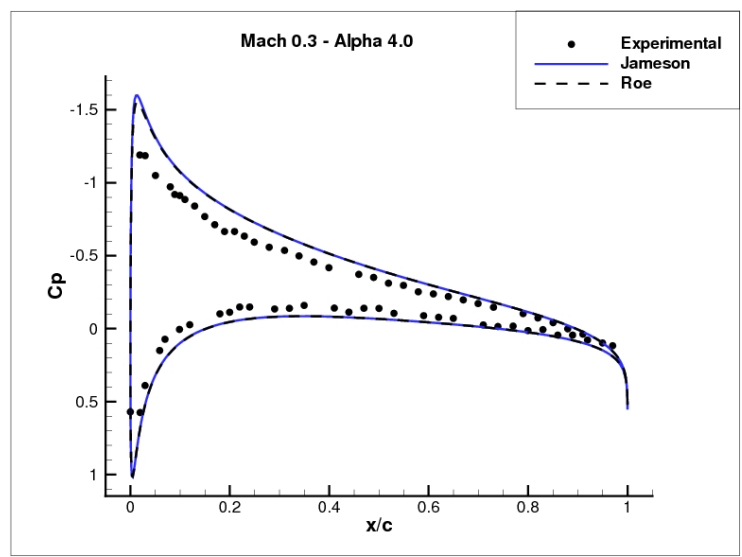

(b)

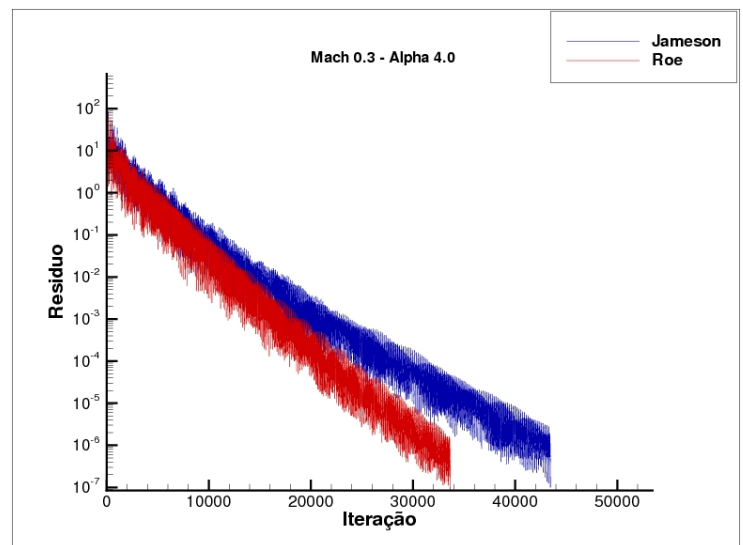

Figura 5.4: Resultado de validação para o perfil Naca 0012 à Mach 0,3 e $\alpha=4,0^{\circ}$ : (a) Distribuição global de $C p$; (b) Histórico de convergência.

(a)

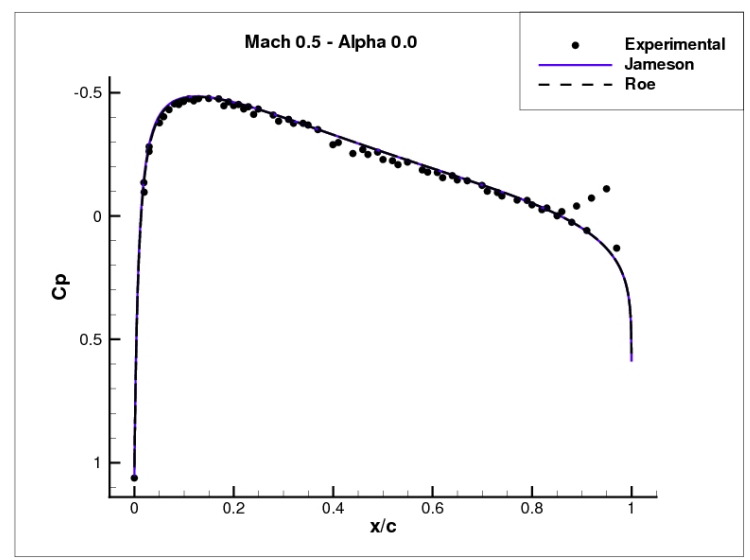

(b)

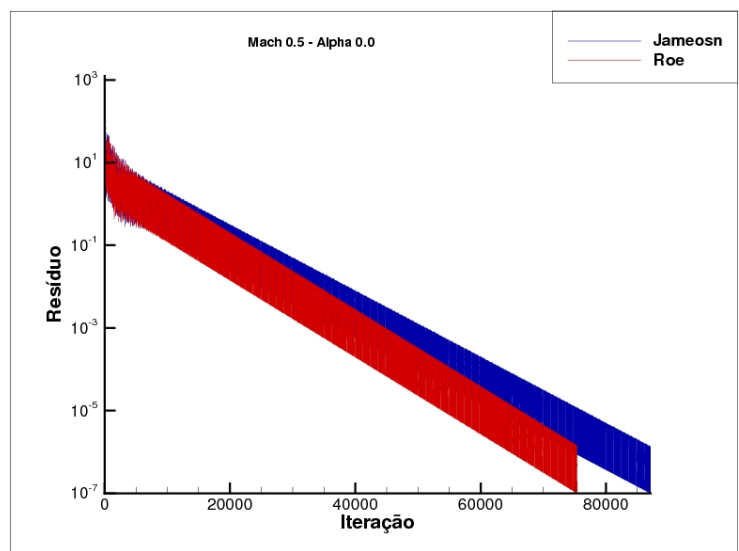

Figura 5.5: Resultado de validação para o perfil Naca 0012 à Mach 0,5 e $\alpha=0,0^{\circ}$ : (a) Distribuição global de $C p$; (b) Histórico de convergência. 
(a)

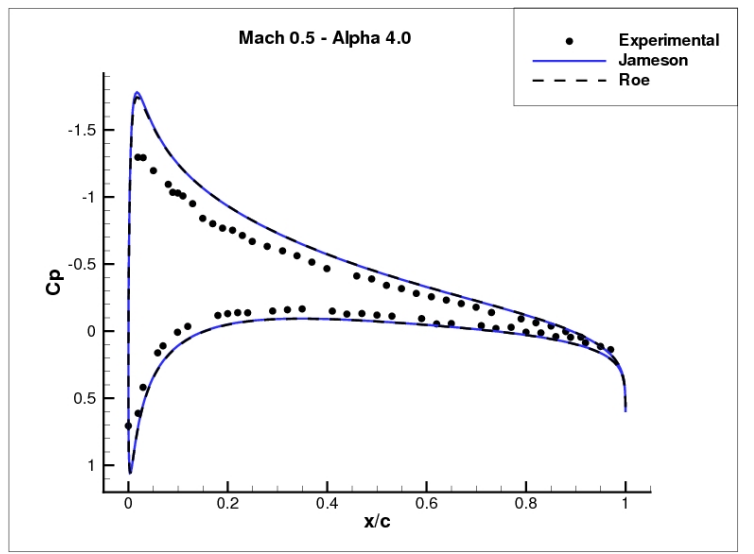

(b)

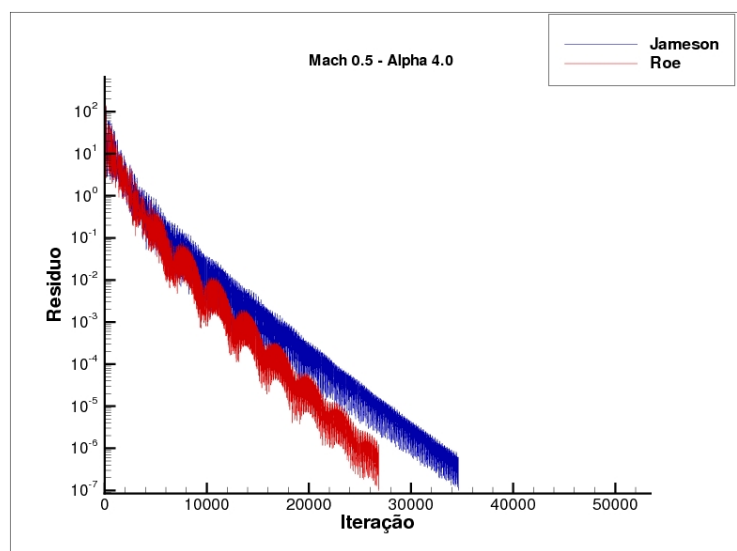

Figura 5.6: Resultado de validação para o perfil Naca 0012 à Mach 0,5 e $\alpha=4,0^{\circ}$ : (a) Distribuição global de $C p$; (b) Histórico de convergência.

(a)

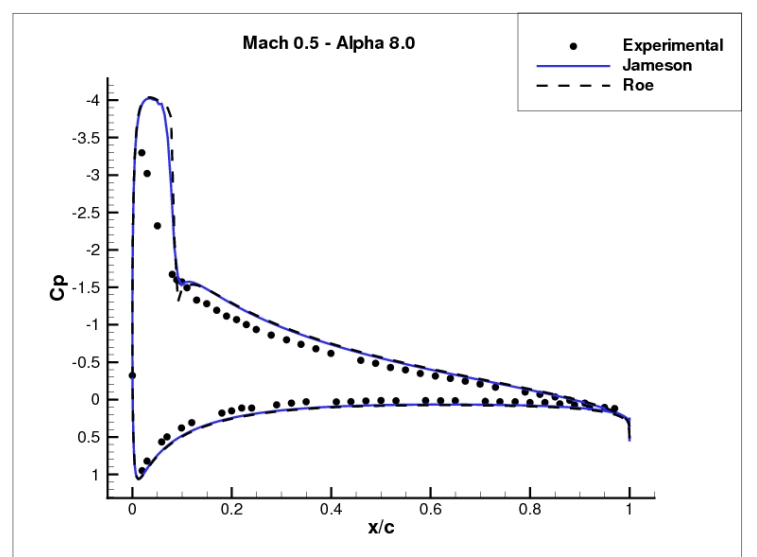

(b)

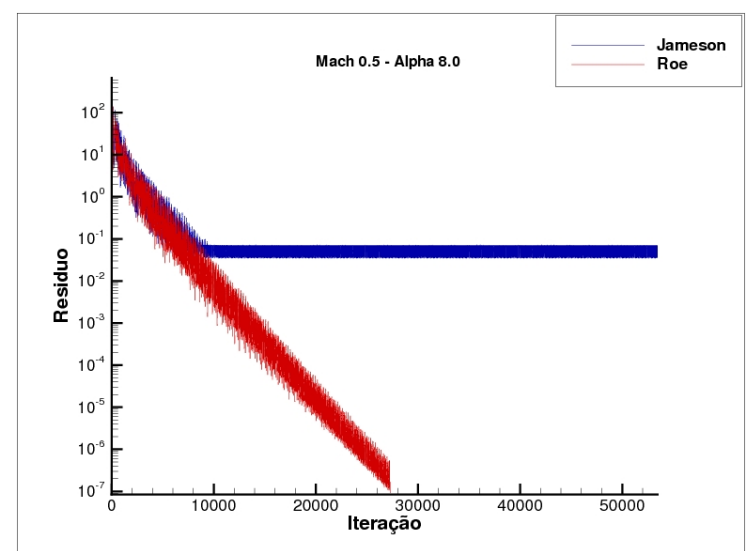

Figura 5.7: Resultado de validação para o perfil Naca 0012 à Mach 0,5 e $\alpha=8,0^{\circ}$ : (a) Distribuição global de $C p$; (b) Histórico de convergência.

As Figuras (5.3) a 5.6 mostram que o método de Roe apresentou taxa de convergência um pouco maior comparado ao método de Jameson. Esses casos mostram que os códigos possuem boa representatividade física em casos subsônicos. No caso 4, o pico de sucção previsto pelos métodos apresenta maior diferença em relação aos dados experimentais.

As Figuras (5.8) a (5.14) apresentam os resultados para os casos transônicos. Pode-se notar novamente que a previsão da distribuição de pressão é bem consistente para todos os casos, exceto pelos casos 10 e 4, que apresentaram uma sucção maior antes da onda de choque. Nos casos que apresentam onda de choque (casos 5, 6, 8, 10, 11 e 12), nota-se a previsão da mesma atrasado em relação ao experimental e de maior intensidade e a maior resolução da onda de choque apresentado pelo método de Roe. Nenhum caso apresentou oscilações próximas à onda de choque, apresentando boa suavidade. 
(a)

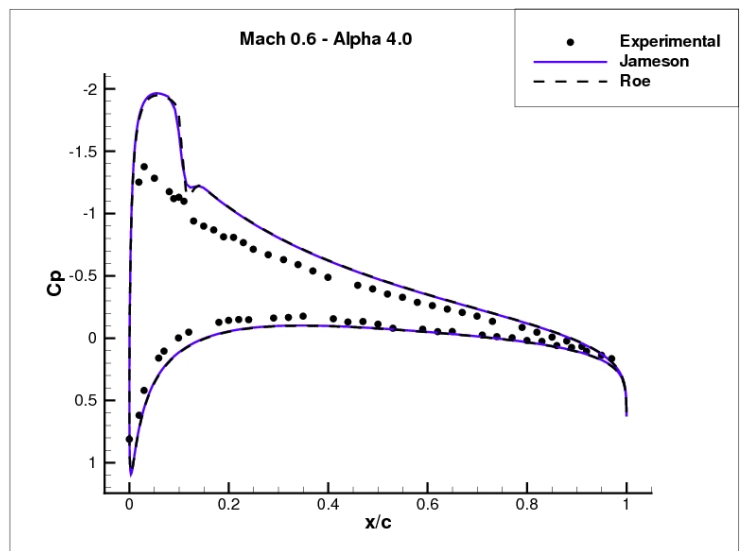

(b)

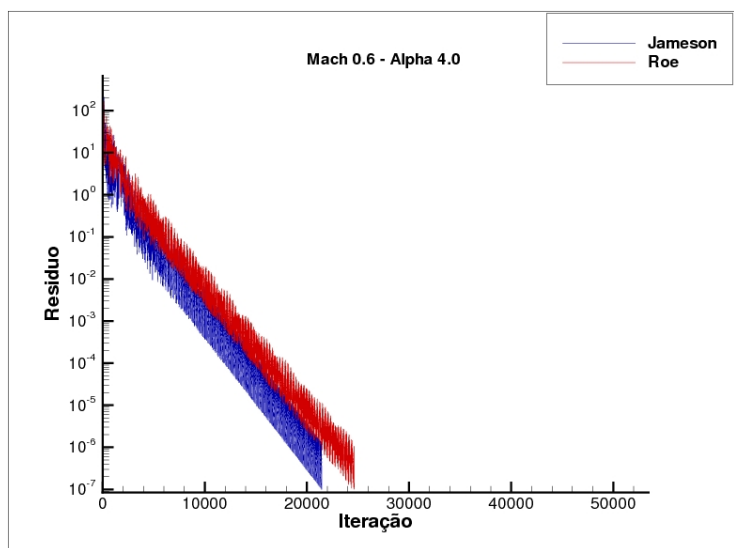

Figura 5.8: Resultado de validação para o perfil Naca 0012 à Mach 0,6 e $\alpha=4,0^{\circ}$ : (a) Distribuição global de $C p$; (b) Histórico de convergência.

(a)

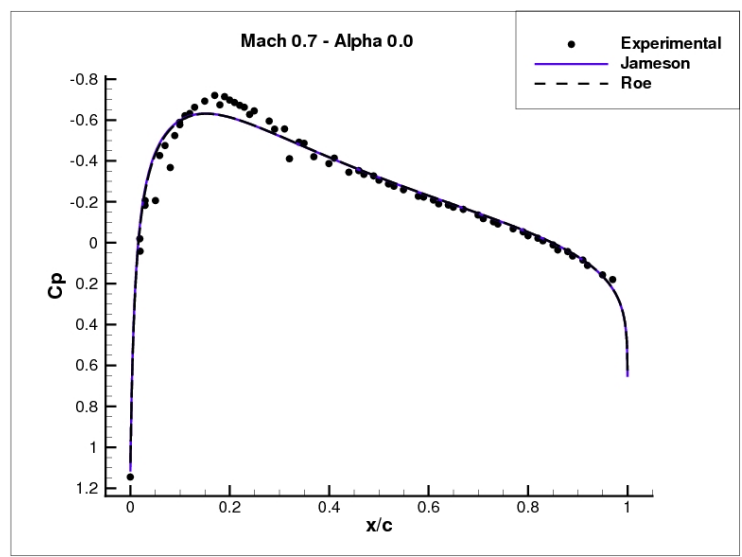

(b)

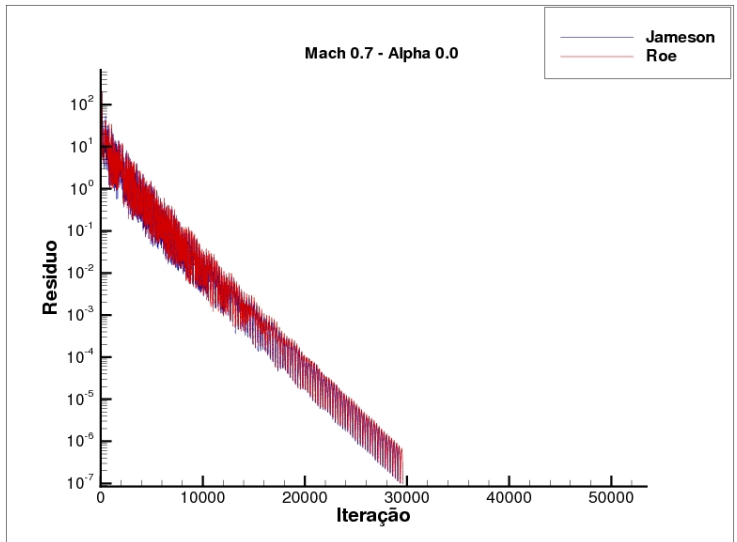

Figura 5.9: Resultado de validação para o perfil Naca 0012 à Mach $0,7 \mathrm{e} \alpha=0,0^{\circ}$ : (a) Distribuição global de $C p$; (b) Histórico de convergência.

(a)

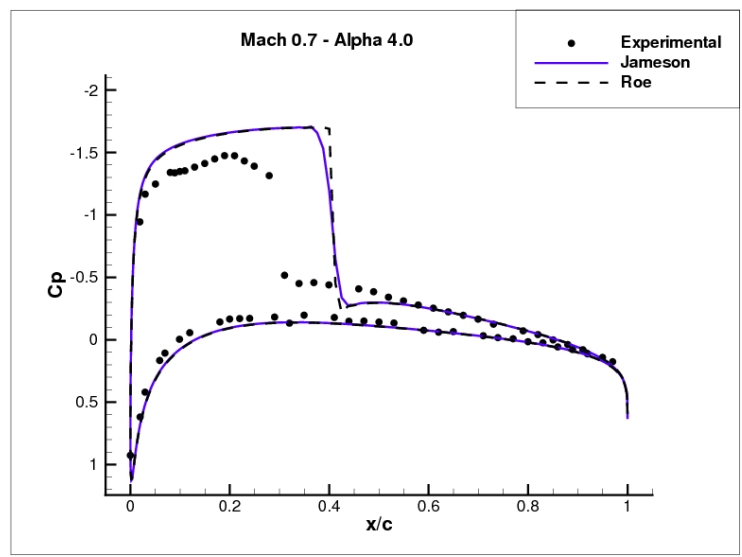

(b)

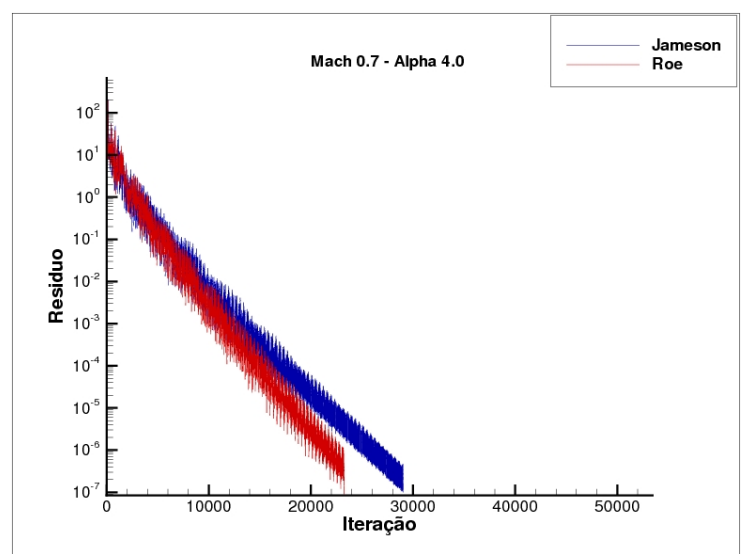

Figura 5.10: Resultado de validação para o perfil Naca 0012 à Mach 0,7 e $\alpha=4,0^{\circ}$ : (a) Distribuição global de $C p$; (b) Histórico de convergência. 
(a)

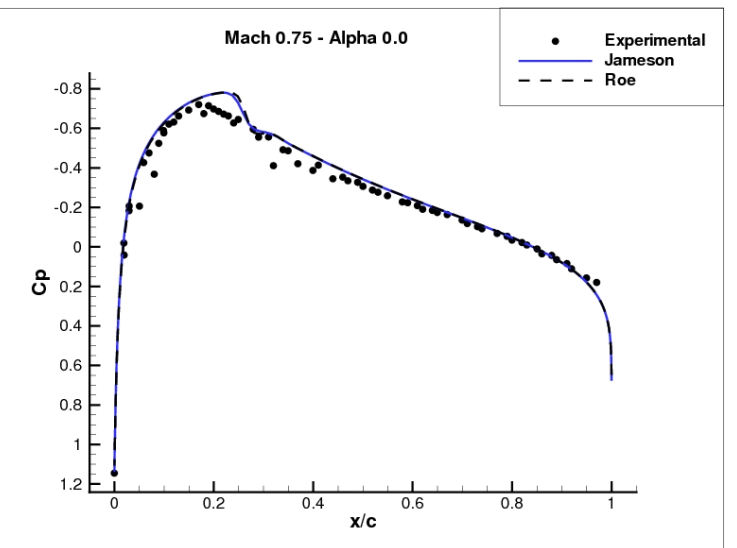

(b)

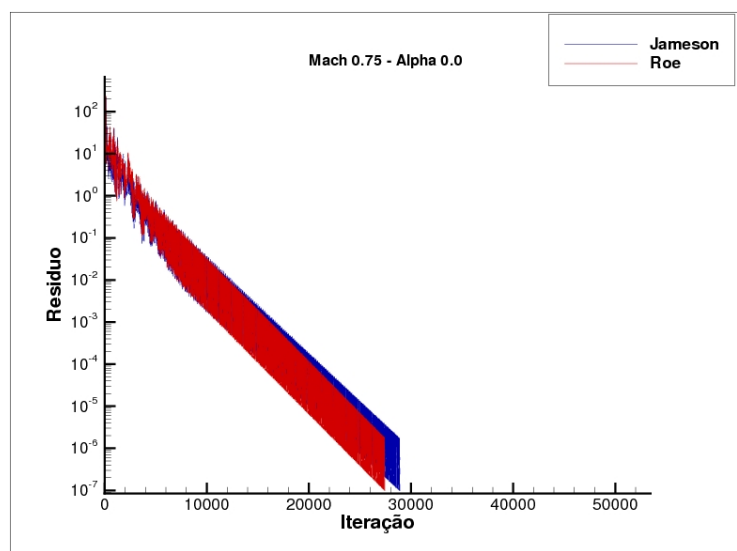

Figura 5.11: Resultado de validação para o perfil Naca 0012 à Mach 0,75 e $\alpha=0,0^{\circ}$ : (a) Distribuição global de $C p$; (b) Histórico de convergência.

(a)

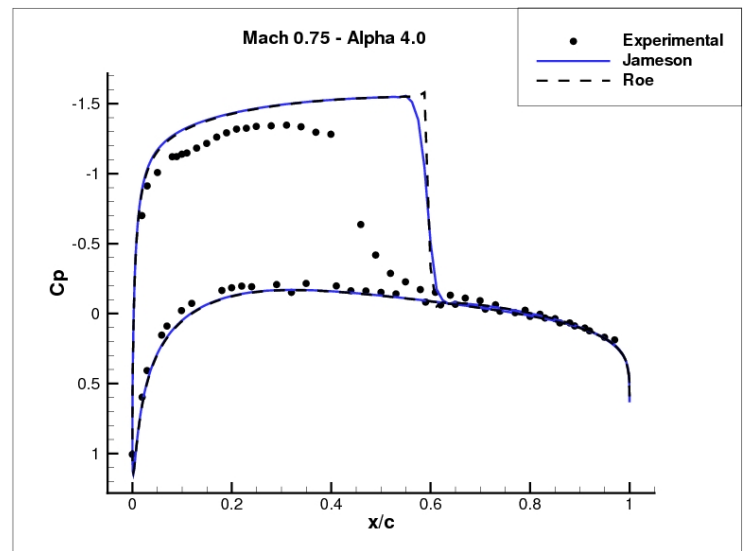

(b)

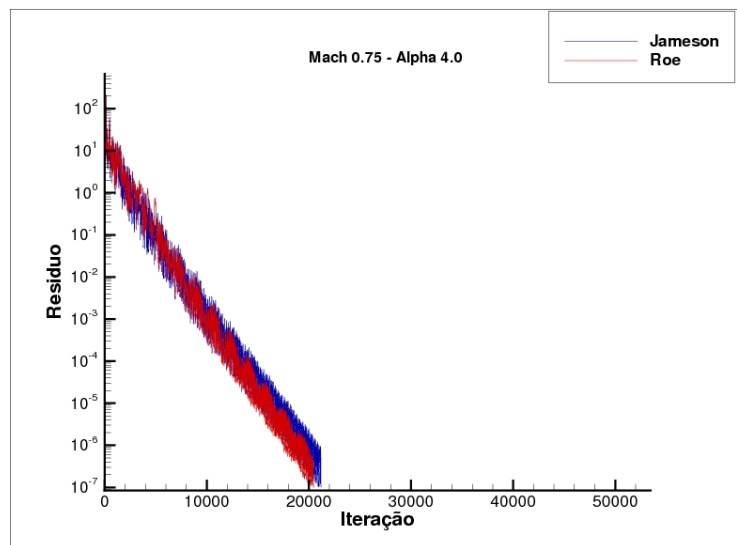

Figura 5.12: Resultado de validação para o perfil Naca 0012 à Mach 0,75 e $\alpha=4,0^{\circ}$ : (a) Distribuição global de $C p$; (b) Histórico de convergência.

(a)

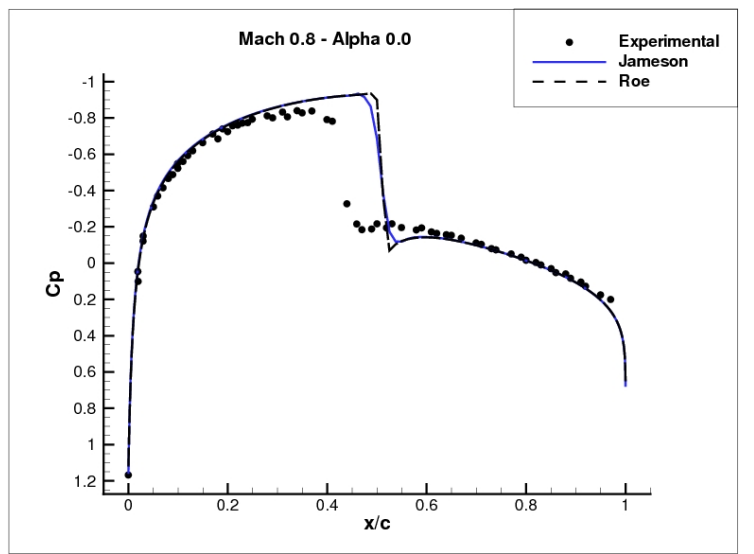

(b)

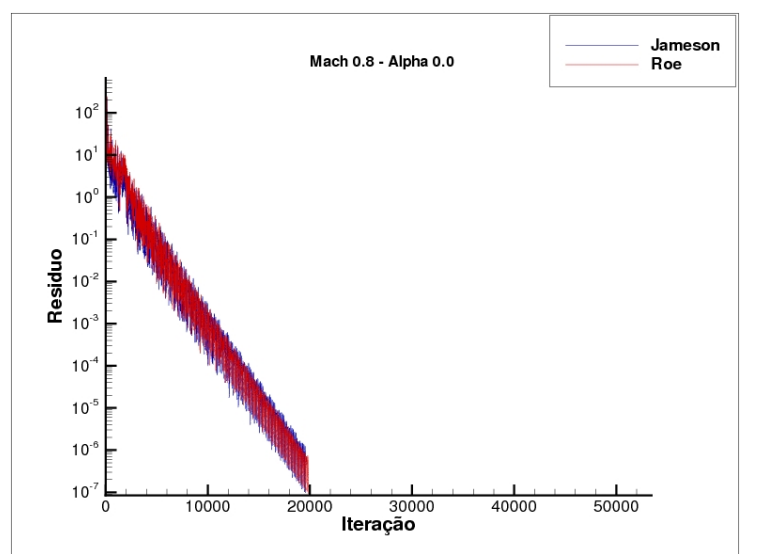

Figura 5.13: Resultado de validação para o perfil Naca 0012 à Mach 0,8 e $\alpha=0,0^{\circ}$ : (a)

Distribuição global de $C p$; (b) Histórico de convergência. 
(a)

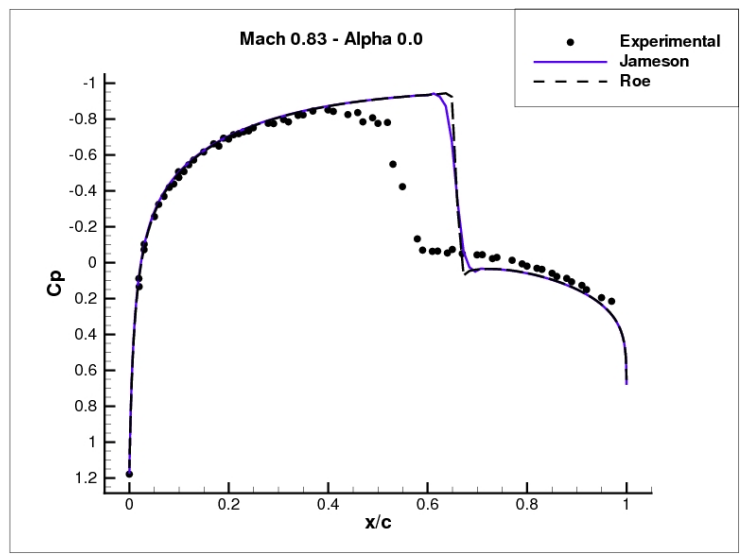

(b)

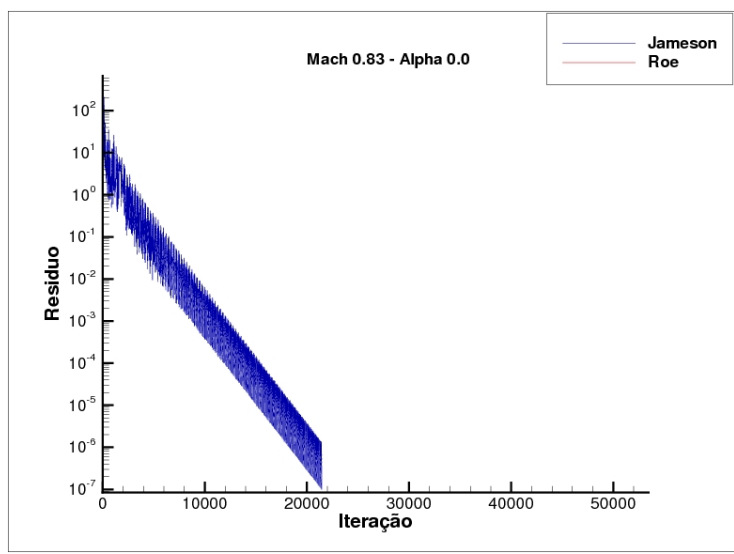

Figura 5.14: Resultado de validação para o perfil Naca 0012 à Mach 0,83 e $\alpha=0,0^{\circ}$ : (a) Distribuição global de $C p$; (b) Histórico de convergência.

\subsection{Testes}

Visando garantir a qualidade da solução com reduzido custo computacional e buscando uma maior robustez dos códigos, foram feitos testes de convergência de malha e ajuste dos parâmetros de configuração dos métodos.

\subsubsection{Limitador de fluxo: valor para $\epsilon_{L I M}$}

A implementação do limitador de fluxo descrita na seção 3.1 .3 necessita que seja determinado o valor para $\epsilon_{L I M}$, mantendo a robustez numérica sem afetar a efetividade do limitador. De acordo com Bigarella (2007), o valor $10^{-4}$ é apropriado. Porém, devido ao aparecimento de over shoots e down shoots (picos para cima e para baixo logo antes e depois da onda de choque respectivamente), foi motivada a análise da influência do parâmetro no resultado e da estabilidade do método implementado. Para essa análise o perfil Rae 2822 é utilizado no regime de $M a c h=0,8$ e ângulo de incidência $\alpha=0,5^{\circ}$. O gráfico de histórico de convergência está na Figura (5.16). O gráfico de $C p$ está mostrado na Figura (5.15). Os valores de $\epsilon_{L I M}$ testados são: $10^{-1}, 10^{-2}, 10^{-4}, 10^{-5}$, $10^{-6}, 10^{-8}$ e $10^{-10}$.

Pode-se notar pela Figura 5.16 que, para os valores $10^{-2}, 10^{-4}$ e $10^{-5}$, a estabilidade do método não foi afetada e para os outros valores a convergência não se verifica.

Pelo gráfico de $C p$, nota-se que, para as soluções que não apresentaram convergência (linhas tracejadas), a solução próxima à onda de choque apresenta oscilações com over shoot e down shoot. Entretanto, para as soluções que apresentaram convergência, nota-se que para o valor $10^{-5} \mathrm{a}$ solução apresenta melhor suavidade próxima à onda de choque, não apresentando nem oscilações, nem over shoots, nem down shoots. Para os valores $10^{-2}$ e $10^{-4}$ um pequeno over shoot e down shoot estão presentes. 
(a)

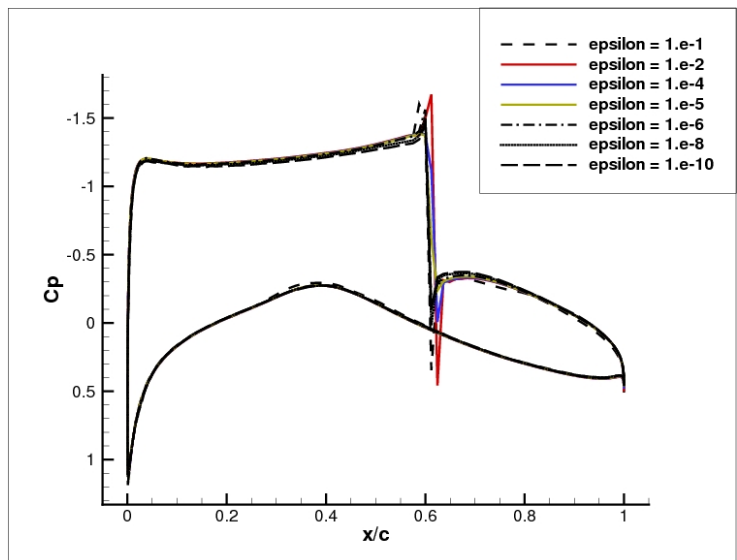

(b)

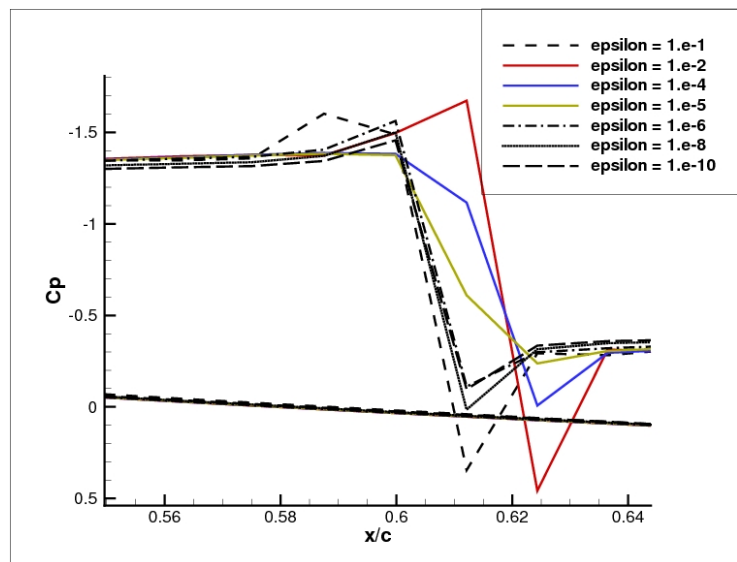

Figura 5.15: Influência do $\epsilon_{L I M}$ na distribuição de $\mathrm{Cp}$ (a); Detalhe da região da onda de choque (b).

(a)

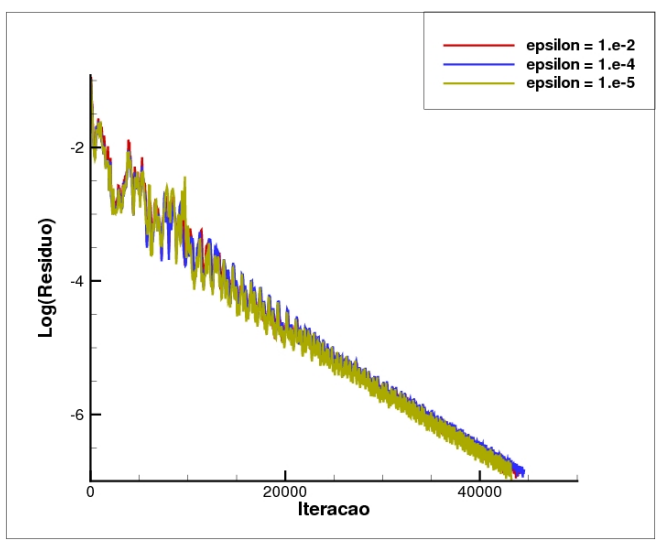

(b)

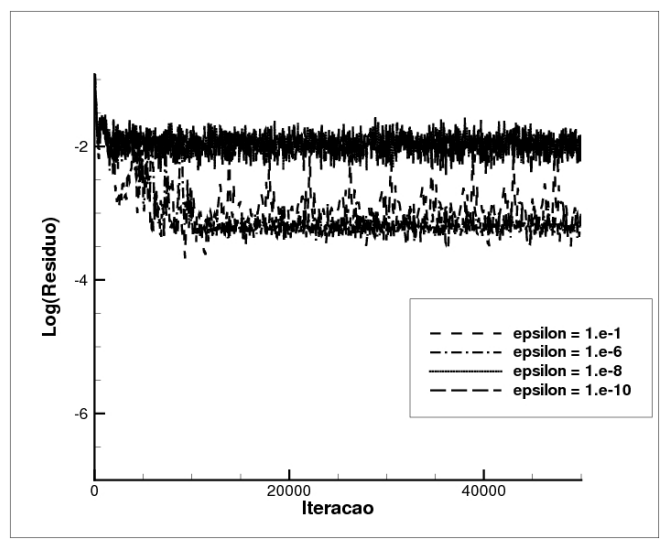

Figura 5.16: Histórico de convergência para os diferentes $\epsilon_{L I M}$ : (a) casos convergidos; (b) casos no quais a estabilidade foi comprometida.

\subsubsection{Tamanho do domínio computacional}

A implementação da técnica de correção de fronteira livre (seção 3.1.5 permite reduzir o tamanho do domínio físico utilizado na simulação. Entretanto, deve-se avaliar qual o limitante para evitar o aumento do erro, mesmo com a utilização da técnica. Para quantificar esse erro, foram efetuados testes simulando o escoamento dos perfis Naca 0012 e Rae 2822 com incidência $0,5^{\circ}$ e Mach 0,8 para 7 malhas distintas, todas com $251 \times 151$ pontos e raios, $70,50,30,20,15,10$ e 7,5 vezes a corda.

Como referência para avaliar os resultados, foi adotada a malha $70-251 \times 151$. Os coeficientes obtidos pela simulação nas malhas em teste são comparados relativamente aos resultados obtidos pela malha de referência. É considerado negligenciável um erro próximo de $5 \%$. Todos os testes foram feitos com critério de parada de resíduo máximo menor que $10^{-8}$. 


\section{Jameson}

Os resultados relativos aos testes para os coeficientes aerodinâmicos podem ser vistos na Figura 5.17). Os valores dos coeficientes são mostrados na Tabela (5.2).

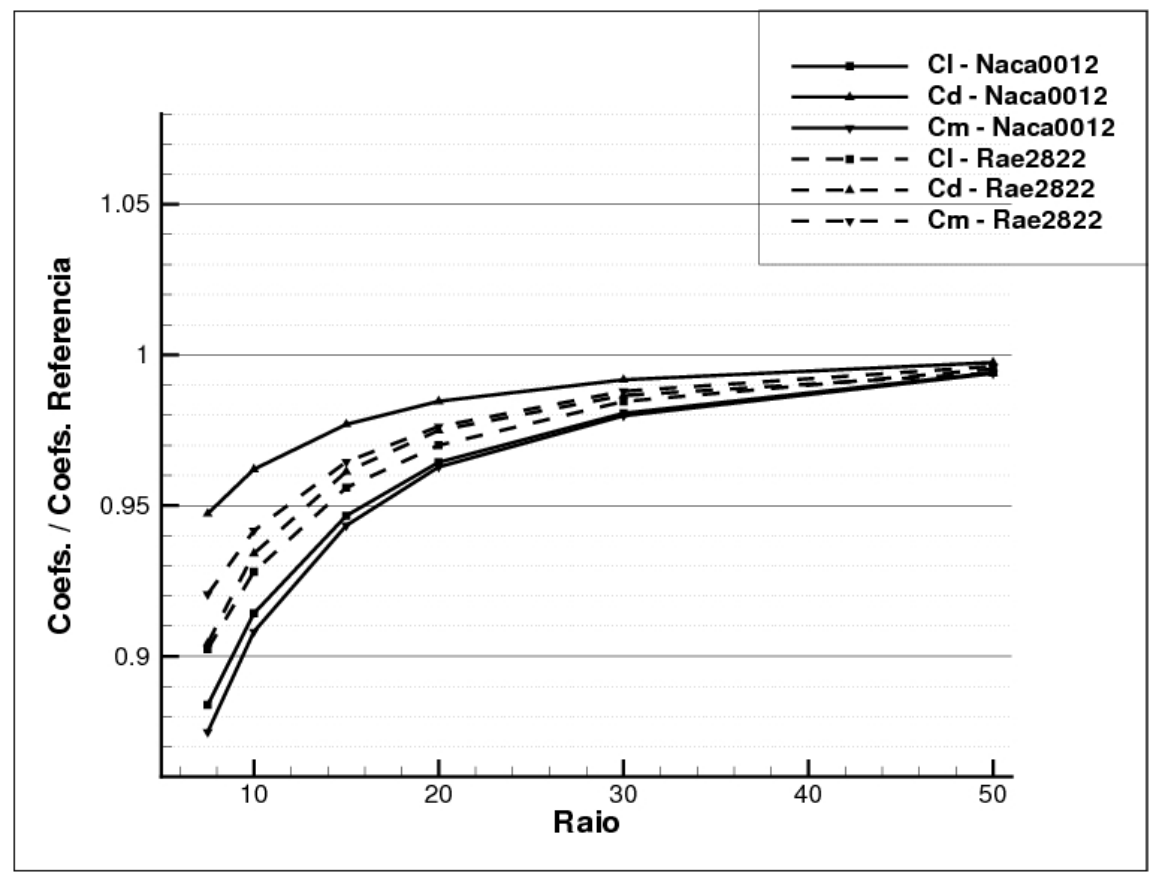

Figura 5.17: Influência do raio da malha nos coeficientes aerodinâmicos (Jameson)

- Perfis Naca 0012 e Rae 2822.

Tabela 5.2: Valores dos coeficientes aerodinâmicos para malhas com tamanho do domínio distintos (Jameson).

Naca

Rae

\begin{tabular}{|c|c|c|c|c|c|c|}
\hline Malha & $C l$ & $C d$ & $\mathrm{Cm}$ & $\mathrm{Cl}$ & $C d$ & $\mathrm{Cm}$ \\
\hline $7.5-251 \times 151$ & 0.1235 & 0.01059 & -0.04164 & 0.6297 & 0.03253 & -0.3718 \\
\hline $10-251 \times 151$ & 0.1277 & 0.01075 & -0.04322 & 0.6297 & 0.03253 & -0.3718 \\
\hline $15-251 \times 151$ & 0.1323 & 0.01092 & -0.04490 & 0.6486 & 0.03347 & -0.3809 \\
\hline $20-251 \times 151$ & 0.1347 & 0.01101 & -0.04583 & 0.6581 & 0.03395 & -0.3855 \\
\hline $30-251 \times 151$ & 0.1370 & 0.01109 & -0.04664 & 0.6679 & 0.03435 & -0.3901 \\
\hline $50-251 \times 151$ & 0.1389 & 0.01115 & -0.04730 & 0.6753 & 0.03461 & -0.3934 \\
\hline $70-251 \times 151$ & 0.1397 & 0.01118 & -0.04760 & 0.6785 & 0.03482 & -0.3949 \\
\hline
\end{tabular}

Pode-se notar na Figura (5.17) que, para uma malha com raio de 15 vezes a corda, a maior variação dos coeficientes $(\mathrm{Cm})$ é próxima de $5 \%$. Logo foi adotado um raio de 15 vezes a corda para a geração das malhas utilizando o método de Jameson. Também nota-se que a influência da redução do raio nos coeficientes é independente do perfil, pois pode-se observar o mesmo comportamento para as duas geometrias. 


\section{Roe}

Os mesmos testes aplicados ao método de Jameson foram realizados com os métodos de Roe. Os resultados relativos aos testes para os coeficientes aerodinâmicos podem ser vistos na Figura (5.18). Os valores dos coeficientes são mostrados na Tabela (5.3).

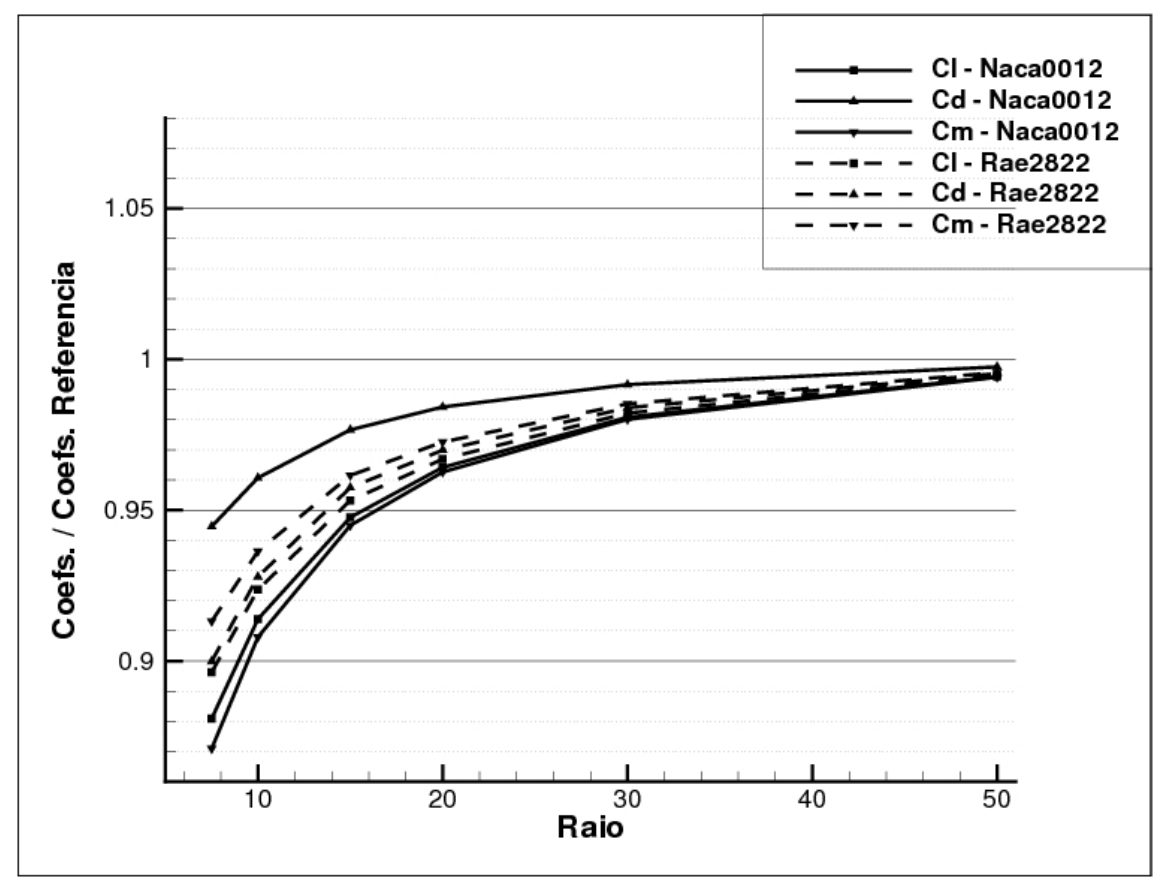

Figura 5.18: Influência do raio da malha nos coeficientes aerodinâmicos (Roe) - Perfis Naca 0012 e Rae 2822.

Tabela 5.3: Valores dos coeficientes aerodinâmicos para malhas com raio distintos (Roe).

\begin{tabular}{c||c|c|c||c|c|c}
\multicolumn{9}{c}{ Naca } \\
\hline Malha & $C l$ & $C d$ & $C m$ & $C l$ & $C d$ & $C m$ \\
7.5-251x151 & 0.1233 & 0.01154 & -0.04192 & 0.6041 & 0.03189 & -0.3589 \\
10-251x151 & 0.1279 & 0.01174 & -0.04369 & 0.6226 & 0.03289 & -0.3681 \\
15-251x151 & 0.1326 & 0.01193 & -0.04548 & 0.6425 & 0.03394 & -0.3779 \\
20-251x151 & 0.1349 & 0.01202 & -0.04633 & 0.6517 & 0.03438 & -0.3823 \\
30-251x151 & 0.1372 & 0.01211 & -0.04717 & 0.6620 & 0.03487 & -0.3873 \\
$50-251 \times 151$ & 0.1391 & 0.01218 & -0.04784 & 0.6705 & 0.03528 & -0.3914 \\
$70-251 \times 151$ & 0.1399 & 0.01222 & -0.04813 & 0.6740 & 0.03544 & -0.3931
\end{tabular}

Pode-se notar na Figura (5.18) que o método de Roe apresentou comportamento muito próximo dos resultados para o método de Jameson. Para uma malha com raio de 15 vezes a corda, a maior variação dos coeficientes $(\mathrm{Cm}$ e $\mathrm{Cl})$ é próxima de $5 \%$. Logo este valor foi adotado para as simulações. Também nota-se que a influência da redução do raio nos coeficientes é independente do perfil. Porém para o perfil Rae 2822, a sensibilidade ao tamanho do domínio foi menor para raios maiores ou iguais à 15 . 


\subsubsection{Número de pontos na direção radial}

Esse teste analisa o efeito da redução do número de pontos na direção radial do domínio (direção $\eta$ do domínio computacional). Como resultado da seção anterior, o raio adotado para o domínio físico é 15 vezes a corda. A referência é a mesma adotada anteriormente $(70-251 \times 151)$. As malhas testadas têm os números de pontos na direção $\eta$ do domínio computacional iguais a $151,131,101,81,71$ e 61.

\section{Jameson}

Os resultados relativos podem ser vistos na Figura (5.19) e os valores na Tabela (5.4).

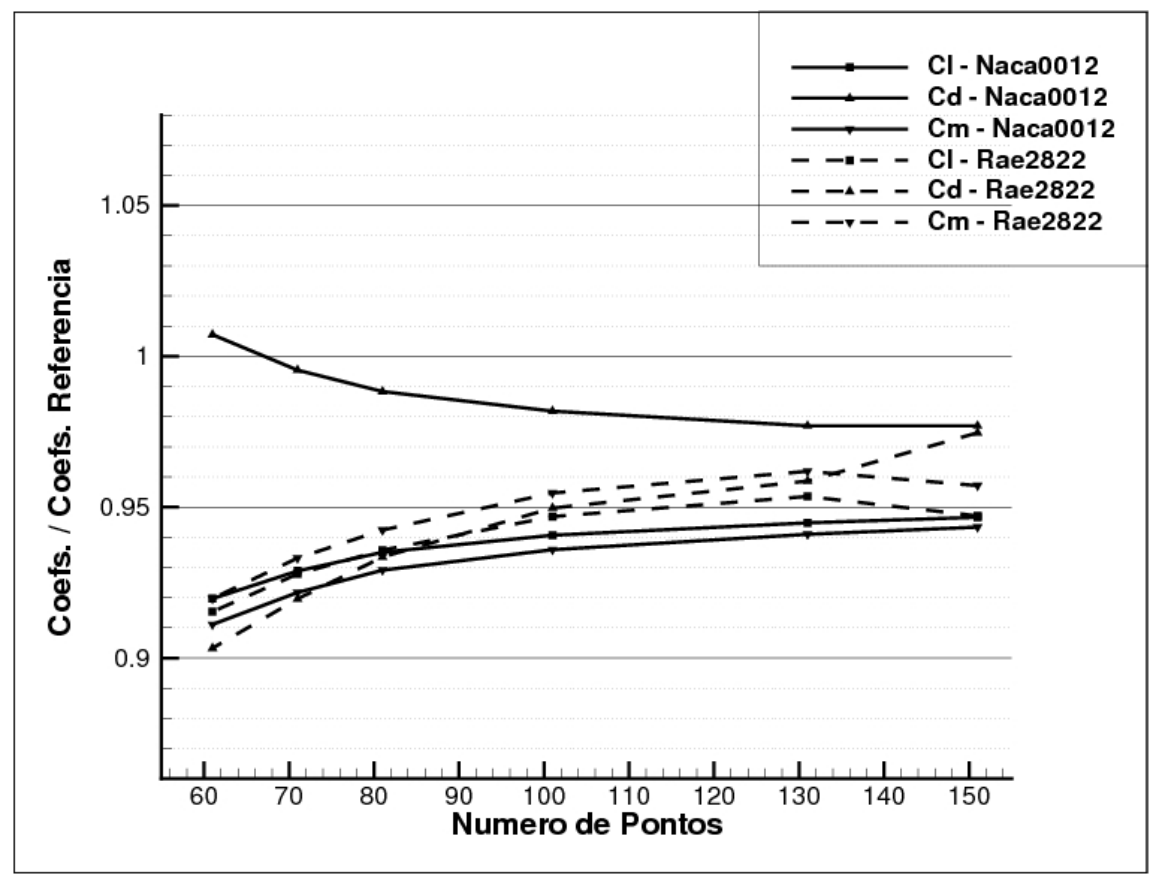

Figura 5.19: Influência do número de pontos na direção $\eta$ nos coeficientes aerodinâmicos (Jameson)

- Perfis Naca 0012 e Rae 2822.

Tabela 5.4: Valores dos coeficientes aerodinâmicos em função do número de pontos na direção $\eta$ (Jameson).

\begin{tabular}{c||c|c|c||c|c|c}
\multicolumn{9}{c}{ Naca } & Rae \\
\hline Malha & $C l$ & $C d$ & $C m$ & $C l$ & $C d$ & $C m$ \\
15-251x61 & 0.1284 & 0.01126 & -0.04337 & 0.6210 & 0.03145 & -0.3632 \\
$15-251 \times 71$ & 0.1297 & 0.01113 & -0.04387 & 0.6294 & 0.03202 & -0.3684 \\
$15-251 \times 81$ & 0.1306 & 0.01105 & -0.04422 & 0.6348 & 0.03250 & -0.3721 \\
$15-251 \times 101$ & 0.1314 & 0.01097 & -0.04455 & 0.6424 & 0.03307 & -0.3770 \\
$15-251 \times 131$ & 0.1320 & 0.01092 & -0.04479 & 0.6469 & 0.03338 & -0.3798 \\
$15-251 \times 151$ & 0.1323 & 0.01092 & -0.04490 & 0.6486 & 0.03347 & -0.3809
\end{tabular}


Pode-se ver na Figura 5.19 que a malha com 131 pontos na direção $j$ apresenta uma variação próxima de $5 \%$ dos coeficientes, sendo o $\mathrm{Cl}$ aquele com menor variação. Mesmo que o coeficiente de momento esteja com uma variação mais próxima dos $6 \%$, esse erro será negligenciado. É interessante notar que a variação do arrasto foi em sentido oposto aos dos outros parâmetros. Portanto, foi adotado 131 pontos na direção $j$, com o método de Jameson.

\section{Roe}

Utilizando o método de Roe, realizaram-se os mesmos testes aplicados ao método de Jameson. Os resultados relativos podem ser vistos na Figura (5.20) e os valores na Tabela (5.5).

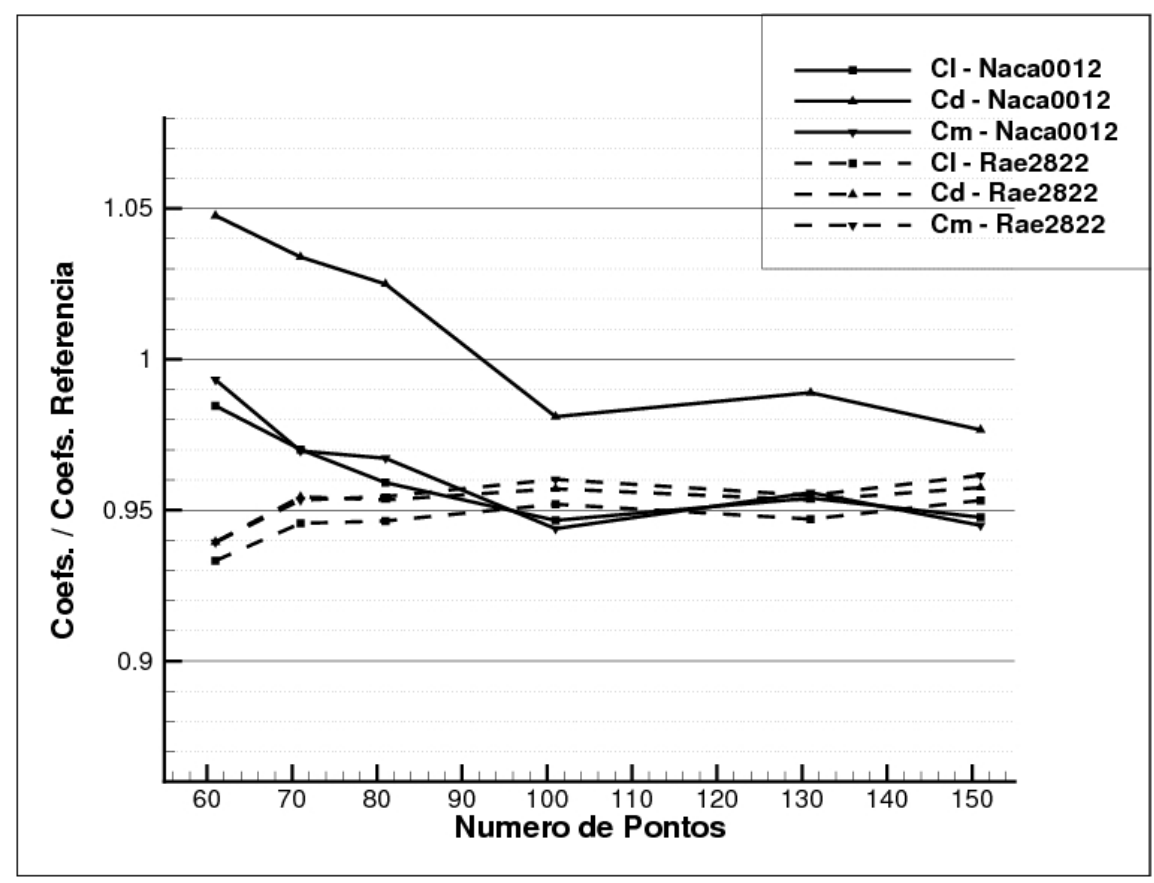

Figura 5.20: Influência do número de pontos na direção $\eta$ nos coeficientes aerodinâmicos (Roe) - Perfis Naca 0012 e Rae 2822.

Tabela 5.5: Valores dos coeficientes aerodinâmicos em função do número de pontos na direção $\eta$ (Roe).

\begin{tabular}{c||c|c|c||c|c|c}
\multicolumn{9}{c}{ Naca } \\
\hline Malha & $C l$ & $C d$ & $C m$ & $C l$ & $C d$ & $C m$ \\
$15-151 \times 151$ & 0.1326 & 0.01193 & -0.04548 & 0.6425 & 0.03394 & -0.3779 \\
$15-151 \times 131$ & 0.1335 & 0.01208 & -0.04600 & 0.6383 & 0.03379 & -0.3753 \\
$15-151 \times 101$ & 0.1325 & 0.01198 & -0.04542 & 0.6416 & 0.03392 & -0.3774 \\
$15-151 \times 81$ & 0.1342 & 0.01252 & -0.04655 & 0.6379 & 0.03379 & -0.3752 \\
$15-151 \times 71$ & 0.1357 & 0.01263 & -0.04666 & 0.6374 & 0.03383 & -0.3747 \\
$15-151 \times 61$ & 0.1378 & 0.01280 & -0.04780 & 0.6290 & 0.03330 & -0.3692
\end{tabular}

Pode-se ver na Figura (5.20) que a malha com 71 pontos na direção $j$ apresenta uma variação próxima de $5 \%$ nos valores dos coeficientes. A geometria Naca 0012 apresenta maior sensibilidade 
e em sentido oposto à tendência da geometria Rae 2822. Comparando com o método de Jameson, o método de Roe é menos sensível à malha, exceto pela curva de $C d$ do perfil Naca 0012. A malha adotada, com o método de Roe, tem 71 pontos na direção $\eta$.

\subsubsection{Número de pontos em torno do perfil}

Esse teste analisa o efeito da redução do número de pontos na direção $\xi$ do domínio computacional. Como resultado das seções anteriores, o raio adotado para o domínio físico é 15 vezes a corda e o número de pontos na direção radial é 131 e a malha de referência adotada é a mesma das seções anteriores $(70-251 \times 151)$. Os testes avaliam as malhas com número de pontos na direção $\xi$ iguais a $231,201,171,151$ e 131.

\section{Jameson}

Os resultados podem ser vistos na Figura (5.21) e os valores na Tabela (5.6).

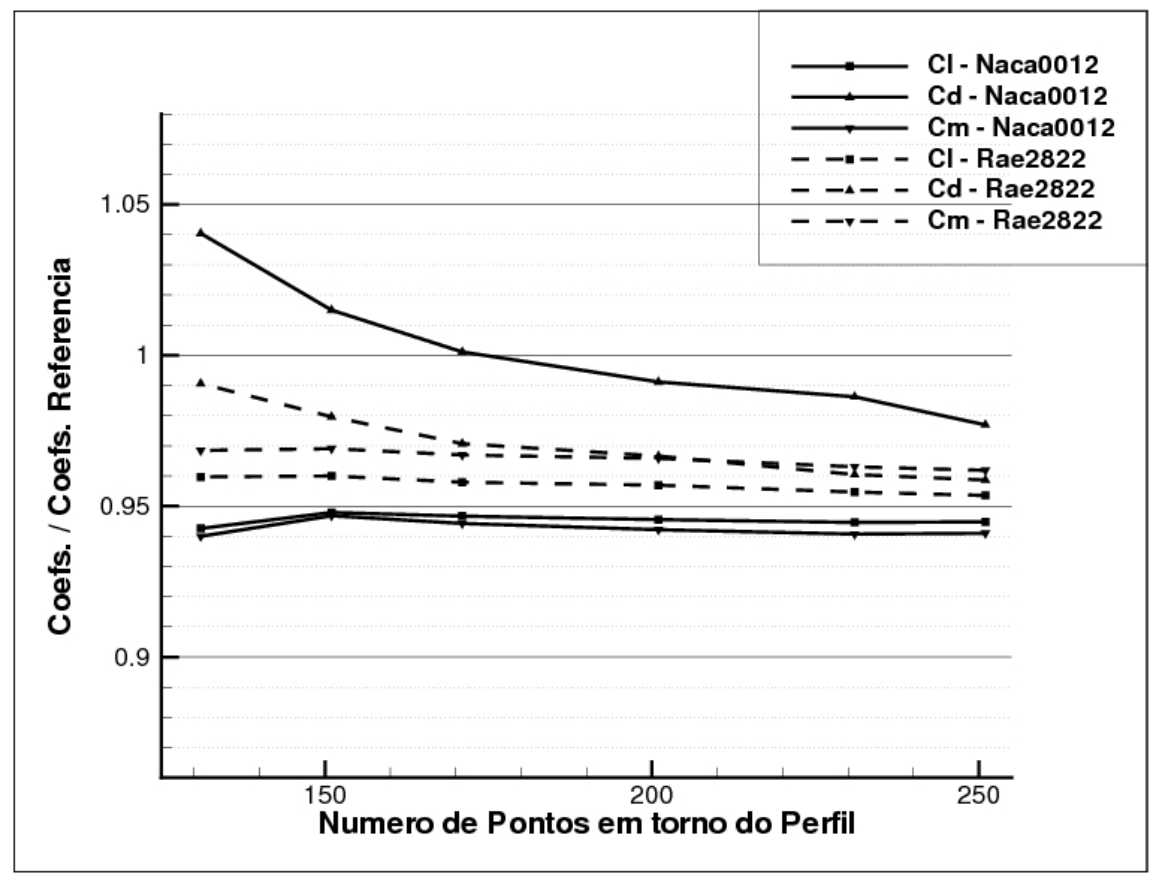

Figura 5.21: Influência do número de pontos na direção $\xi$ nos coeficientes aerodinâmicos (Jameson) - Perfis Naca 0012 e Rae 2822.

Pode-se ver pelo gráfico que a malha $15-151 \times 131$ induz um erro não muito maior que $5 \%$ nos coeficientes aerodinâmicos. Portanto essa malha é adotada para as simulações. A sensibilidade à malha mantém a tendência observada na Figura (5.19).

\section{Roe}

Aplicou-se ao método de Roe os mesmos testes descritos para o método de Jameson. Os resultados podem ser vistos na Figura (5.22) e os valores na Tabela 5.7). 
Tabela 5.6: Valores dos coeficientes aerodinâmicos em função do número de pontos na direção $\xi$ (Jameson).

\begin{tabular}{c||c|c|c||c|c|c}
\multicolumn{9}{c}{ Naca } \\
\hline Malha & $C l$ & $C d$ & $C m$ & $C l$ & $C d$ & $C m$ \\
15-131x131 & 0.1317 & 0.01163 & -0.04745 & 0.6511 & 0.03449 & -0.3824 \\
15-151x131 & 0.1324 & 0.01135 & -0.05069 & 0.6513 & 0.03411 & -0.3826 \\
$15-171 \times 131$ & 0.1322 & 0.01119 & -0.04948 & 0.6499 & 0.03380 & -0.3818 \\
$15-201 \times 131$ & 0.1321 & 0.01108 & -0.04849 & 0.6492 & 0.03365 & -0.3814 \\
15-231x131 & 0.1319 & 0.01102 & -0.04780 & 0.6476 & 0.03344 & -0.3803 \\
15-251x131 & 0.1320 & 0.01092 & -0.04479 & 0.6469 & 0.03338 & -0.3798
\end{tabular}

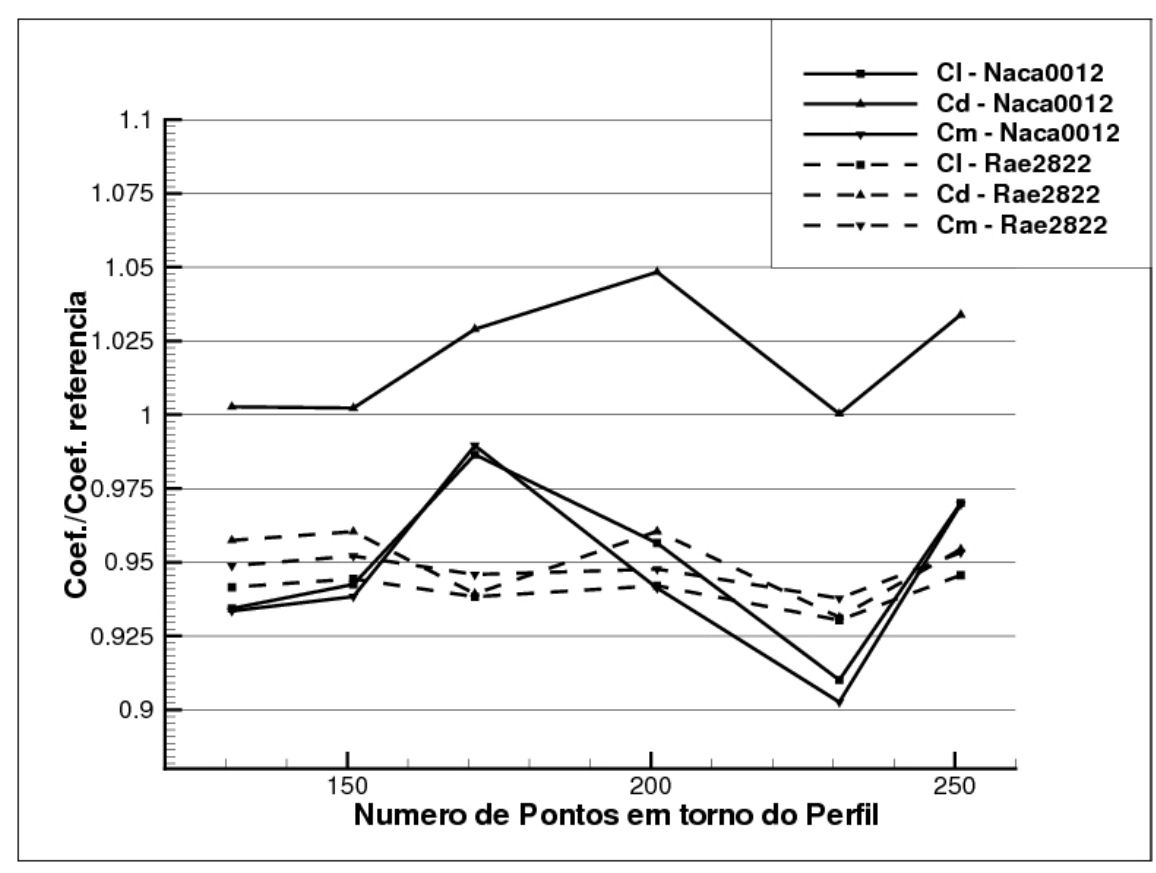

Figura 5.22: Influência do número de pontos na direção $\xi$ nos coeficientes aerodinâmicos (Roe) - Perfis Naca 0012 e Rae 2822.

Tabela 5.7: Valores dos coeficientes aerodinâmicos em função do número de pontos na direção $\xi$ (Roe).

\begin{tabular}{c||c|c|c||c|c|c}
\multicolumn{1}{c}{ Naca } & \multicolumn{1}{c}{ Rae } \\
\hline Malha & $C l$ & $C d$ & $C m$ & $C l$ & $C d$ & $C m$ \\
20-131x61 & 0.1335 & 0.01319 & -0.04589 & 0.6281 & 0.03429 & -0.3692 \\
$20-151 \times 61$ & 0.1329 & 0.01292 & -0.04558 & 0.6317 & 0.03401 & -0.3694 \\
$20-171 \times 61$ & 0.1321 & 0.01285 & -0.04505 & 0.6372 & 0.03428 & -0.3730 \\
$20-201 \times 61$ & 0.1323 & 0.01290 & -0.04509 & 0.6370 & 0.03417 & -0.3730 \\
$20-231 \times 61$ & 0.1328 & 0.01290 & -0.04540 & 0.6364 & 0.03408 & -0.3726 \\
$20-251 \times 61$ & 0.1303 & 0.01285 & -0.04463 & 0.6215 & 0.03337 & -0.3653
\end{tabular}

Pode-se ver pelo gráfico que a malha 20 - 151x71 induz um erro não muito maior que $5 \%$ nos coeficientes aerodinâmicos. Portanto, essa é a malha adotada. Neste caso, observa-se que o método de Roe é mais sensível à malha, porém com tendência a estabilizar para malhas com menor número de pontos. 


\subsubsection{Resíduo máximo}

$\mathrm{Na}$ busca por redução do custo computacional, deve-se determinar o máximo resíduo para o qual os valores dos coeficientes aerodinâmicos convergem. Para isso utiliza-se a malha 15 151x131 para o método de Jameson e a malha 20 - 151x71 para o método de Roe, ambos com $C F L=0,5$ e se observa a evolução dos coeficientes ao longo das iterações. O resultado é novamente comparado com o caso de referência (malha 70-251x151) com resíduo máximo menor que $10^{-8}$.

\section{Jameson}

Na Figura (5.23) (a) pode-se ver o efeito do resíduo máximo nos coeficientes aerodinâmicos em valores relativos. Na Figura 5.23 (b) observa-se o detalhe na região em que os valores alcançam a convergência. A Tabela (5.8) tem alguns valores para fim de ilustração.

(a)

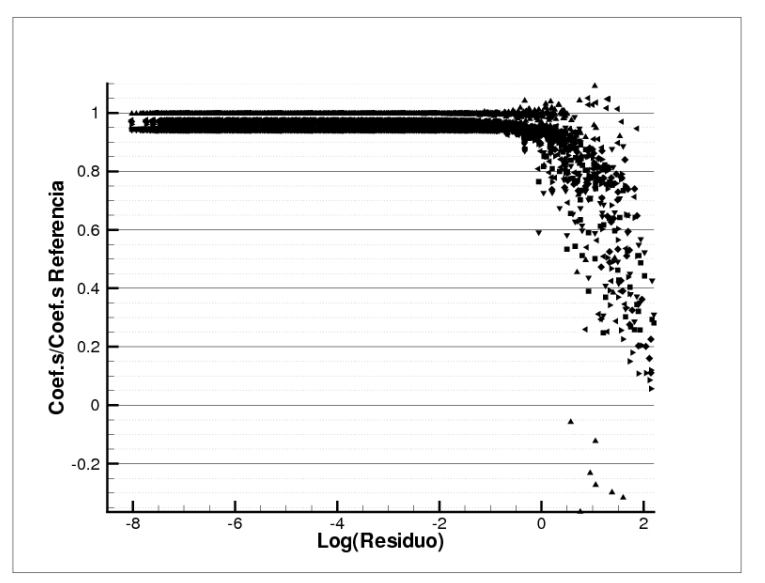

(b)

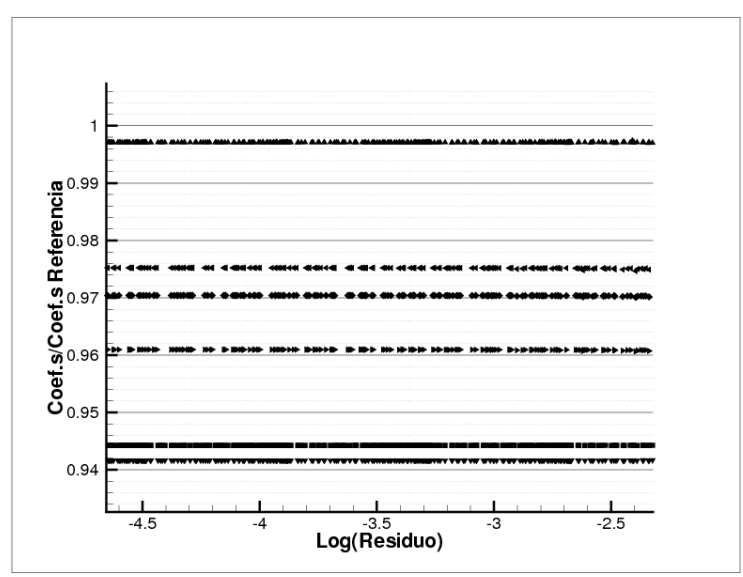

Figura 5.23: Influência do resíduo máximo nos coeficientes aerodinâmicos (Jameson): (a) Perfis Naca 0012 e Rae 2822; (b) Detalhe.

De acordo com o teste, a condição de parada de resíduo máximo menor que $1 \times 10^{-4}$ é suficiente para obter convergência dos coeficientes aerodinâmicos. Por economia de tempo, esse valor foi adotado.

\section{Roe}

O teste de influência do resíduo aplicado para o método de Jameson foi aplicado ao método de Roe. Na Figura (5.24)(b), observa-se o detalhe na região em que os valores alcançam a convergência. A Tabela (5.9) mostra alguns valores para fim de ilustração.

De acordo com o teste, a condição de parada de resíduo máximo menor que $1 \times 10^{-4}$ é suficiente para obter convergência dos coeficientes aerodinâmicos. Por economia de tempo, esse resíduo será adotado. 
Tabela 5.8: Valores dos coeficientes aerodinâmicos em função do resíduo máximo (Jameson)

\begin{tabular}{c|c|c|c}
\multicolumn{4}{c}{- Perfil Naca 0012. } \\
Resíduo & $C l$ & $C d$ & $C m$ \\
\hline 145.99660203 & 4.0989 & 0.13295 & -0.02030 \\
8.3307184779 & 5.4456 & 0.05269 & -0.02078 \\
0.4905977743 & 0.1296 & 0.01087 & -0.04383 \\
0.0423365634 & 0.1318 & 0.01113 & -0.04483 \\
0.0051096985 & 0.1319 & 0.01115 & -0.04482 \\
0.0003351463 & 0.1319 & 0.01115 & -0.04482 \\
0.0000505362 & 0.1319 & 0.01115 & -0.04482 \\
0.0000020047 & 0.1319 & 0.01115 & -0.04482 \\
0.0000004083 & 0.1319 & 0.01115 & -0.04482
\end{tabular}

(a)

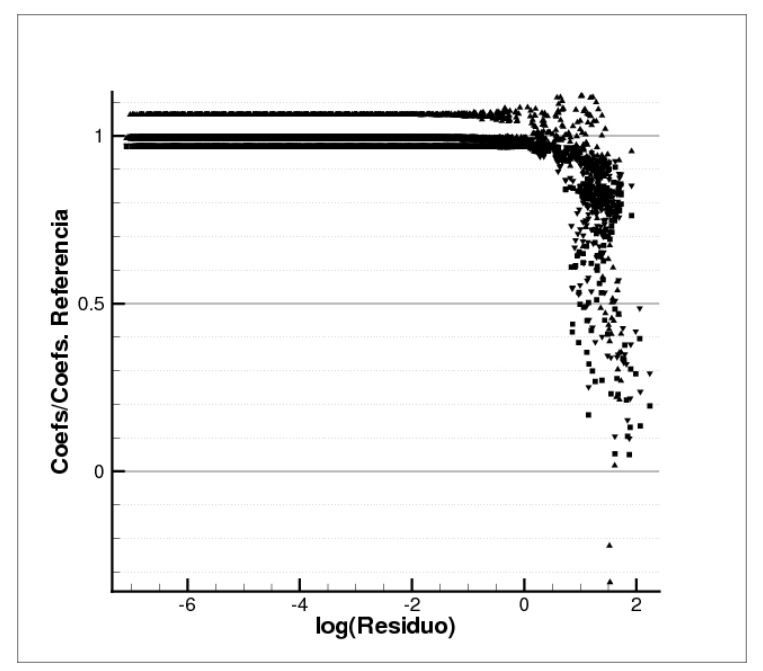

(b)

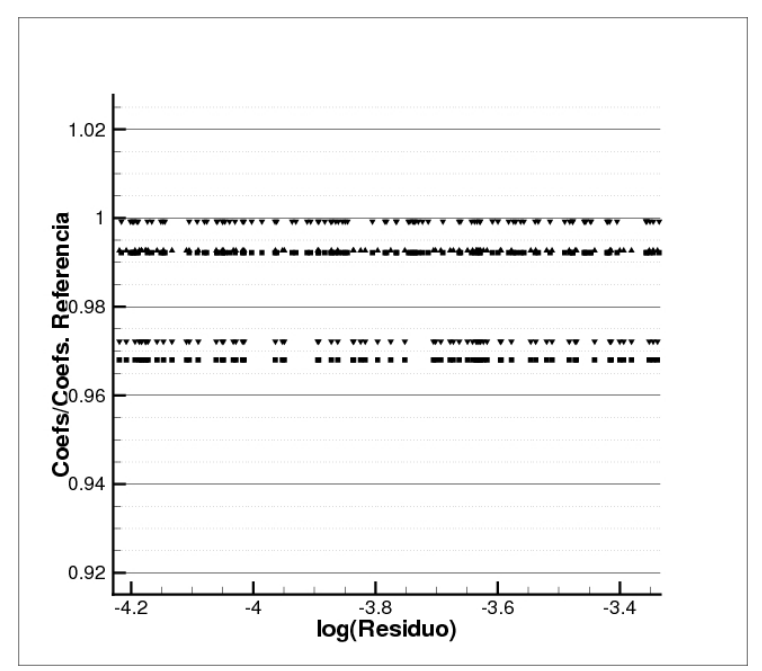

Figura 5.24: Influência do resíduo máximo nos coeficientes aerodinâmicos (Roe): (a) Perfis Naca 0012 e Rae 2822; (b) Detalhe.

Tabela 5.9: Valores dos coeficientes aerodinâmicos em função do resíduo máximo (Roe)

\begin{tabular}{|c|c|c|c|}
\hline \multicolumn{4}{|c|}{ - Perfil Naca 0012.} \\
\hline Resíduo & $\mathrm{Cl}$ & $C d$ & $\mathrm{Cm}$ \\
\hline 97.0383507 & 0.0397 & 0.13613 & -0.01949 \\
\hline 3.61349100 & 0.1294 & 0.01321 & -0.04368 \\
\hline 0.17132375 & 0.1354 & 0.01318 & -0.04651 \\
\hline 0.00858018 & 0.1358 & 0.01324 & -0.04667 \\
\hline 0.00134487 & 0.1358 & 0.01324 & -0.04667 \\
\hline 0.00000755 & 0.1358 & 0.01324 & -0.04667 \\
\hline 0.00000215 & 0.1358 & 0.01324 & -0.04667 \\
\hline 0.00000009 & 0.1358 & 0.01324 & -0.04667 \\
\hline
\end{tabular}

\subsection{6 $C F L$ e resíduo suavizado}

Para reduzir o tempo de processamento, a utilização do resíduo suavizado foi empregada. Visando analisar o valor máximo de $C F L$ a ser empregado, várias simulações foram feitas usando 
os valores $0,4,0,5,0,75,1,0,1,5,2,0,2,5,3,0$. Adotou-se o valor $\epsilon_{\text {resm }}=0,2$ e o número de iterações para a técnica variam de 0 a 7 .

Como o tempo gasto tem caráter aleatório, uma média foi obtida. Para simulações com o mesmo número de iterações da técnica, calcula-se a média do tempo gasto por iteração entre todas as simulações com diferentes $C F L$ s. Esse valor médio é multiplicado pelo total de iterações usado por cada simulação, obtendo um valor para o tempo gasto para cada simulação. As simulações tiveram um limitante máximo para as iterações da integração temporal de 150000 iterações e foram excluídos os resultados que apresentaram instabilidade.

\section{Jameson}

Na Figura (5.25) observa-se os tempos obtidos nos testes. Nota-se, para o método de Jameson, que a técnica de resíduo suavizado permite a utilização de altos valores de $C F L$ para o método explícito. A melhor configuração obtida foi com $C F L$ 3, 0 e duas iterações de suavização de resíduo. Por uma questão de robustez, utiliza-se margem de segurança, adotando os valores $\epsilon_{\text {resm }}=0,2$, $C F L=2,75$ e 3 iterações.

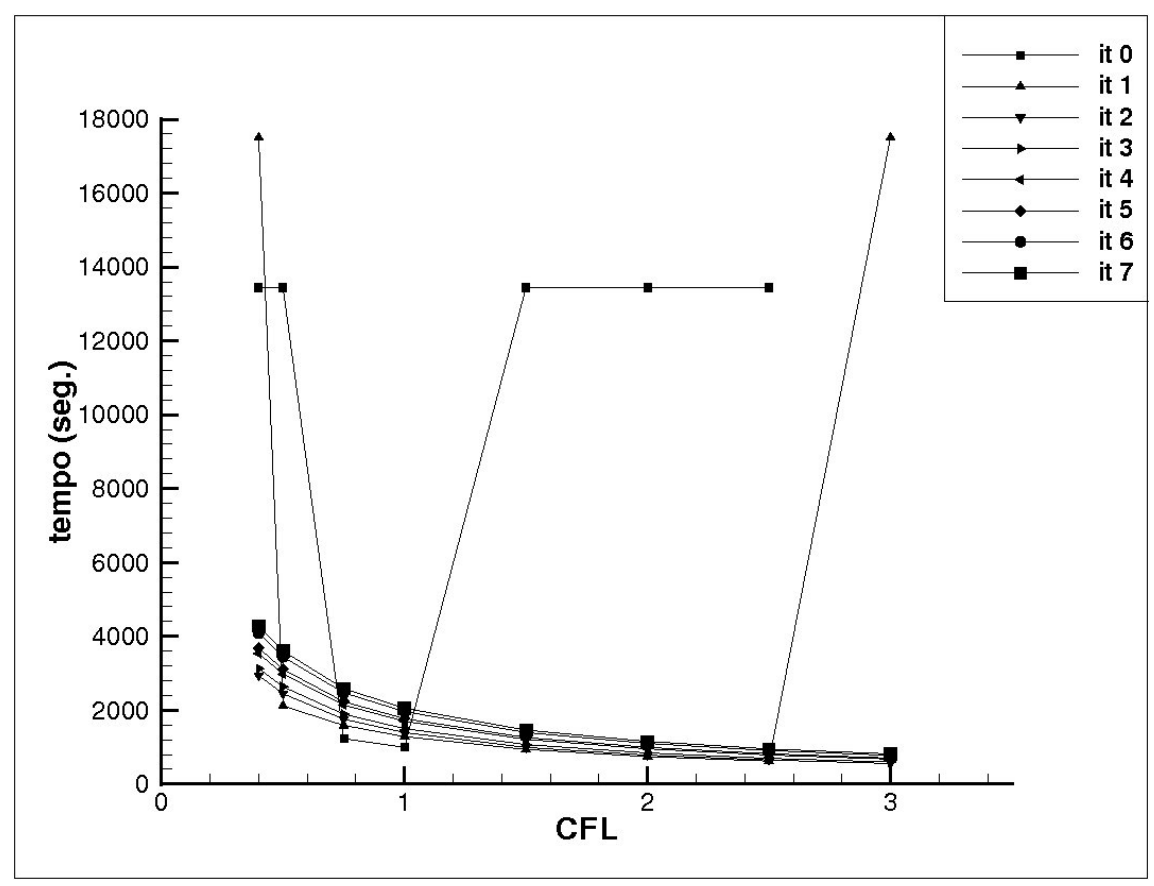

Figura 5.25: Tempo de processamento Vs $C F L$ utilizado (Jameson).

\section{Roe}

Assim como feito com o método de Jameson, aplicou-se ao método de Roe o teste da técnica de resíduo suavizado. Na Figura (5.26), observa-se os tempos obtidos nos testes. Nota-se, para o método de Roe, que a técnica de resíduo suavizado também permite a utilização de maiores valores de $C F L$, porém o limite superior foi $C F L=2,5$. A melhor configuração obtida foi 
com $C F L$ 2, 5 e uma iteração de suavização de resíduo. Assim, como para o método de Jameson, será utilizada uma margem de segurança. Logo, para a técnica serão adotados os parâmetros $\epsilon_{\text {resm }}=0,2, C F L=2,5$ e 3 iterações para o resíduo suavizado.

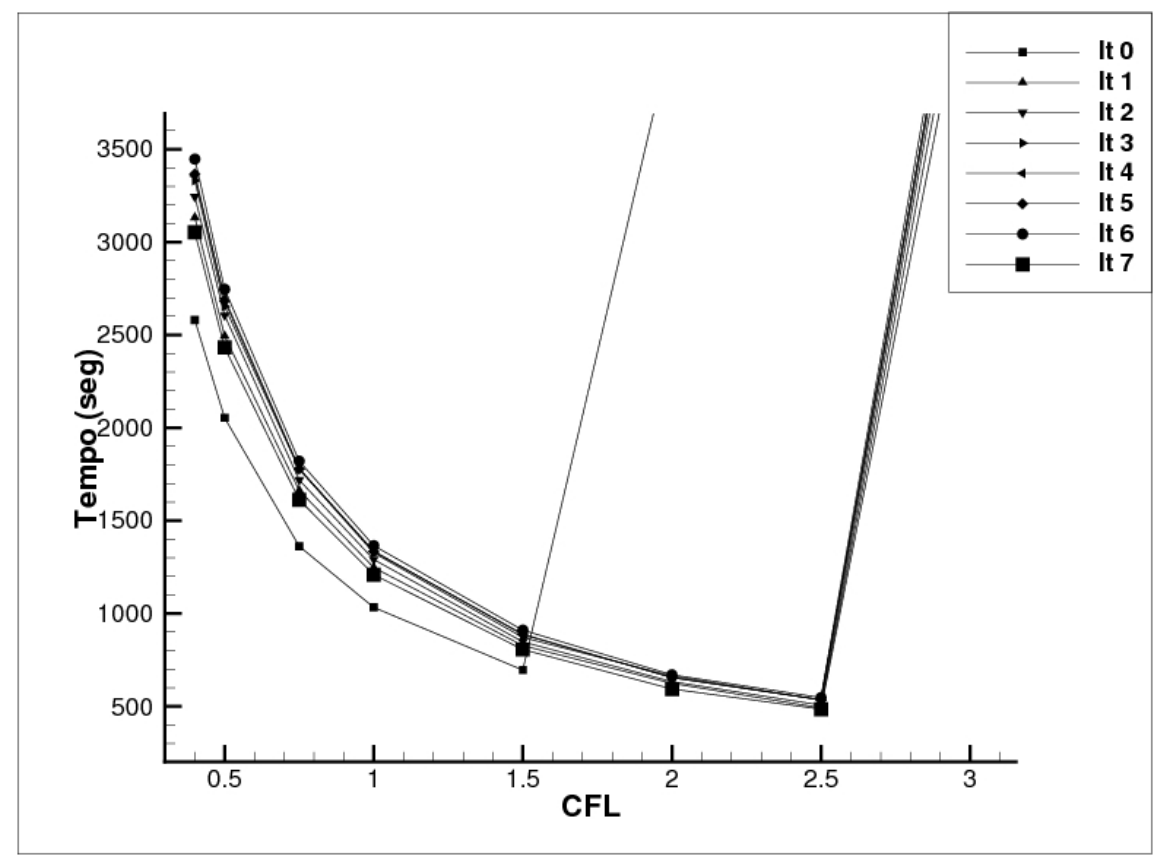

Figura 5.26: Tempo de processamento Vs $C F L$ utilizado (Roe).

Os testes apresentados até o momento garantem a boa qualidade da solução das simulações numéricas. Assim como demonstrado, os códigos implementados são capazes de prever a distribuição de pressão ao redor no aerofólio. Os testes de malha e parâmetros de simulação mostram que os parâmetros adotados permitiram a redução do tempo de simulação sem perda da qualidade da solução. Logo, esses códigos estão aptos para serem usados como funções objetivos. Na seção 5.3. é apresentada a verificação do algoritmo genético. São utilizadas soluções de benchmark para comparar com as soluções numéricas e mostrar que o algoritmo genético é capaz de resolver o problema multiobjetivo em estudo neste trabalho.

\subsection{Verificação do algoritmo genético}

Nesta seção, são apresentadas as verificações do algoritmo genético. Dois tipos de problemas são usados, com uma e duas variáveis de projeto totalizando cinco problemas testes. Ambos os problemas apresentam dois objetivos. Em todos os casos, o AG encontrou a $P F_{\text {true }}$ do problema. A configuração do AG foi de 40 indivíduos por população e 200 gerações. A probabilidade de crossover é $75 \%$ e a probabilidade de mutação é de $25 \%$. 


\subsubsection{Problema com uma variável de projeto}

\section{Problema 1-2-1}

Definido por:

$$
\begin{array}{ll}
\text { Minimizar: } & f_{1}=x^{2} \\
& f_{2}=(x-2)^{2}
\end{array}
$$

Sujeito a:

$$
-10 \leq x \leq 10
$$

O domínio da solução é $0 \leq x \leq 2$. A Figura (5.27)(a) ilustra a frente de Pareto do problema e a Figura 5.27)(b) a solução encontrada pelo AG.

(a)

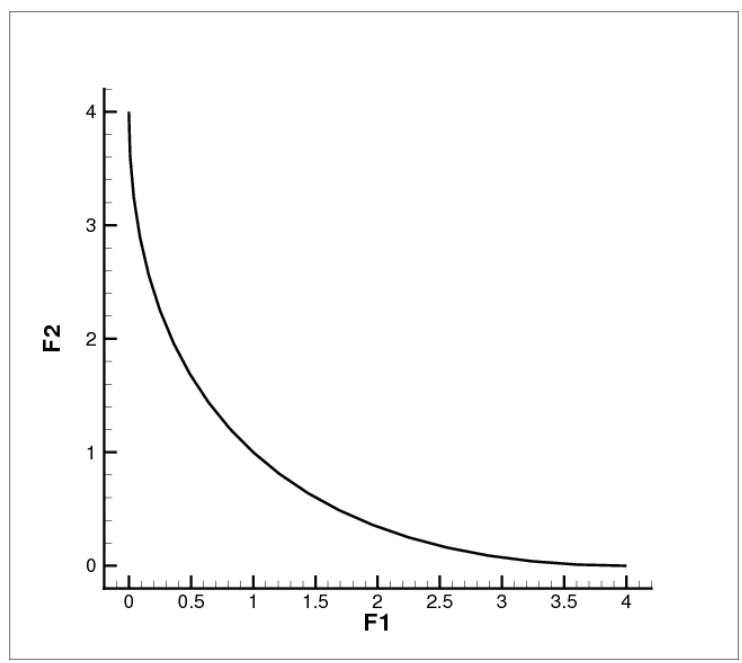

(b)

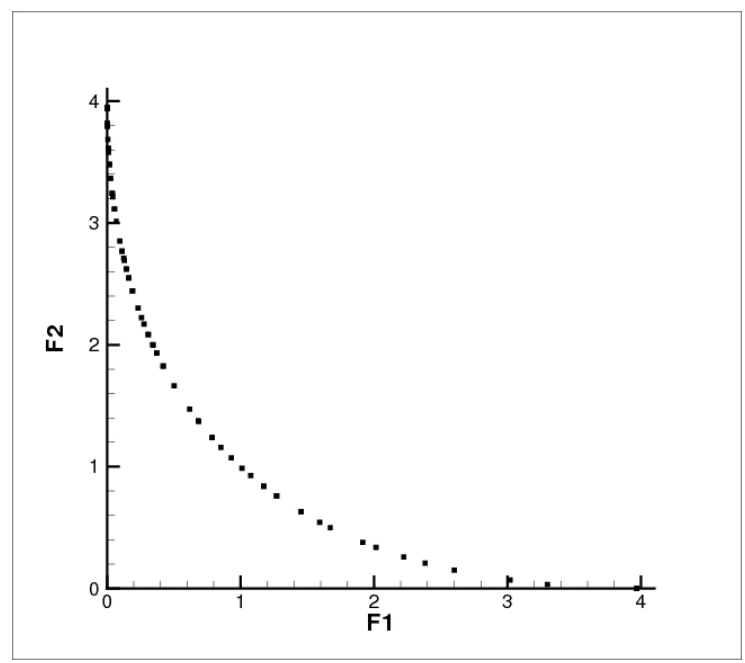

Figura 5.27: Solução analítica (a); solução aproximada (b).

\section{Problema 1-2-2}

Definido por:

$$
\begin{gathered}
\text { Minimizar: } f_{1}= \begin{cases}-x & ; \text { se } x \leq 1 \\
-2+x & ; \text { se } 1<x \leq 3 \\
4-x & ; \text { se } 3<x \leq 4 \\
-4+x & ; \text { se } 4<x\end{cases} \\
f_{2}=(x-5)^{2}
\end{gathered}
$$

Sujeito a:

$$
-5 \leq x \leq 10
$$

O domínio da solução é $1 \leq x \leq 2$ e $4 \leq x \leq 5$. A Figura $(5.28)$ (a) ilustra a frente de Pareto do problema e a Figura (5.28)(b) a solução encontrada pelo AG. 
(a)

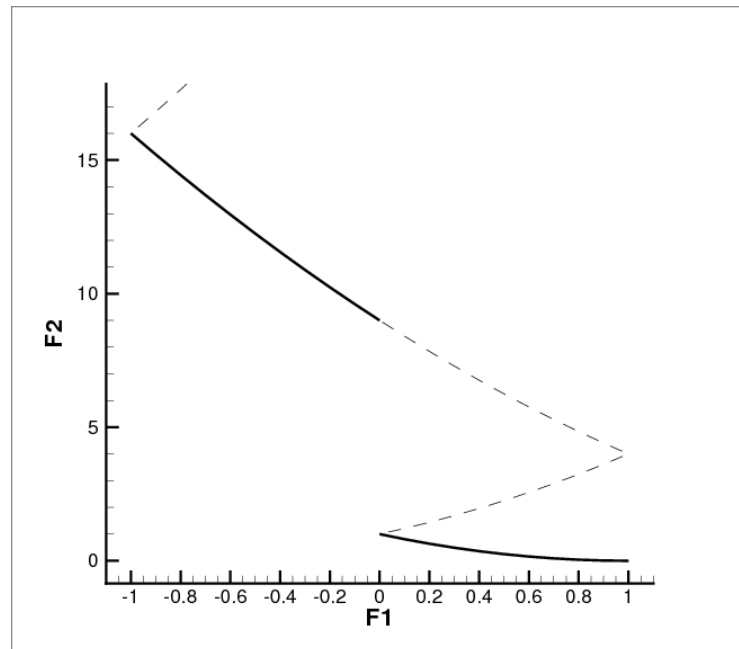

(b)

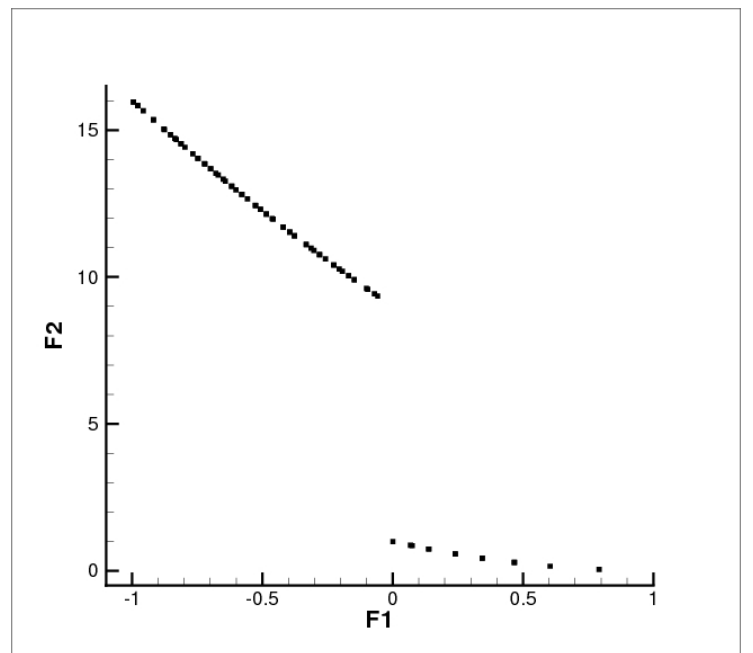

Figura 5.28: Solução analítica (a); solução aproximada (b).

\subsubsection{Problema com duas variáveis de projeto}

\section{Problema 2-2-1}

Definido por:

$$
\begin{array}{ll}
\text { Minimizar: } & f_{1}=(x-2)^{2}+(y-1)^{2} \\
f_{2} & =9 x-(y-1)^{2}
\end{array}
$$

Sujeito a:

$$
\begin{aligned}
& x^{2}+y^{2}-225 \leq 0 \\
& x-3 y+10 \leq 0 \\
& -20 \leq x, y \leq 20
\end{aligned}
$$

O domínio da solução é representado na Figura (5.29)(c). A Figura (5.29)(a) ilustra a frente de Pareto do problema e a Figura (5.29)(b), a solução encontrada pelo AG.

\section{Problema 2-2-2}

Definido por:

$$
\begin{aligned}
\text { Minimizar: } & f_{1}=2 \sqrt{x} \\
f_{2} & =x(1-y)+5
\end{aligned}
$$

Sujeito a:

$$
\begin{aligned}
& 1 \leq x \leq 4 \\
& 1 \leq y \leq 2
\end{aligned}
$$

O domínio da solução é $1 \leq x \leq 4$ e $y=2$. A Figura (5.30)(a) ilustra a frente de Pareto do problema e a Figura (5.30)(b) a solução encontrada pelo AG. 
(a)

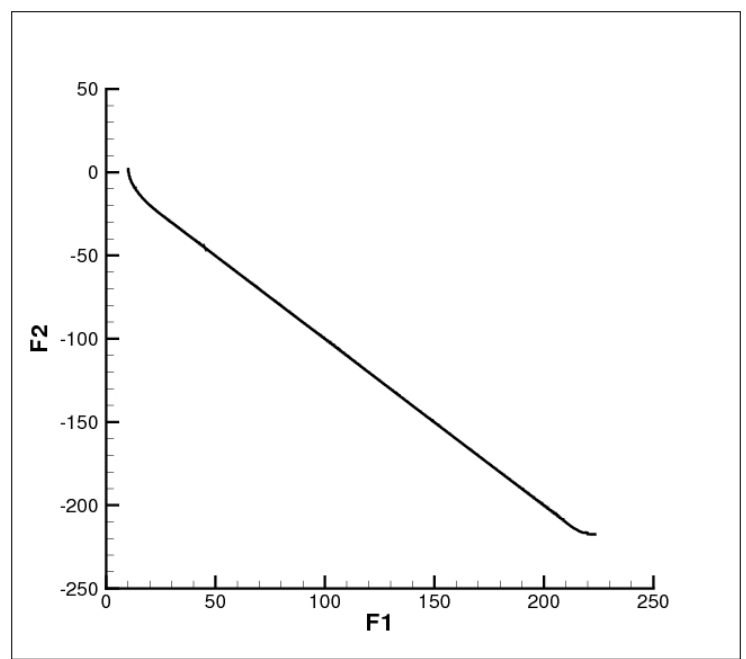

(b)

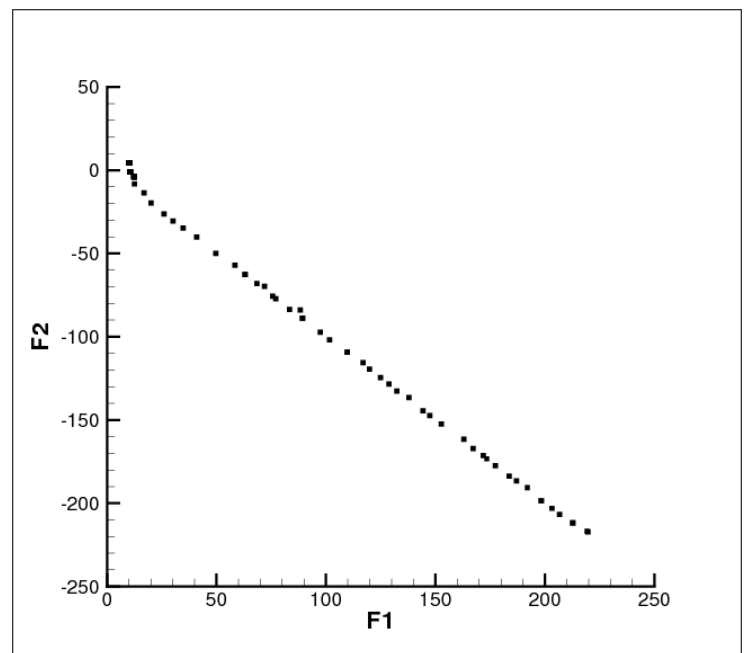

(c)

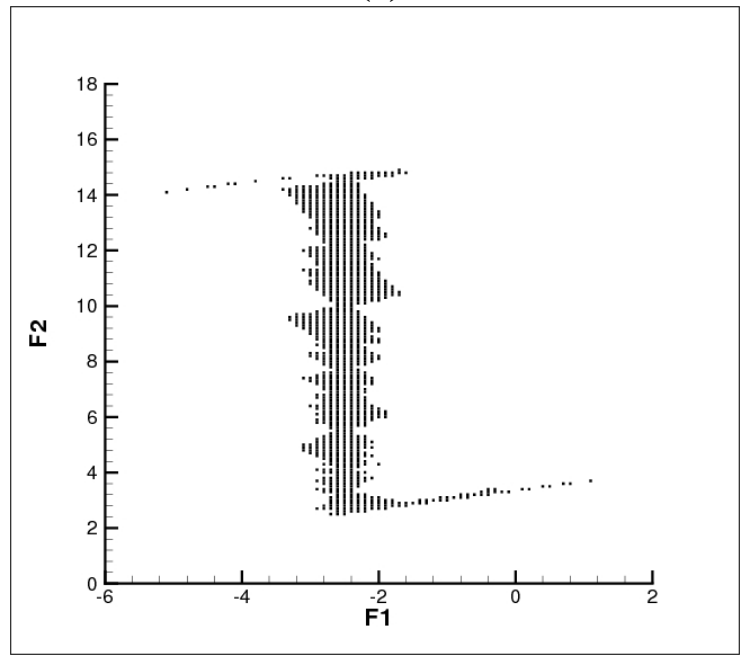

Figura 5.29: Solução analítica (a); solução aproximada (b); domínio (c).

Este capítulo apresentou a validação e verificação dos códigos implementados para efetuar o estudo do problema de otimização multiobjetivo. No próximo capítulo são apresentados os resultados das otimizações, que são organizados em: problemas de objetivo simples e problemas multiobjetivos. Os resultados para os problemas multiobjetivos são discutidos em 3 seções: comparação entre formulação viscosa e invíscida, comparação entre as parametrizações e comparação entre o método centrado e upwind. 
(a)

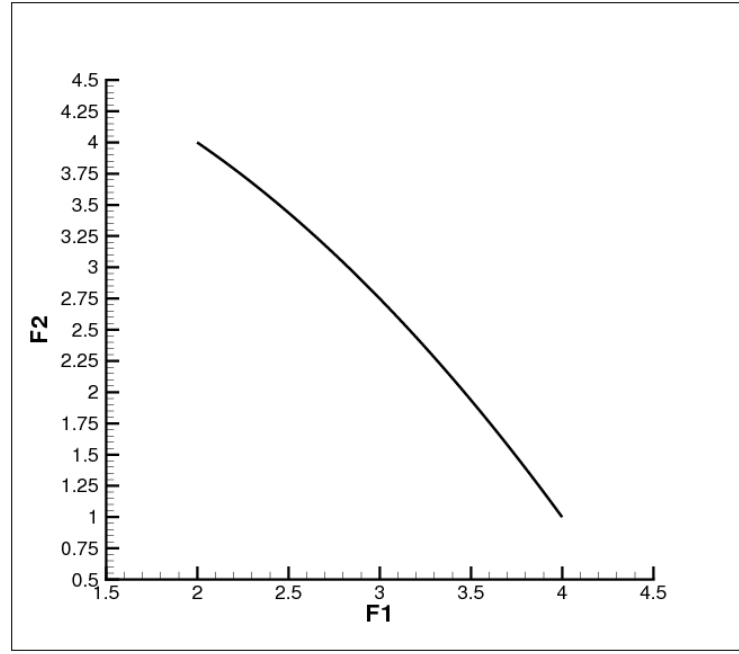

(b)

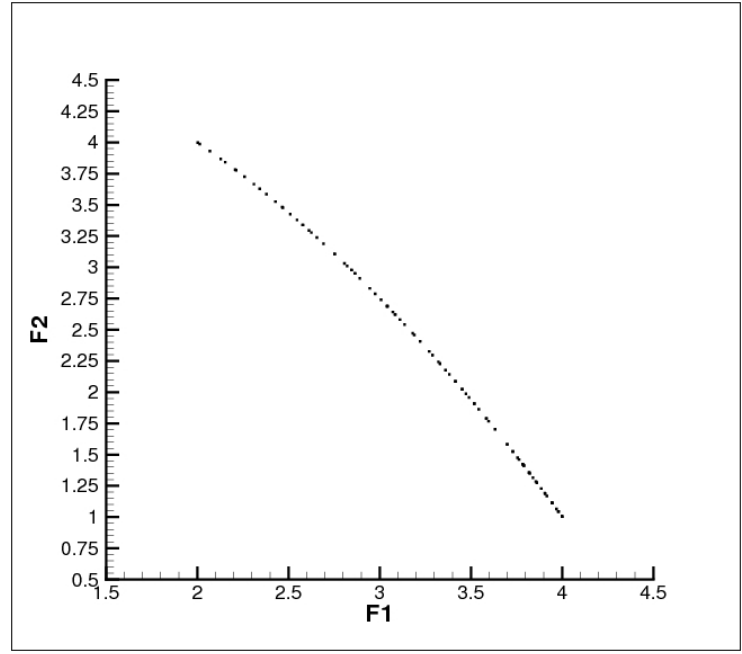

(c)

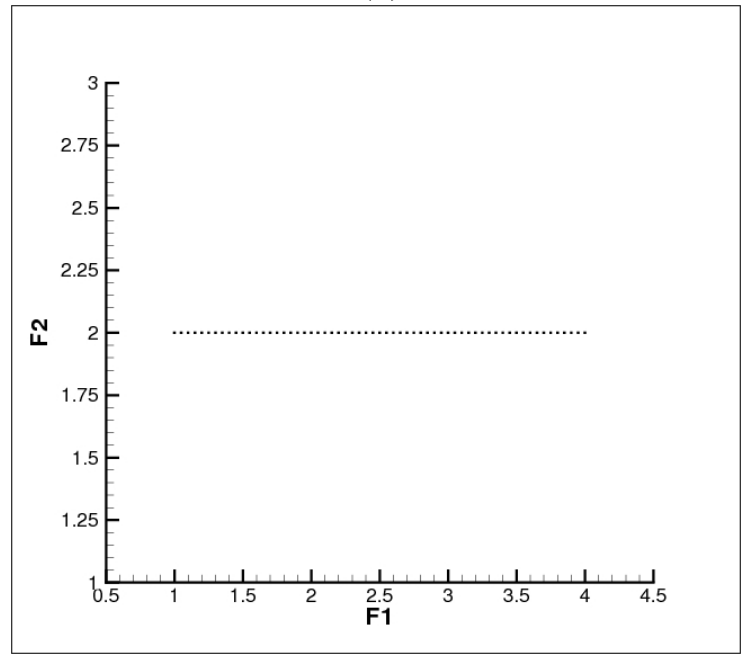

Figura 5.30: Solução analítica (a); solução aproximada (b); domínio (c). 



\section{6}

Resultados

Dédalus projetou asas, juntando penas de aves de vários tamanhos, amarrando-as com fios e fixando-as com cera, para que não se descolassem. Foi moldando com as mãos $e$ com a ajuda de seu filho Ícaro, de forma que estas asas se tornassem perfeitas como as das aves. (mito de Dédalus)

Os resultados obtidos neste trabalho estão organizados em duas categorias: otimização de objetivo simples (single-objective) e otimização multiobjetivo. A primeira foi aplicada como um estudo preliminar do problema e está apresentada na seção 6.1 a seguir. O segundo é apresentado na seção 6.2 .

\subsection{Otimização de objetivo simples}

Como um trabalho preliminar, estudou-se o problema de otimização aerodinâmica de objetivo simples. O AG aqui adotado está descrito na seção (4.1). Para sua configuração, adotou-se uma população de 150 indivíduos, $70 \%$ de probabilidade de crossover e $5 \%$ de mutação. Também foi aplicada uma estratégia de implementação na qual otimizações preliminares são efetuadas para aumentar a convergência do AG. No presente caso, 10 pré-rodadas foram executadas com 5 gerações em cada. Cada uma dessas pré-rodadas tem uma população inicial aleatória e evoluem até completar as 5 gerações. Ao final dessas rodadas, é feita uma seleção elitista dos $N$ melhores indivíduos para aplicar na otimização propriamente dita. Essa técnica aparece como um serrilhado nas primeiras gerações da curva de evolução do fitness. Nas subseções seguintes são apresentados os resultados para esse estudo preliminar. 


\section{Função de avaliação 1}

Com o objetivo de maximizar o $\frac{L}{D}$ mantendo o $C l$ próximo de 0,2 e a intensidade do momento de arfagem baixa, a primeira função de avaliação utilizada foi:

$$
F_{1}=\frac{\frac{L}{D}}{(|C l-0.2|+1.0) \cdot(|C m|+1.0)},
$$

onde a soma das constantes no denominador com $|C l-0,2|$ e com $|C m|$ tem a função de evitar a divisão por zero.

(a)

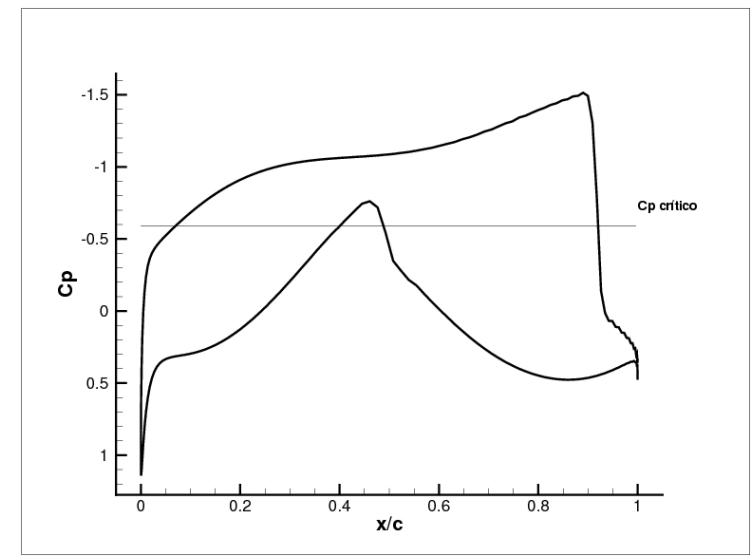

(b)

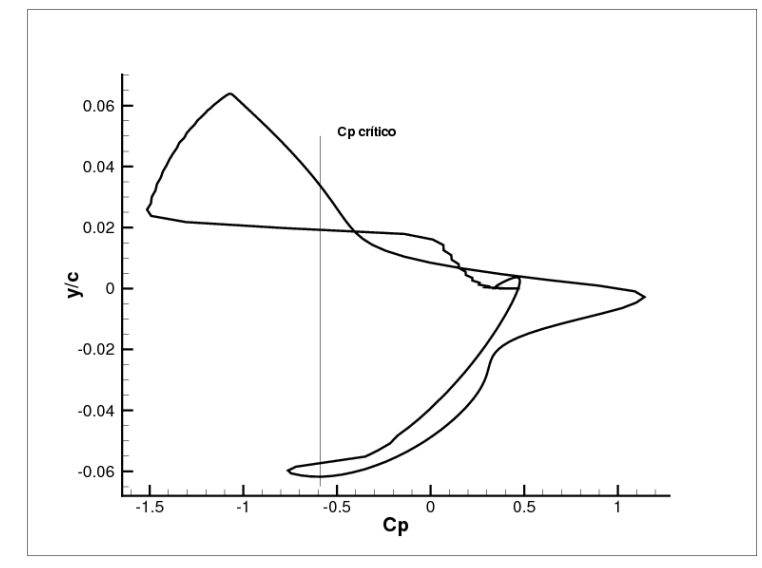

(c)

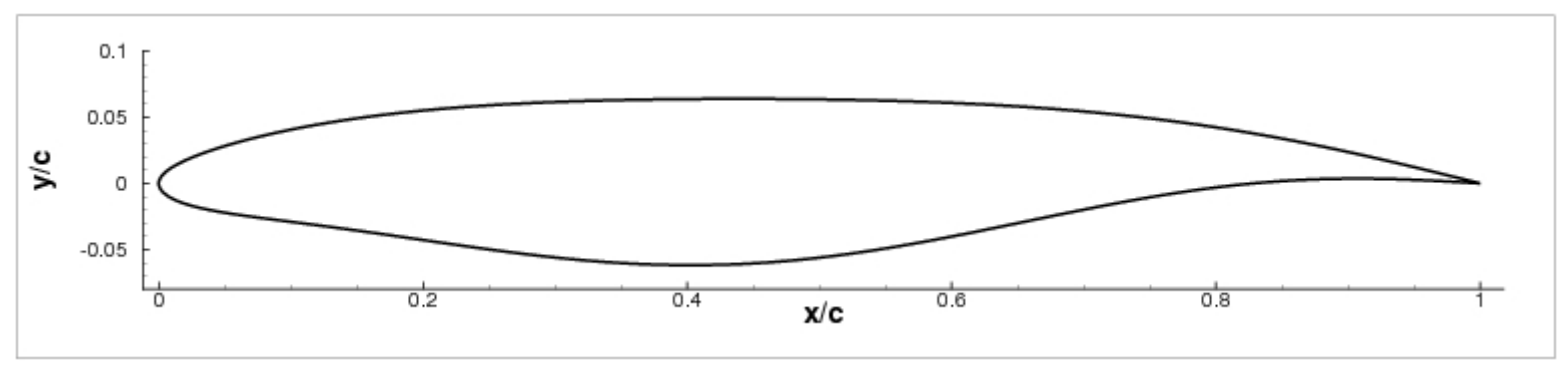

Figura 6.1: Distribuição de Cp, Resultado para a função 1: (a) Cp Vs x; (b) Cp Vs y; (c) geometria do perfil.

Os gráficos de $C p$ podem ser vistos na Figura 6.1), a evolução da otimização na 6.2)(a) e os contornos de Mach na 6.2)(b). A geometria apresenta suavidade e boa área interna necessária para incluir sistemas e combustível e espessura próximo de $10 \%$, necessário para projeto estrutural. Observa-se um abaulado no intradorso, causando um pico de sucção na região. A onda de choque é bem atrasada e de grande intensidade. Do gráfico de contorno de Mach, observa-se que a região de escoamento supersônico se estende até uma corda de distância para cima do perfil. A otimização atingiu a convergência em aproximadamente 140 gerações. 
(a)

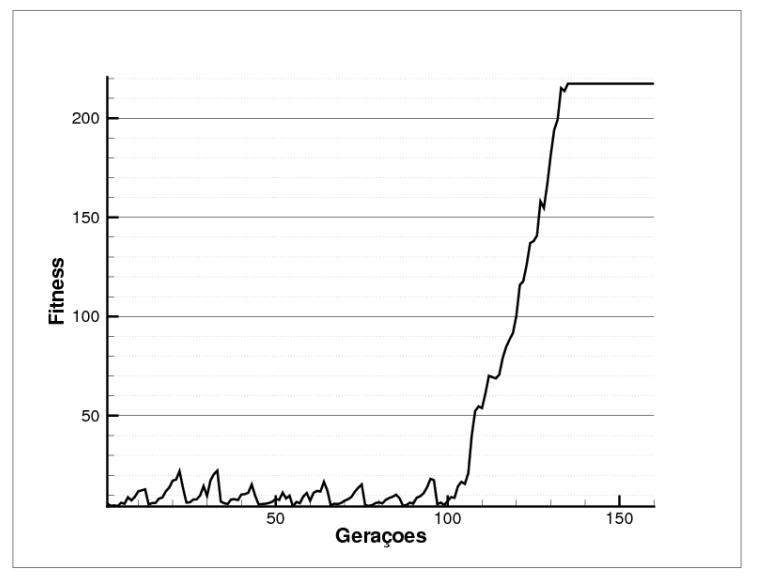

(b)

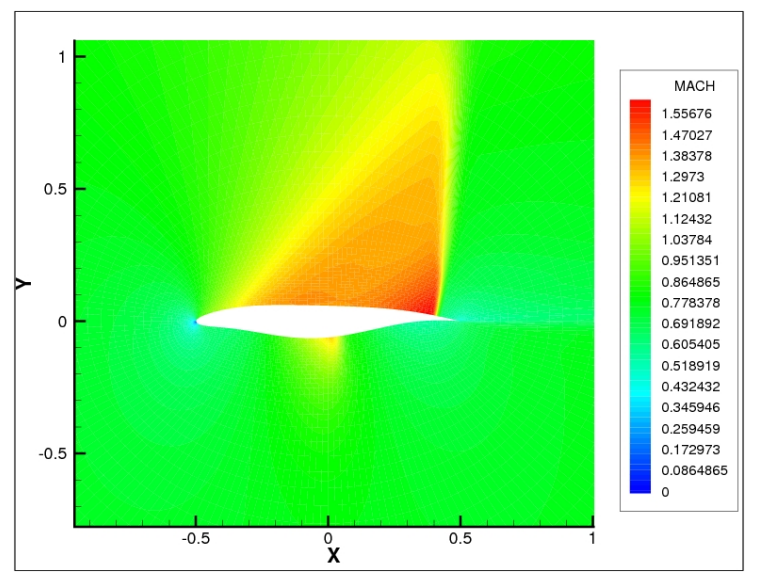

Figura 6.2: Função de avaliação 1: (a) Evolução da função de avaliação; (b) Curva de contorno de Mach.

\section{Função de avaliação 2}

Como a tentativa de priorizar valores para coeficientes de sustentação próximos de 0,2 não foi efetivo no caso 1, tentou-se a seguinte função de avaliação:

$$
F_{2}=\frac{L}{D}
$$

Os gráficos de $C p$ podem ser vistos na Figura 6.3, a evolução da otimização na 6.4) (a) e os contornos de Mach na 6.4)(b). A geometria apresenta suavidade, boa área interna, assim como no caso 1 , e espessura próxima de $12 \%$, maior que no caso 1 . Observa-se que o intradorso não apresenta abaulado e que a curva de $C p$ nessa região não apresenta pico de sucção. A onda de choque é bem atrasada e de grande intensidade. Do gráfico de contorno de Mach se observa que a região de escoamento supersônico se estende até uma corda de distância para cima do perfil. A otimização atingiu a convergência em aproximadamente 90 gerações.

\section{Função de avaliação 3}

Como uma última proposta de função de avaliação, aplicou-se uma minimização do $C d$ com as restrições para $\mathrm{Cl}$ e $\mathrm{Cm}$ :

$$
F_{3}=\frac{\frac{1}{C d}}{(|C l-0.2|+1.0) \cdot(|C m|+1.0)},
$$

onde a soma das constantes no denominador com $|C l-0,2|$ e com $|C m|$ tem a função de evitar a divisão por zero, como no caso 1 .

Os gráficos de $C p$ podem ser vistos na Figura 6.5), a evolução da otimização na 6.6) (a) e os contornos de Mach na (6.6)(b). Esta geometria também apresenta suavidade e boa área interna e 
(a)

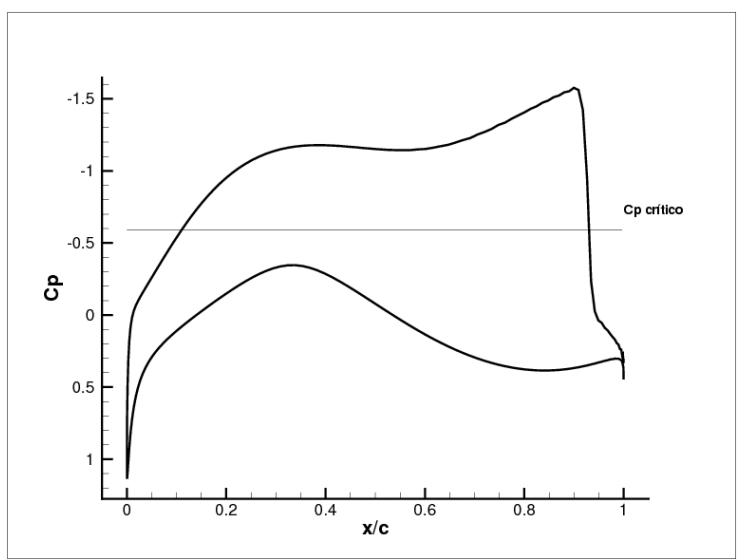

(b)

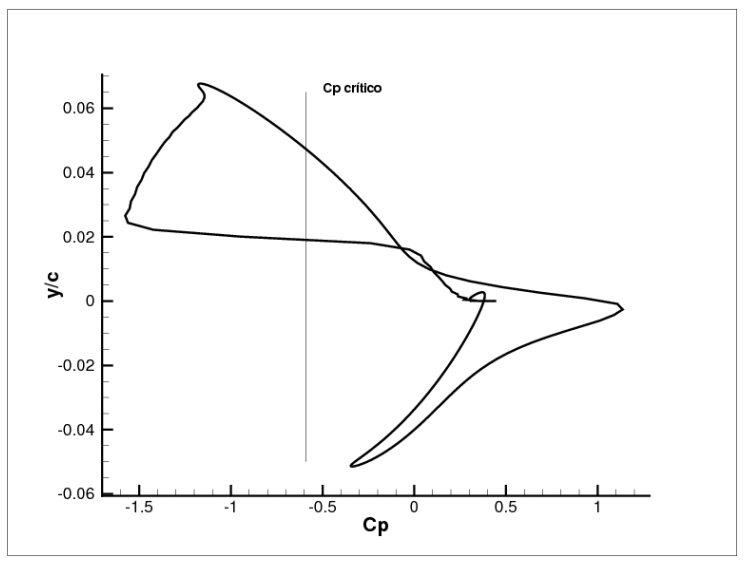

(c)

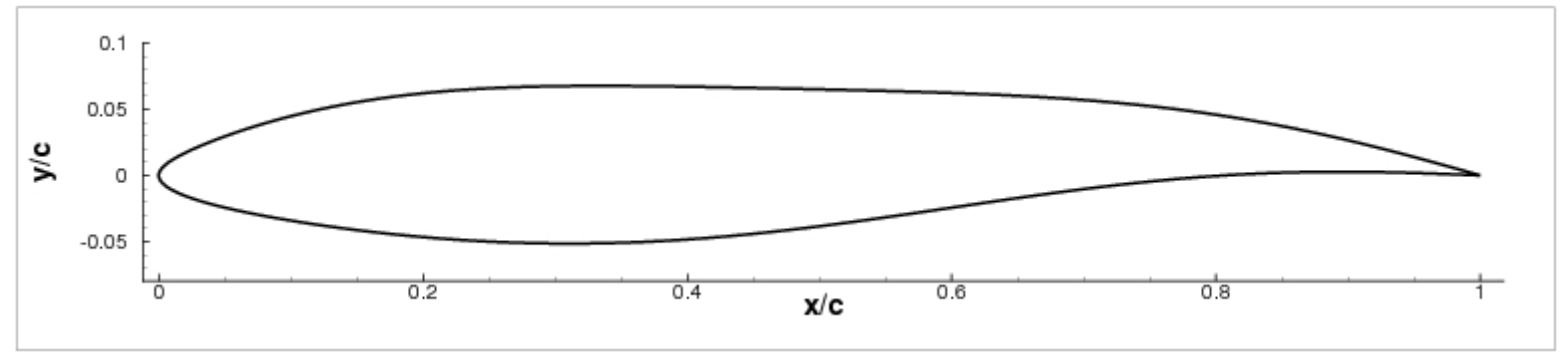

Figura 6.3: Distribuição de Cp, Resultado para a função 2: (a) Cp Vs x; (b) Cp Vs y; (c) geometria do perfil.

(a)

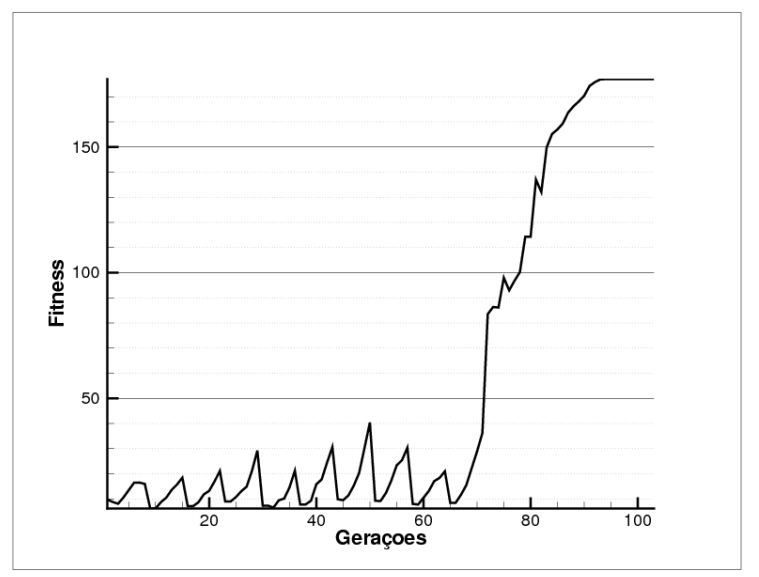

(b)

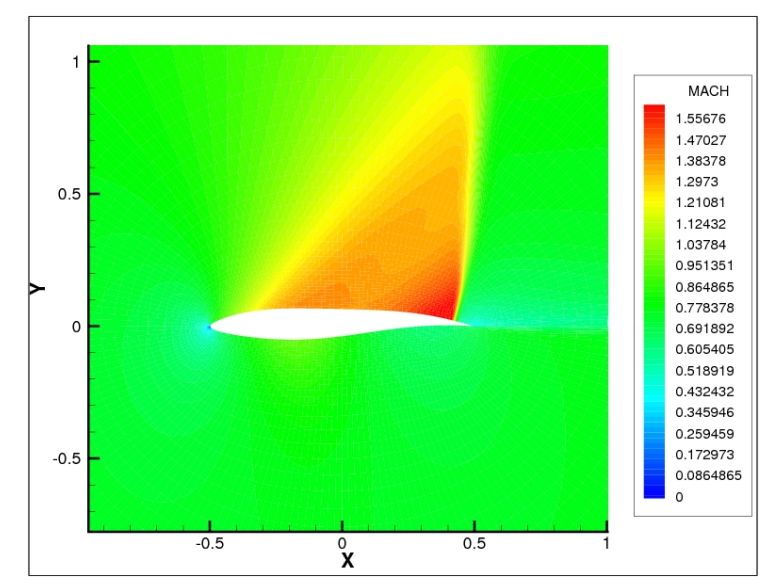

Figura 6.4: Função de avaliação 2: (a) Evolução da função de avaliação; (b) Curva de contorno de Mach.

espessura próxima de $12 \%$. Também se observa que o intradorso não apresenta abaulado e que a curva de $C p$ nessa região não apresenta pico de sucção. A onda de choque é bem atrasada e de grande intensidade. Do gráfico de contorno de Mach, observa-se que a região de escoamento supersônico se extende até uma corda de distância para cima do perfil. A otimização atingiu a convergência em aproximadamente 100 gerações. 
(a)

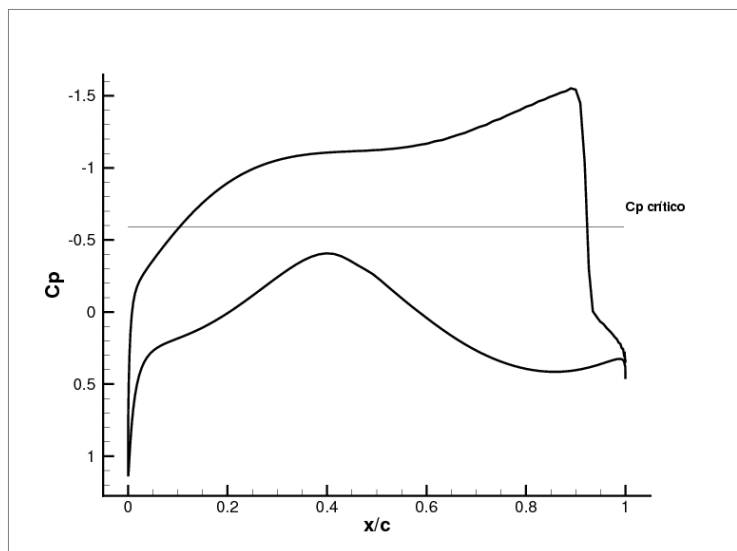

(b)

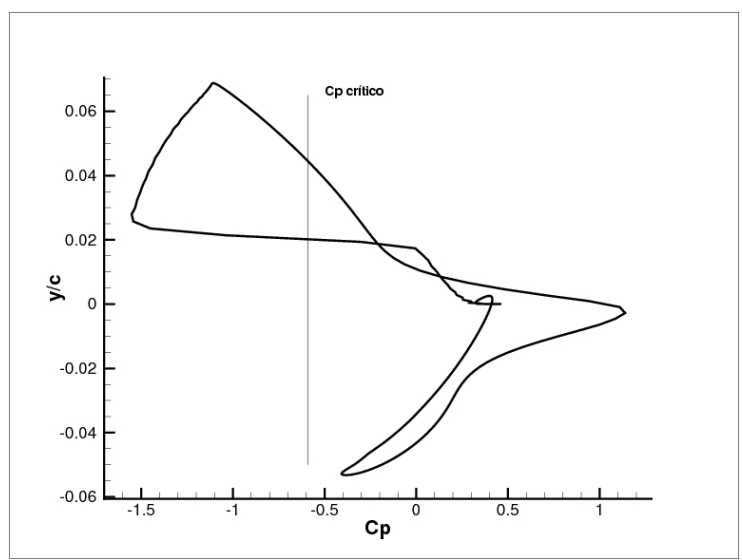

(c)

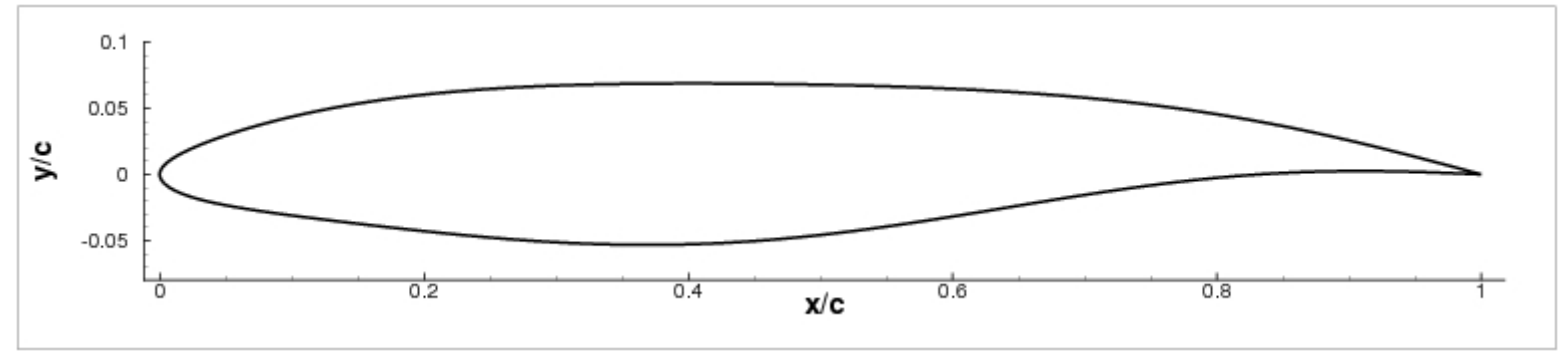

Figura 6.5: Distribuição de Cp, Resultado para a função 3: (a) Cp Vs x; (b) Cp Vs y; (c) geometria do perfil.

(a)

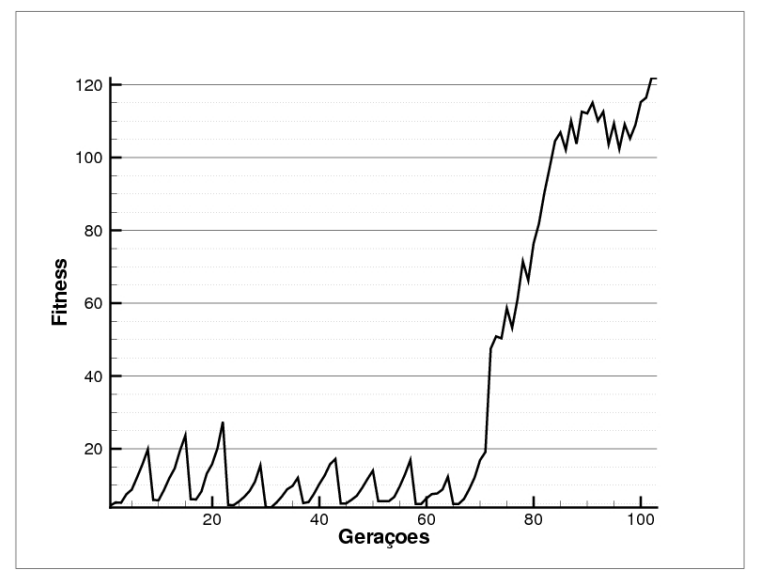

(b)

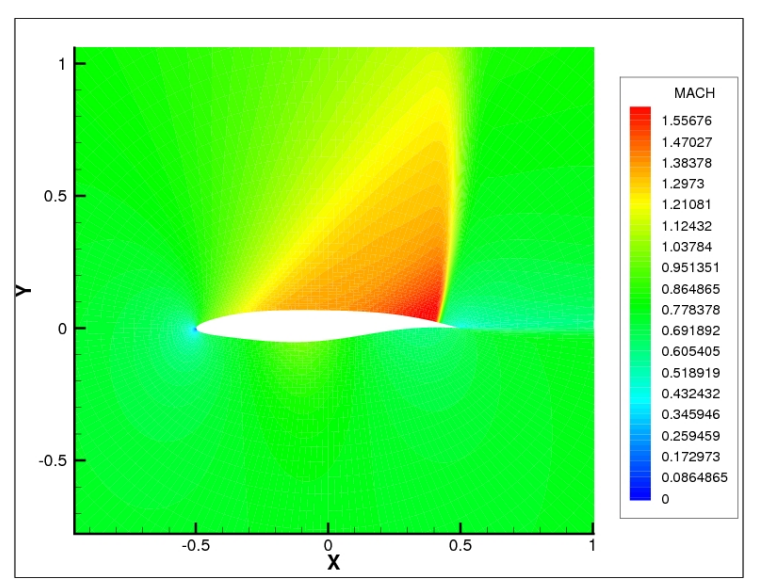

Figura 6.6: Função de avaliação 3: (a) Evolução da função de avaliação; (b) Curva de contorno de Mach.

\section{Comparação dos resultados}

Os resultados obtidos pela otimização de objetivo simples fornecera os cromossomos apresentados na Tabela 6.1. Nota-se uma pequena diferença entre os valores, porém os resultados para os coeficientes aerodinâmicos levaram a resultados de $\frac{L}{D}$ bem distintos, como se pode observar na 
Tabela 6.2. Com isso, pode-se concluir que o modelo adotado (parametrização da geometria mais modelo computacional) fornece uma função de avaliação muito sensível.

Tabela 6.1: Comparação dos resultados:

Cromossomos.

\begin{tabular}{|c|c|c|c|}
\hline Func. & 1 & 2 & 3 \\
\hline$r_{l e}$ & 0.00708 & 0.00607 & 0.00696 \\
$X_{u p}$ & 0.30117 & 0.31299 & 0.31204 \\
$Z_{u p}$ & 0.06158 & 0.06761 & 0.06754 \\
$Z x x_{u p}$ & -0.40495 & -0.48243 & -0.46272 \\
$X_{l o}$ & 0.30962 & 0.39263 & 0.40606 \\
$Z_{l o}$ & -0.05697 & -0.05144 & -0.05523 \\
$Z x x_{l o}$ & 0.83529 & 0.79990 & 0.72419 \\
$\alpha_{t e}$ & 8.75698 & 8.96715 & 8.19425 \\
$\beta_{t e}$ & 10.46727 & 13.37919 & 13.83556 \\
$Z_{t e}$ & 0.0 & 0.0 & 0.0 \\
$d Z_{t e}$ & 0.0 & 0.0 & 0.0 \\
\hline
\end{tabular}

Tabela 6.2: Comparação dos resultados: Coeficientes aerodinâmicos.

\begin{tabular}{|c|c|c|c|c|}
\hline Func. & $C l$ & $C d$ & $C m$ & $\frac{L}{D}$ \\
\hline 1 & 0.590 & 0.002994 & -0.304 & 197.0 \\
\hline 2 & 0.726 & 0.008204 & -0.380 & 88.49 \\
\hline 3 & 0.655 & 0.005456 & -0.355 & 120.0 \\
\hline
\end{tabular}

Dos resultados da Tabela 6.2, nota-se que o AG maximizou a eficiência aerodinâmica aumentando o valor do $C l$. Por isso, não foi efetiva a tentativa de priorizar os valores próximos de 0,2 . Porém, a utilização do divisor nas funções 1 e 3 apresentou uma pressão evolutiva para selecionar os indivíduos com $\mathrm{Cl}$ um pouco menores.

Na Figura 6.7)(a), nota-se uma grande geração de sustentação pelas geometrias, principalmente pela região supersônica. Porém, essa região é responsável também por uma grande componente do momento. Nas Figuras 6.7)(b), nota-se que a geração do arrasto é menor no intradorso do perfil e duas principais regiões do perfil são responsáveis por sua geração: a região próxima à estagnação e a região logo antes da onda de choque.

É possível observar que, na maior extensão dos perfis, os gradientes de pressão são favoráveis. Esse é um comportamento que evita o descolamento da camada limite. Nota-se também, na mesma região, que as ondas de choque aparecem em uma posição bem atrasada, o que geralmente é visto como uma vantagem; neste caso, porém, são ondas de choques de grande intensidade. Na posição de bordo de fuga, a camada limite é mais espessa, o que leva a uma interação maior entre o choque e a camada limite, fenômeno negligenciado pelo modelo adotado.

Com este resultado, chega-se à conclusão de que esse tipo de otimização é limitado para o problema. Portanto, implementadou-se uma técnica de otimização multiobjetivo cujos resultados são mostrados na seção a seguir.

\subsection{Otimização multiobjetivo}

Para o estudo da otimização multiobjetivo, foram efetuadas 10 otimizações para cada caso. As métricas descritas no capítulo 4 são representadas graficamente com seu valores, média e desvio 
(a)

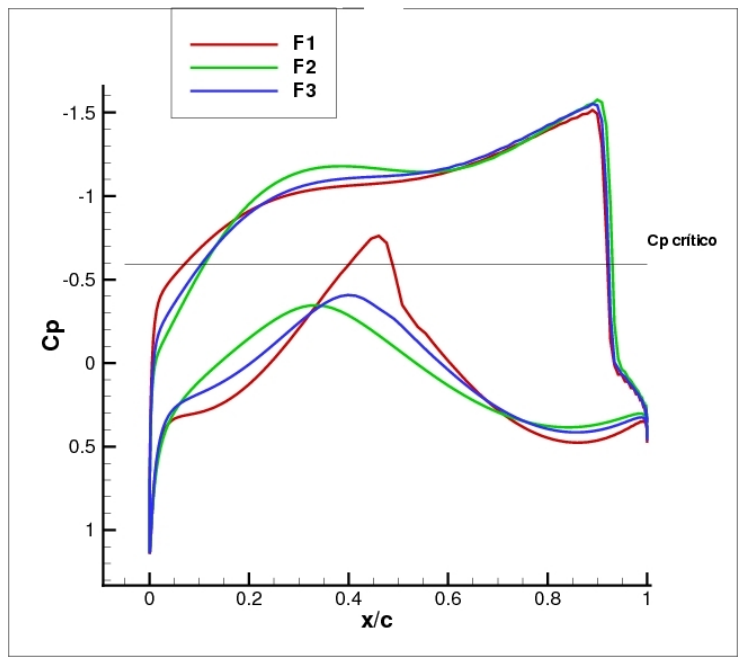

(b)

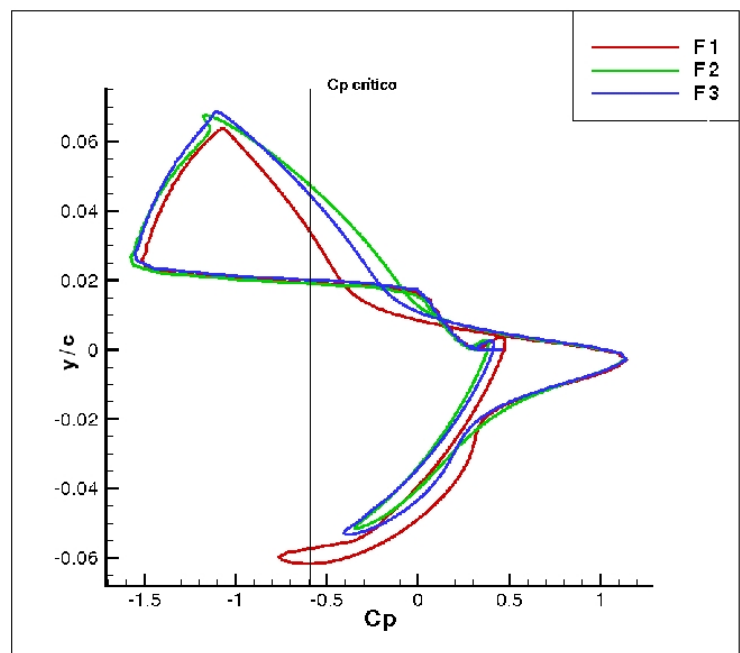

(c)

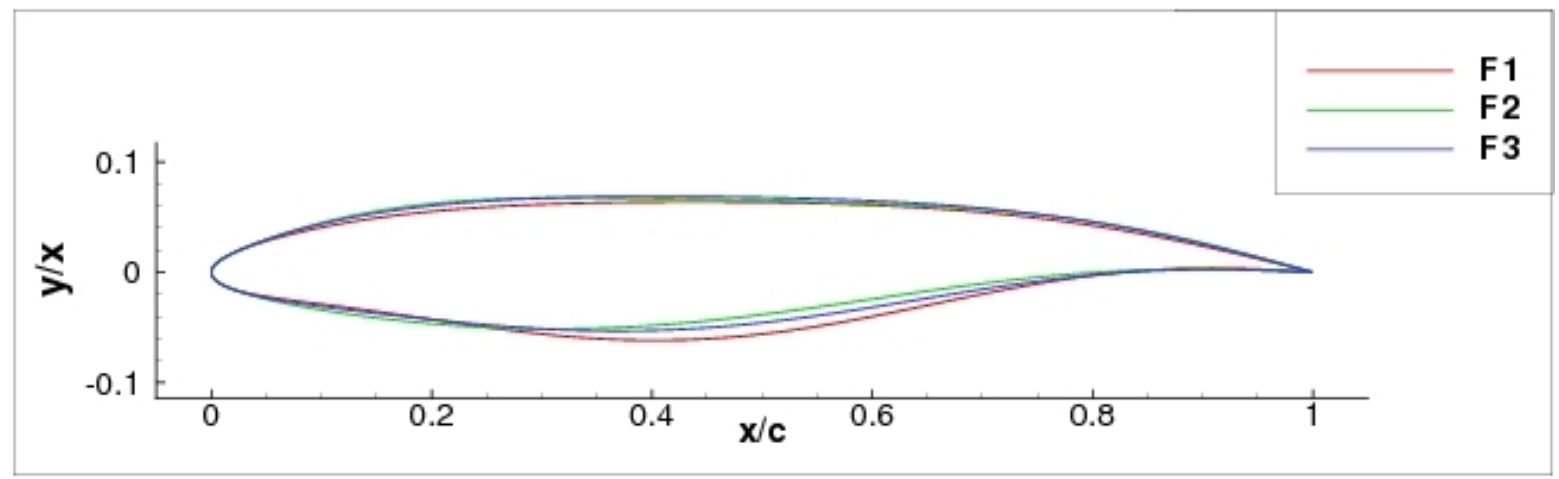

Figura 6.7: Distribuição de Cp, Comparação: (a) Cp Vs x; (b) Cp Vs y; (c) geometria.

padrão na forma de um gráfico de erro, permitindo observar a robustez dos dados. Além de observar a evolução das métricas, analiza-se a frente de Pareto obtida para cada caso. Para definir essa frente, todos os elementos não dominados das 10 avaliações da otimização de cada caso foram utilizados.

Na subseção 6.2.1, são apresentadas as soluções de referência utilizadas para a métrica de otimalidade. Na subseção 6.2.2, são discutidas as diferenças entre a utilização dos modelo viscoso e invíscido. Na subseção 6.2.3, a diferença entre as parametrizações e, na subseção 6.2.4, o esquema centrado com o upwind.

\subsubsection{Soluções de referência}

Como visto no capítulo 4, para avaliar uma otimização multiobjetivo existem métricas apropriadas para quantificar as características desejadas da população. Como foi proposto no mesmo capítulo, para representar a otimalidade da solução são usadas, neste trabalho, soluções pré-existentes, que são perfis aerodinâmicos já conhecidos na literatura. Esses perfis foram simulados pelas técni- 
cas utilizadas nas otimizações. Dos resultados são selecionados os perfis dominantes e utilizados nas métricas propostas no capítulo 4.

As Tabelas 6.3), 6.4), 6.5) e 6.6 apresentam, respectivamente, os resultados para os perfis doiminantes utilizando a técnica de Jameson, Roe, modo viscosodo Mses e seu modo invíscido.

Tabela 6.3: Coeficientes aerodinâmicos para os Perfis de Referência (Jameson) - 21 geometrias.

\begin{tabular}{c|c|c|c}
\hline Perfil & $C l$ & $C d$ & $C m$ \\
\hline ames02 & 0.028047 & 0.000897 & 0.014982 \\
c141a & 0.370203 & 0.001554 & -0.179205 \\
c141d & 0.437026 & 0.001241 & -0.205094 \\
c5e & 0.385250 & 0.003788 & -0.176567 \\
cast102 & 0.503446 & 0.002167 & -0.238624 \\
dfvlrr4 & 0.897688 & 0.017867 & -0.464831 \\
giiia & 0.029048 & 0.000821 & 0.036092 \\
giiib & 0.025103 & 0.000543 & 0.008231 \\
k3 & 1.108651 & 0.063753 & -0.637815 \\
kc135a & 0.266120 & 0.017591 & -0.113072 \\
ls417 & 0.847124 & 0.063926 & -0.479725 \\
nlr7301 & 0.646281 & 0.015405 & -0.316175 \\
np19510 & 0.435586 & 0.001852 & -0.251756 \\
rae69ck & 0.455703 & 0.001636 & -0.239031 \\
sc(2)-0404 & 0.362514 & 0.004643 & -0.181493 \\
sc(2)-0503 & 0.414721 & 0.006730 & -0.198734 \\
sc(2)-0518 & 0.983865 & 0.060537 & -0.548894 \\
sc(2)-0614 & 1.175314 & 0.047690 & -0.619791 \\
sc(2)-1010 & 1.686764 & 0.113071 & -0.879110 \\
sc20714 & 1.197988 & 0.044793 & -0.633207 \\
vr15 & 0.020384 & 0.001161 & 0.019542
\end{tabular}


Tabela 6.4: Coeficientes aerodinâmicos para os Perfis de Referência (Roe) - 17 geometrias.

\begin{tabular}{c|c|c|c}
\hline Perfil & $C l$ & $C d$ & $C m$ \\
\hline ames01 & -0.098696 & -0.000569 & 0.070449 \\
ames02 & -0.243097 & -0.000750 & 0.112450 \\
apex16 & 0.787547 & 0.035595 & -0.428986 \\
c5c & 0.191590 & 0.000057 & -0.103894 \\
c5e & 0.209706 & 0.001915 & -0.093853 \\
giiia & -0.047831 & 0.001619 & 0.044583 \\
giiib & 0.006752 & 0.001034 & 0.016438 \\
k3 & 0.310478 & 0.002932 & -0.193393 \\
nlr7301 & 0.594341 & 0.014421 & -0.288690 \\
np19510 & 0.051734 & 0.000697 & -0.078654 \\
sc(2)-0012 & 0.003256 & 0.003738 & -0.002329 \\
sc(2)-0404 & 0.411390 & 0.003741 & -0.204965 \\
sc(2)-0412 & 0.826977 & 0.009348 & -0.401278 \\
sc(2)-0518 & 1.054138 & 0.071809 & -0.597174 \\
sc(2)-0712 & 1.360086 & 0.055991 & -0.719301 \\
sc(2)-1010 & 1.667933 & 0.112783 & -0.869540 \\
vr15 & -0.143065 & 0.001090 & 0.096365
\end{tabular}

Tabela 6.5: Coeficientes aerodinâmicos para os Perfis de Referência (Mses invíscido) - 15 geometrias.

\begin{tabular}{c|c|c|c}
\hline Perfil & $C l$ & $C d$ & $C m$ \\
\hline apex16 & 0.781620 & 0.030966 & -0.221000 \\
dfvlrr4 & 0.885900 & 0.014342 & -0.230100 \\
dsma523a & 0.881750 & 0.004824 & -0.210500 \\
dsma523b & 1.104230 & 0.008782 & -0.260080 \\
k3 & 1.042210 & 0.051134 & -0.324330 \\
kc135a & 0.260290 & 0.016192 & -0.041200 \\
ls417 & 0.818440 & 0.057596 & -0.245200 \\
nlr7301 & 0.641460 & 0.012534 & -0.148650 \\
sc(2)-0412 & 0.968710 & 0.009664 & -0.233510 \\
sc(2)-0414 & 1.070450 & 0.028540 & -0.286770 \\
sc(2)-0518 & 1.118440 & 0.069640 & -0.343360 \\
sc(2)-0614 & 1.314550 & 0.057681 & -0.374860 \\
sc(2)-0712 & 1.430350 & 0.056509 & -0.397490 \\
sc20714 & 1.154740 & 0.036649 & -0.307280 \\
sc(2)-1010 & 1.681750 & 0.105679 & -0.445020
\end{tabular}


Tabela 6.6: Coeficientes aerodinâmicos para os Perfis de Referência (Mses viscoso) - 36 geometrias.

\begin{tabular}{c|c|c|c}
\hline Perfil & $C l$ & $C d$ & $C m$ \\
\hline airfoil_12 & 0.711620 & 0.010523 & -0.164010 \\
apex16 & 0.458400 & 0.019526 & -0.126330 \\
c141a & 0.157290 & 0.008178 & -0.042210 \\
c141b & 0.181540 & 0.008055 & -0.046600 \\
c141c & 0.251950 & 0.007542 & -0.059050 \\
c141d & 0.303750 & 0.007587 & -0.068740 \\
c141e & 0.360910 & 0.007724 & -0.079600 \\
c5a & 0.126300 & 0.007979 & -0.045600 \\
c5b & 0.246960 & 0.007755 & -0.070930 \\
c5c & 0.278240 & 0.007744 & -0.077390 \\
c5d & 0.298420 & 0.007628 & -0.078180 \\
c5e & 0.311600 & 0.008433 & -0.064670 \\
cast102 & 0.351990 & 0.008397 & -0.081050 \\
dfvlrr4 & 0.577540 & 0.011446 & -0.149530 \\
dsma523a & 0.486190 & 0.008797 & -0.138150 \\
dsma523b & 0.734120 & 0.011349 & -0.174650 \\
giiia & 0.011840 & 0.007544 & 0.020300 \\
giiib & 0.045570 & 0.007082 & 0.009640 \\
giiic & 0.065380 & 0.006923 & 0.003820 \\
k2 & 0.111200 & 0.007504 & -0.081880 \\
k3 & 0.433760 & 0.020309 & -0.151010 \\
kc135a & 0.171690 & 0.020734 & -0.026210 \\
kc135b & 0.253340 & 0.011332 & -0.033230 \\
1s417 & 0.307650 & 0.030376 & -0.114070 \\
n0011sc & 0.001260 & 0.007588 & 0.000040 \\
n1722343 & 0.344420 & 0.007436 & -0.066240 \\
np19510 & 0.325430 & 0.008077 & -0.120440 \\
nplx & 0.170160 & 0.007051 & -0.070950 \\
rae5215 & 0.366200 & 0.007493 & -0.082760 \\
rae69ck & 0.302690 & 0.007590 & -0.091180 \\
sc(2)-0414 & 0.435210 & 0.008903 & -0.110230 \\
sc(2)-0518 & 0.365080 & 0.021302 & -0.106370 \\
sc(2)-0614 & 0.649480 & 0.013892 & -0.147690 \\
sc(2)-0712 & 0.803660 & 0.012948 & -0.169990 \\
sc20714 & 0.723980 & 0.016643 & -0.169450 \\
whitcomb & 0.538530 & 0.009073 & -0.147600
\end{tabular}




\subsubsection{Comparação entre modelo viscoso e invíscido: Mses}

O objetivo desta seção é a comparação entre a otimização utilizando o modelo viscoso, mais caro, e o modelo invíscido. Além da diferença na previsão da onda de choque, o fenômeno da transição de escoamento laminar para turbulento influencia as funções objetivo. A técnica de previsão para a transição, utilizada pelo código Mses no modo viscoso, possibilita ao AG experimentar entre perfis com maior ou menor porção de escoamentos laminares na sua superfície.

As Figuras A.1 - A.7) e A.12 - A.18 mostram a evolução das métricas. Nos dois casos, nota-se que a evolução da factíbilidade da população (Figuras A.1 A.12) é assintótica com média tendendo-se à $75 \%$. O desvio padrão mostra uma relativa robustez do AG para os dois casos.

Para a métrica Spacing (Figuras A.2 e A.13, observam-se valores próximos a 0,2, mostrando uma boa representação da $P F$. Essa qualidade da solução também se observa para a métrica ARAI (Figuras A.3 A.14), na qual os valores ficaram entre 0,15 e 0,2, sendo que, para o modelo viscoso, a curva ficou abaixo da curva do modelo invíscido.

Já as métricas ER, InvER e GER (ver Figuras A.4 A.6 A.15 A.17) mostram que para o modo viscoso, a otimização avançou na otimalidade, obtendo, em média, mais soluções dominantes em comparação com o modo invíscido e o desvio padrão mostra uma maior robustez no caso viscoso. A métrica $N D W D_{G E R}$ (Figuras A.7 e A.18) mostra que as PFs encontradas avançaram na dominância em relação às soluções de referência. Porém, o modelo invíscido avançou pouco, sendo a otimização utilizando o modo viscoso mais satisfatória do ponto de vista da otimzalidade.

As Figuras A.8 e A.19 mostram as geometrias do perfis pertencentes às $P F$ s dos dois casos. Os agrupamentos dos perfis foram definidos pela técnica de agrupamento de dados $k$-means 1 Para o caso invíscido foram encontrados 9 grupos e, para o caso viscoso, 10. O agrupamento foi aplicado diretamente às coordenadas $y$ das geometrias e no título das figuras estão os coeficientes aerodinâmicos médios (centróide) das soluções do grupo. As Figuras 6.8-6.11 mostram os perfis mais próximos do centróide de seu grupo com a distribuição de $C p$.

As geometrias obtidas com o modelo invíscido são mais suaves em comparação às obtidas com o modo viscoso do Mses. Porém, em geral, notam-se "abaulados"no intradorso, como se pode ver nos grupos 1, 2 e 6 da Figura (A.8) e nos grupos 1, 3, 4, 5, 7 e 8 da Figura (A.19). Essa característica gera uma onda de choque muito forte na superfície inferior dos aerofólios. No grupo 10 (Figura 6.11), pode-se ver um grupo de perfis com geometria anômala de pequeno raio de bordo de ataque e cuja curvaq de $C p$ apresentou instabilidade numérica próximo ao bordo de ataque. Todas as geometrias apresentam $C p$ acima do $C p_{c r}$, sendo que para os grupos de menor $C l$, a onda de choque aparece mais adiantado.

As Figuras A.9 e A.20 mostram as visualizações dos cromossomos das geometrias para os dois casos com os grupos separados. Podem-se notar os padrões de cromossomos bem definidos para cada grupo. Nota-se, para os grupos 1, 3, 4, 5, 6, 7 e 9 do caso invíscido e os grupos 1, 2, 3,

\footnotetext{
${ }^{1}$ Para maior detalhes sobre a técnica, ver (Duda et al., 2000)
} 

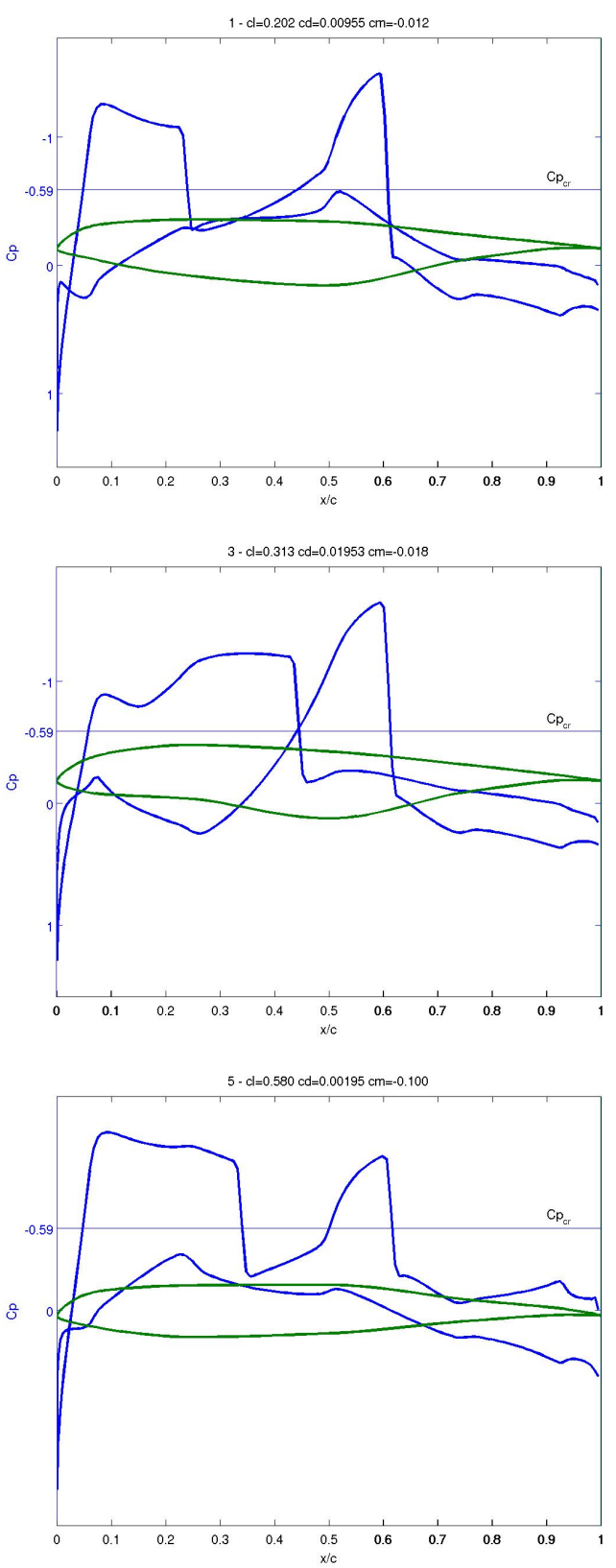
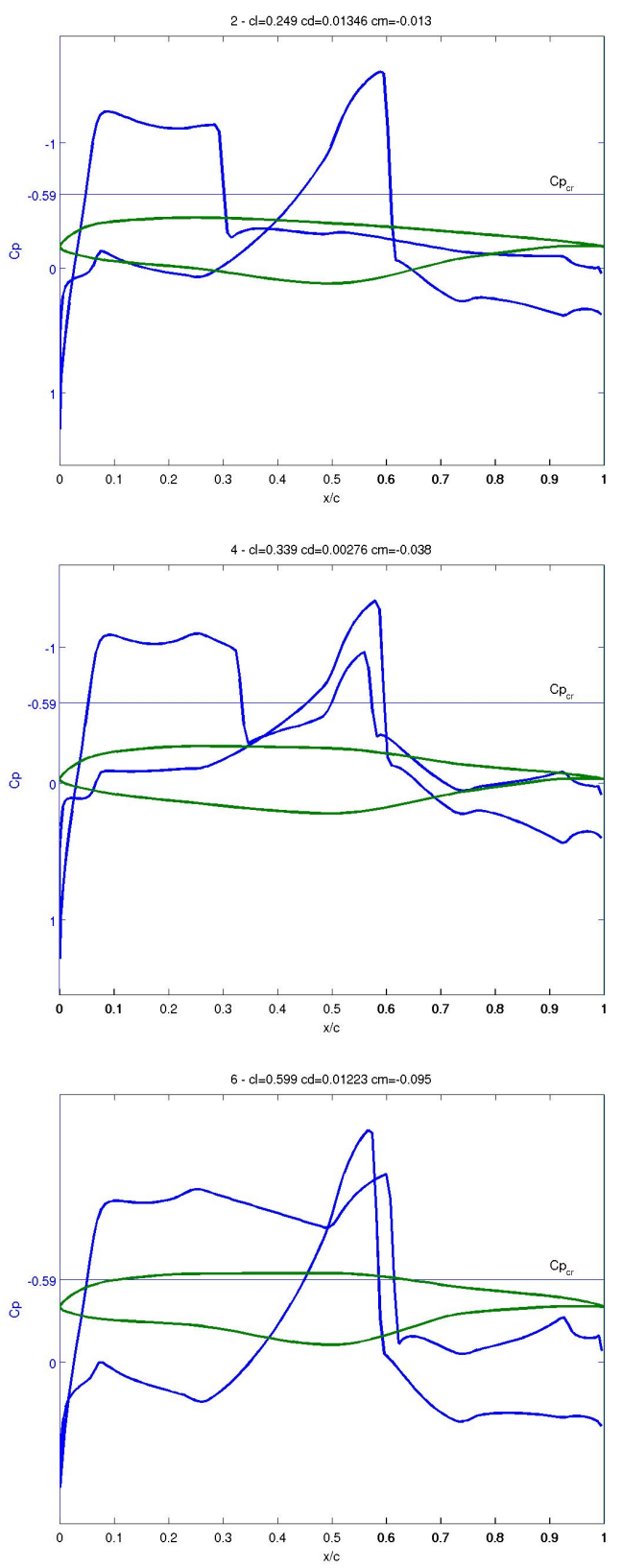

Figura 6.8: Distribuição de Cp para os elementos centróides do agrupamento, para a otimização usando Mses no modo invíscido.

5 e 6 do caso viscoso uma relação linear muito forte entre os genes 8 e 9 e entre os genes 9 e 10 (Nielson et al., 1997). Também é visível para todos os grupos que os genes 5 e 6 apresentaram um agrupamento forte próximo dos valores 1 para o gene 5 e 0 para o gene 6.

As Figuras A.10) e A.21 apresentam as matrizes de gráficos de dispersão para os coeficientes aerodinâmicos e os parâmetros de desempenho adotados para a análise. Pelos histogramas, nota-se que, para o caso invíscido, as soluções presentes na frente de Pareto estão mais bem distribuídas em comparação ao caso viscoso. Observa-se também que, para ambos, o aumento do $C l$ tende a aumentar a intensidade do $C m$, o que se explica pela observação das curvas de $C p$, onde os perfis 
com maior $C l$ apresentam uma onda de choque mais atrasado, aumentando a região de sucção e a componente de momento gerada pela região posterior do perfil.

Também se observa a tendência de aumento do $C l$ para obter maiores valores de $\frac{L}{D}$. Assim como visto no capítulo 1 , o aumento do $C l^{2}$ leva ao aumento do arrasto por efeitos tridimensionais, impedindo seu aumento indefinido e, conseqüentemente, limitando o $\frac{L}{D}$ final da aeronave. Como esperado, o caso invíscido apresentou valores para a eficiência aerodinâmica maiores que no caso viscoso. Porém, foram encontrados valores extremamente altos de $\frac{L}{D}$, o que põe em dúvida a confiabilidade dos resultados. A relação entre $C d$ e $C m$ nos dois casos apresenta o mesmo padrão, porém o modelo viscoso apresentou maior intensidade para os dois parâmetros.
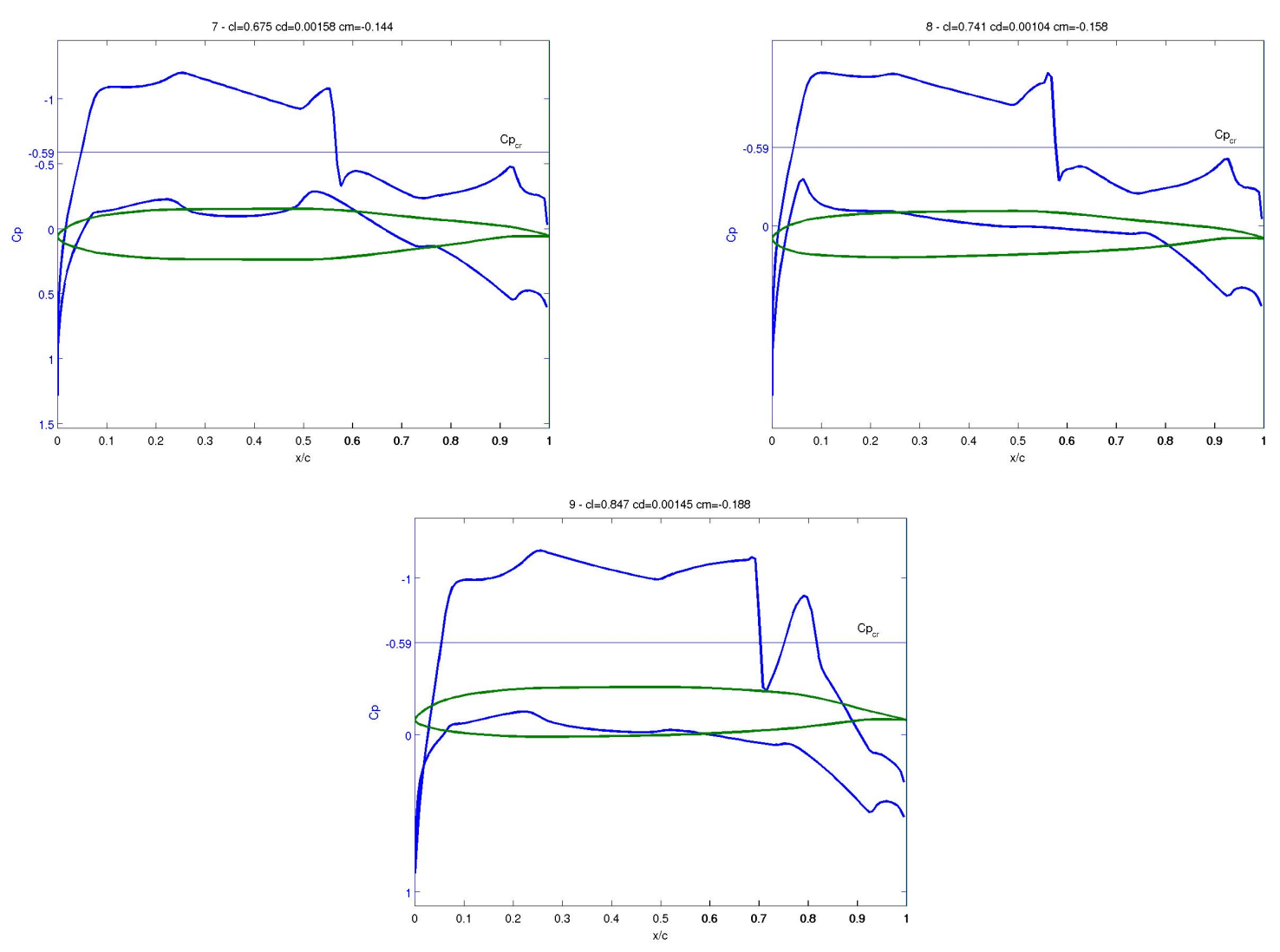

Figura 6.9: Distribuição de Cp para os elementos centróides do agrupamento, para a otimização usando Mses no modo invíscido.

As Figuras A.11) e A.22 apresentam as relações entre os coeficientes aerodinâmicos e os parâmetros geométricos: espessura máxima e sua posição (thick e $X_{t}$ ), Camber máximo e sua posição $\left(X_{c}\right)$, área interna do perfil (S) e raio de bordo de ataque $\left(R_{l e}\right)$. Observando a espessura máxima e sua posição, notam-se dois agrupamentos das soluções em relação ao $C l$. Para maiores valores de sustentação, tem-se um grupo de geometrias mais finas e a espessura máxima mais adiantada. Para valores de $C l$ menores, perfis mais espessos e de espessura mais atrasada. Porém, para o modelo viscoso, a relação tem uma tendência linear de aumento da sustentação com o aumento da espessura. De forma equivalente, notam-se os agrupamentos na comparação da espessura com o $\mathrm{Cm}$, de forma inversa: um grupo de valores maiores para espessura e sua posição e $C m$ maior (mais 

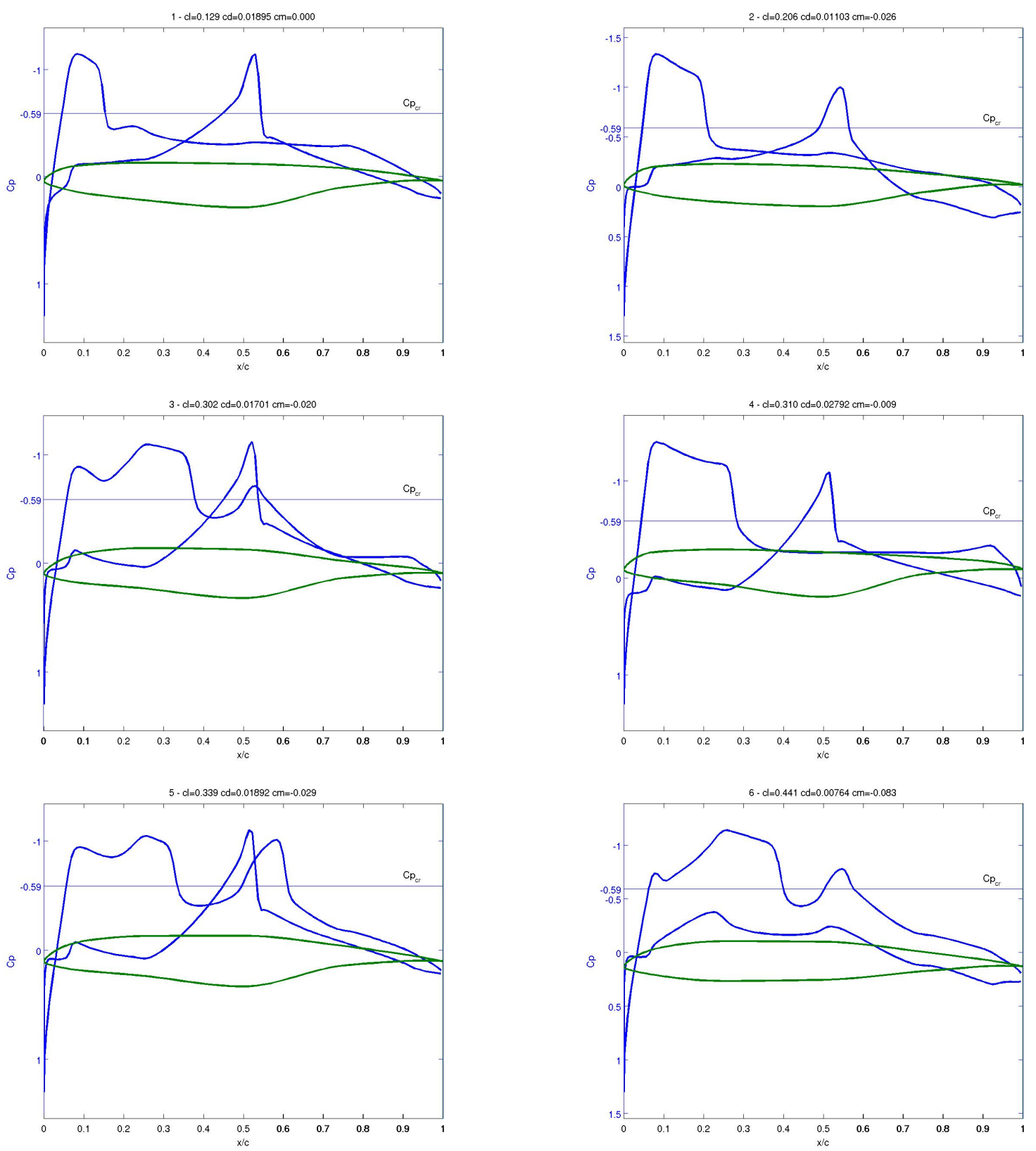

Figura 6.10: Distribuição de Cp para os elementos centróides do agrupamento, para a otimização usando Mses no modo viscoso.

próximo de zero); e um outro grupo com valores menores para $C m$ e espessura. Comparando a espessura e o $C d$, nota-se claramente um aumento do arrasto com o aumento da espessura para o caso viscoso. Tal relação não é notada de forma tão clara para o caso invíscido. Equivalentemente, observa-se que o $\frac{L}{D}$ cai para valores maiores de espessura.

Para o Camber, nota-se que ambos os casos apresentam dois grupos bem definidos em relação à posição: um grupo com o camber de um quarto da corda para frente e outro grupo com camber da metade da corda para trás. Também se observa a relação de aumento do $C l$ com o aumento do arqueamento. Novamente, o modelo viscoso apresentou a tendência de forma mais clara. Também verifica-se o aumento da sustentação para perfis com arqueamento mais atrasado. Não se observa 

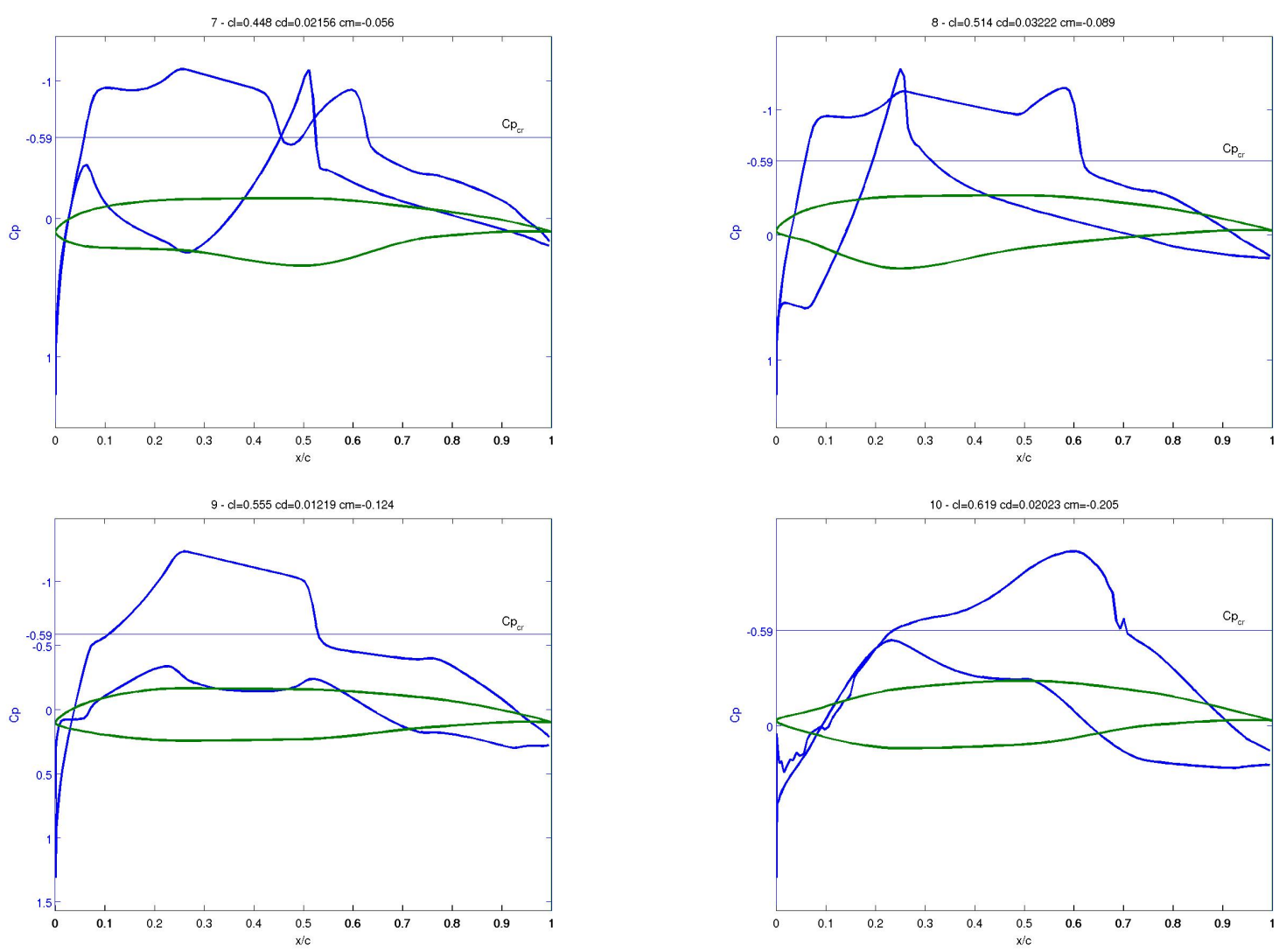

Figura 6.11: Distribuição de Cp para os elementos centróides do agrupamento, para a otimização usando Mses no modo viscoso.

uma relação entre o arrasto e o Camber e o $\frac{L}{D}$. Em relação ao $C m$, observa-se um aumento de sua intensidade com o aumento do Camber e também quando sua posição está mais próxima ao bordo de fuga do perfil.

A área do perfil e o raio de bordo de ataque não apresentaram nenhuma relação aparente, salvo por uma leve tendência de aumento do $C l$ com o aumento da área. Para o raio de bordo de ataque, nota-se um aglomerado para valores próximos de $5 \cdot 10^{-3}$. 


\subsubsection{Comparação entre as parametrizações}

O objetivo desta seção é comparar as parametrizações, utilizando a técnica centrada para simular o escoamento. Como visto no capítulo 3, esse caso compara otimizações que usam o mesmo modelo matemático e técnica de solução, ao contrário dos casos apresentados nas seções 6.2.2 e 6.2 .4 .

Como já esperado, devido à natureza das parametrizações, a utilização de pontos de controle apresentou maior factibilidade (ver Figuras A.23 e A.34). Essa parametrização também se mostrou melhor em relação à diversidade da população encontrada, fato evidenciado nas duas métricas de diversidade adotadas (ver Figuras A.24, A.35, A.25 e A.36, nas quais a parametrização por pontos de controle tem valores ligeiramente mais baixos. Também se pode notar nas Figuras (A.24) e A.25, entre as gerações 60 e 70, uma mudança brusca das métricas. Tal fato é consequiência de sensibilidade ao restart, descrito no capítulo 4 . Devido a uma perda de precisão dos genes causados por um erro de implementação, que causou um truncamento de pontos flutuantes, aplicou-se uma "mutação"que adicionou aleatoriamente valores na porção truncada do ponto flutuante. Não se notou sensibilidade ao restart para o caso Parsec. Nos gráficos com a média e o desvio padrão, nota-se que o AG é robusto em todas as métricas.

Observando as figuras relativas às métricas de otimalidade (ver A.26 A.29 A.37 A.40, notase que a parametrização Parsec conseguiu atingir a $P F_{\text {ref }}$ e, em poucos casos, ultrapassá-la, o que não ocorreu com a parametrização por pontos de controle. O caso também apresentou sensibilidade ao restart, porém em vez de influênciar a diversidade da população, essa sensibilidade reduziu a otimalidade da população. As duas parametrizações se mostraram equivalentes na robustez, porém a parametrização por ponto de controle mostrou melhor estabilidade.

As Figuras A.30 e A.41 mostram que as geometrias encontradas com a parametrização por pontos de controle são mais apropriadas, apresentando melhor suavidade na distribuição da espessura e do camber. Porém, para a parametrização por pontos de controle, nota-se alguns casos anômalos. Em geral, nessa parametrização, observa-se uma tendência a perfis com um leve abaulado no intradorso, como observado nos casos de objetivo simples. Também se observa que os centróides dos agrupamentos apresentam valores de $C l$ bem menores que na parametrização Parsec, assim como os valores de $C d$. Isso evidencia que as restrições geométricas impostas não foram suficientes para esse tipo de parametrização. Nas Figuras (6.12) e (6.14), pode-se ver a distribuição de $C p$ do perfil centróide para o método centrado com parametrização por ponto de controle e, nas Figuras 6.15) e 6.16, para o método centrado com parametrização Parsec.

$\mathrm{Na}$ comparação entre o modelo viscoso e invíscido se observou uma tendência a apresentar a onda de choque mais atrasado para $\mathrm{Cl}$ maiores, o que não se observa para os resultados obtidos pelo método Jameson nas duas parametrizações. Todos os grupos apresentam escoamento supersônico e um leve pico de sucção no intradorso na região do bordo de ataque, além de uma tendência ao aparecimento de um pico de sucção no intradorso devido ao "abaulado"existente. As Figuras 6.13)(a) e (b) mostram as curvas de $C p$ Vs $x$ e $C p$ Vs $y$ do agrupamento 7, evidenciando que o 

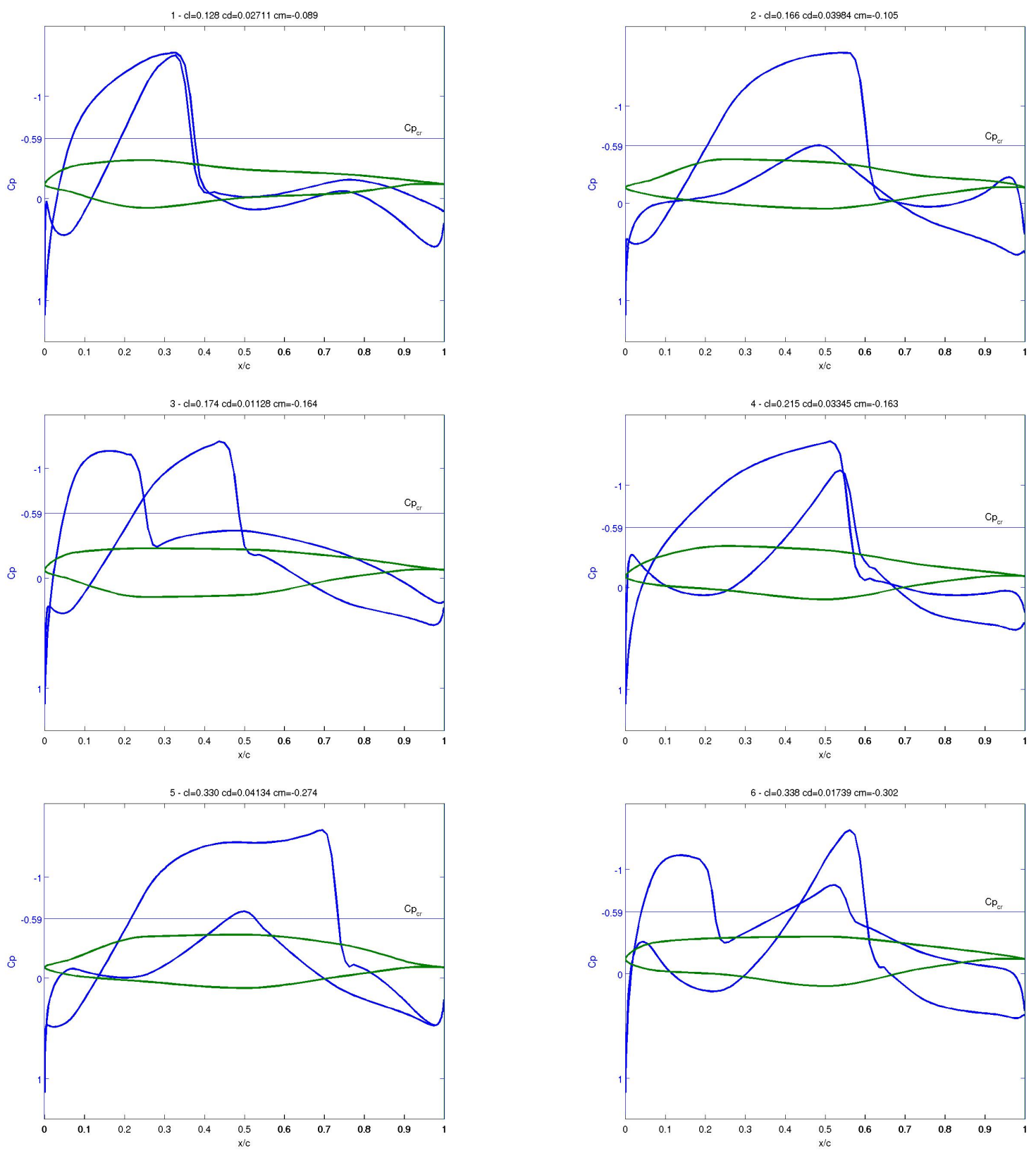

Figura 6.12: Distribuição de Cp para os elementos centróides do agrupamento, para a otimização usando método centrado e parametrização por ponto de controle.

pico de sucção citado funciona como mecanismo de redução de arrasto quando analisado com o modelo invíscido. O grupo 7 da Figura (6.14) apresenta um bordo de fuga em formato de cúspide, porém com boa suavidade da geometria e da curva de coeficiente de pressão. A parametrização Parsec forneceu apenas os agrupamentos 4 e 6 com geometria aplicável em projeto, devido à sua suavidade. Também é possível notar instabilidades na curva de $C p$ para os agrupamentos 2, 5, 7, e 8 , o que não se observa na outra parametrização. No geral a parametrização por ponto de controle tem geometrias mais apropriadas para aplicação aeronáutica.

Das Figuras (A.32) e (A.43), notam-se as diferenças entre as PFs encontradas. Os gráficos de histograma mostram que a parametrização por pontos de controle explorou melhor a $P F$ 
(a)

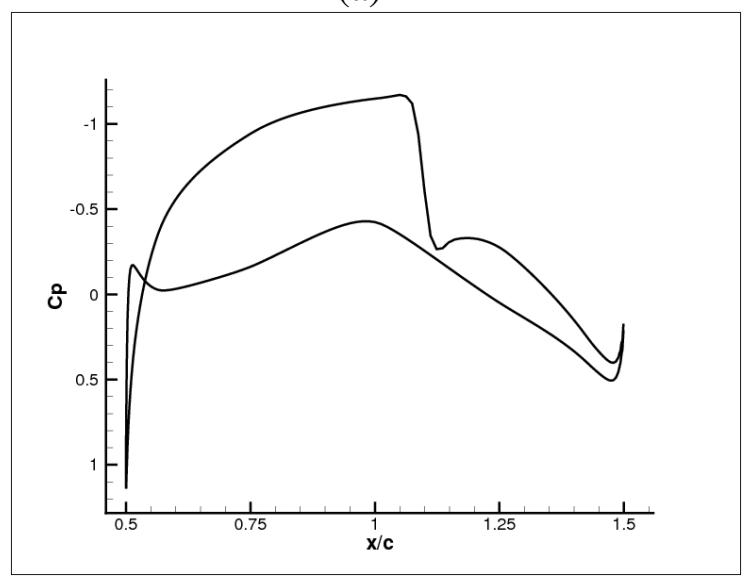

(b)

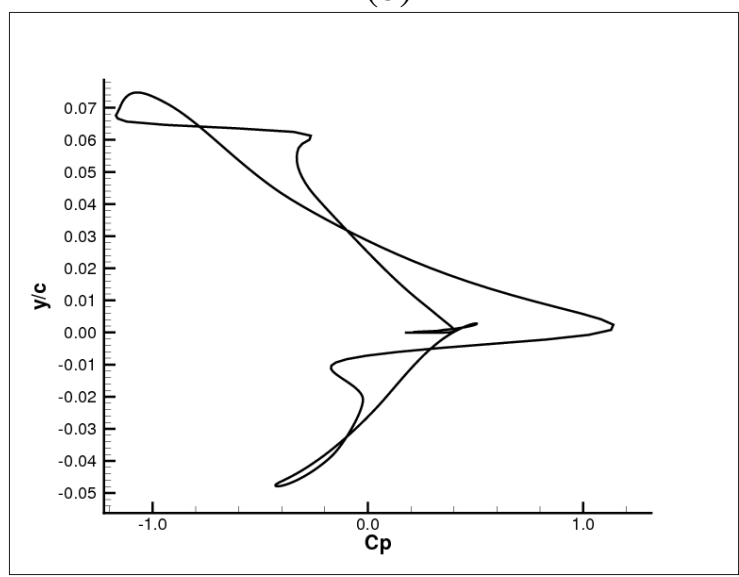

Figura 6.13: Curvas de $C p$ do agrupamento 7 para a otimização usando método centrado e parametrização por ponto de controle.
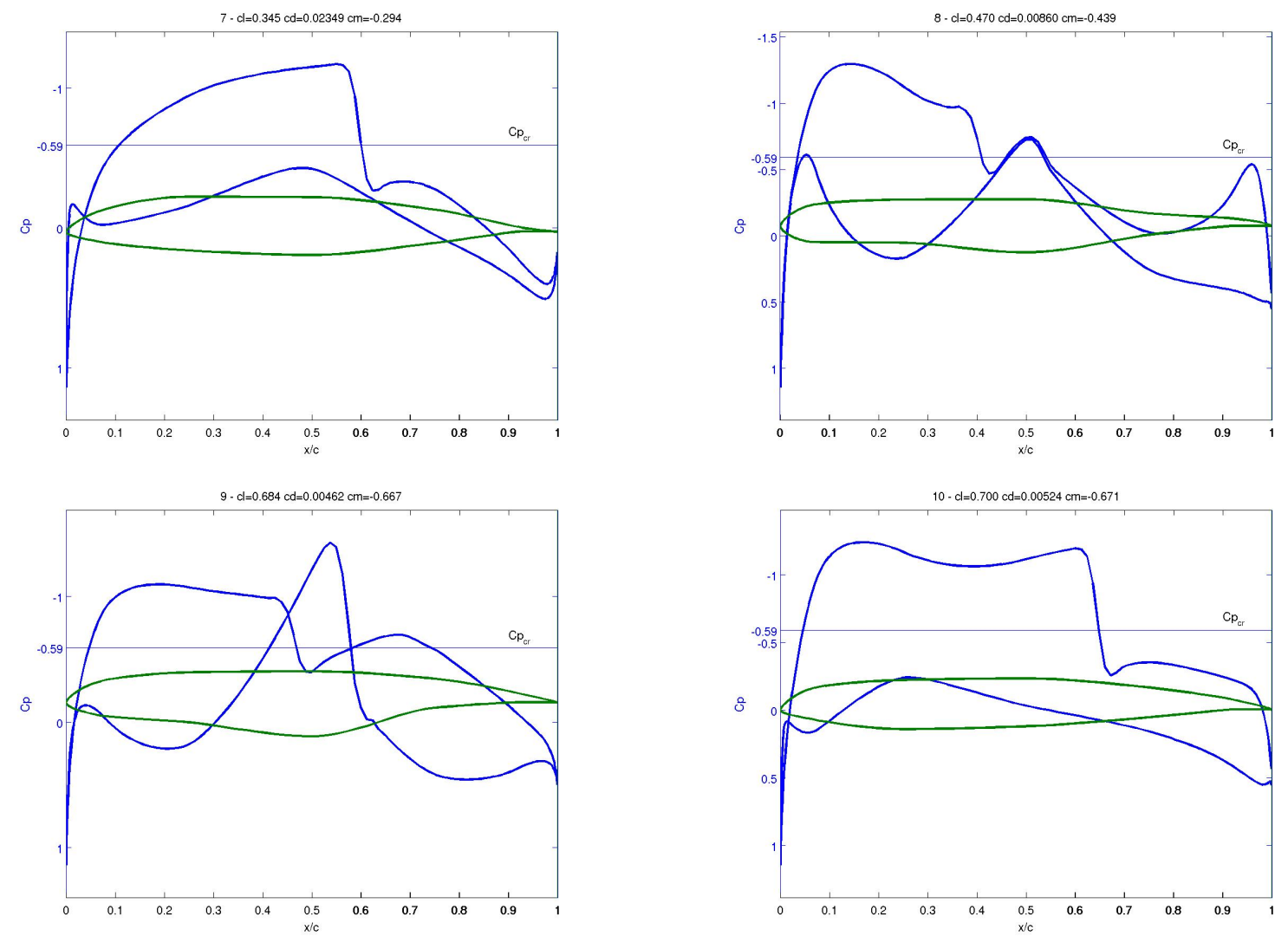

Figura 6.14: Distribuição de Cp para os elementos centróides do agrupamento, para a otimização usando método centrado e parametrização por ponto de controle.

, confirmando os resultados apresentados pelas métricas de diversidade. A parametrização Parsec apresenta uma relação $\mathrm{Cl}$ - $\mathrm{Cm}$ mais dispersa, porém mantendo uma tendência de redução da intensidade do momento com a redução da sustentação. O mesmo se observa com a outra parametrização, embora, essa relação seja bem menos dispersa. Os valores de $C l$ altos são priorizados no 

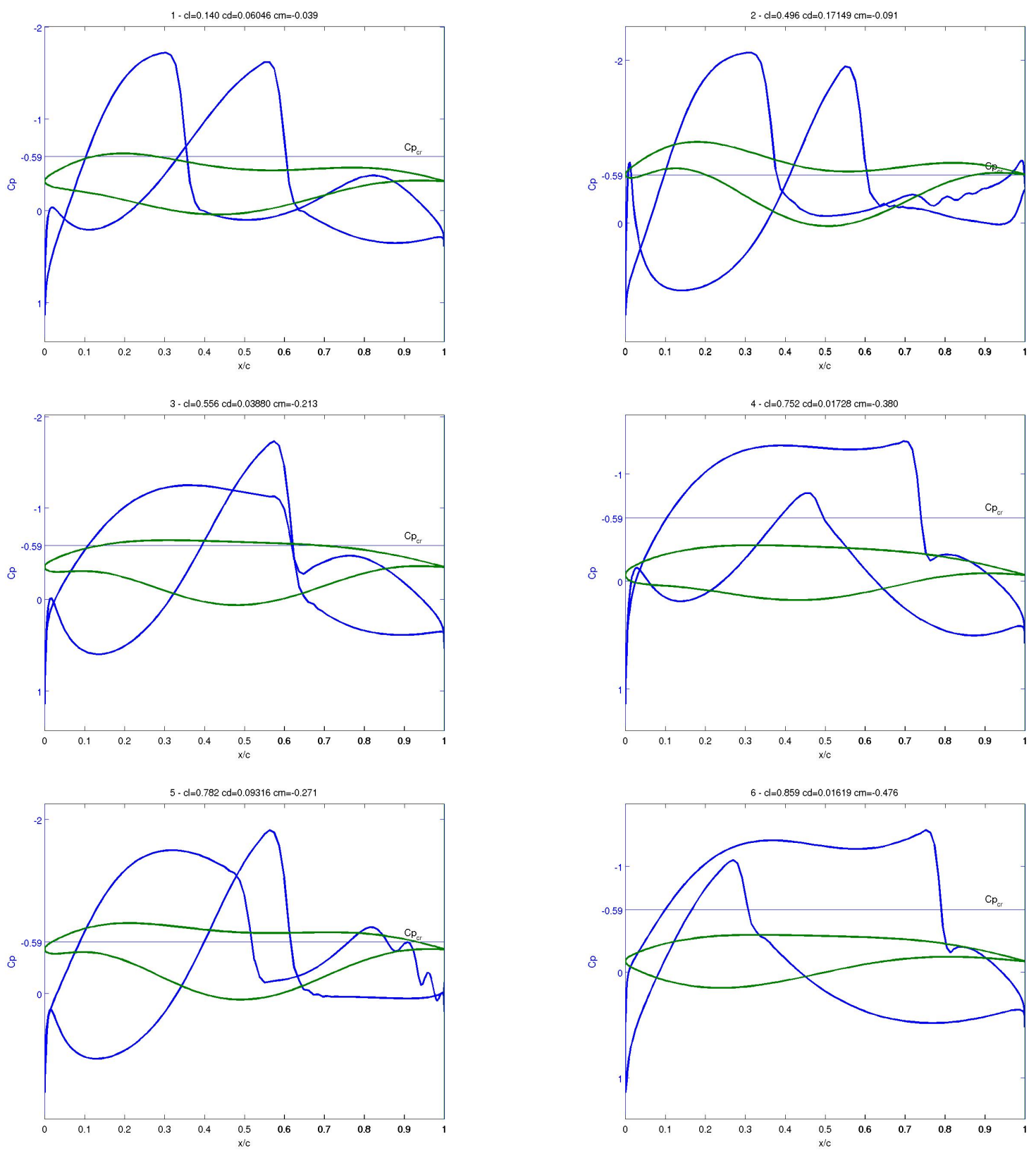

Figura 6.15: Distribuição de Cp para os elementos centróides do agrupamento, para a otimização usando método centrado e parametrização Parsec.

caso Parsec, no qual os valores de $C d$ são maiores também. Por outro lado, a parametrização por ponto de controle priorizou os valores mais baixos de $C l$, assim como de $C d$.

Na parametrização Parsec, observa-se que a região de ótimo para o $\frac{L}{D}$ é muito acentuada, caracterizada por uma estreita faixa de $C l$, o que não é desejado. A parametrização por ponto de controle apresenta uma faixa de valores de $C l$ mais larga e os valores maiores de eficiência aerodinâmica.

A relação entre $C d-C m$ mostra que os perfis derivados da parametrização por pontos de controle encontraram uma $P F$ mais avançada que o caso Parsec, mas com uma região de momento de arfagem mais intenso. 
Na Figura A.33, nota-se que a parametrização por pontos de controle tem relações dispersas entre as características geométricas e os coeficientes aerodinâmicos. Nota-se uma maior concentração do raio de bordo de ataque próximo ao valor $4 \cdot 10^{-3}$. A posição do camber tem 3 agrupamentos levemente dispersos. Na Figura (A.44), para a parametrização Parsec, notam-se padrões de relação entre as características geométricas e os parâmetros aerodinâmicos. Os valores para o raio de bordo de ataque são mais bem explorados e são maiores do que os valores encontrados na outra parametrização. A posição do camber tem 2 agrupamentos bem definidos: um à frente do perfil e outro bem atrás, sendo este priorizado pela otimização. Pode-se observar o aumento do arrasto com o aumento da espessura e do camber, além de uma tendência ao aumento do $\mathrm{Cl}$ com o camber, mas pouco acentuada, ao contrário do aumento do $\mathrm{Cl}$ com a espessura. Os valores para o volume interno do perfil para o caso Parsec foram maiores em comparação ao outro caso.

\subsubsection{Comparação entre esquema centrado e upwind}

O objetivo desta seção é comparar as otimizações efetuadas com o método centrado e upwind, lembrando que o método de Roe, em média $40 \%$ mais caro por iteração que o método de Jameson, tem por vantagem a melhor resolução na região da onda de choque. Portanto, é importante saber se a utilização desse método apresenta alguma vantagem significativa na otimização que compense seu maior custo.

Pode-se ver nas Figuras (A.34 e e $A .45$ que os dois métodos apresentam curvas de evolução da factibilidade equivalentes e com razoável robustez. Nas Figuras (A.35), (A.46), A.36) e (A.47), observa-se que os dois métodos evoluíram para valores próximos a 0,06 para a métrica Spacing e 0,04 para a métrica ARAI. Nota-se que o método upwind é sensível ao restart (descrito no capitulo 4), melhorando a diversidade. Para as duas métricas, a robustez foi melhor para o método centrado.

Das métricas de otimalidade (ver Figuras A.37 A.40 A.48 A.51) observa-se que os dois métodos se aproximaram da $P F_{r e f}$, mas não avançaram muito no nível de dominância, mantendo a métrica InvER com valores baixos e a métrica GER próximo de zero. Vale notar que a sensibilidade ao restart do método Roe ajudou a melhorar a otimalidade da população. A robustez para as diferentes métricas foi satisfatória, porém notam-se, em todas elas, instabilidades que aparecem como picos nas curvas de evolução das métricas.

Observando as Figuras (A.41), A.42, A.52) e (A.53), nota-se que os agrupamentos encontrados (ver seção 6.2.2) são bem parecidos, assim como os padrões dos cromossomos encontrados. O método de Jameson apresentou valores de $C l$ maiores se comparado com o método upwind. Para todos os agrupamentos, a maioria das geometrias não são aplicáveis por apresentarem pouca suavidade na distribuição de camber e espessura. Os grupos 4 e 6 para o método centrado e 5 e 8 para o método upwind visualmente apresentam geometrias mais viáveis. Os agrupamentos 2, 3, 4 e 8 no caso centrado e os agrupamentos 3, 4, 5, 6, 7, 9 e 10 para o método upwind apresentam forte relação linear entre os genes $Y_{x x l o}-\alpha_{t e}$ e $\alpha_{t e}-\beta_{t e}$. 

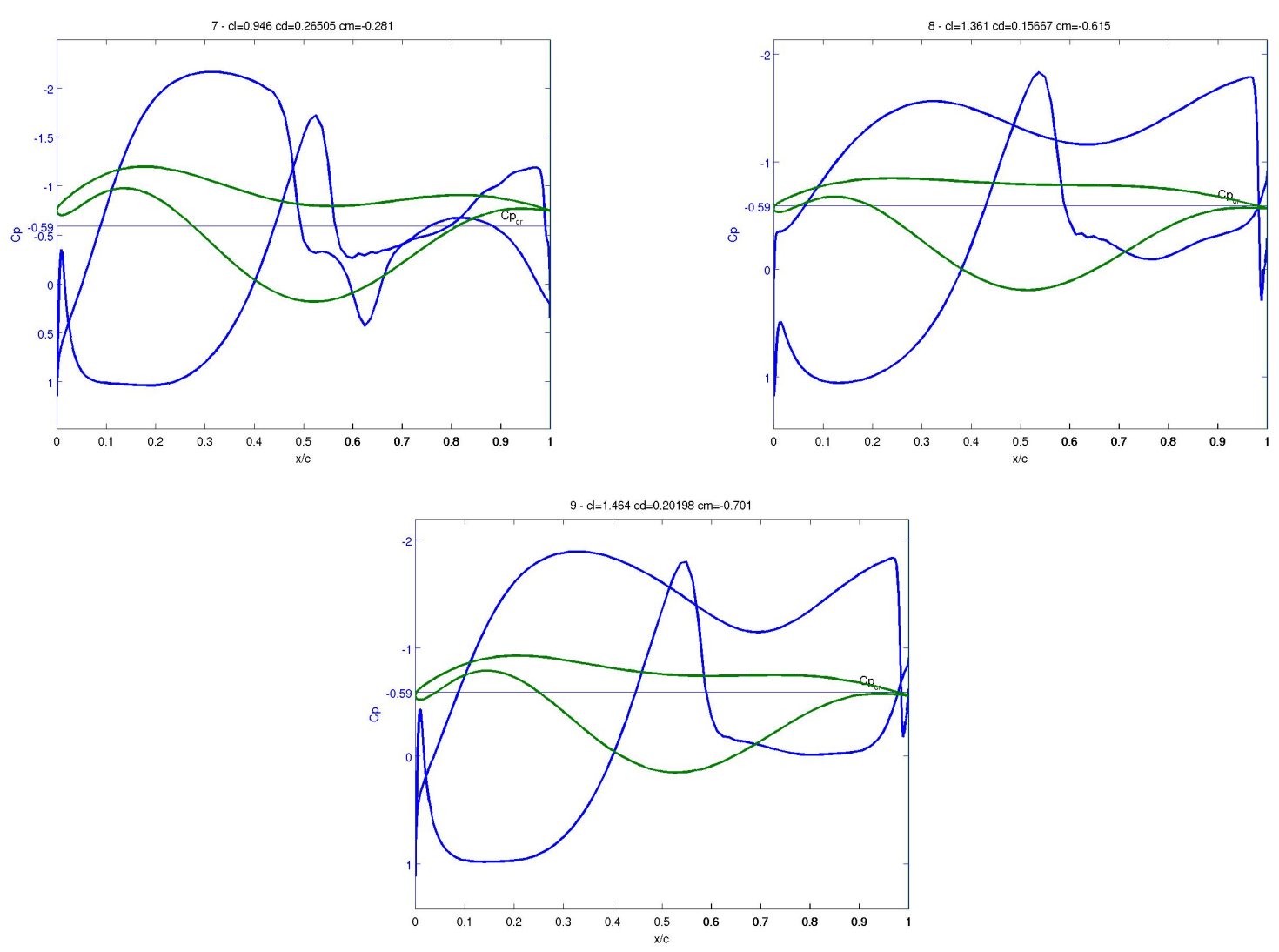

Figura 6.16: Distribuição de Cp para os elementos centróides do agrupamento, para a otimização usando método centrado e parametrização Parsec.

Comparando as Figuras 6.17) e 6.18) com as Figuras 6.15) e 6.16, nota-se que a as geometrias anômalas estão presentes nos dois casos, assim como as instabilidades numéricas, embora, elas sejam menos frequentes na aplicação do método de Roe. Os "abaulados"presentes nos grupos 2, 3, 5, 7, 8 e 9 no método centrado também aparecem nos grupos 2, 3, 4, 6, 7, 9 e 10 no método upwind. Os grupos mais aplicáveis ( 5 e 8 para o método de Roe e 4 e 6 para o método centrado) não se diferenciam muito.

As Figuras (A.43, A.44, A.54 e A.55) apresentam grande semelhança nas PFs encontradas pelos dois métodos, assim como as mesmas relações entre os coeficientes aerodinâmicos com as características geométricas dos perfis. Nota-se que o método centrado explorou melhor a $P F$ se comparado com o método de Roe, pois este apresenta uma região não explorada da frente, visível na relação entre $C d$ e $C m$. 

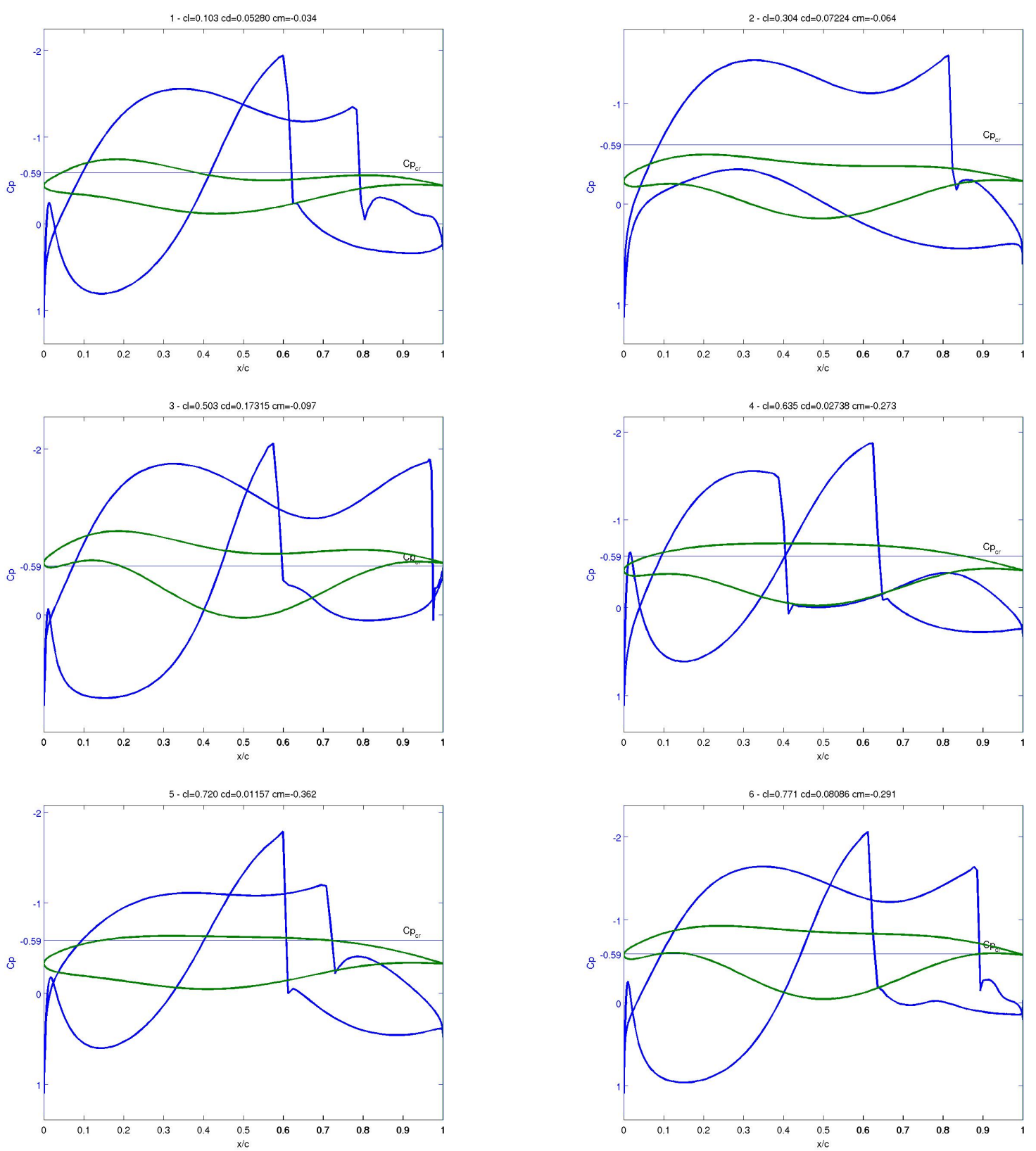

Figura 6.17: Distribuição de $C p$ para os elementos centróides do agrupamento, para a otimização usando método upwind e parametrização Parsec. 

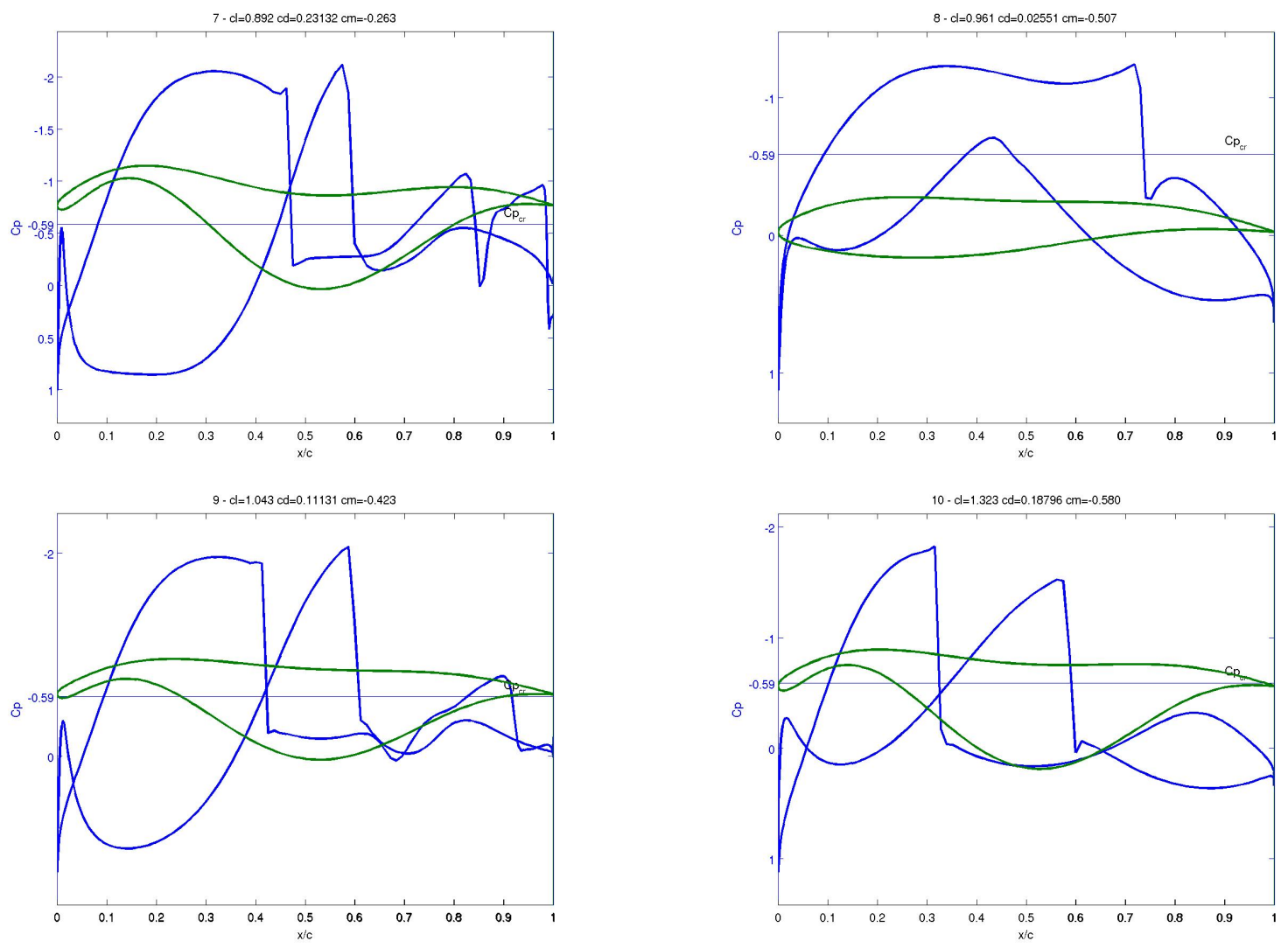

Figura 6.18: Distribuição de Cp para os elementos centróides do agrupamento, para a otimização usando método upwind e parametrização Parsec. 

No presente trabalho, foi estudado o problema de otimização aerodinâmica multiobjetivo para perfis transônicos, com restrições geométricas e de estabilidade da solução numérica, utilizando diferentes parametrizações da geometria e técnicas de simulação numérica. A otimização dos parâmetros aerodinâmicos foi efetuada utilizando o algoritmo genético NSGA-II. As funções objetivo foram definidas utilizando duas definições para a geometria: parametrização Parsec e por pontos de controle. Além disso, quatro métodos de simulação numérica para escoamentos compressíveis foram utilizados: método de Jameson, método de Roe e o código Mses no modo viscoso e invíscido. Utilizou-se malha estruturada para a discretização da geometria e sua geração foi feita utilizando um método de suavização por equação diferencial parcial elíptica com controle de aglomeração de pontos. Os métodos de Jameson (centrado) e de Roe (upwind) foram usados para os casos invíscidos e o código Mses para o estudo da influência da viscosidade na otimização.

Os códigos implementados no trabalho foram verificados e validados. Os de CFD foram validados utilizando resultados experimentais dos aerofólios Naca 0012 e Rae 2822 em regimes subsônicos e transônicos. A validação mostrou que os métodos são capazes de prever relativamente bem a distribuição de pressão em torno dos aerofólios. Também foi feito o teste de convergência de malha desses métodos para reduzir o custo computacional sem grandes perdas de qualidade das soluções. O algoritmo genético foi verificado utilizando problemas conhecidos (benchmark). Para todos os problemas testados, o AG se mostrou capaz de encontrar a frente de Pareto $(P F)$ do problema.

Foram efetuadas 5 otimizações com o objetivo de analisar comparativamente o comportamento do AG nos seguintes casos: (a) diferença entre o modelo viscoso e invíscido; (b) diferença entre as 
parametrizações; e (c) diferença entre o uso do método centrado e upwind. Todas as otimizações foram analisadas utilizando métricas de avaliação para problemas multiobjetivo. Para avaliar a otimalidade das soluções, foi proposta uma métrica que utiliza soluções pré-existentes, aproximadas ou exatas. As frentes de Pareto obtidas pelas otimizações foram analisadas utilizando a técnica k-means de análise de agrupamento e as técnicas de visualização de dados: matriz de gráficos de dispersão e gráficos de coordenadas paralelas. Para as geometrias centróides dos agrupamentos, foram analisadas as curvas de distribuição do coeficiente de pressão ao longo da superfície.

A otimização multiobjetivo fornece um conjunto de soluções pertencentes à frente de Pareto do problema. Como essas soluções são aceitas como representação aproximada dessa frente, é interessante que as soluções formem uma população bem diversificada, evitando aglomerados de soluções e melhorando a representação da $P F$. As métricas utilizadas para analisar a diversidade das PF obtidas mostram que, em todos os casos estudados, se encontraram soluções bem distribuídas na frente de Pareto. O modelo viscoso obteve valores levemente melhores para a ARAI; a parametrização por ponto de controle se mostrou melhor que a parametrização Parsec e os resultados obtidos mostram que entre a utilização do método de Jameson e de Roe não há diferença significativa.

A observação das métricas de otimalidade para os casos estudados mostram que o modelo viscoso avançou mais na otimalidade se comparado com o modelo invíscido. Na comparação entre as parametrizações, a Parsec foi melhor que a utilização dos pontos de controle, mas nos dois casos as soluções encontradas avançaram pouco além da $P F$ de referência. Para os solvers (Jameson e Roe), as otimizações chegaram na $P F_{\text {ref }}$ mas não avançaram.

A observação das geometrias mostra que o modelo invíscido resultou em geometrias mais suaves que o modelo viscoso. Porém, para ambos os casos apareceram abaulados no intradorso, causando um pico de sucção e, em alguns casos, uma onda de choque na superfície inferior do aerofólio. Essa característica é responsável por reduzir a área entre as curvas de $C p$ das superfícies superior e inferior, diminuindo o valor do $C l$, visto que para grupos de maior sustentação as geometrias não apresentam abaulados.

Os gráficos de coordenadas paralelas mostram que os valores de cromossomos encontrados pelos dois modelos, em geral, diferem entre si, salvo para alguns grupos onde a diferença se concentra em alguns genes. Os gráficos de histograma para os coeficientes aerodinâmicos mostram que o modo invíscido é melhor que o modo viscoso para encontrar soluções mais bem distribuídas, com regiões pontuais de maior agrupamento. Os altíssimos valores para a eficiência aerodinâmica observados no caso invíscido põem em questão a confiabilidade dos resultados, pois esses valores, apesar das geometrias suaves, estão fora de uma representabilidade física.

A relação entre os coeficientes aerodinâmicos e os parâmetros geométricos dos perfis não são similares para os dois modelos, apresentando padrões bem distintos para alguns parâmetros, enquanto para outros não se observam relações.

As geometrias obtidas pela parametrização Parsec apresentam pouca suavidade e, conseqüentemente, as curvas de $C p$ também. A parametrização por pontos de controle apresenta suavidade 
muito melhor das geometrias, porém com a tendência de abaulados no intradorso. Para os dois casos, as geometrias têm a tendência de formar um leve pico de sucção próximo ao bordo de ataque no intradorso e se observa um leve drop. Esses resultados estão em concordância com os resultados para a otimização de objetivo simples e os resultados obtidos por Nemec et al. (2002) e Oyama et al. (2000b). Em todos os agrupamentos são observadas regiões de escoamento supersônico e, como não foi imposta nenhuma restrição para a velocidade do escoamento ao redor do perfil, têmse algumas ondas de choque intensos. Os histogramas mostram que a parametrização por pontos de controle exploram melhor a $P F$. Também foi observado que para valores mais altos de $\frac{L}{D}$ a faixa de $C l$ é mais larga que na parametrização Parsec. A $P F$ para a parametrização por ponto de controle é mais avançada que a $P F$ obtida pela outra. Em geral, as relações entre parâmetros geométricos e coeficientes aerodinâmicos são mais dispersos para a parametrização por ponto de controle.

A comparação entre o método centrado e o método upwind mostra não haver diferença significativa entre as duas técnicas. Os mesmos padrões são observados nos agrupamentos, nos cromossomos, na visualização da $P F$ e na relação entre coeficientes aerodinâmicos e parâmetros geométricos. Isso significa que o AG não apresentou sensibilidade à utilização entre as duas técnicas. Como o método centrado é mais barato, ele se torna mais adequado para a utilização.

As observações mostram que a utilização do código Mses no modo invíscido fornece resultados pouco confiáveis e o modo viscoso fornece mais geometrias com pouca suavidade (possivelmente pela interação onda de choque-camada limite), mas que avançam na otimalidade em relação à referência mais do que o modelo invíscido. A utilização da parametrização por pontos de controle fornece geometrias aplicáveis, porém ainda com pouca suavidade. A diferença entre o método centrado e upwind não é significativa, tornando o método centrado mais interessante pelo custo computacional. Os resultados invíscidos mostram que os métodos de Jameson e de Roe são melhores em comparação com o código Mses.

Conclui-se também dos resultados obtidos que a utilização da parametrização por pontos de controle é interessante. Entretanto, ainda é necessária a utilização de uma parametrização que garanta maior suavidade ou a imposição de restrições sobre a suavidade da geometria e/ou da distribuição das propriedades em torno do perfil. A utilização do modelo viscoso torna os resultados da otimização melhores do ponto de vista da otimalidade. Na utilização de modelos de correção viscosa, como no caso do Mses, é necessária a utilização de métodos invíscidos que forneçam resultados com maior representatividade física. 

Do presente trabalho, ficam problemas em aberto a serem desenvolvidos em trabalhos futuros. Inicialmente, é necessária a redução do custo computacional. Para isso, sugere-se a implementação de integração temporal implícita e técnicas de aceleração de convergência. Assim como utilizado no código Mses, a condição inicial da simulação pode ser modificada para reduzir o tempo de simulação. Também deve-se rever a geração e técnica de movimentação da malha para a redução do tempo de computação. Como observado dos resultados, torna-se necessária a utilização do modelo viscoso. Para isso uma implementação eficiênte e a avaliação de distintas técnicas devem ser feita para avaliar as vantagens e desvantagem das mesmas. Como resultado direto dos dados obtidos no estudo, pode-se criar um modelo utilizando redes neurais para simular as funções objetivas. 

APÊNDICE

\section{$A$}

\section{Gráficos de resultado das otimizações}

Quem não sabe o que é CFL não merece estar vivo.

(João Luiz F. de Azevedo)

Este apêndice contém os gráficos com os resultados obtidos pelas otimizações multiobjetivo efetuadas no presente trabalho. Os gráficos são compostos das curvas de evolução das métricas de desempenho para problemas multiobjetivo, das visualizações dos agrupamentos das geometrias obtidas na frente de Pareto, das visualizações dos cromossomos utilizando a técnica de coordenadas paralelas, as projeções das frentes de Pareto obtidas utilizando a matriz de gráficos de dispersão e com a mesma técnica são visualizadas as relações entre os coeficientes aerodinâmicos e os parâmetros geométricos dos perfis.

O apêndice está organizado da seguinte forma: na seção A.1.1 estão os resultados para a otimização utilizando a parametrização por pontos de controle e o código Mses no modo invíscido; na seção A.1.2 estão os resultados para a otimização utilizando a parametrização por pontos de controle e o código Mses no modo viscoso; na seção A.1.3 estão os resultados para a otimização utilizando a parametrização por pontos de controle e o método centrado; na seção A.2.1 estão os resultados para a otimização utilizando a parametrização Parsec e o método centrado; na seção A.2.2 estão os resultados para a otimização utilizando a parametrização Parsec e o método upwind.

\section{A.1 Parametrização por pontos de controle}

\section{A.1.1 Mses modo invíscido}



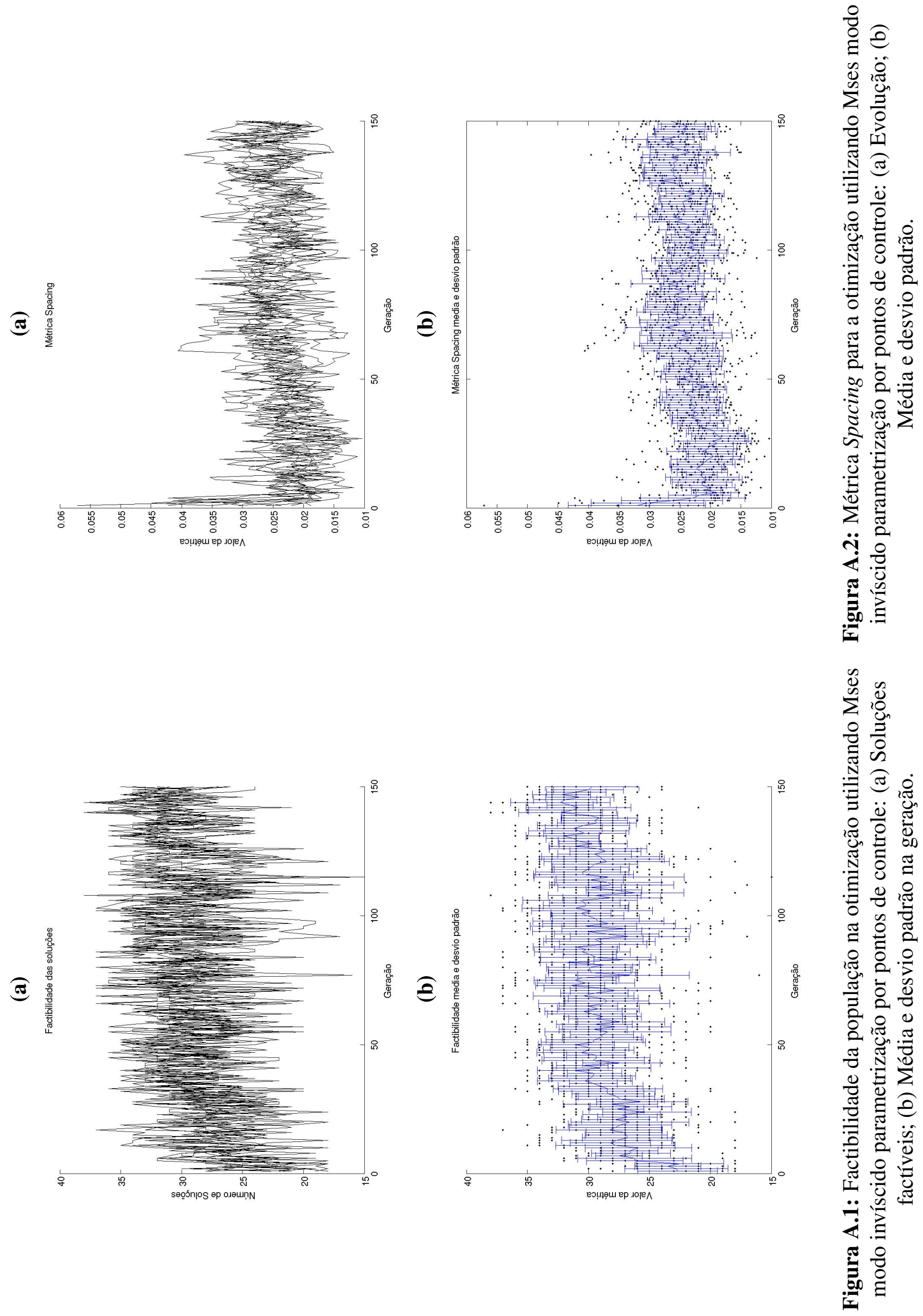

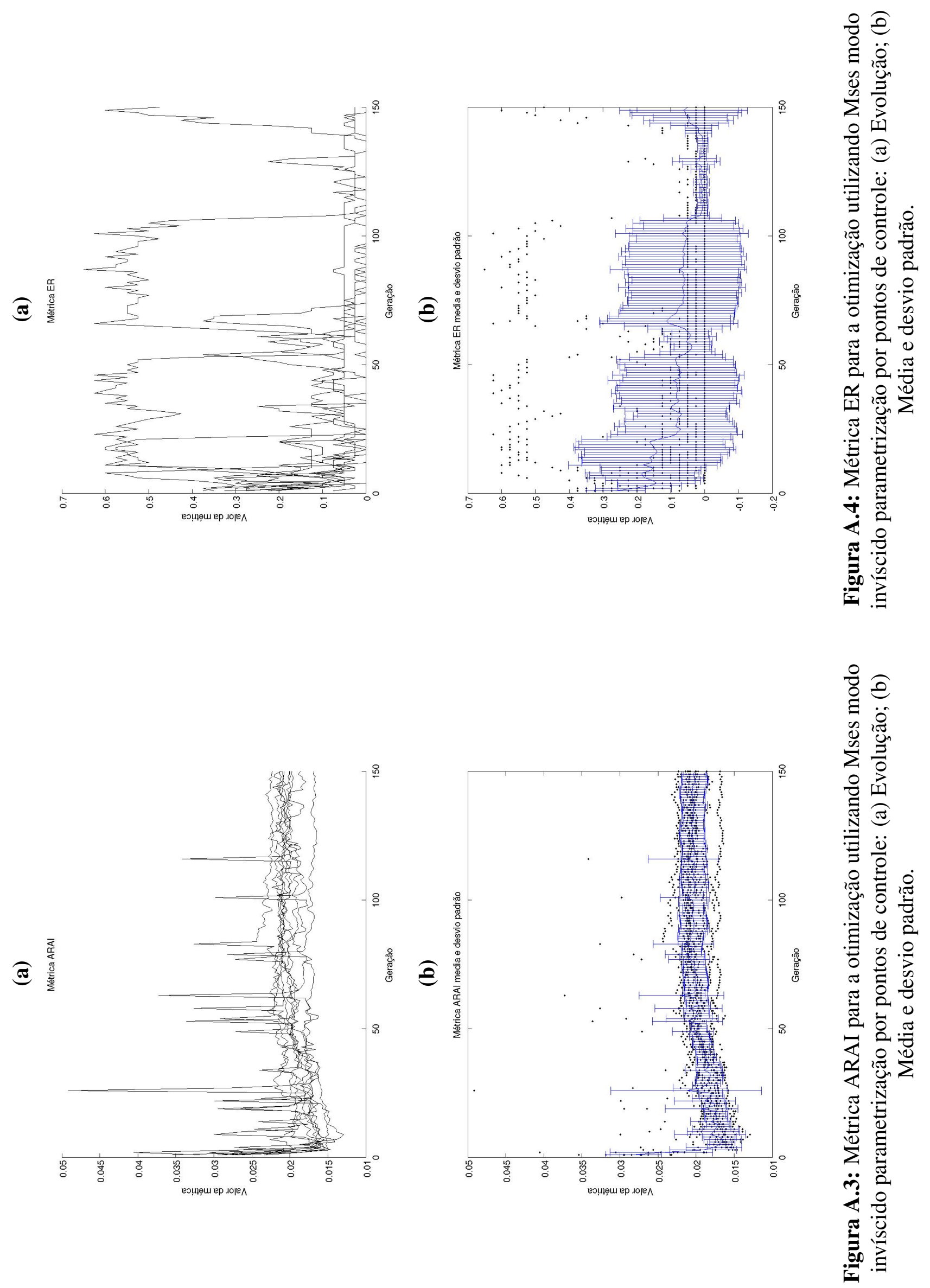

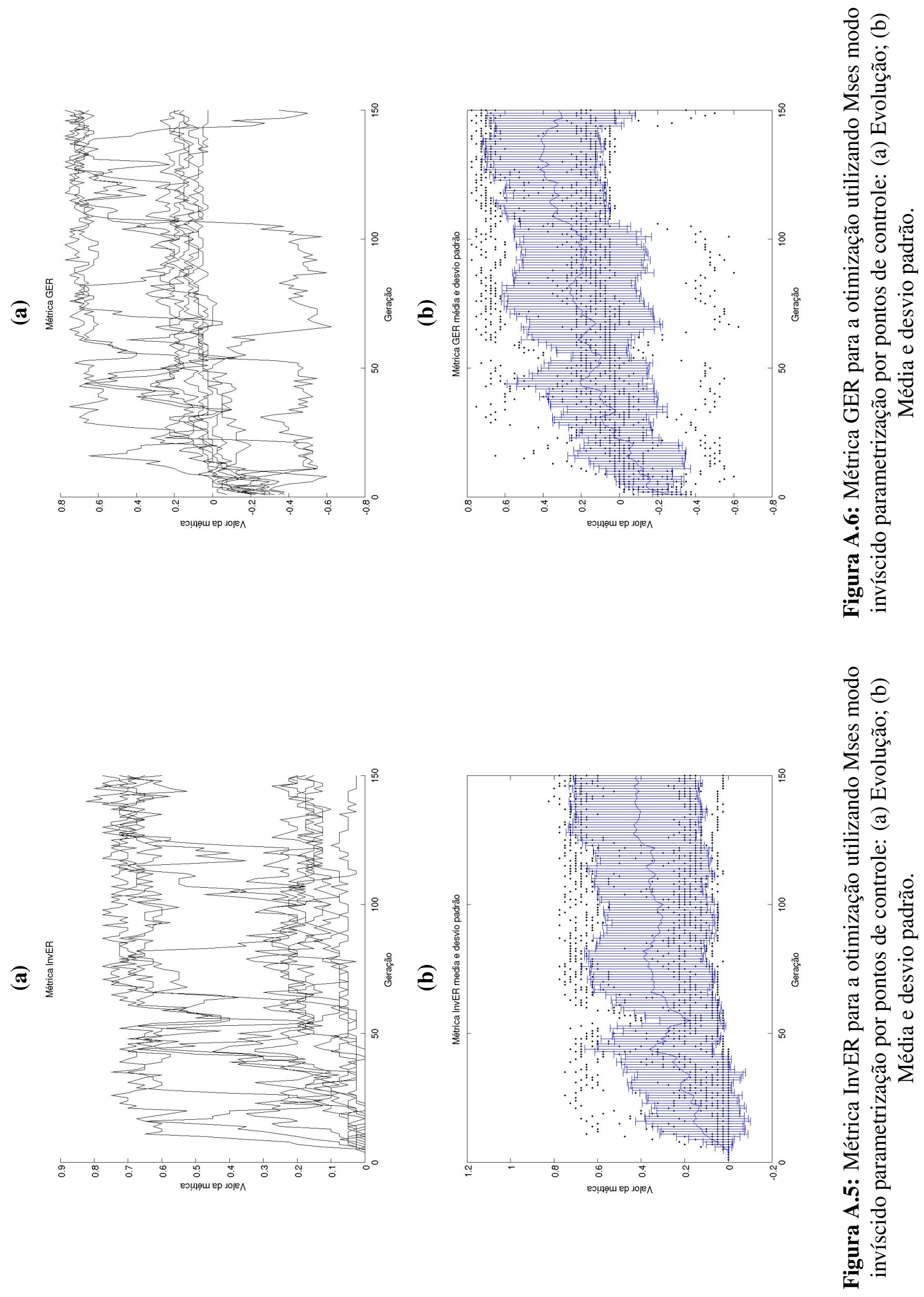
(a)

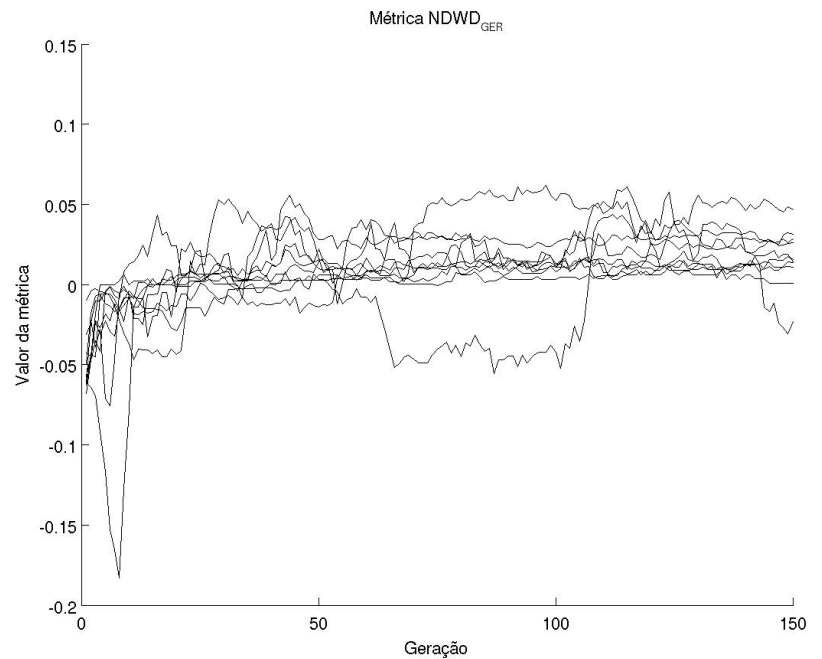

(b)

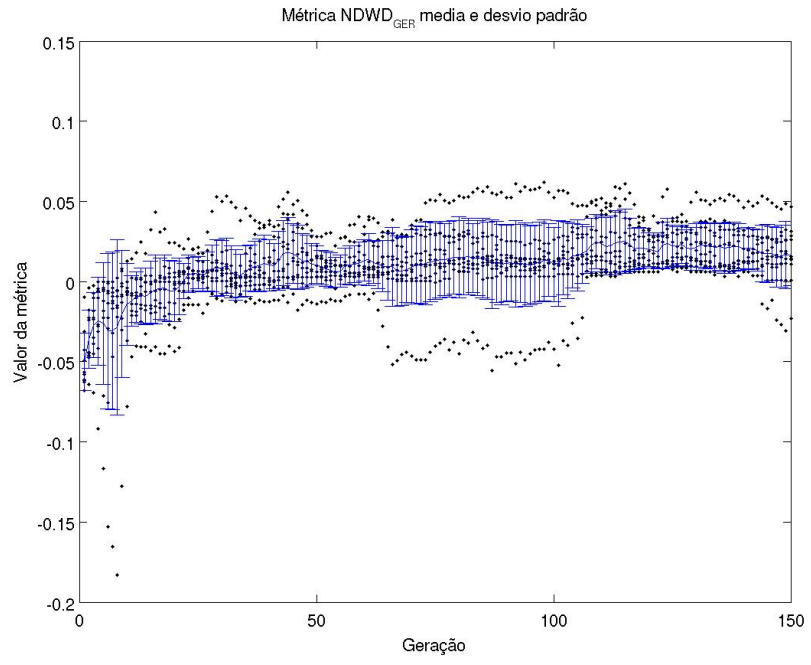

Figura A.7: Métrica $N D W D_{G E R}$ para a otimização utilizando Mses modo invíscido parametrização por pontos de controle: (a) Evolução; (b) Média e desvio padrão. 

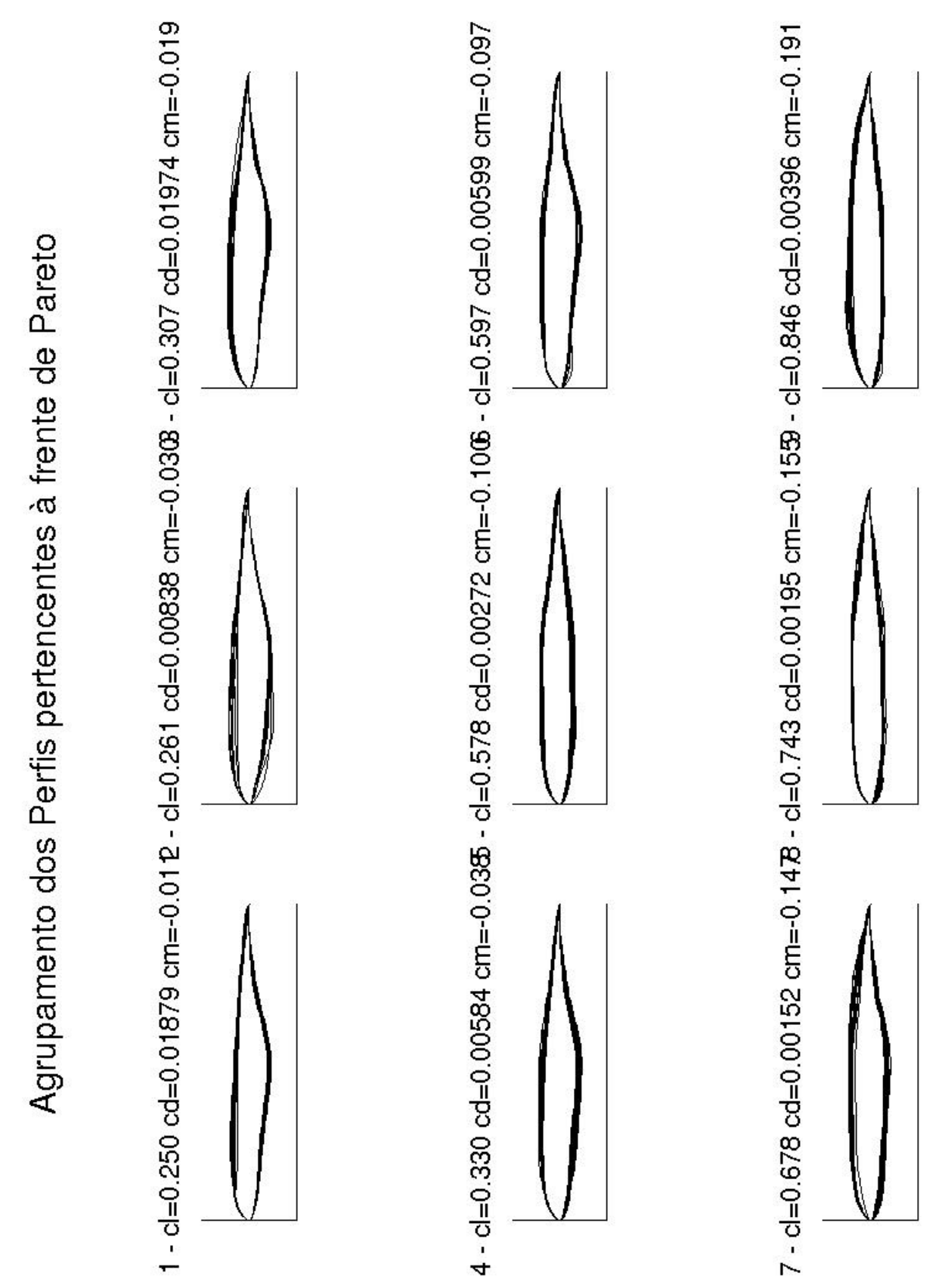

0
0
0
0
0
0

远

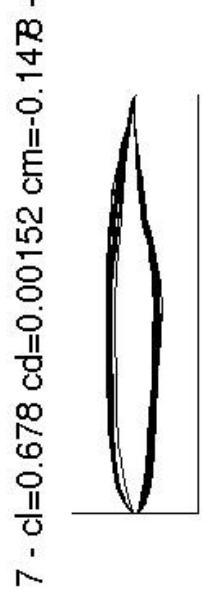

$\stackrel{\mathscr{0}}{\mathscr{0}}$

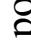

శึ

․ㅗㄹ 


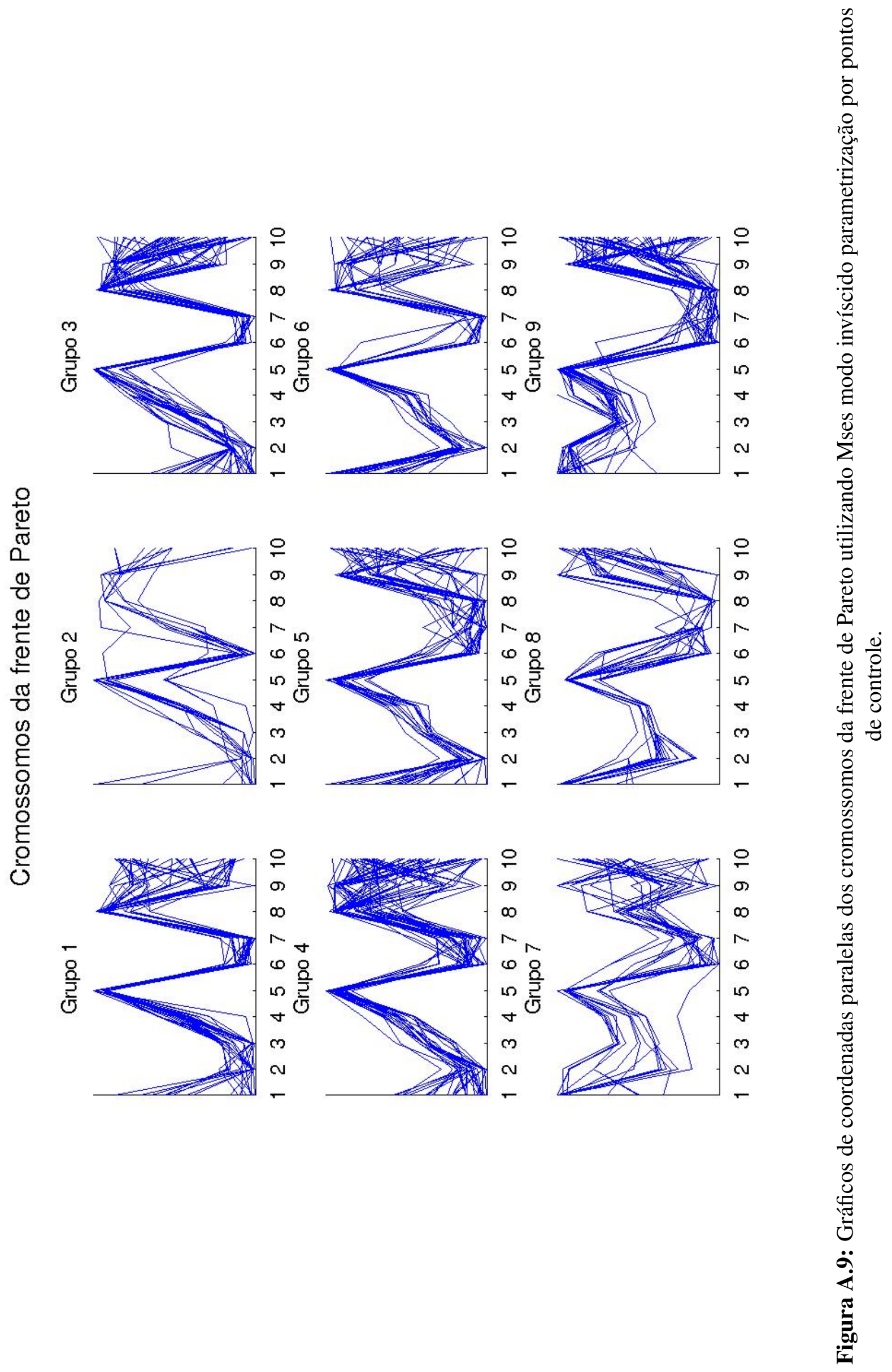



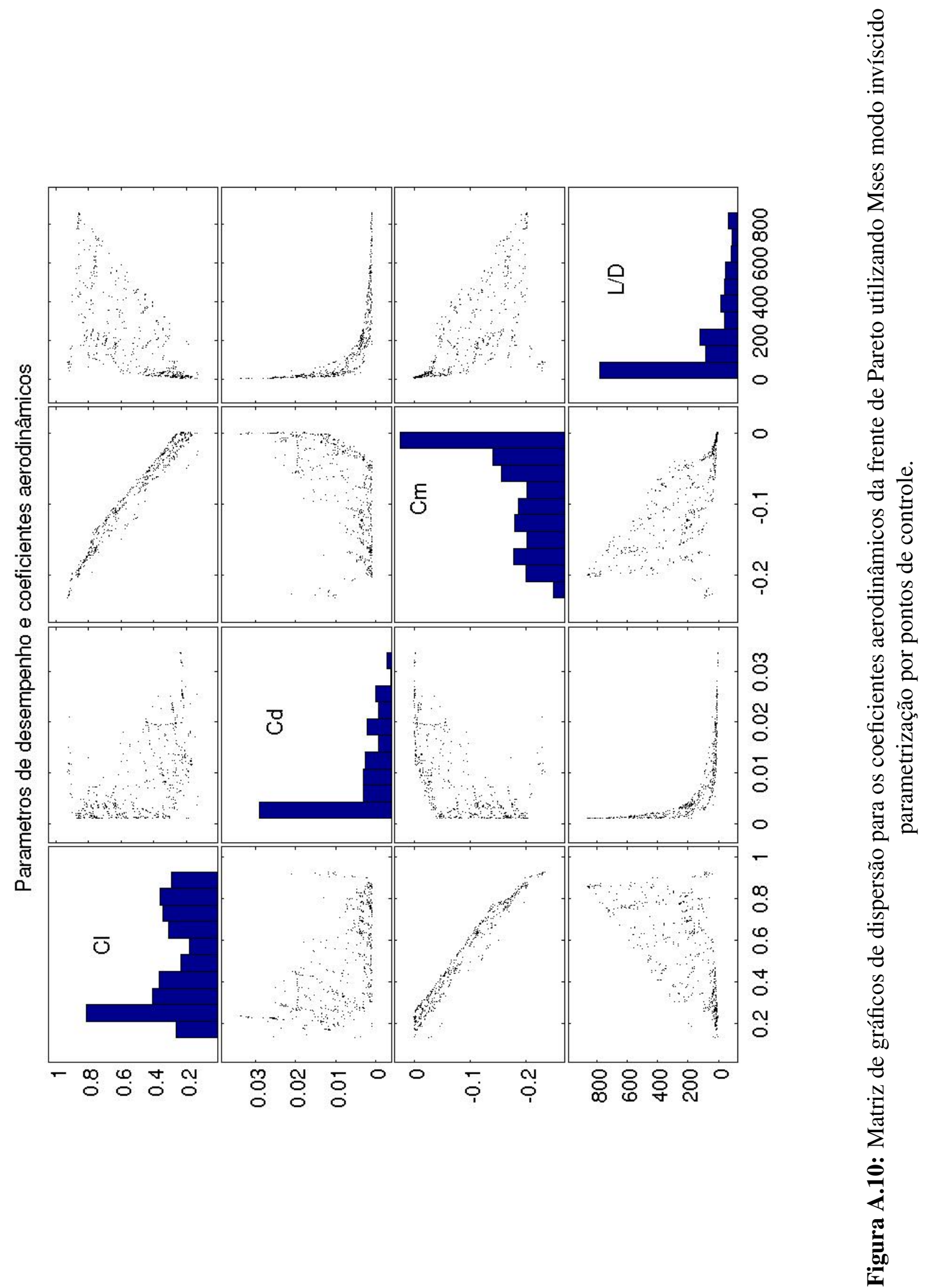


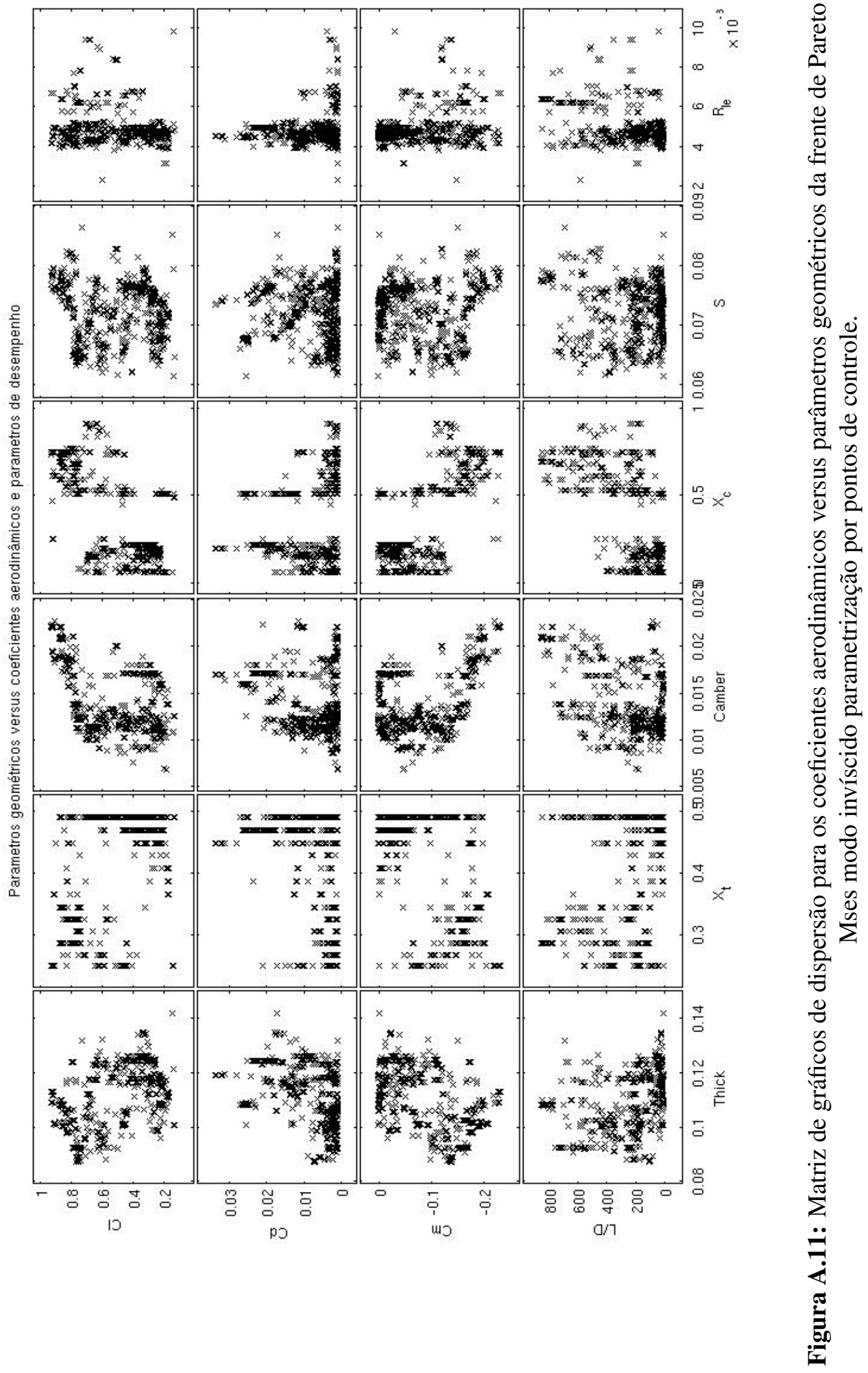




\section{A.1.2 Mses modo viscoso}

(a)

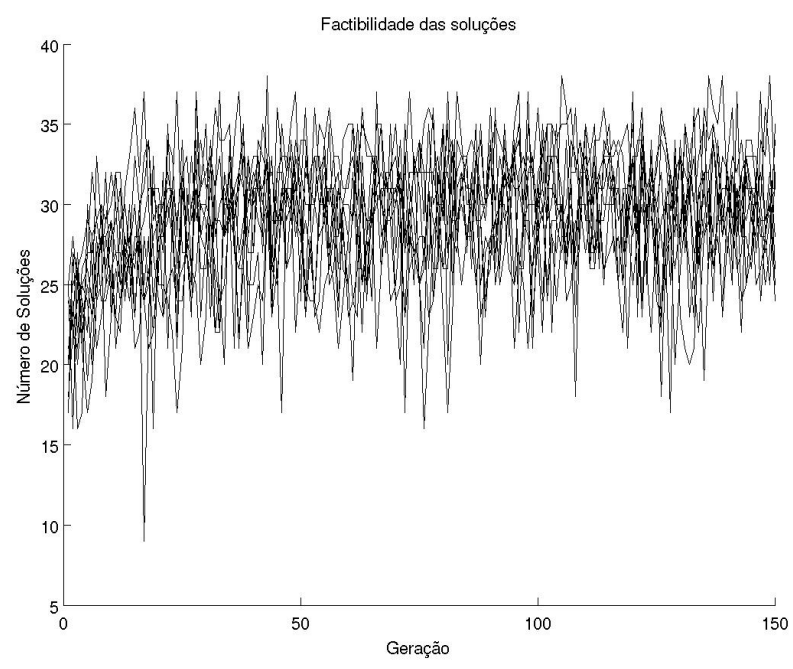

(b)

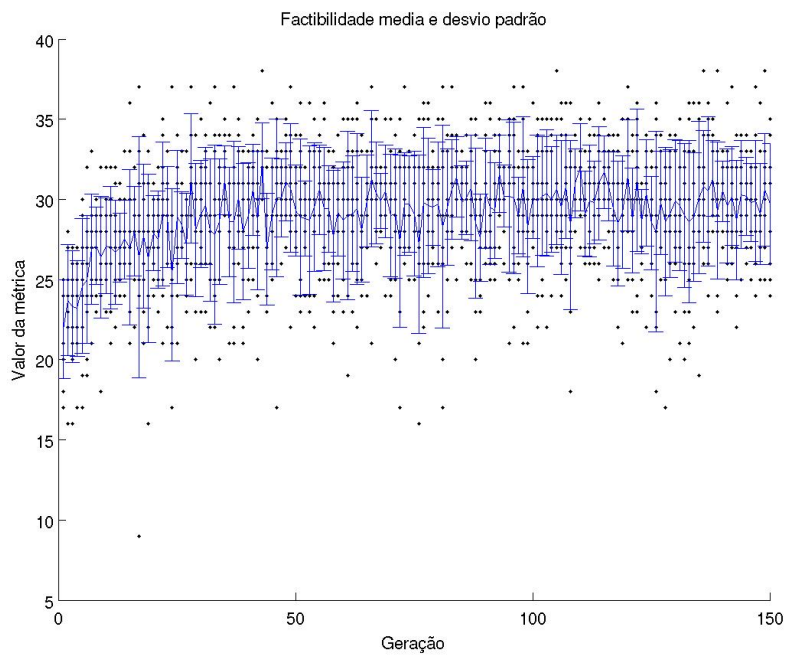

Figura A.12: Factibilidade da população na otimização utilizando Mses modo viscoso parametrização por pontos de controle: (a) Soluções factíveis; (b) Média e desvio padrão na geração. 

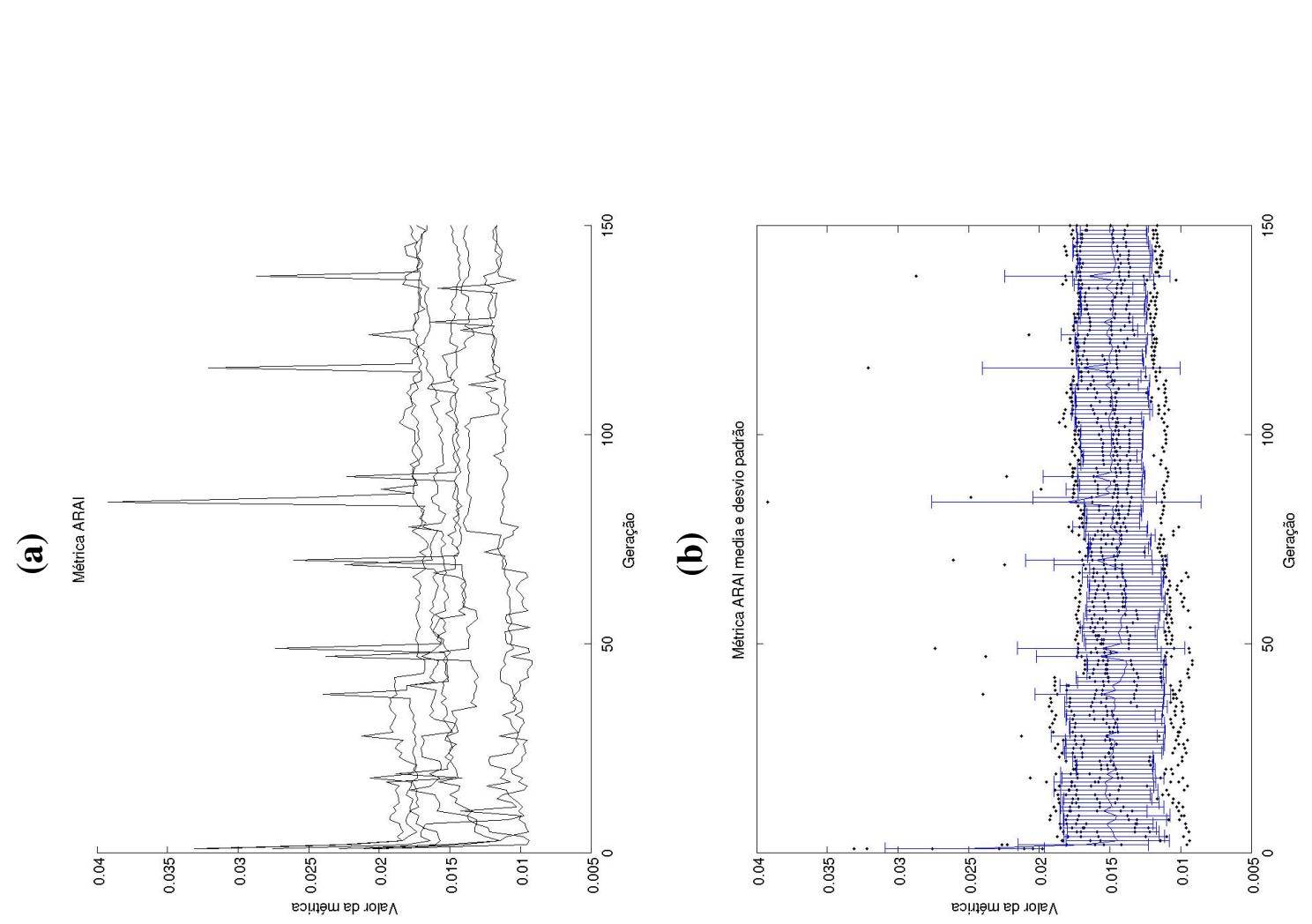

융 :

क 0

$\sum_{0}^{\infty} \ddot{0}$

총

寻

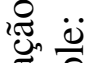

폰

当泀

这

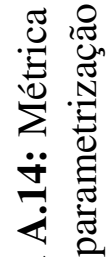

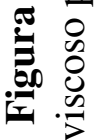

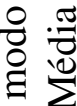

$\sum$

包
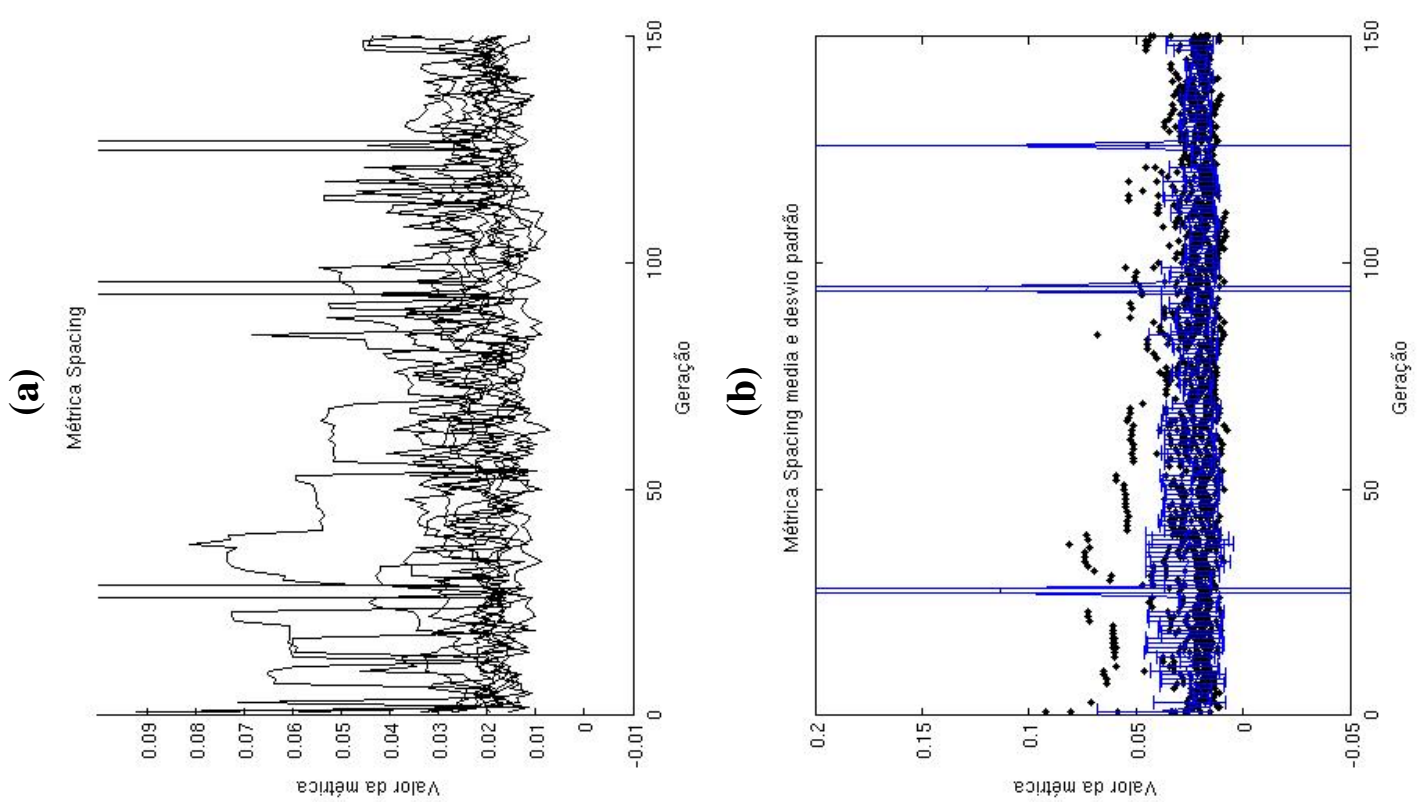

,

콜

코

త

r.

원

.

.

ช 0

줄 옹

$\stackrel{2}{2}$ 品

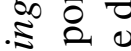

¿ั

๘

范

$\ddot{\ddot{\Xi}}$

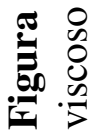



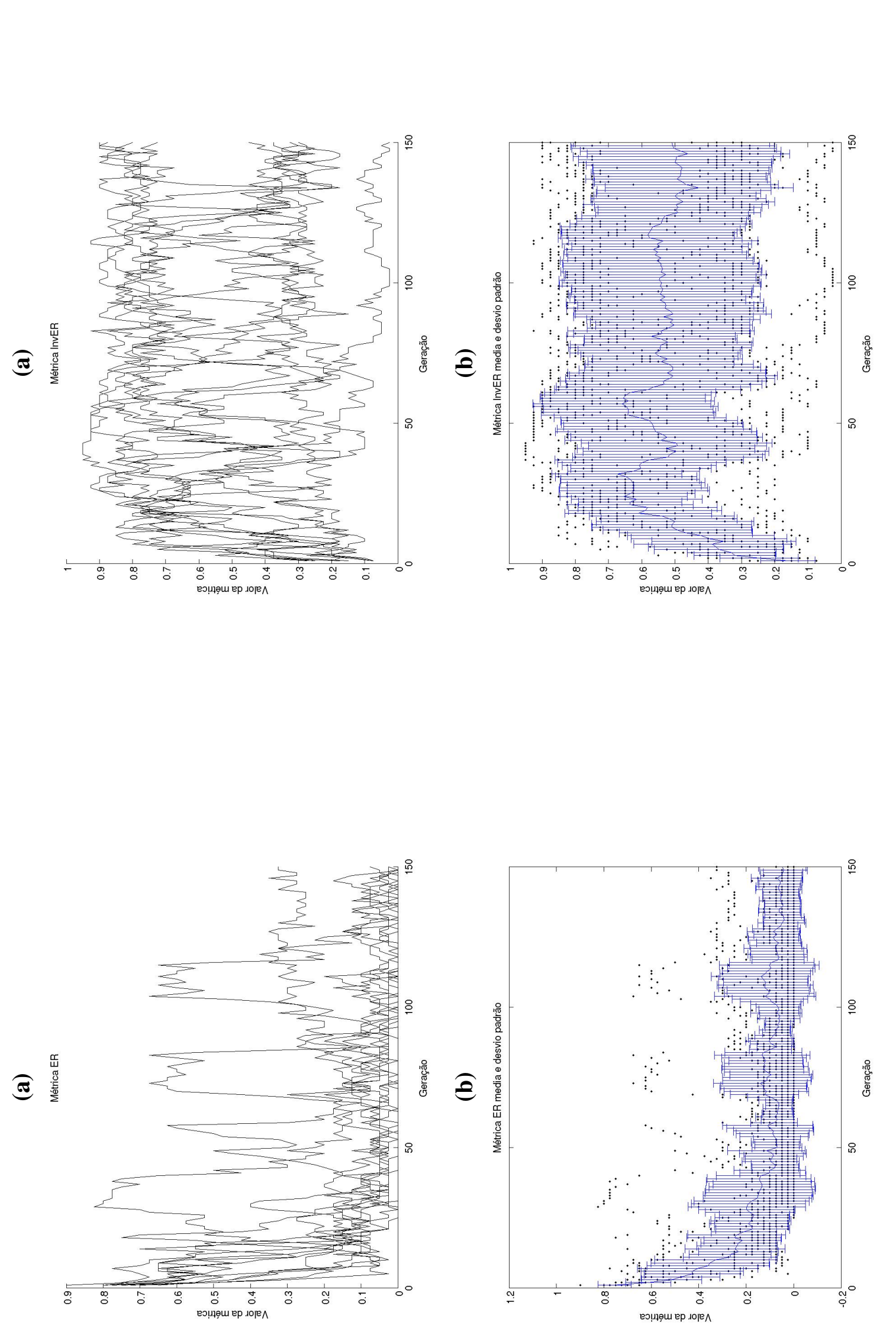

:

$\sum \ddot{\infty}$

윰

촌

త

워

త్త్ర

긍 

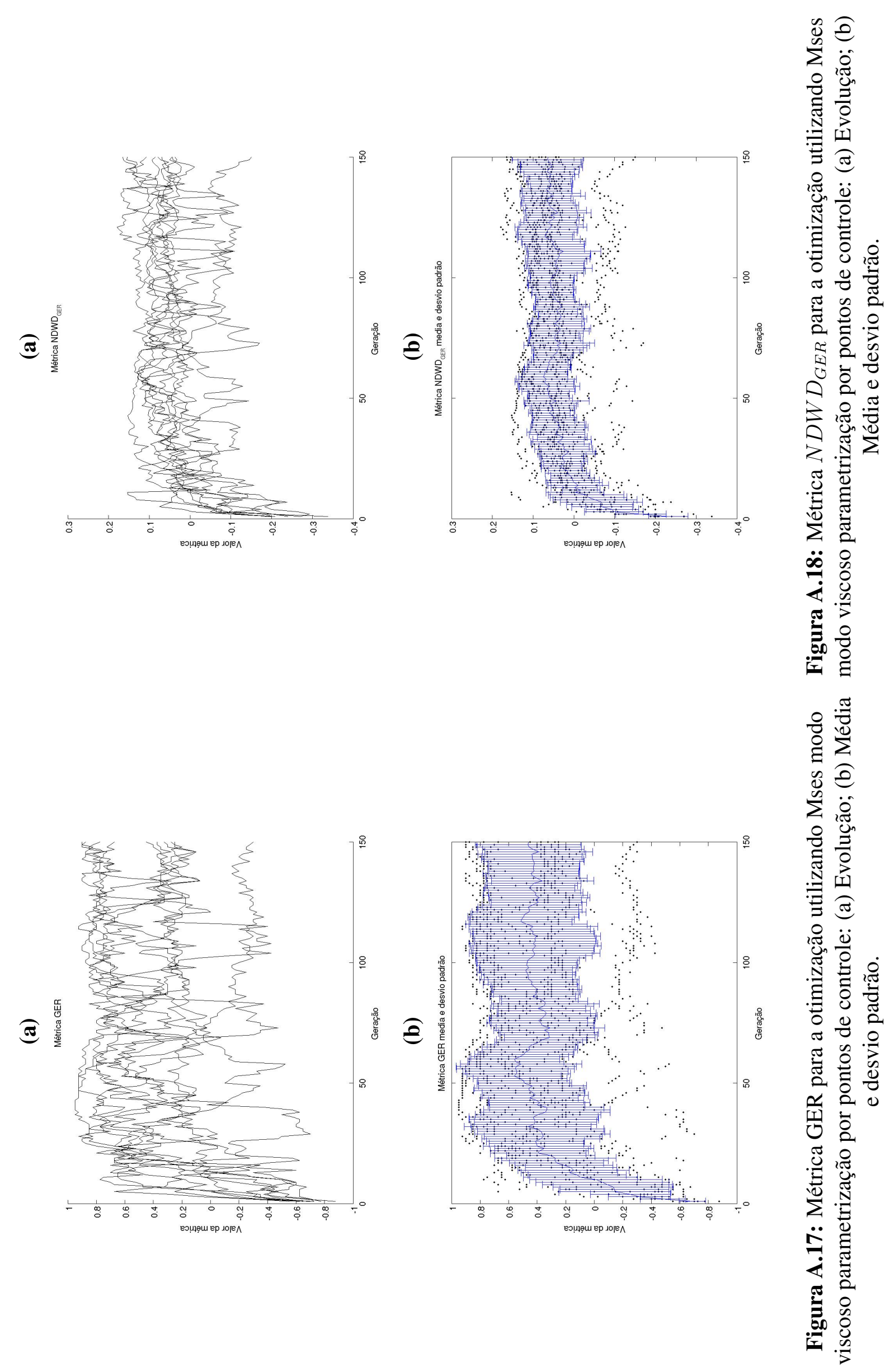

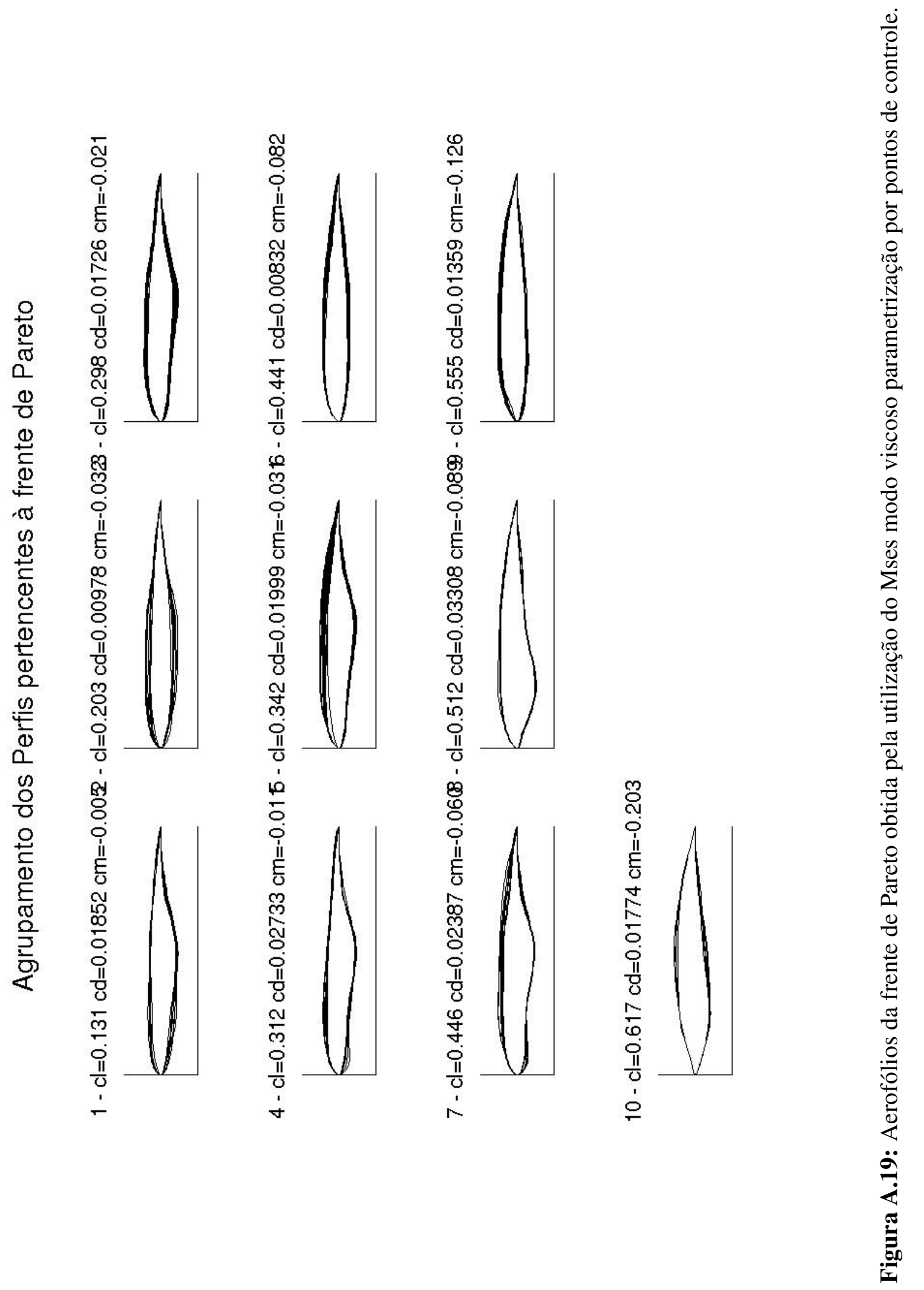

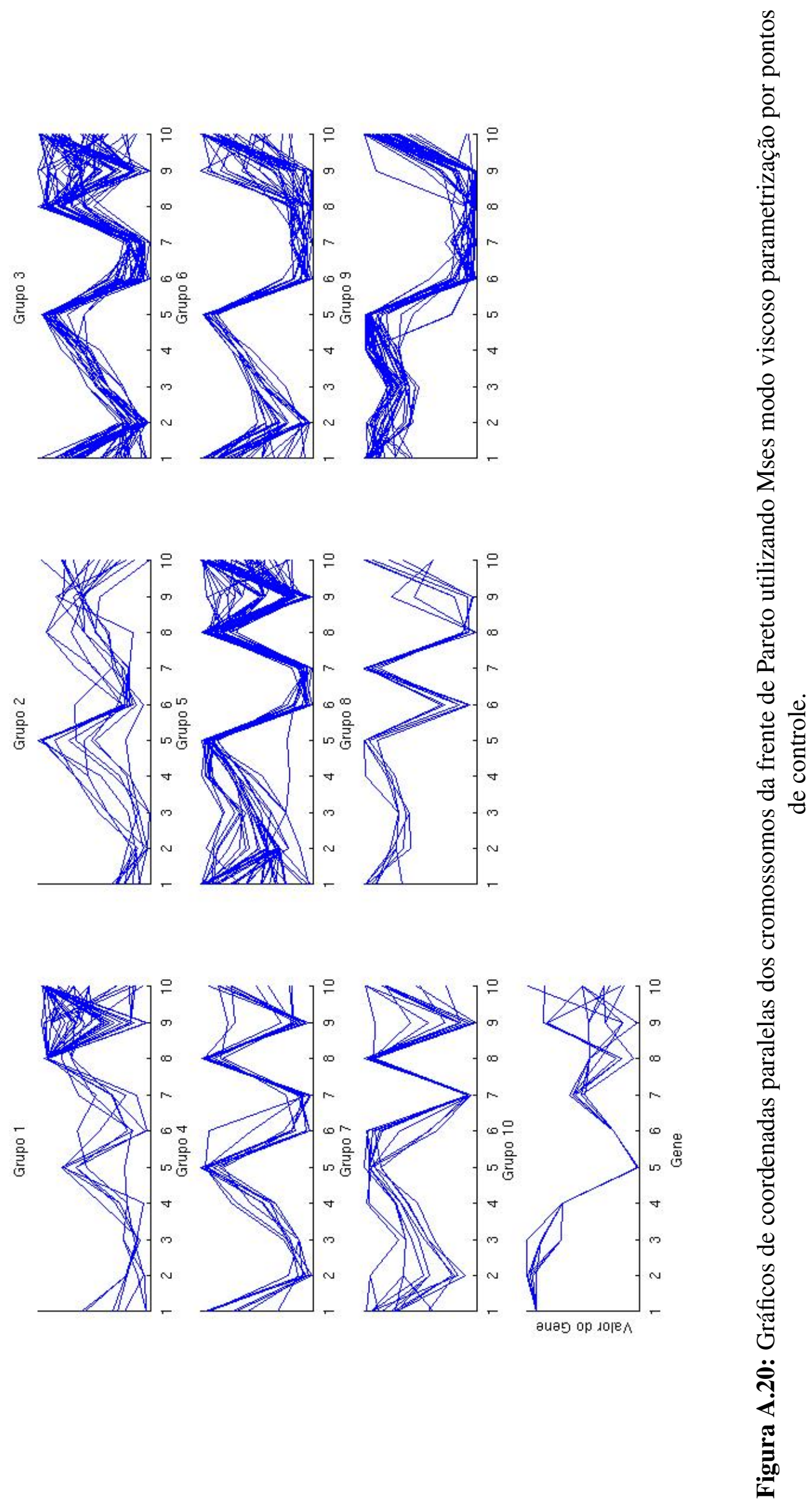


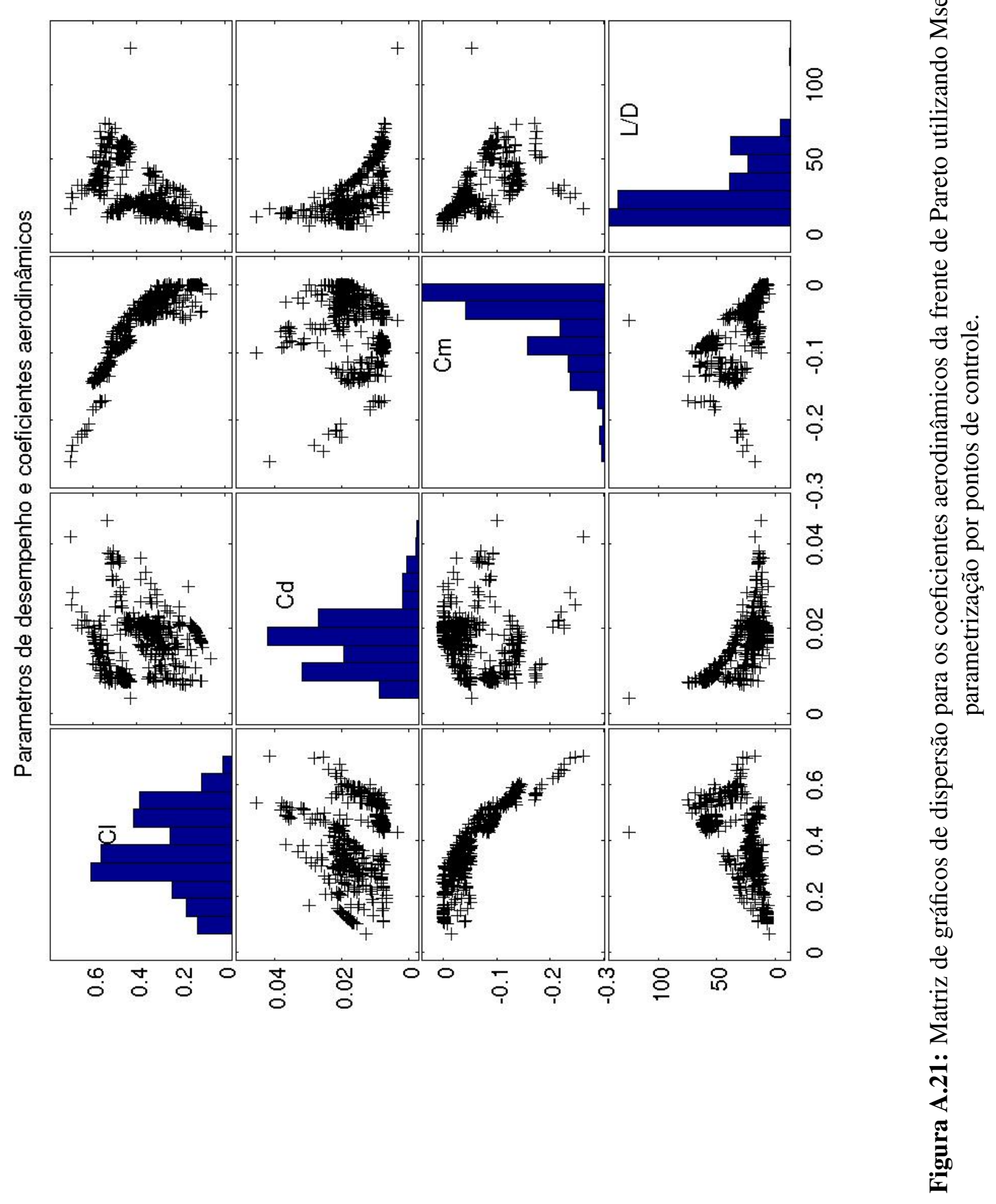




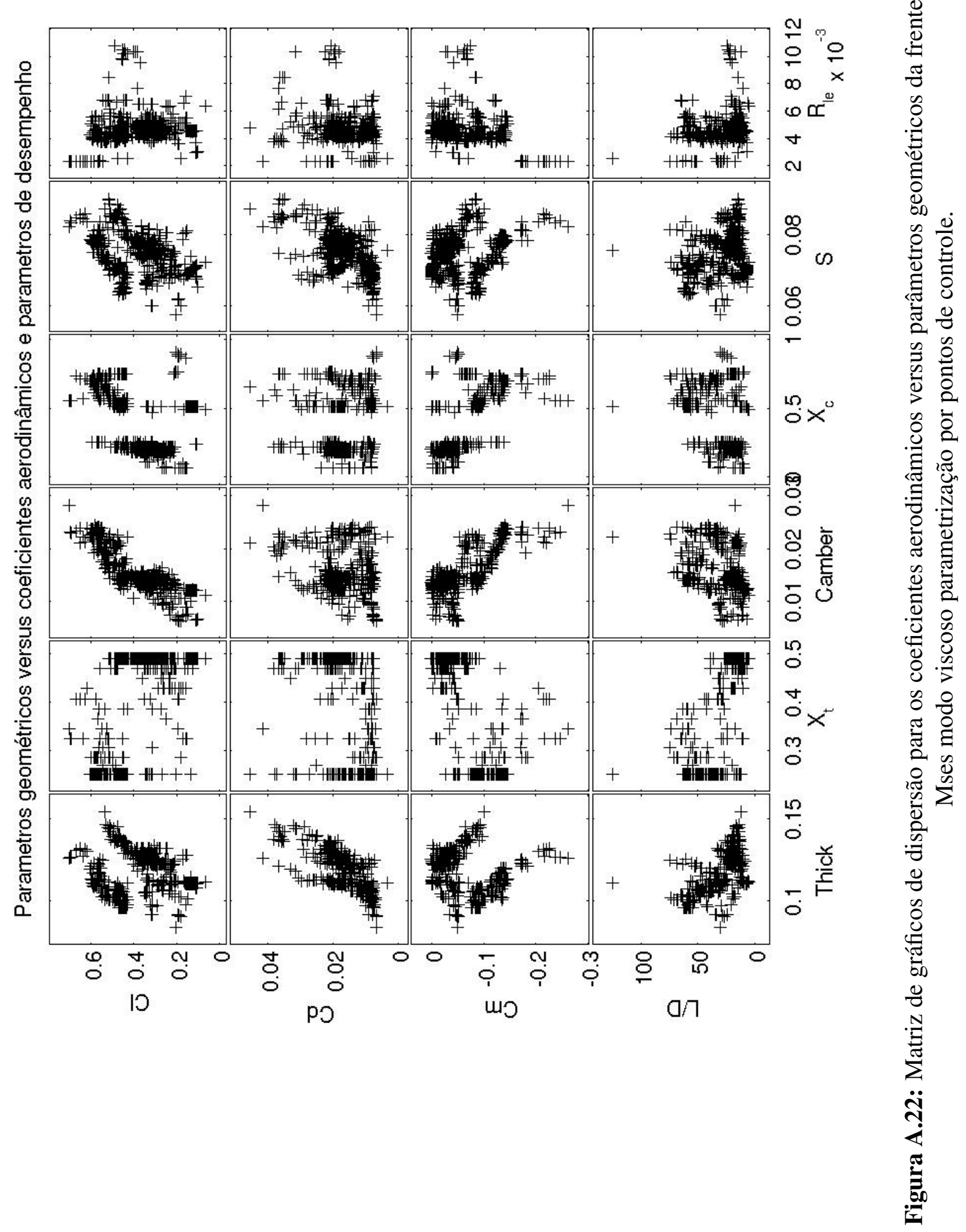




\section{A.1.3 Método centrado Jameson}

(a)

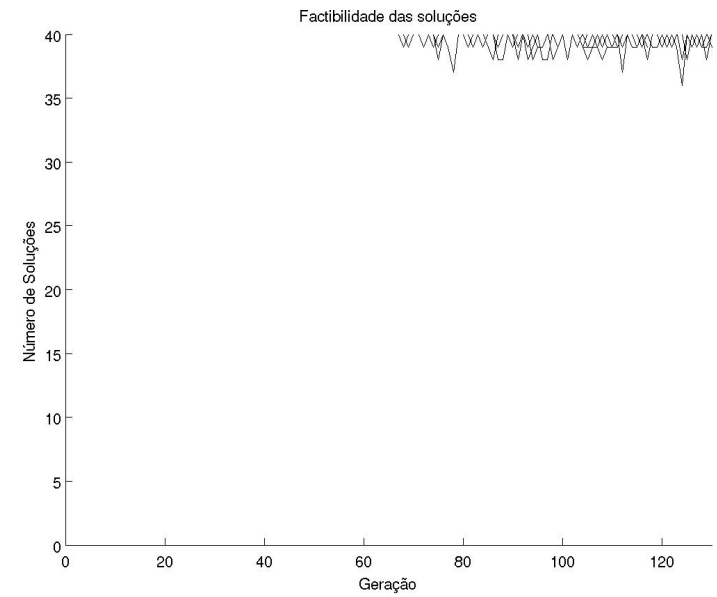

(b)

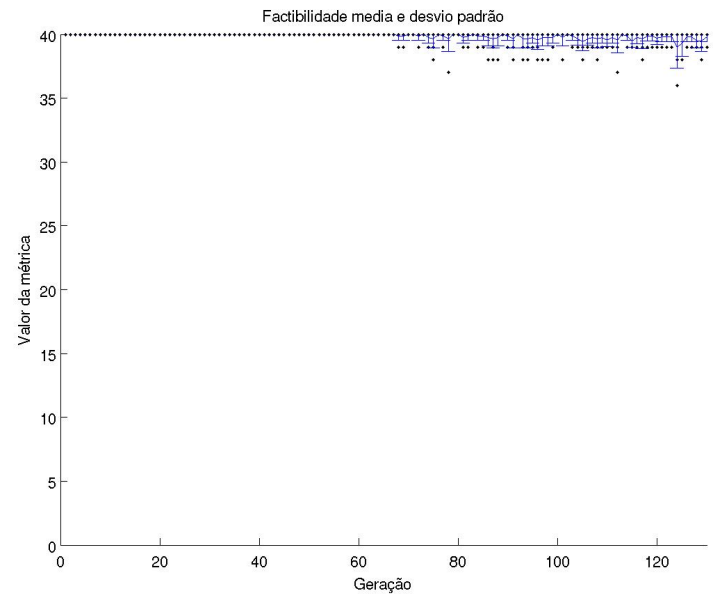

Figura A.23: Factibilidade da população na otimização utilizando método centrado parametrização por pontos de controle: (a) Soluções factíveis; (b) Média e desvio padrão na geração. 


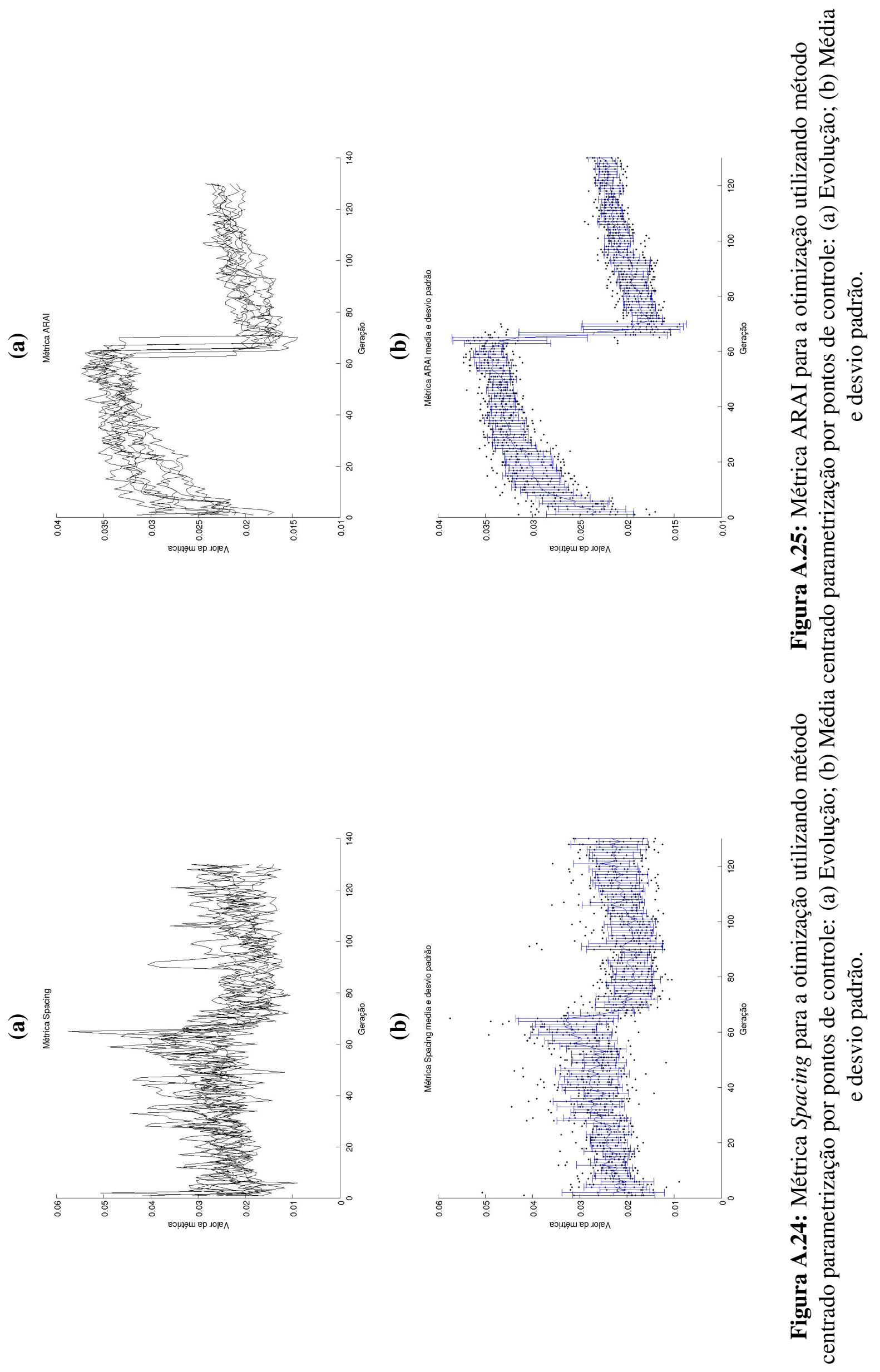




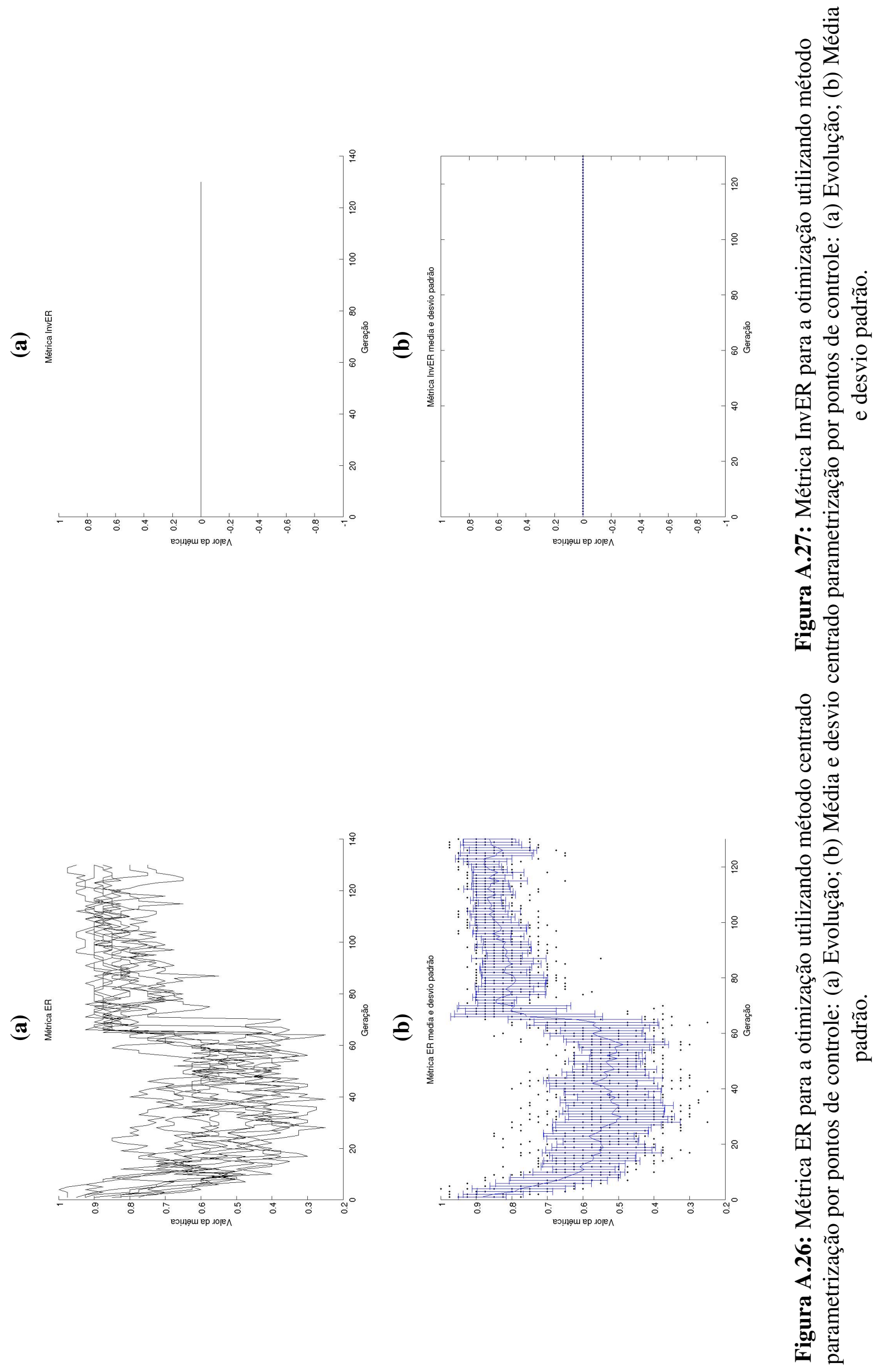



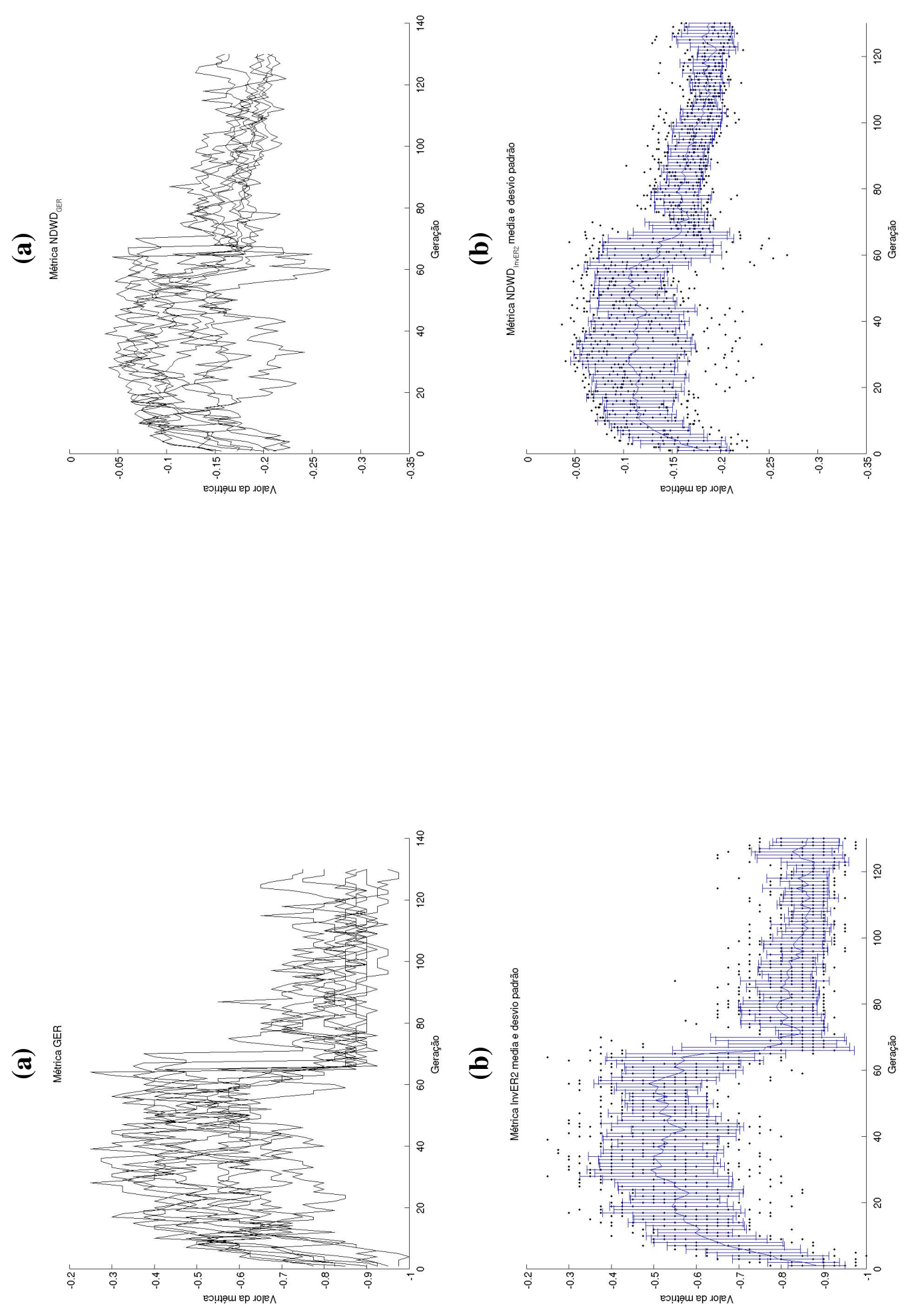

夏 

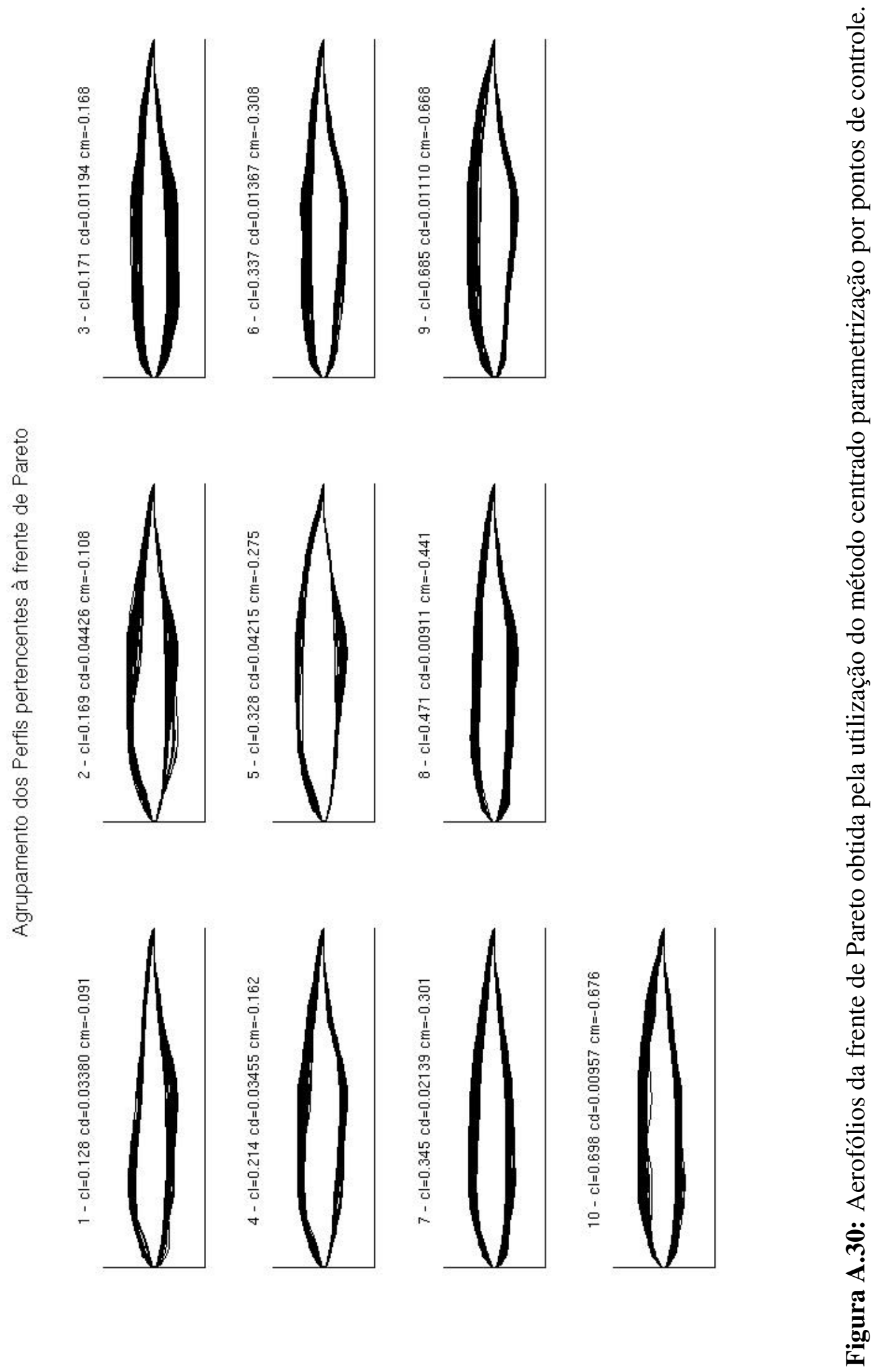

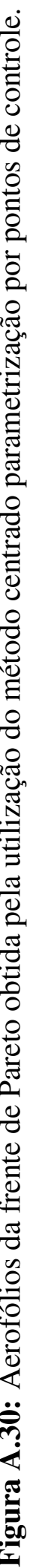



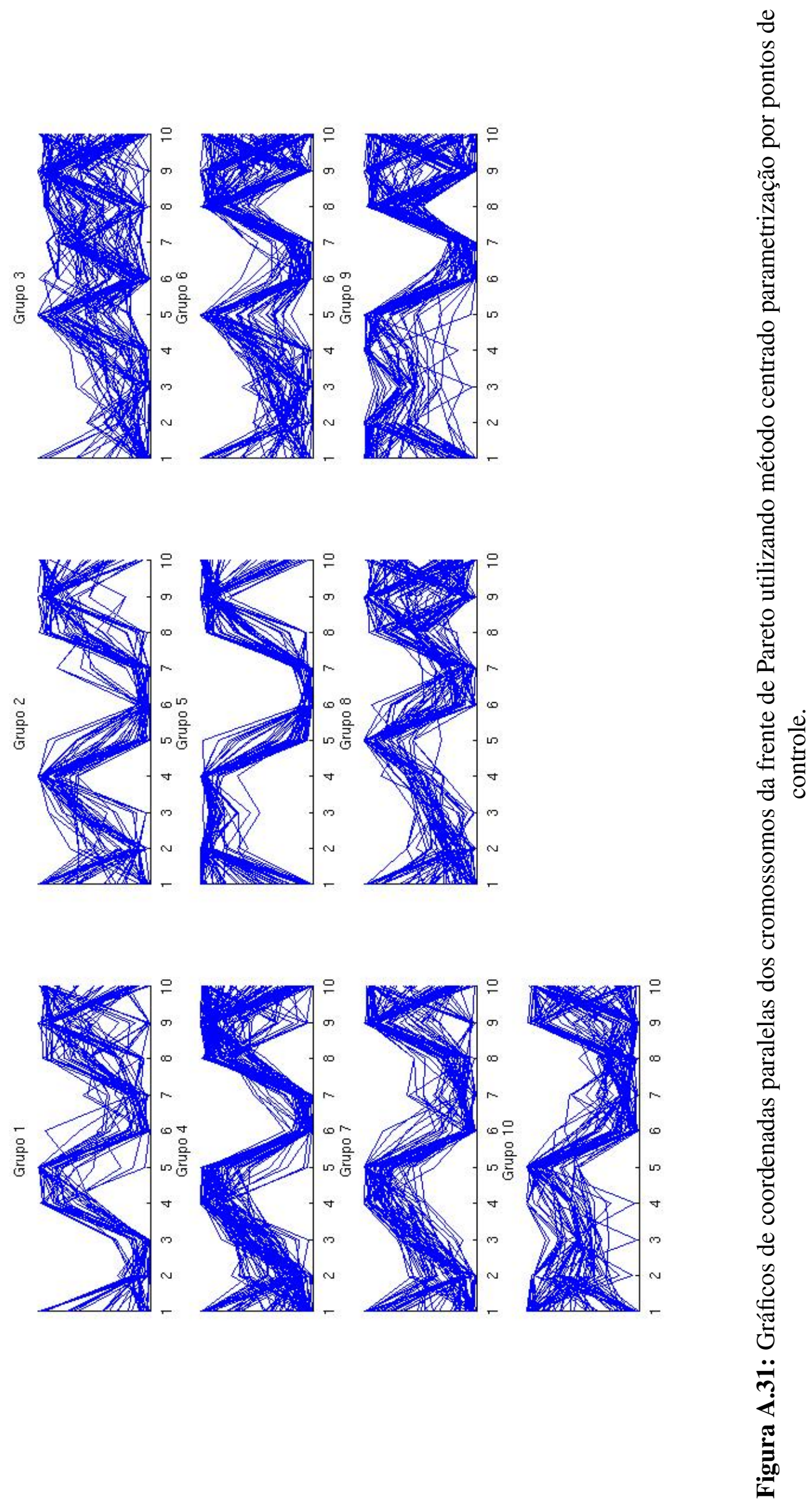

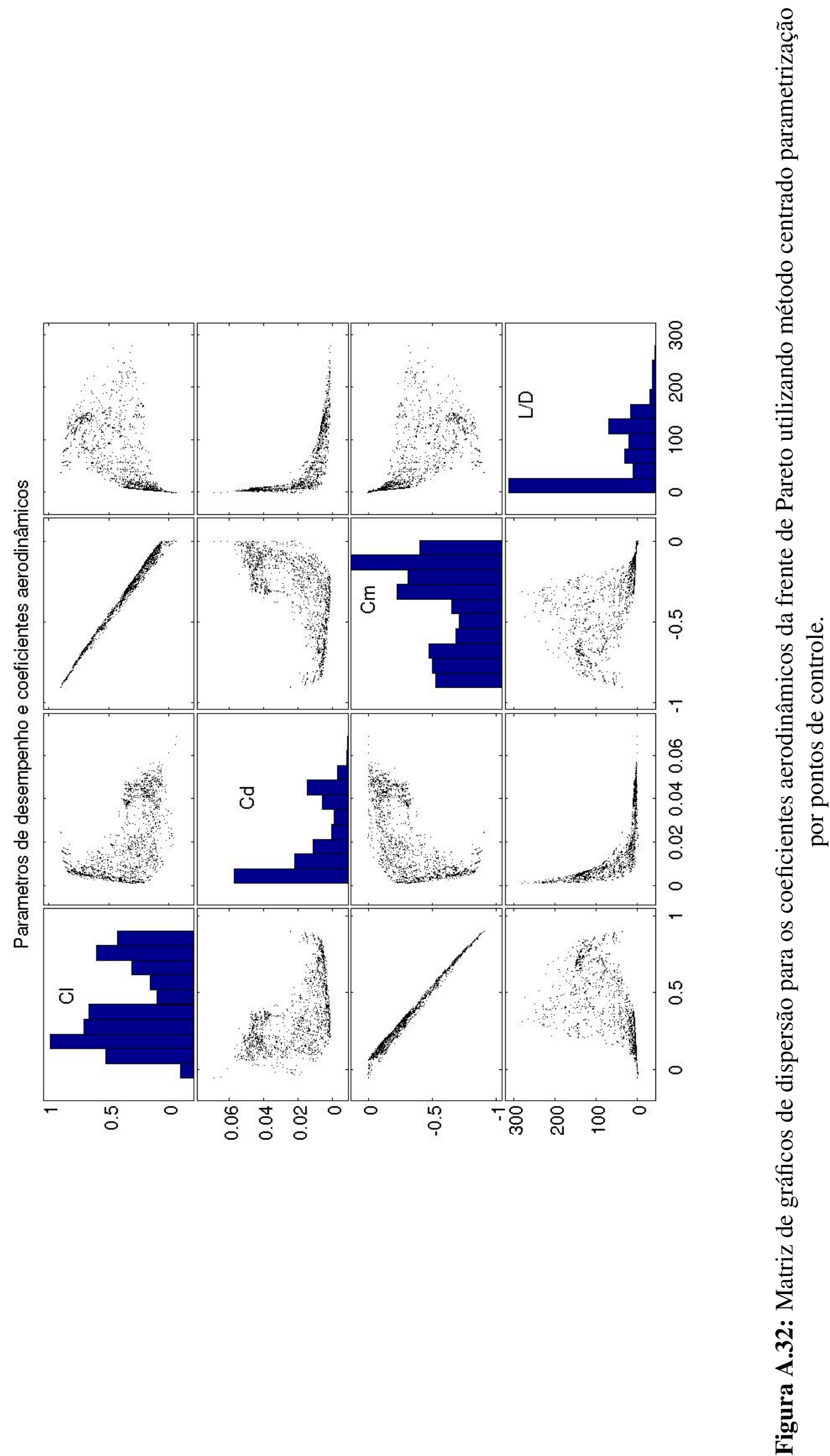


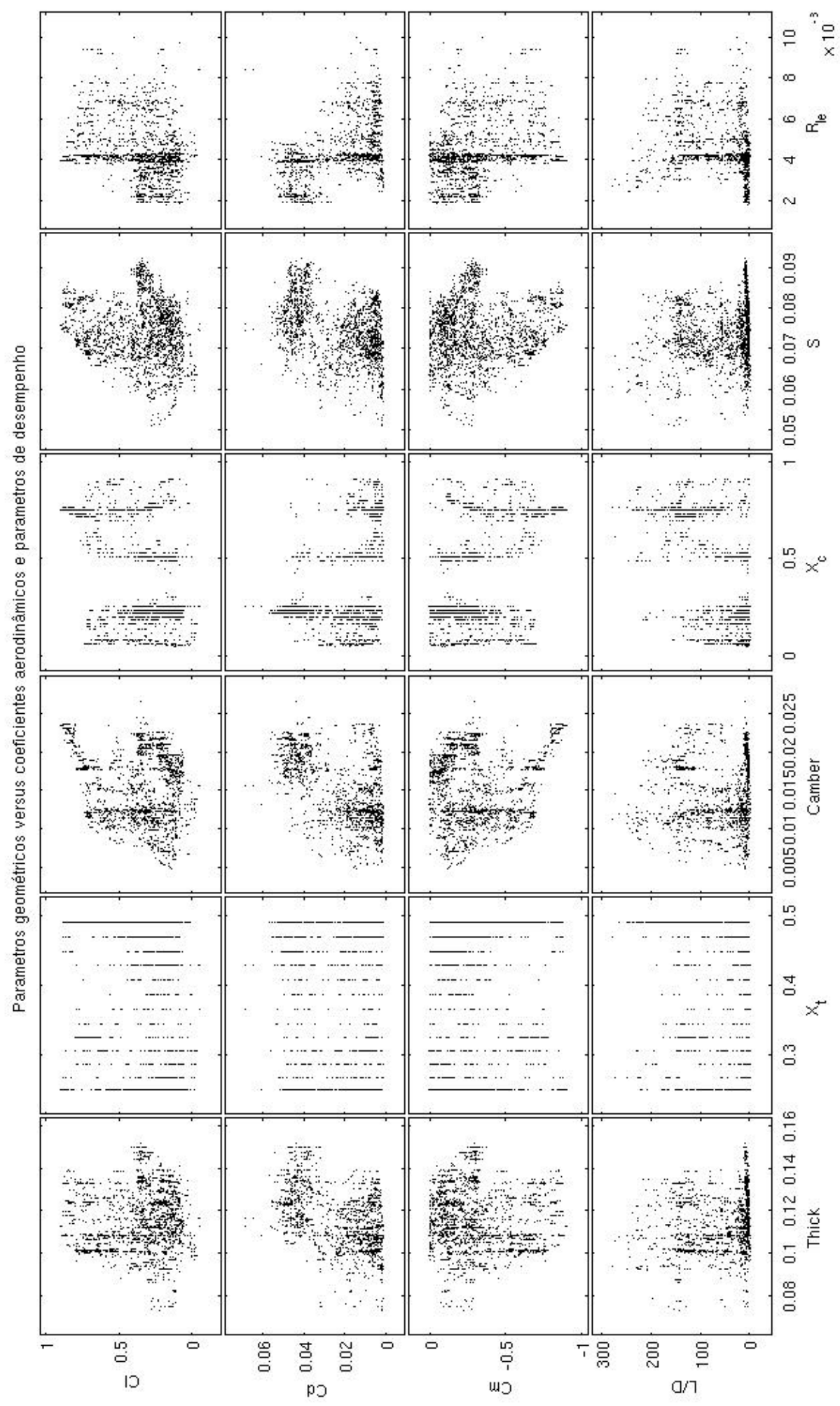

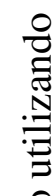

$\frac{1}{2}$

\%

苞

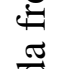

o

苞

离

过

苟

ô

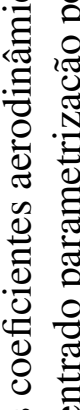

os

흘 융

讯 


\section{A.2 Parametrização Parsec}

\section{A.2.1 Método centrado Jameson}

(a)

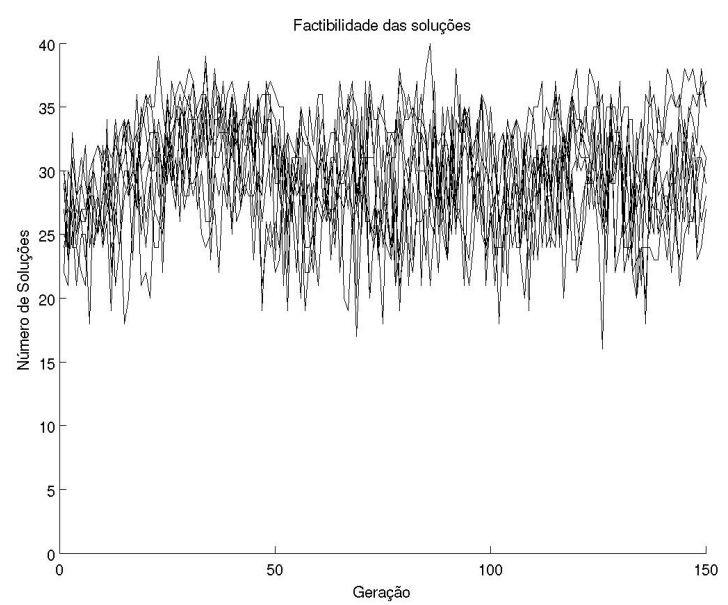

(b)

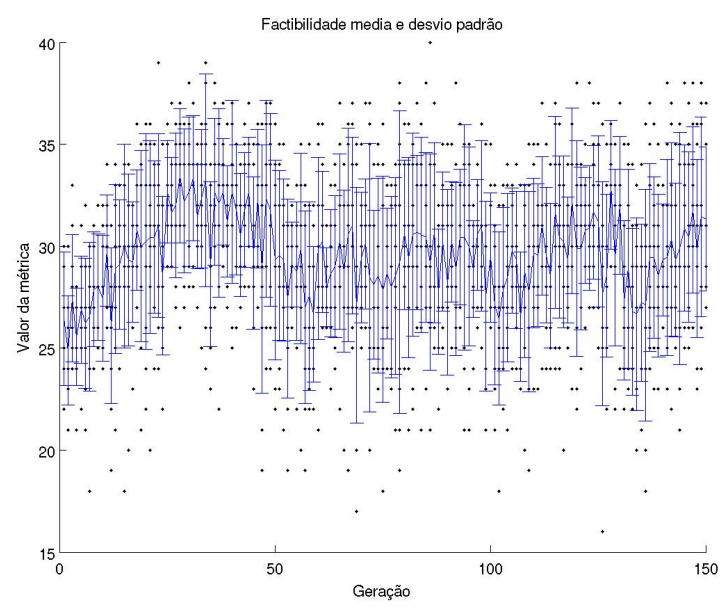

Figura A.34: Factibilidade da população na otimização utilizando método centrado parametrização Parsec: (a) Soluções factíveis; (b) Média e desvio padrão na geração. 

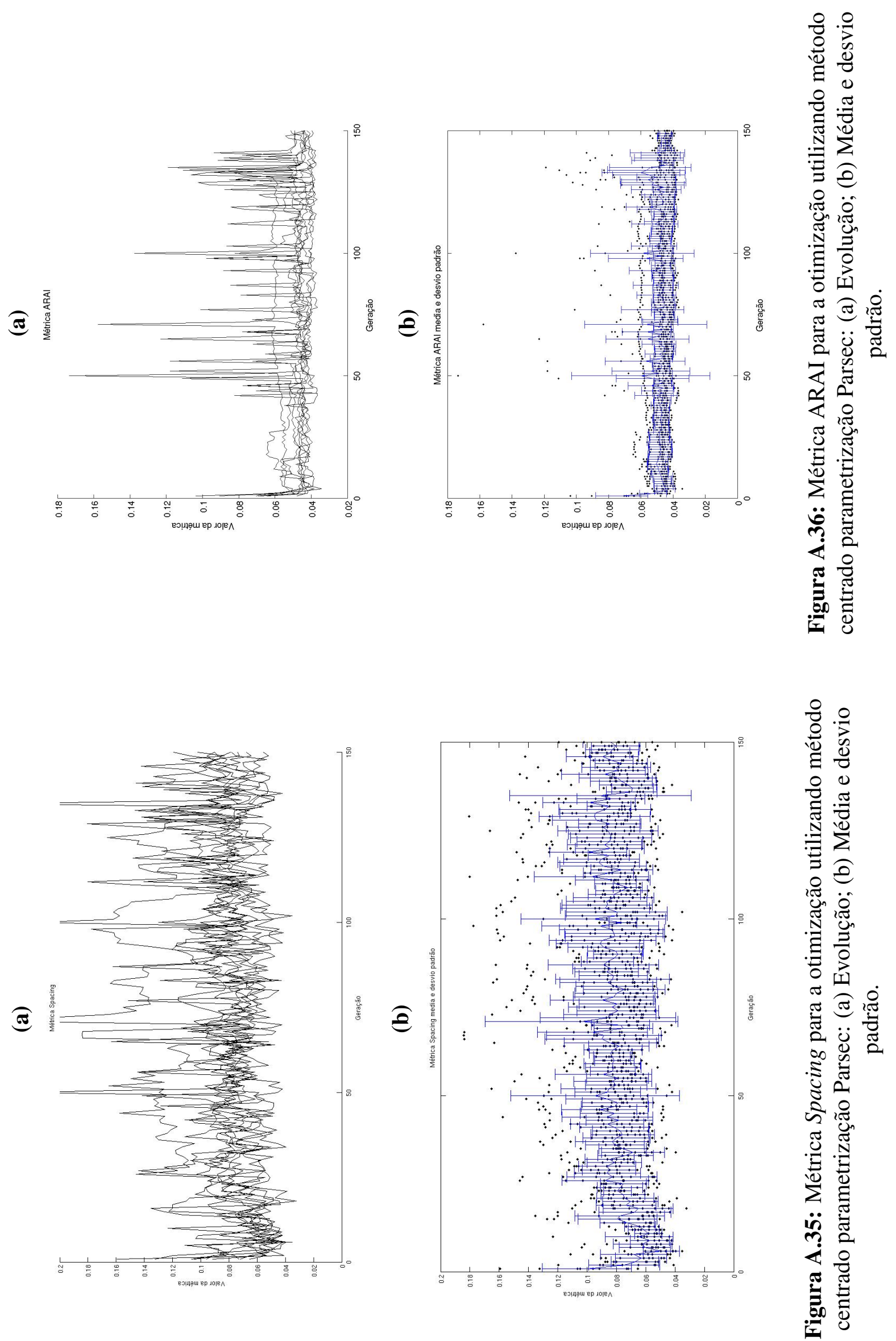

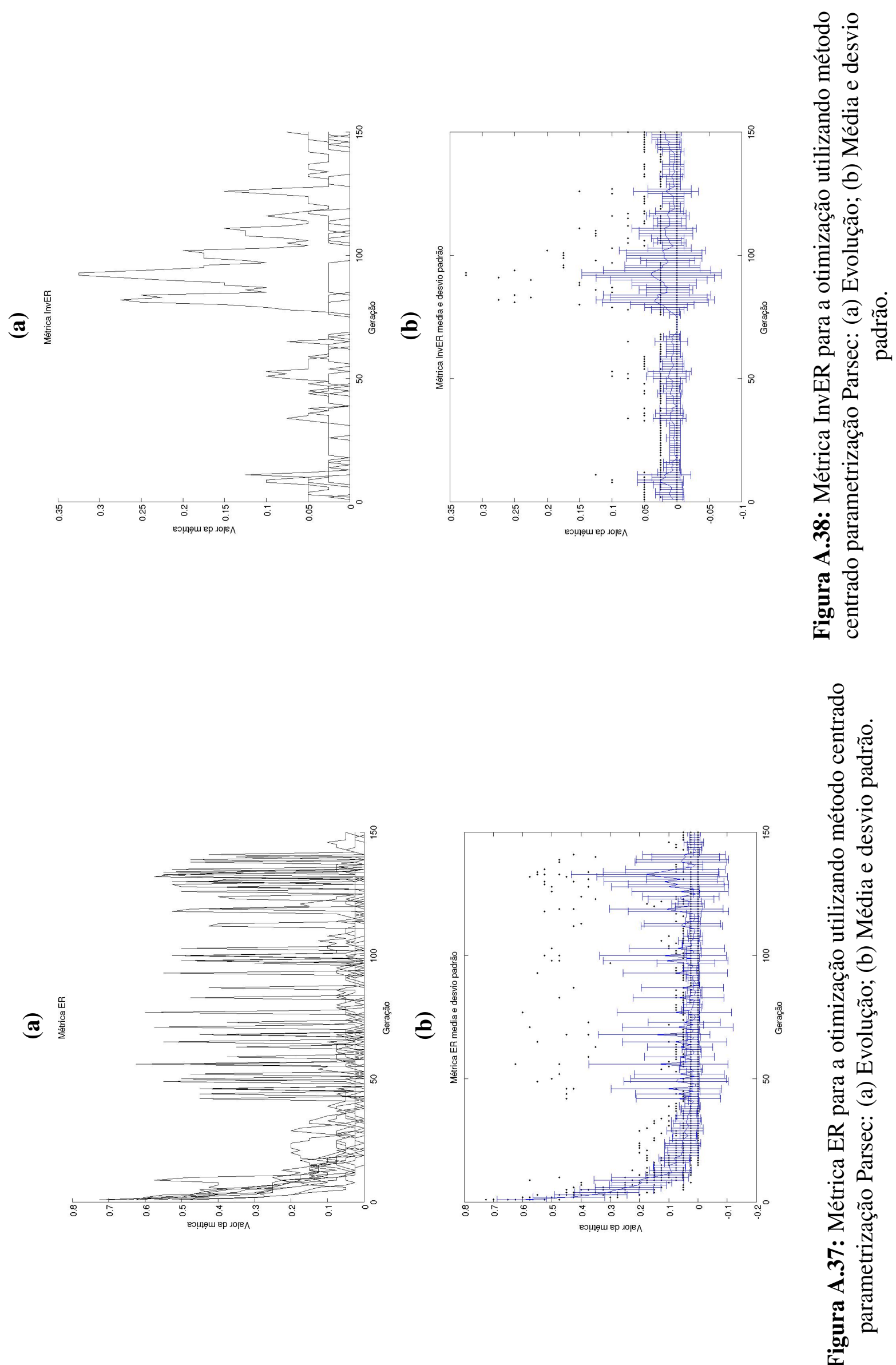

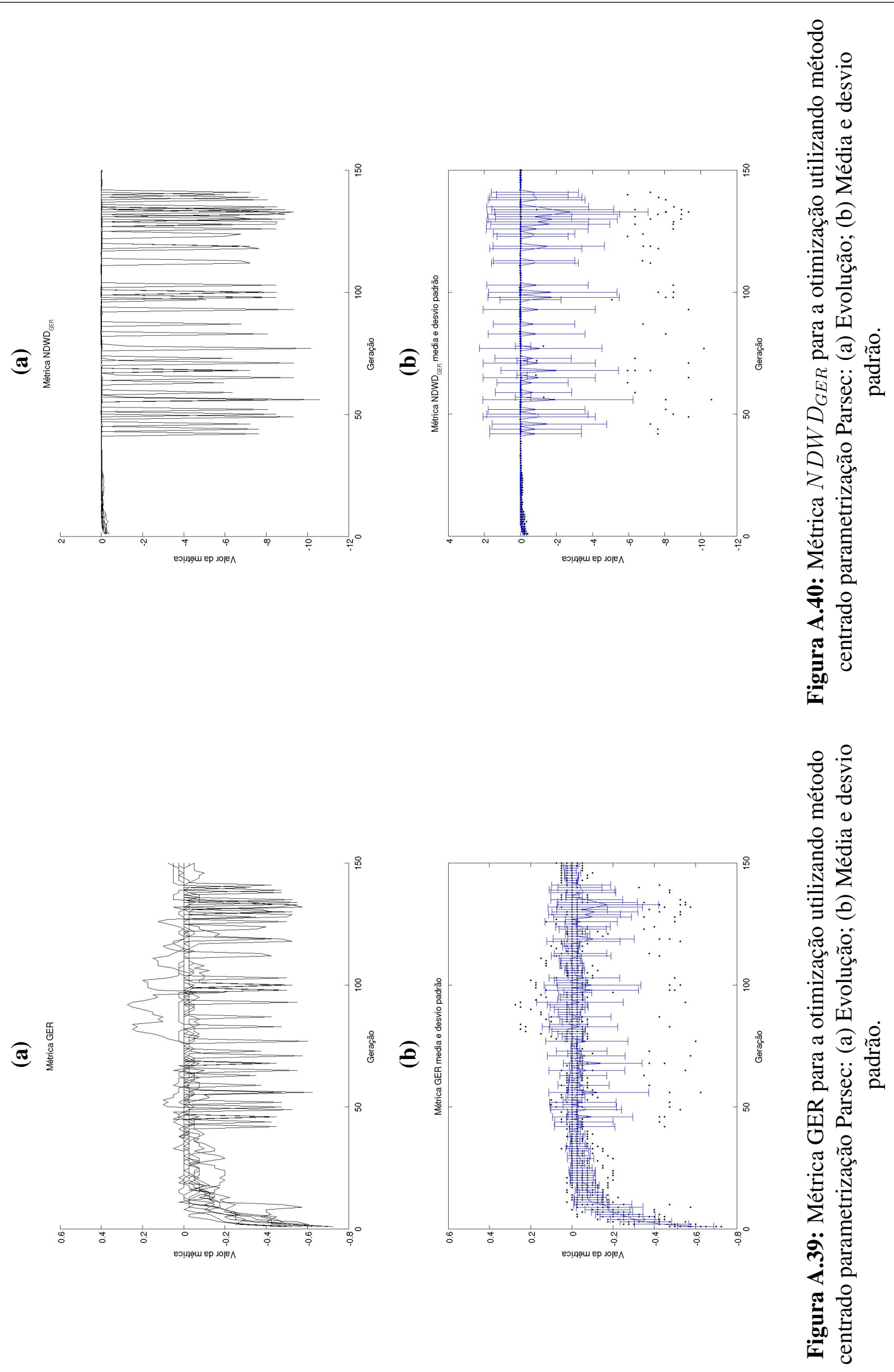

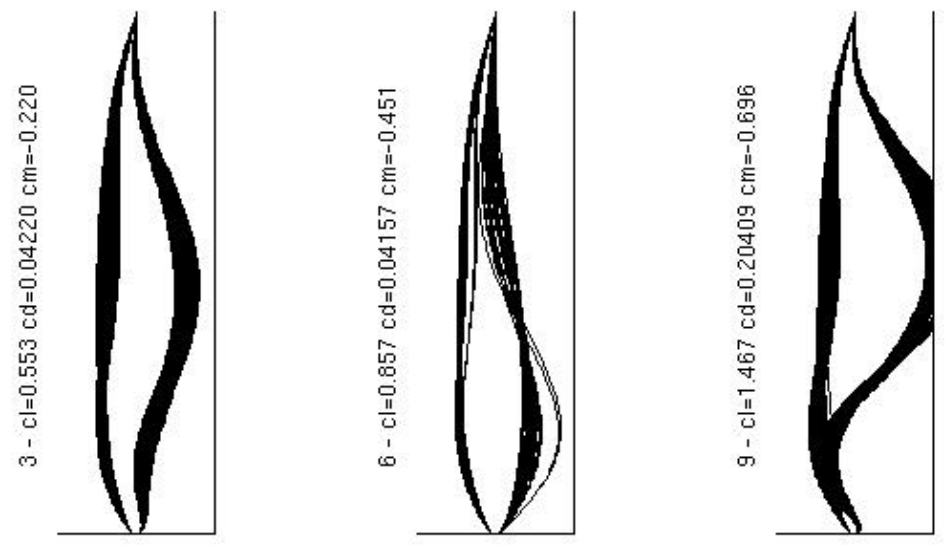

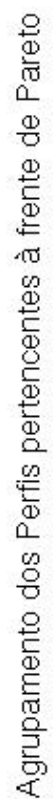
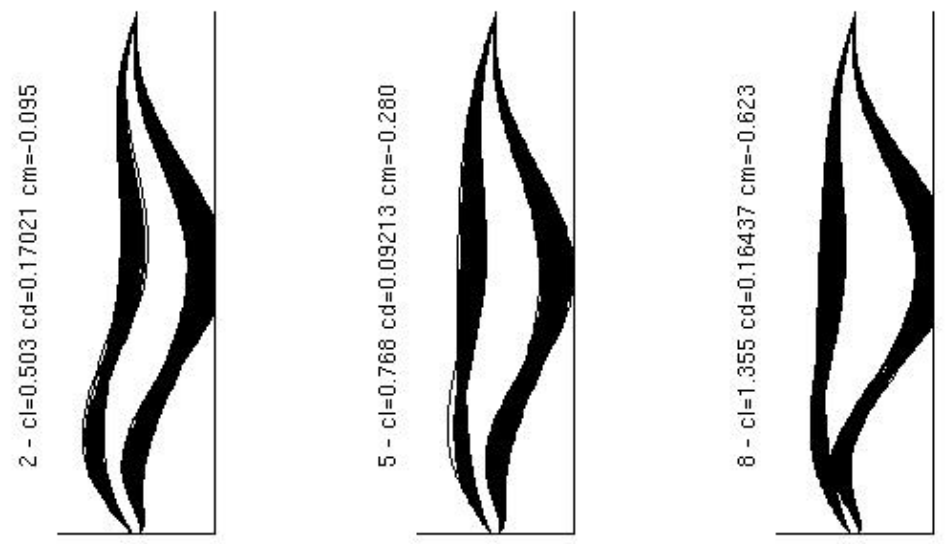

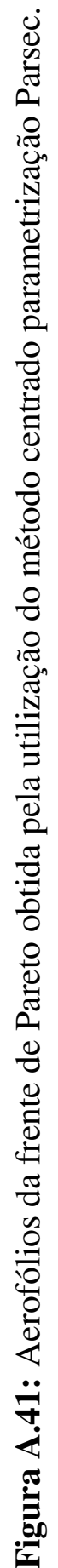
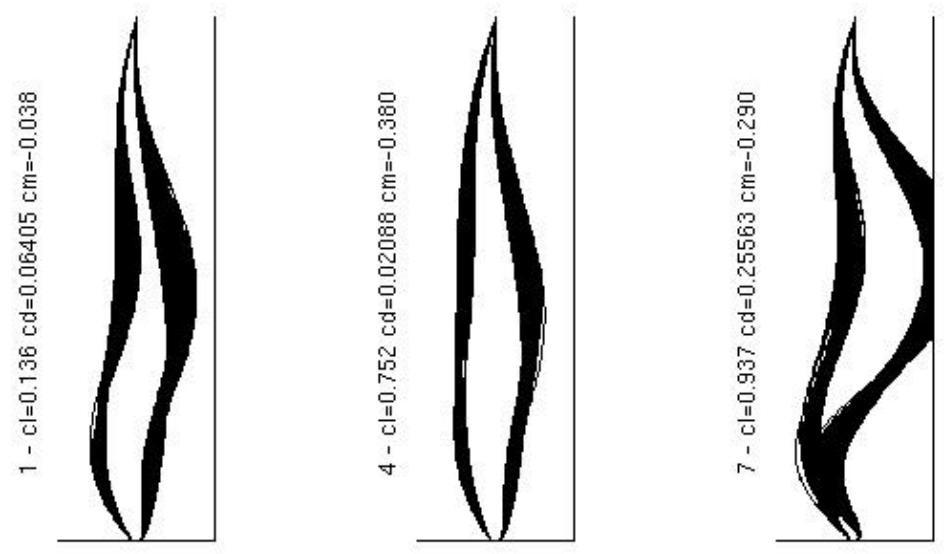


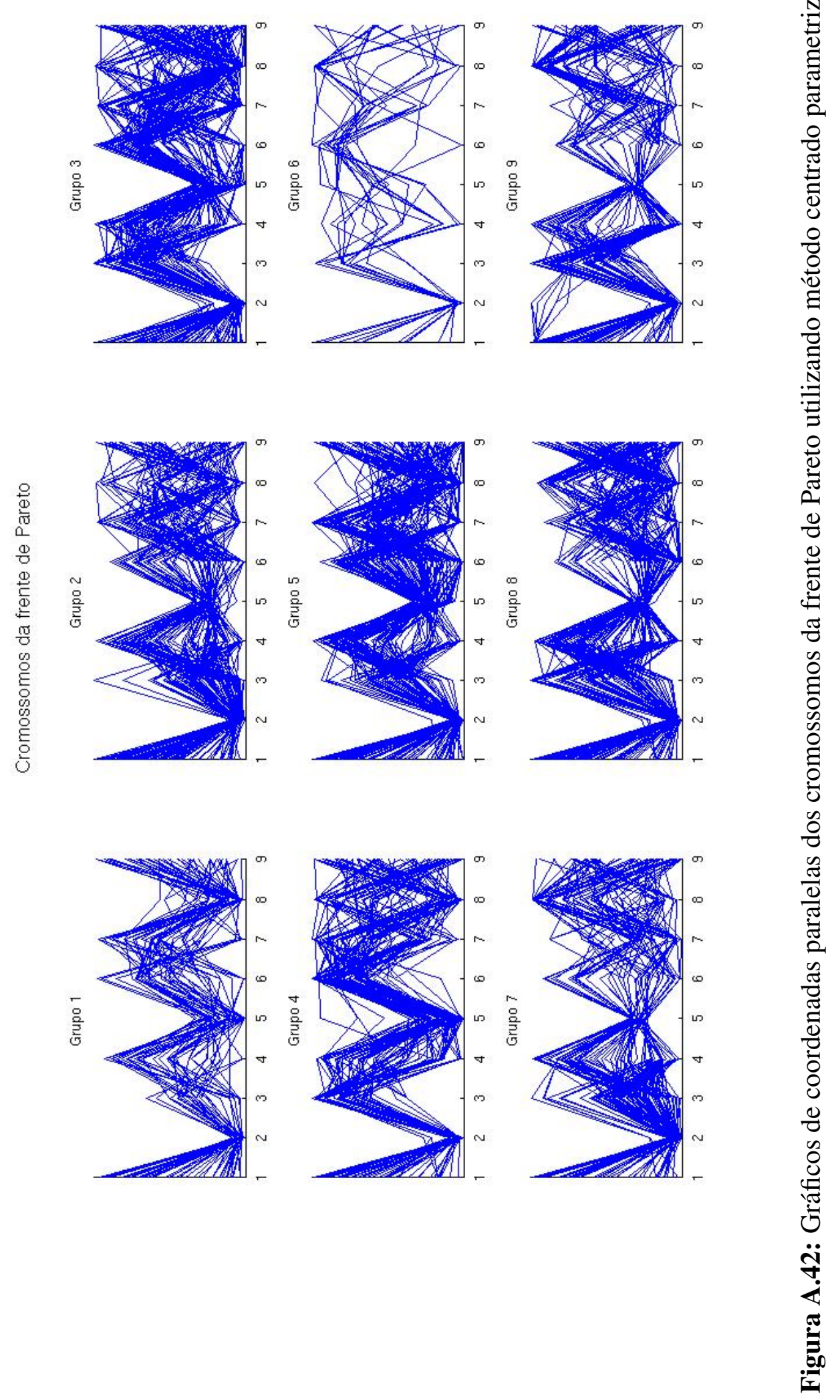



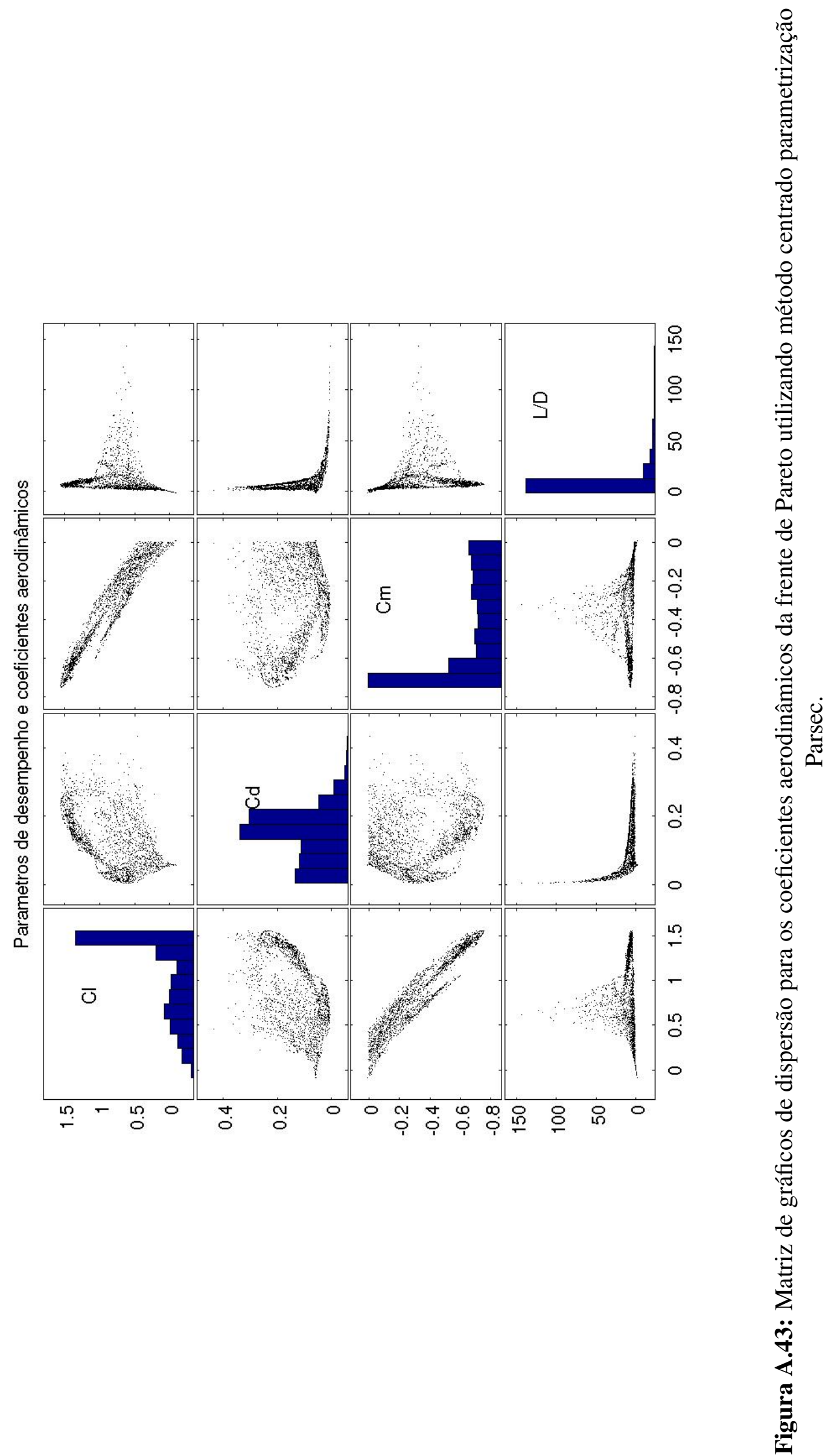


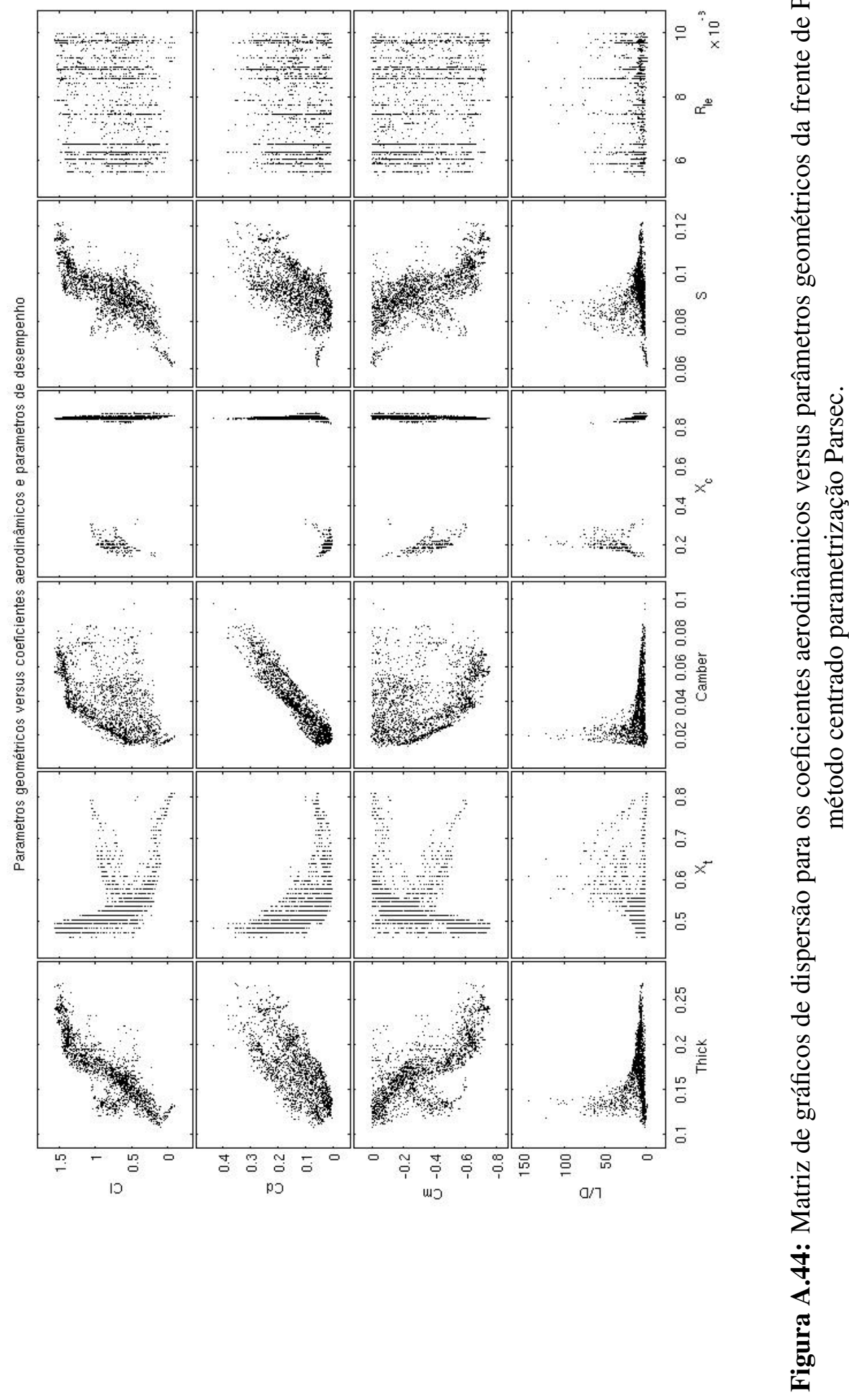




\section{A.2.2 Método upwind Roe}

(a)

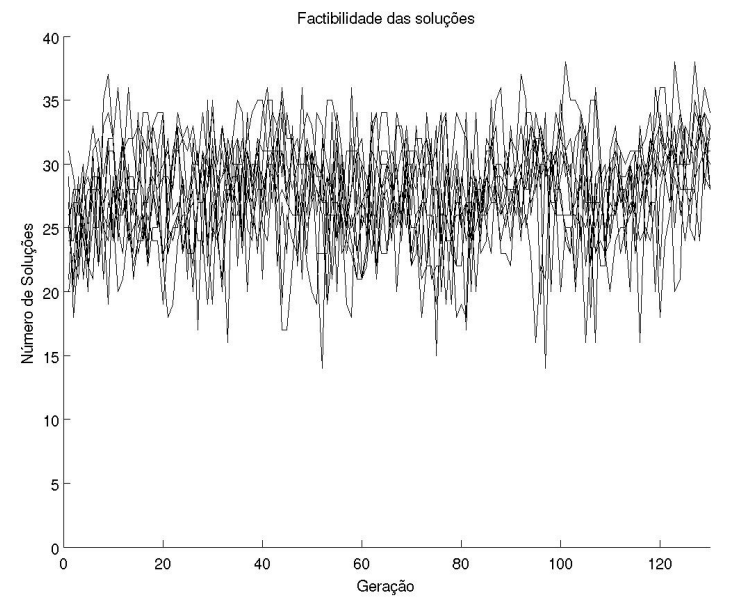

(b)

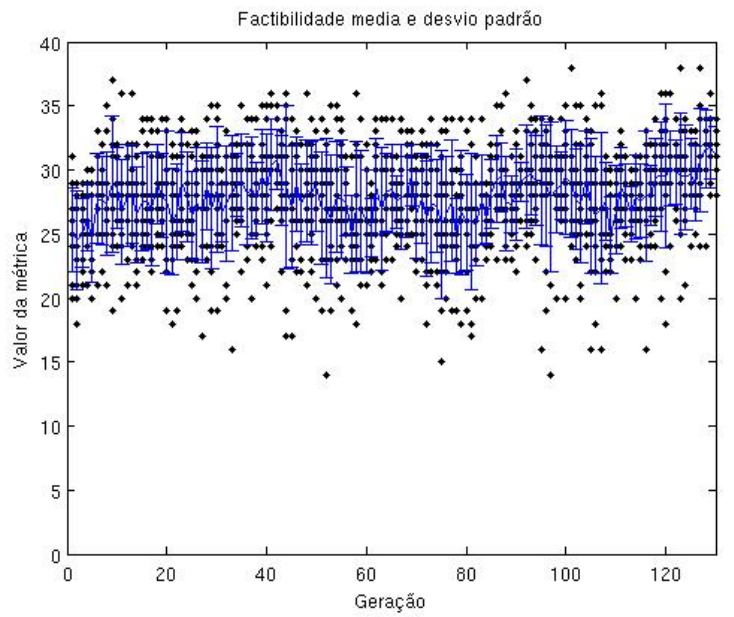

Figura A.45: Factibilidade da população na otimização utilizando método upwind parametrização Parsec: (a) Soluções factíveis; (b) Média e desvio padrão na geração. 

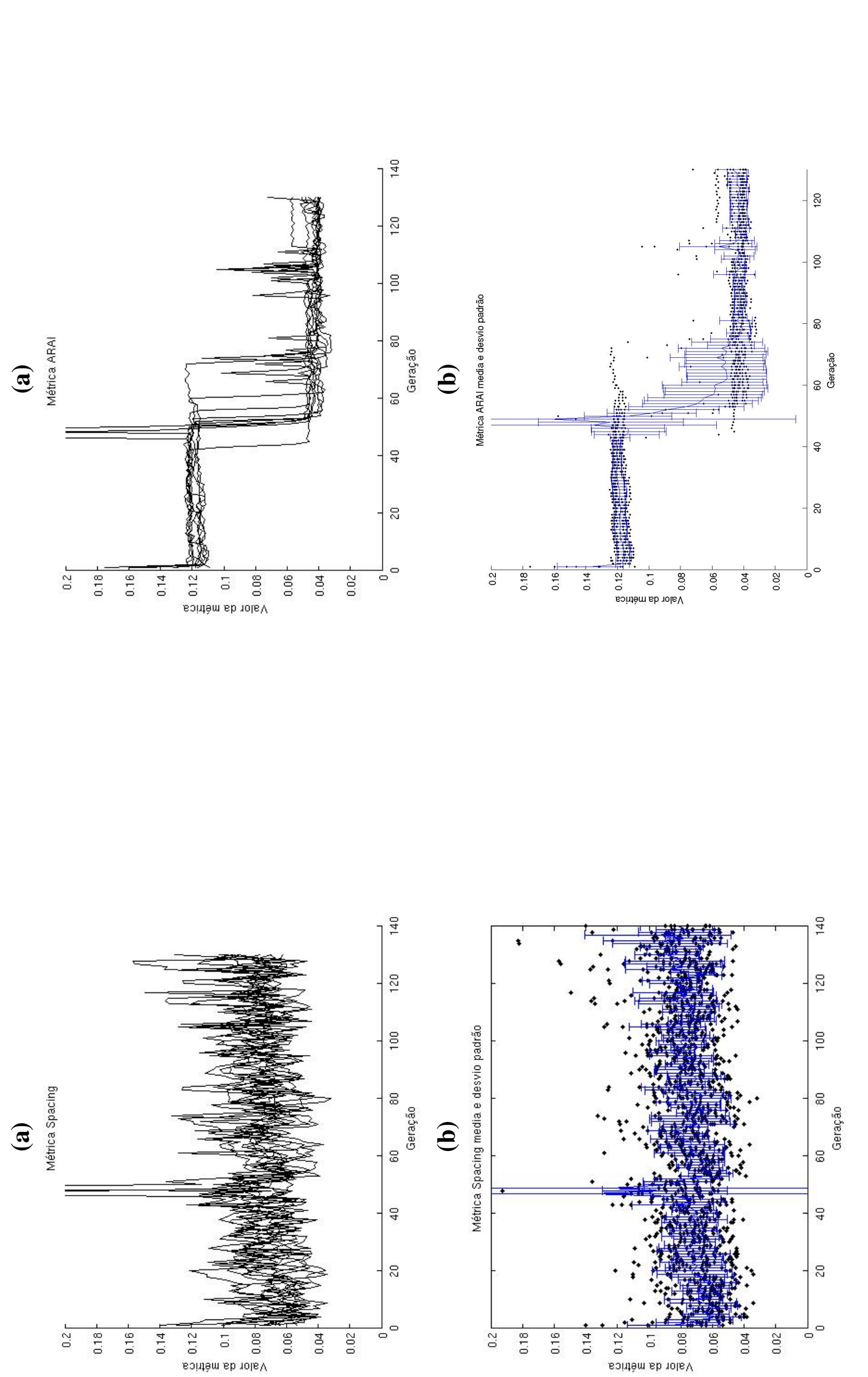

웡 


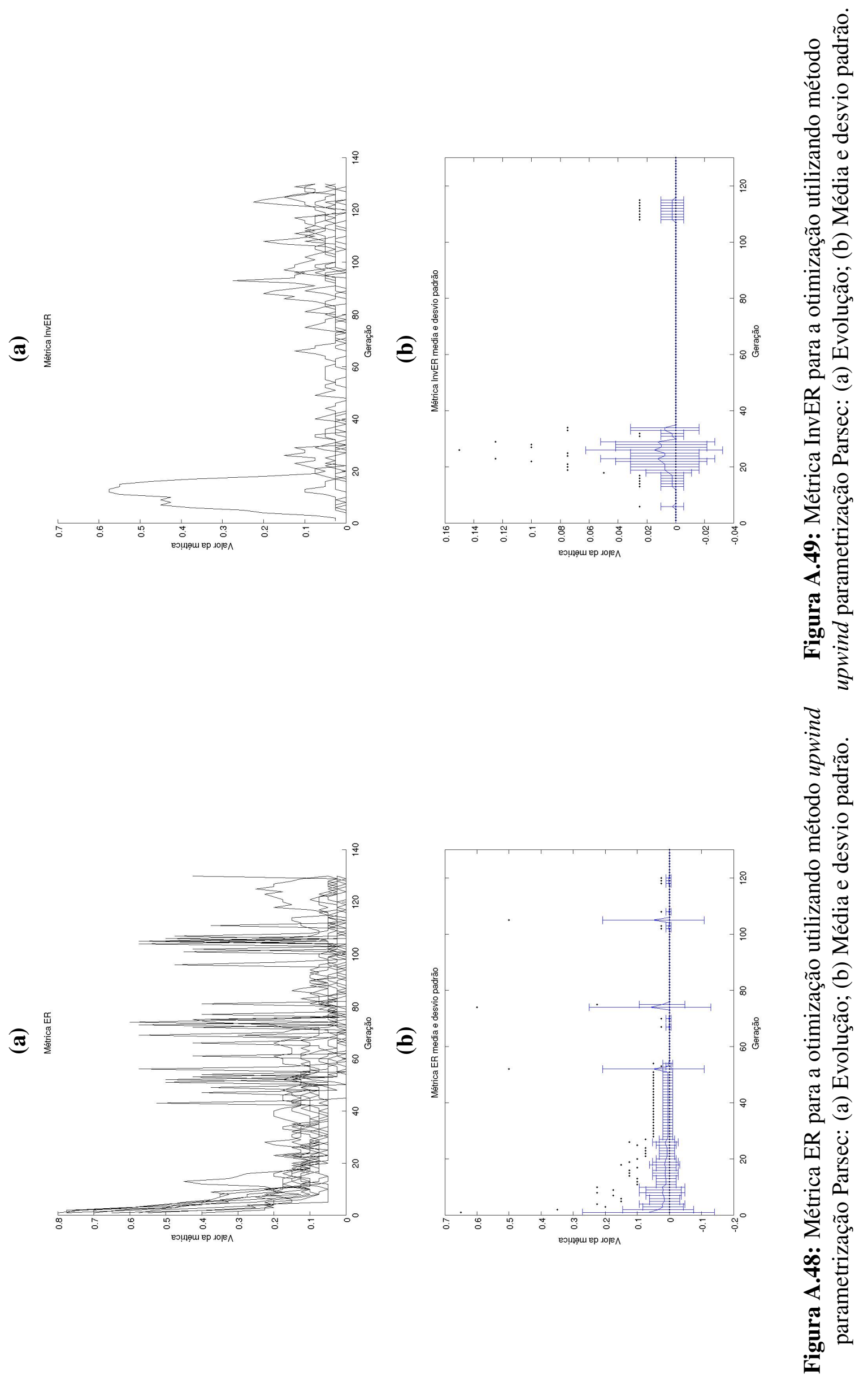



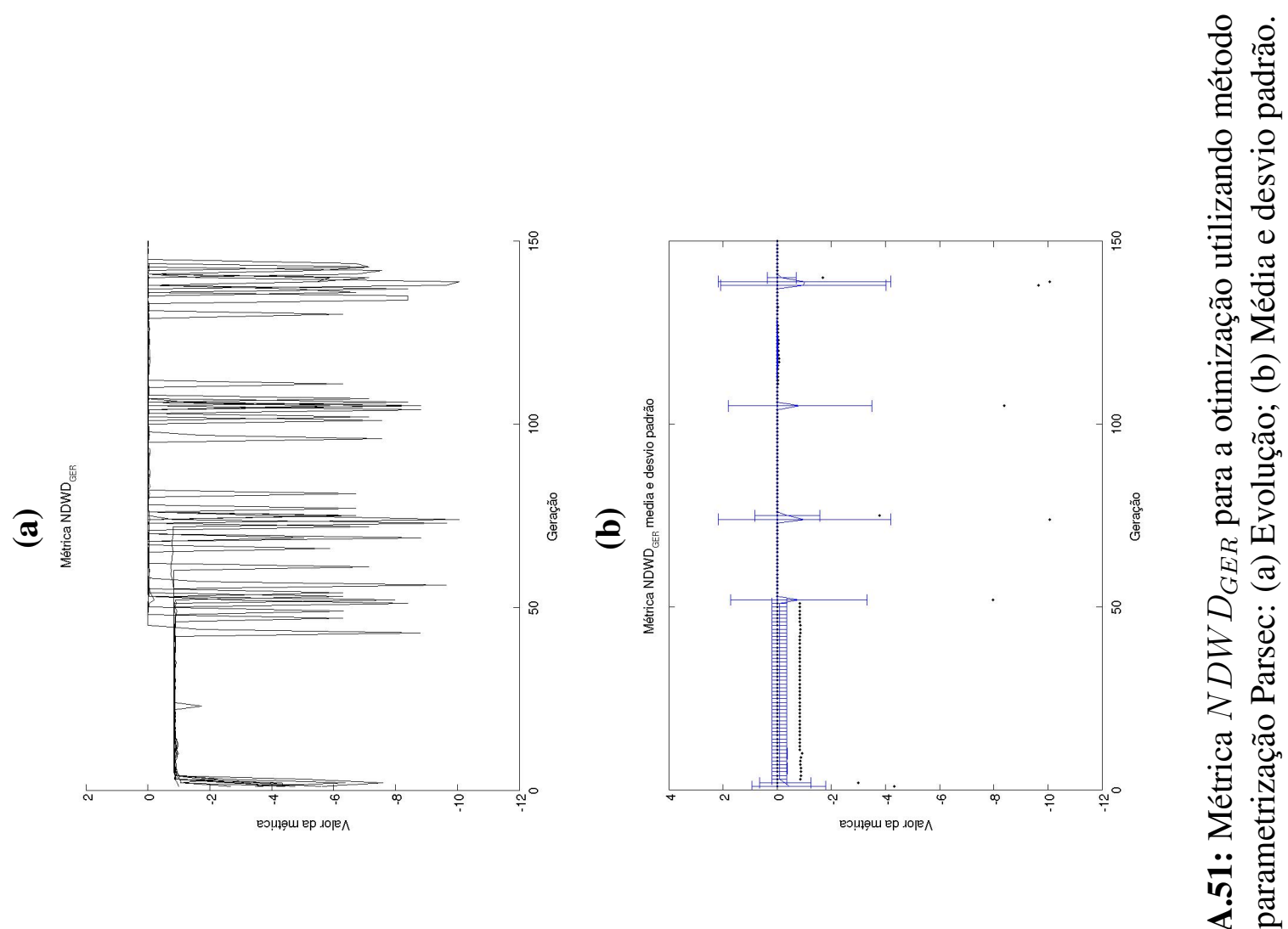

党

ָ)

-

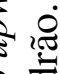

융 :

岂.
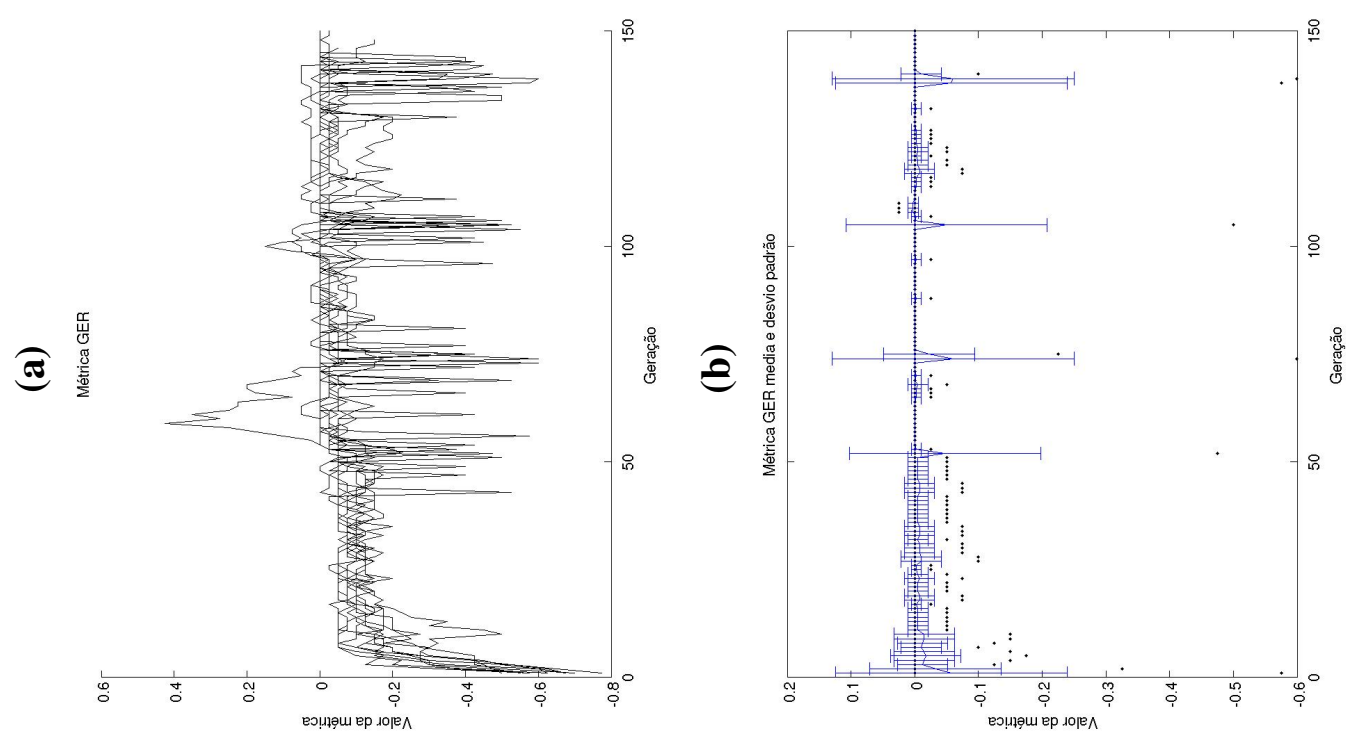

융

กิ

고

兰

ชิ

는

.

要

$\pi>$

플 되

๑

$\frac{1}{0} \dot{0}$

ชี

芭

ஜि

¿

클 

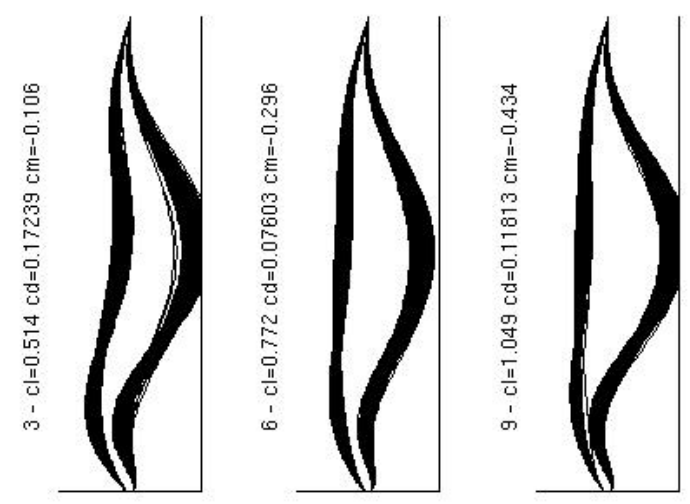

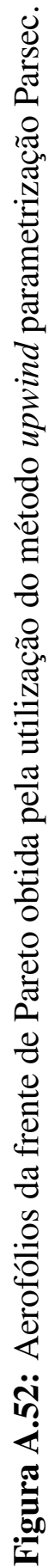

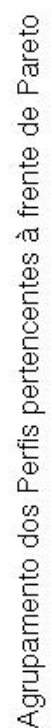
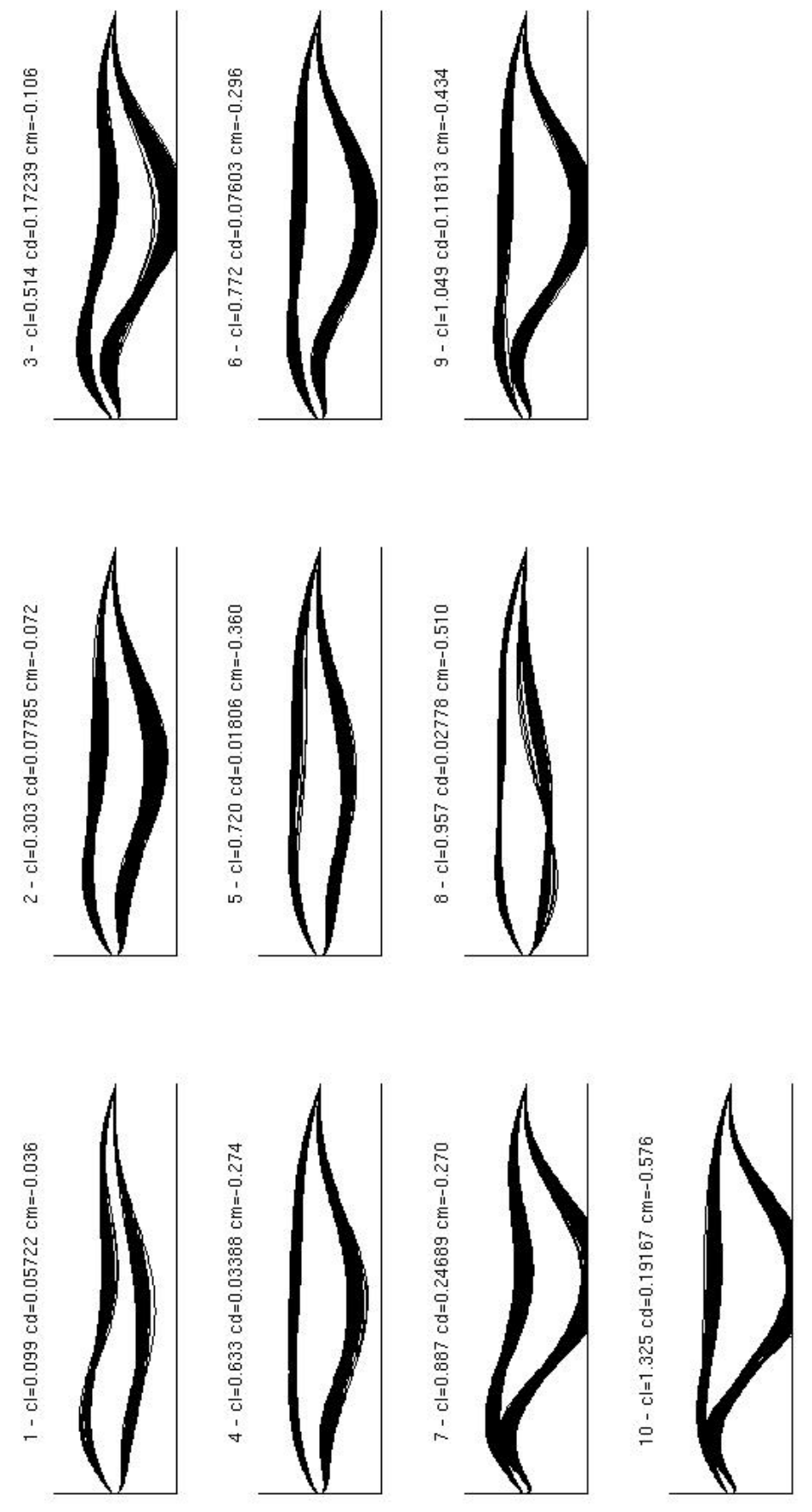

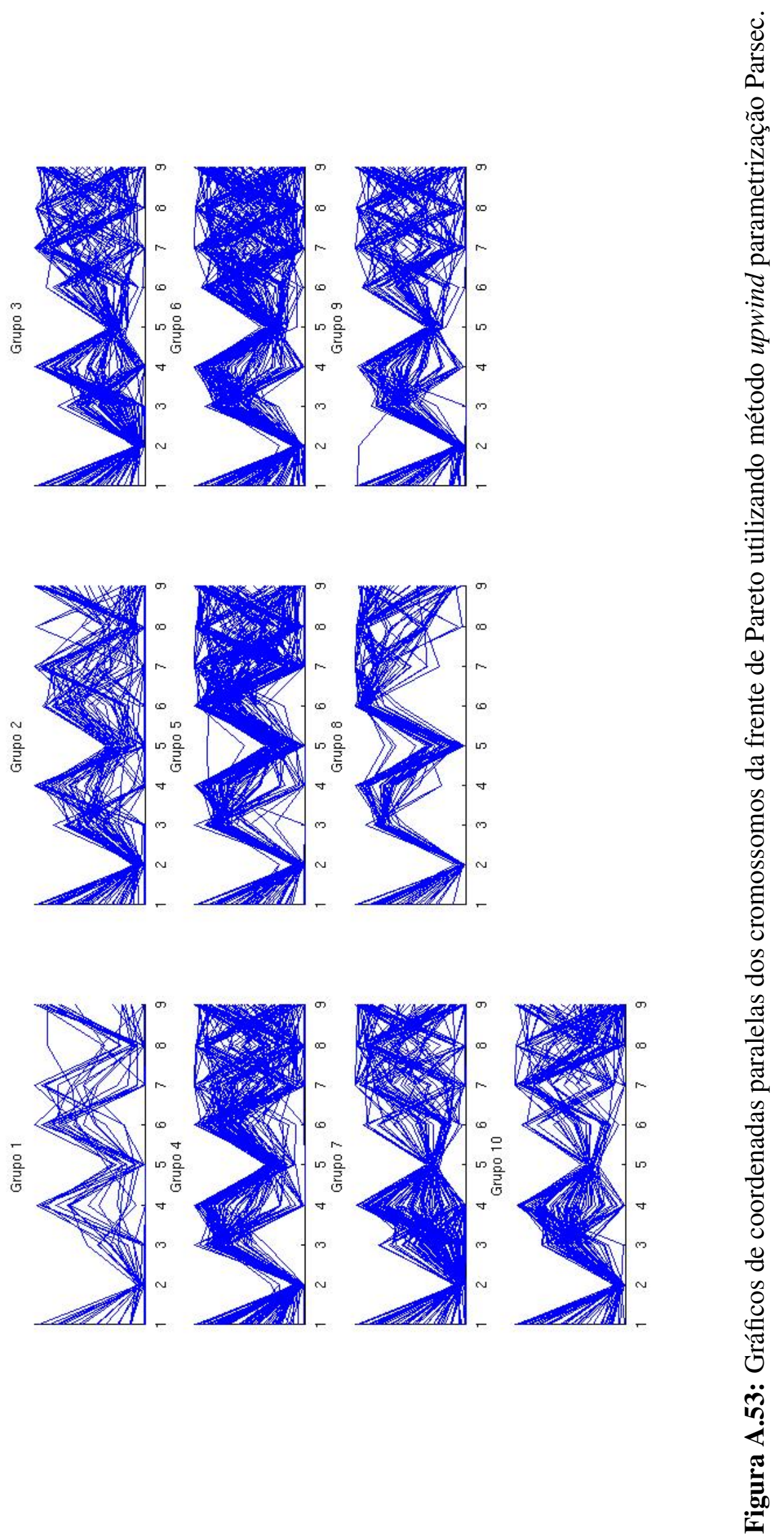

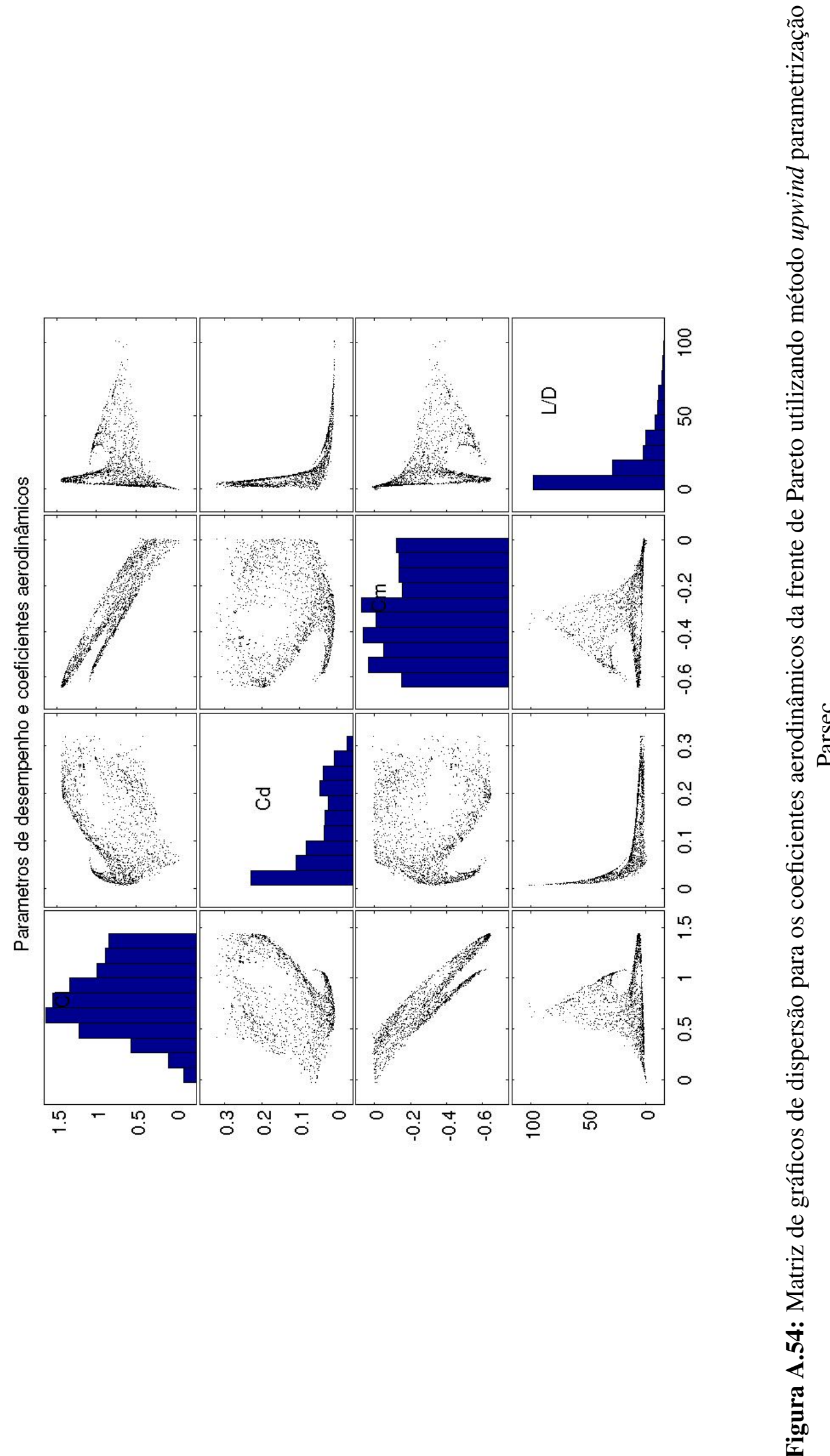


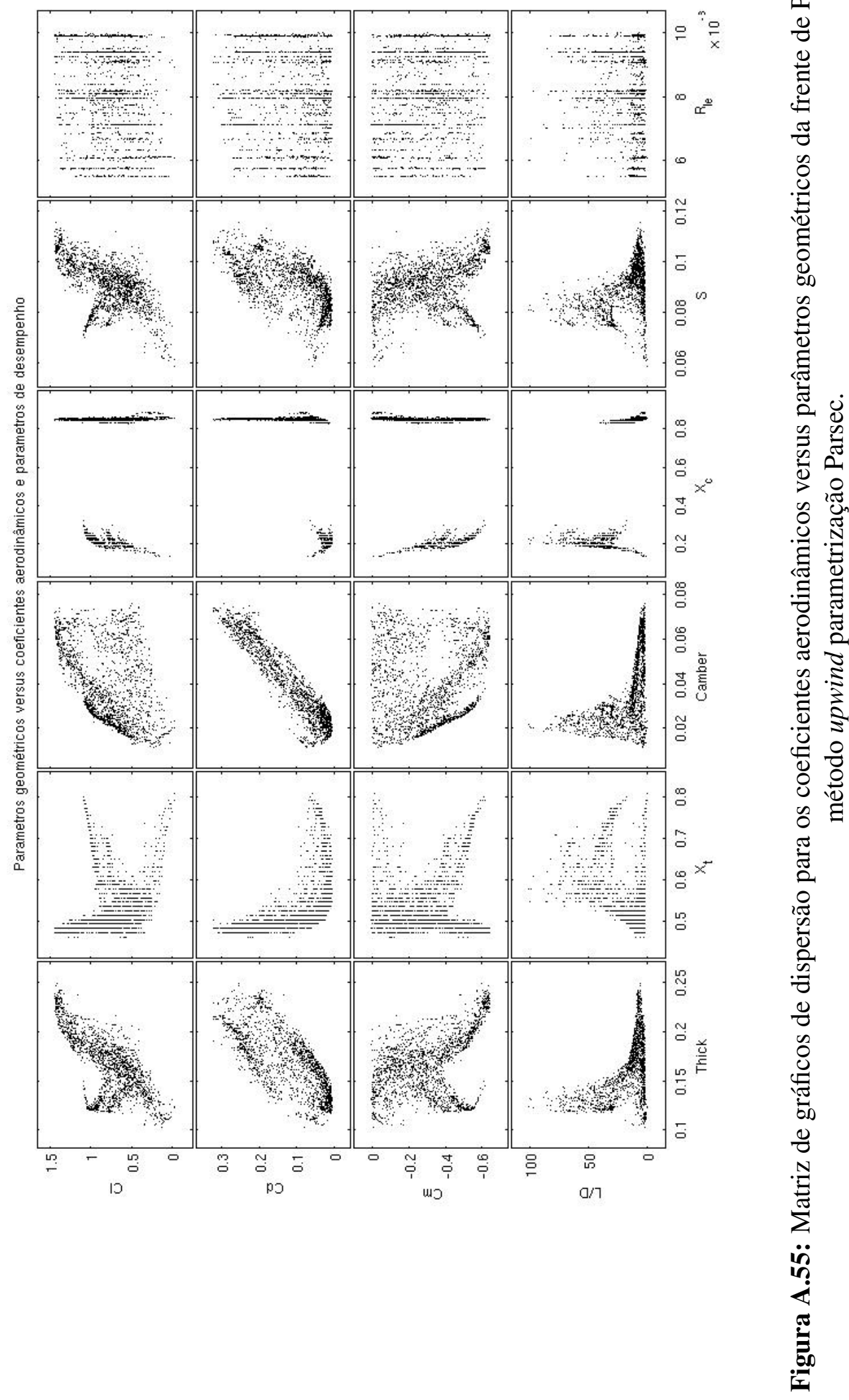



Referências Bibliográficas

VAn Albada, G.; VAn LeEr, B.; Roberts, W. A comparative study of computational methods in cosmic gas dynamics. astronomy and astrophysics. Astronomy and Astrophysics, v. 108, p. 76 $-84,1982$.

Anderson, J. A survey of multiobjective optimization in engineering design. Relatório Técnico LiTH-IKP-R-1097, Department of Mechanical Engineering, Linköping University, 58183 Linkiöping, Sweden, 2000.

Anderson, J. D. Computational fluid dynamics. McGraw-Hill International Editions, 1995.

Anderson, J. D. A history of aerodynamics and its impact on flaying machines. Cambridge University Press, 1999.

ANG, K. H.; LI, Y. Multi-objective benchmark studies for evolutionary computation. Genetic and Evolutionary Computation Conference. Workshop Program, p. 393-396, 2001.

Azevedo, J. L. F.; Korzenowsk, H.; DA Silva, L. F. F. On the development of unstructured grid finite volume solvers for high speed flows. Journal of the Brazilian Society of Mechanical Sciences, 1992.

BAeck, T.; Fogel, D.; Z., M. Advanced algorithms and operators. Bristol, UK, UK: IOP Publishing Ltd., 1999.

BARTH, T.; JESPERSEN, D. The design and application of upwind schemes on unstructured meshes. In: Proc. AIAA 27th Aerospace Sciences Meeting, Reno, 1989.

BEAM, R. M.; WARMING, R. F. An implicit finite-difference algorithm for hyperbolic systems in conservation law form. Journal of Computation Physics, v. 22, p. 87-109, 1976.

BEAM, R. M.; WARMING, R. F. An implicit factored scheme for the compressible navier-stokes equations. AIAA Journal, v. 16, p. 393-402, 1978. 
Bigarella, E. D. V. Advanced turbulence modelling for complex aerospace application. Tese de Doutoramento, Instituto Tecnológico de Aeronáutica, Sião José dos Campos, Brazil, 2007.

BorIS, J. P.; BooK, D. L. Flux-corrected transport i: Shasta, a fluid-transport algorithm that works. Journal of Computation Physics, v. 11, p. 38-69, 1973.

BorIS, J. P.; BooK, D. L. Flux-corrected transport iii: Minimal error fct methods. Journal of Computation Physics, v. 23, p. 276-299, 1976.

BORIS, J. P.; BOOK, D. L.; HAIN, K. H. Flux-corrected transport ii: Generatization of the method. Journal of Computation Physics, v. 18, p. 248-283, 1974.

BRILEY, W. R.; MCDONALD, H. Solution of the three-dimensional navier-stokes equations by an implicit technique. In: Proceedings of the Fourth International Conference on Numerical Methods in Fluid Dynamics, Springer Berlin / Heidelberg, 1975, p. 105-110.

CAO, H. V.; BLOM, G. A. Navier-stokes/genetic optimization of multi-element airfoils. AIAA, , n. 96-2487, 1996.

Coello, C. A. C.; van Veldhuizen, D. A.; B., L. G. Evolutionary algorithms for solving multi-objective problem. Kluwer Academis Publishers, 576 p., 2002.

Courant, R.; IsAaCson, E.; ReEs, M. On the solution of non-linear hyperbolic differential equations by finite differences. Communication in Pure Applied Mathematic, p. 243-255, 1952.

DEB, K. Multi-objective optimization using evolutionaty algorithms. John Wiley \& Sons, 2004.

Deb, K.; Agrawal, S.; Pratab, A.; Meyarivan, T. A fastelitist non-dominated sorting genetic algorithmfor multi-objective optimization: Nsga ii. Relatório Técnico, 2000a.

Deb, K.; Agrawal, S.; Pratap, A.; Meyarivan, T. A fast elitist non-dominated sorting genetic algorithm for multi-objective optimization: Nsga-ii. Springer, 2000b, p. 849-858.

Deb, K.; Goldberg, D. E. An investigation of niche and species formation in genetic function optimization. 1989, p. 1-16.

DEB, K.; JAIN, S. Running performance metrics for evolutionary multi-objective optimization. Relatório Técnico, 2002.

Deb, K.; Pratap, A.; Agarwal, S.; Meyarivan, T. A fast and elitist multiobjective genetic algorithm: Nsga-ii. IEEE Transactions on Evolutionary Computation, v. 6, p. 182-197, 2002.

Drela, M.; Giles, M. B. Ises: A two-dimensional viscous aerodynamic design code. AIAA, , n. 87-0424, 1987. 
Duda, R. O.; Hart, P. E.; Stork, D. G. Pattern classification. Wiley-Interscience Publication, 2000.

Fletcher, C. A. J. Computational techniques for fluid dynamics 2: Specific techniques for different flow categories. Springer-Verlag, 484 p., 1987.

FonsecA, C. M.; Fleming, P. J. Genetic algorithms for multiobjective optimization: Formulation, discution and generalization'. 1993, p. 416-423.

Fromm, J. E. A method for reducing dispersion in convective difference schemes. Journal of Computation Physics, v. 3, p. 176-189, 1968.

Gen, M.; Cheng, R. Genetic algorithm and engineering design. New York: Wiley-IEEE, 1997.

Godunov, S. A finite difference method for the numerical computation and discontinuous solutions of the equations of fluid dynamics. Mat. Sb., v. 47, p. 271-306, 1959.

GOLDBERG, D. E. Genetic algorithms for search, optimization and machine learning. Boston, MA, USA: Addison-Wesley Longman Publishing Co., Inc., 1989.

HARTEn, A. On a class of high resolution total variation stable finite differences schemes. Journal of numerical analisis, v. 21, p. 1-23, 1984.

HINTERDING, R. Representation, mutation and crossover issues in evolutionary computation. In: Proc. of the 2000 Congress on Evolutionary Computation, Piscataway, NJ: IEEE Service Center, 2000, p. 916-923.

HIRSCH, C. Numerical computation of internal and external flows volume 1: Fundamentals of numerical discretization. Chichester: John Wiley \& Sons, 1991a.

HIRSCH, C. Numerical computation of internal and external flows volume 2: Computational methods for inviscid and viscous flows. Chichester: John Wiley \& Sons, $1991 \mathrm{~b}$.

Holland, J. H. Adaptation in natural and artificial systems by john h. holland. The University of Michigan Press, , n. 53, p. 15-15, 1975.

Holst, T. L. Genetic algorithms applied to multi-objective aerospace shape optimisation. AIAA, , n. 2004-6512, 2004.

Inselberg, A.; Dimsdale, B. Parallel coordinates for vizualizing multi-dimensional geometry. in Computer Graphies 1987 - Proceedings of CG international’ 87, p. 25-44, 1987.

Inselberg, A.; Dimsdale, B. Parallel coordinates: a tool for visualizing multidimensional geometry. Proceedings of Visualization '90, p. 361-378, 1990. 
JAMESON, A. Iterative solution of transonic flows over airfoils and wings, including flows at mach 1. Comm. Pure. Appl. Math., 1974.

JAMESON, A. Remarks on the calculation of transonic potential flow by finite volume method. 1978.

JAMESON, A. Acceleration of transonic potential flow calculations on arbitrary meshes by the multiple grid method. AIAA, 1979.

Jameson, A.; Caughey, D. A. A finite volume methos for transonic potential flow calcultation. AIAA, 1977.

JAMESOn, A.; ChIPMAn, R. Fully conservative numerical solutions for unsteady irrotational transonic flow about airfoils. 1979.

JAmeson, A.; Schimidt, W.; TURKel, E. Numerical simulation of the euler equations by finite volume methods using runge-kutta time stepping schemes. AIAA Journal, , n. 81-1259, 1981.

LAX, P. D.; Wendroff, B. System of conservation laws. Communications of Pure applied mathematic, p. 217-237, 1960.

VAN LEER, B. Towards the ultimate conservative difference scheme iv: A new approach to numerical convection. Journal of Computation Phisics, v. 23, p. 276-299, 1977.

VAN LEER, B. Towards the ultimate conservative difference scheme v: A second-order sequel to godunov's method. Journal of Computation Phisics, v. 32, p. 101-136, 1979.

VAN LEER, B. Upwind and high-resolution methods for compressible flow: From donor cell to residual distribution schemes. Communication in Computational Physics, p. 192-206, 2006.

VAN Leer, B.; Thomas, L.; Roe, P. L. A comparison of numerical flux formulas for the euler and navier-stokes equations. Paper AIAA-87-1104-CP, 1987.

Mair, W. A.; Birdsall, D. L. Aircraft performance. Cambridge: Cambridge University Press, 1998.

MARleR, R.; ARORA, J. Survey of multi-objective optimization methods for engineering. Structural and Multidisciplinary Optimization, v. Volume 26, Number 6, p. 369-395, 2004.

MichalewicZ, Z. Genetic algorithm + data structure = evolution programs. Springer, 1992.

Milne-Thomson, L. M. Theoretical aerodynamics. Toronto, Ontario, Canada: General Publishing Company, 1958.

MitChell, M. MIT-Press, 1996. 
NemeC, M.; Pullian, T. H.; ZingG, D. Multipoint and multi-objective aerodynamic shape optimization. AIAA Journal, v. 42, p. 1057-1065, 2002.

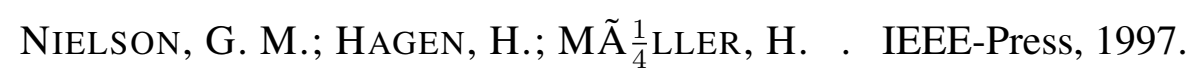

OBAYASHI, S. Genetic algorithm for aerodynamic inverse optimization. Genetic Algorithm in Engeneering Systems: Innovations and Applications, , n. 414, 1995.

OBAYASHI, S.; OYAmA, A. Three-dimensional aerodynamic optimization with genetic algorithms. Proceedings of the Third ECCOMAS Computational Fluid Dynamics Conference, p. 420-424, 1996.

OBAYASHI, S.; SASAKI, D. Multiobjective aerodynamic design and vizualization of supersonic wing by using adaptative range multiobjective genetic algorithms. v. 1, 2004.

OSHer, S.; SOlOMON, F. Upwind difference scheme for hyperbolic systems of conservation laws. Mathematic of computation, v. 38, n. 158, p. 339-374, 1982.

Oyama, A.; Obayashi, S.; NAKahashi, K.; Hirose, N. Aerodynamic wing optimisation via evolutionary algorithms based on structured coding. CFD Journal, 2000a.

Oyama, A.; Obayashi, S.; Nakahashi, K.; Hirose, N. Aerodynamic wing optimization via evolutionary algorithms based on structures coding. CFD Journal, $2000 \mathrm{~b}$.

Oyama, A.; OBAyashi, S.; NAKAhashi, K.; NAKAmURA, T. Euler/navier-stokes optimization of supersonic wing design based on evolutionary algorithm. AIAA Journal, v. 37, n. 10, p. 1327-1329, 1999.

Oyama, A.; Obayashi, S.; Nakahashi, K.; NAKAmura, T. Aerodynamic optimization of transonic wing design based on evolutionary algorithm. ICNPAA, 2000c.

OyAma, A.; OBAyASHI, S.; NAKAMURA, T. Real-coded adaptive range genetic algorithm applied to transonic wing optimization. Applied Soft Computing Journal, v. 3, n. 1, p. 179-187, 2001.

Papadimitriou, C. Computational complexity. Reading, Massachusetts: Addison-Wesley, 1994.

Quagliarella, D.; CiOPPA, A. D. Genetic algorithms applied to the aerodynamic design of transonic airfoils. AIAA, , n. 94-1896-CP, 1994.

RAY, T.; TSAI, H. M. Genetic algorithm for aerodynamic inverse optimization. AIAA Journal, v. 42, n. 2, 2004.

RoE, P. L. Approximate riemman solver, parameter vectors. Journal of Computational Physics, , n. 43 , p. $357-372,1981$. 
Roe, P. L. Characteristic-based scheme for the euler equations. Annual Reviews of Fluid Mechanics, , n. 18, p. 337-365, 1986.

RoE, P. L.; PIKE, J. Efficient construction and utilisation of approximate riemann solutions. In: Proc. of the sixth int'l. symposium on Computing methods in applied sciences and engineering, VI, Amsterdam, The Netherlands, The Netherlands: North-Holland Publishing Co., 1985, p. 499-518.

Roskan, D. J.; LAN, D. C.-T. E. Airplane aerodynamics and performance. Kansas, USA: Design, Analysis and Researsh Corporation, 1997.

Schlichting, H. Boundary-layer theory. McGraw-Hill Book Company, 1955.

SCHOTT, J. R. Multidisciplinary optimization of a transport aircraft wing using particle swarm optimization. Tese de Doutoramento, Department of Aeronautics and Astronautics, MIT, Cambridge, MA, 1995.

SLATER, J. W. Rae 2822 transonic airfoil. Http://www.grc.nasa.gov/WWW/wind/valid/ raetaf/raetaf04/raetaf04.html, 2002.

SobIECZKy, H. Parametric airfoils and wings. Numerical Fluid Mechanics, v. 1, p. 71-88, 1998.

Song, W.; Keane, A.; Eres, H.; Pound, G.; Cox, S. Two dimensional airfoil optimisation using cfd in a grid computing environment. Euro-Par, 2003.

SONG, W.; KEANE, A. J. A study of shape parameterisation methods for airfoil optimisation. AIAA-2004-4482 10th AIAA/ISSMO, 2004a.

Song, W.; KeAne, A. J. A study of shape parametrisation methods for airfoil optimisation. AIAA Paper, , n. 2004-4482, 2004b.

TERRY, E. L. N. Extension of the aerodynamic design program mses for the simulation of boundary layer suction. Dissertação de Mestrado, Delf University of Technology, 2004.

THIBERT, J. J.; OHMAN, L. H. Naca 0012 airfoil, "experimental data base for computer program assessment. Relatório Técnico AGARD AR-138, 1979.

Thompson, J. F.; Warsi, Z. U. Z.; Mastin, C. W. Numerical grid generation. Elsevier Science Publishing Co., 1985.

TORO, E. F. Riemann solvers and numerical methods for fluid dynamics - A practical introduction - 2nd edition. Berlin: Springer, 1999.

Tuval, A. I. C.; ReIF, M. Convexity algorithms in parallel coodinates. Journal of the ACM, , n. 34, p. 765-801, 1987. 
Veldhuizen, D. A. V.; LAmont, G. B. Evolutionary computation and convergence to a pareto front. In: Stanford University, California, Morgan Kaufmann, 1998, p. 221-228.

Veldhuizen, D. A. V.; LAmont, G. B. On measuring multiobjective evolutionary algorithm performance. In: In 2000 Congress on Evolutionary Computation, press, 2000, p. 204-211.

Venter, G.; SobieszCZANSKi-SObIESKi, J. Multidisciplinary optimization of a transport aircraft wing using particle swarm optimization. AIAA/ISSMO, 2002.

Wesseling, P. On the construction of accurate difference scheme for hyperbolic partial differential equations. J. Eng. Math, v. 7, p. 19-31, 1973.

WhIтсомв, R. T. Review of nasa supercrÃtical airfoils. In: nineth ICAS, 1974.

YAMAмото, K.; INOUE Application of genetic algorithm to aerodynamic shape optimization. AIAA Paper, , n. 95-1650-CP, p. 43-51, 1995.

ZITZleR, E.; ThIElE, L. An avolutionary algorithms for multiobjective optimization: The strength pareto approch. Relatório Técnico, Zurich, Switzerland, 1998a.

ZitZleR, E.; ThIELE, L. Multiobjective optimization using evolutionary algorithms: A comparative case study. Springer, 1998 b, p. 292-301.

ZitzleR, E.; ThIELE, L. Multiobjective evolutionary algorithms: A comparative case study and the strength pareto approach. 1999. 